\begin{abstract}
Title of Document:

THE VALUE OF MORTALITY RISK REDUCTIONS IN DELHI, INDIA

Soma Bhattacharya, Doctor of Philosophy, 2006

\author{
Dissertation Directed By: Prof. Anna Alberini \\ University of Maryland, College Park \\ Prof. Maureen L. Cropper \\ University of Maryland, College Park
}

Road accidents kill nearly 1.2 million people each year worldwide, two-thirds of whom live in developing countries. Traffic crashes may indeed become the third leading cause of death in developing countries by the year 2020 (Murray and Lopez, 1996). For governments in developing countries to make informed decisions about investments in traffic safety, it is imperative that the benefits of road traffic improvements be monetized and compared with costs. This, however, requires estimates of the value of reductions in risk of death.

The goal of the dissertation is to provide estimates of the value of mortality risk reductions in a traffic safety context in Delhi, India. To estimate the value of road safety improvements in Delhi requires understanding the nature of developing country traffic risks. Methods of valuing traffic fatalities used in high-income countries based on seatbelt use or purchase of safer cars are not applicable here.

In my survey I asked 1200 commuters what they would pay to reduce their own risk of dying as a (a) pedestrian, (b) driver of a two-wheeler, and (c) commuter, regardless of travel mode. These scenarios mirror the bulk of fatal accidents in Delhi. I find that mean WTP for mortality risk reduction increases with the size of risk reduction, as predicted by economic theory. WTP for a given risk change increases with income and education. The estimation results broadly confirm the Bayesian updating assumption, in that WTP increases with baseline exposure to risk, measured by commute time, whether the respondent travels as part of his job and whether he drives a two-wheeler. Mean WTP is three times larger for a respondent who drives a two-wheeler and travels on the job than for one who does not. 
The results of my survey indicate that the VSL is individuated, i.e., it varies across groups of potential beneficiaries of traffic safety programs (two-wheeler drivers, persons with bachelors degree, etc.). For the most highly exposed individuals - the VSL is about $\$ 150,000$ (PPP, 2005). Transferred estimates adjusted for income from other developed and developing countries indicate a VSL that is much larger than my estimate. These findings underscore the importance of conducting original valuation studies. 


\title{
THE VALUE OF MORTALITY RISK REDUCTIONS IN DELHI, INDIA
}

\author{
By \\ Soma Bhattacharya \\ Dissertation submitted to the Faculty of the Graduate School of the \\ University of Maryland, College Park, in partial fulfillment \\ of the requirements for the degree of \\ Doctor of Philosophy \\ 2006
}

Advisory Committee:

Professor Anna Alberini, Co-Chair

Professor Maureen L. Cropper, Co-Chair

Professor Kenneth E. McConnell

Professor Kenneth Leonard

Professor Kenneth Beck 
(C) Copyright by

Soma Bhattacharya

2006 


\section{DEDICATION}

To my beloved parents, my loving husband, Mithun and Timmy 


\section{ACKNOWLEDGEMENTS}

This work would not have been realized without the help of countless people both during and before my stay at the University of Maryland who I owe my sincerest thanks from all my heart. First and foremost, I would like to begin by expressing my deepest gratitude to my two advisors Prof. Anna Alberini and Prof. Maureen L. Cropper without whose never-ending encouragement, support and guidance, I would never have finished this Ph.D. Anna's methodical work style and Maureen's meticulous eye for every detail, together with their knowledge and perceptiveness have helped me not just in the culmination of this research, but have also provided valuable lessons for future research.

I would like to express my sincere thanks to Prof. Kenneth E. (Ted) McConnell for serving on my dissertation committee. His valuable comments and suggestions were very useful, especially in designing the survey. Many thanks also to Professors Kenneth Leonard and Kenneth Beck for serving on my dissertation committee and for sparing their valuable time to provide me suggestions and review my manuscript.

I would like to gratefully acknowledge the generous support in the form of a research grant or fellowship by the World Bank's Research Department and its Transportation Research Board, Fondazione Eni Enrico Mattei and Resources for the Future, which enabled me to travel to India for the data collection.

I would also like to thank Dr. P.N. Mari Bhatt of International Institute of Population Sciences and Dr. Suresh Sharma of Institute of Economic Growth for their valuable help with sampling methodology, and Dr. R.G. Mitra, Registrar General, Census 
of India for his help in providing me with Census data in a timely manner. Many thanks also to the survey implementation teams at IMRB International, especially Ashish Sinha, Sabari Girish, Manoj Johri, Gaurav Srivastava, A.V. Surya and their many colleagues for their untiring help.

Finally, I am forever indebted to my family — my loving parents, Swapna and Barid Baran Bhattacharya, for their love, encouragement and support at every step of my life and my brother, Mithun for providing me with moral support and humor in my most difficult times. Needless to say, I am indebted to my husband, Arjun Mukherjee, for his inexhaustible efforts to keep me cheerful perpetually with his wisecracks. I may have never realized these efforts today, but for his loving support and endurance.

Thank you all! 


\section{Table of Contents}

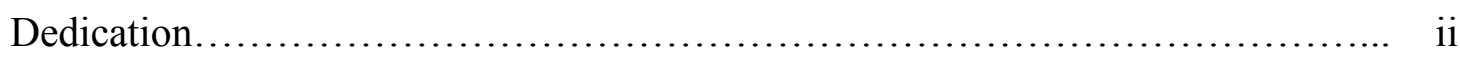

Acknowledgements......................................................

Table of Contents...................................................... v

List of Tables......................................................... viii

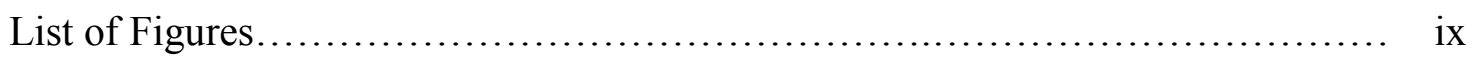

List of Boxes.............................................................. ix

Chapter 1: Introduction............................................... 1

Chapter 2: Literature Review.......................................... 6

2.1: Valuation of Changes in Risk of Mortality ................... 6

2.1.1: The Human Capital Approach........................ 6

2.1.2: The Willingness to Pay Approach....................... 8

2.1.2.1: The Value of a Statistical Life (VSL)............. 10

2.2: Empirical Estimation of the Value of a Statistical Life............ 12

2.2.1: Revealed Preference Approach.......................... 13

2.2.1.1: Averting Behavior Studies...................... 13

2.2.1.2: Hedonic Price Function........................... 18

2.2.1.3: Other Revealed Preference Approaches........... 21

2.2.1.4: Limitations of the Revealed Preference Approach... 22

2.2.2: Stated Preference Approach.......................... 22

2.2.2.1: Contingent Valuation Method (CVM)............. 23

2.2.2.2: Conjoint Analysis.............................. 24

2.2.2.4: Advantages of Stated Preference Studies............ 27

2.2.3: Benefit Transfer Approach............................ 27

2.2.4: VSL in Road Safety................................ 31

2.3: Factors Influencing WTP and hence the VSL................. 32

2.3.1: Size of Risk Reduction............................ 33

2.3.2: Timing of Risk................................... 38

2.3.3: Perception of Risk................................... 39

2.3.4: Private versus Public Risk Reduction................... 41

2.3.5: Individual Characteristics............................. 43

2.3.6: Context....................................... 44

2.4: Eliciting WTP in CV Studies................................ 46

2.4.1: Open-Ended....................................... 47

2.4.2: Dichotomous Choice................................... 47 
2.4.3: Payment Card............................................ 48

2.4.4: Standard Gamble and Chained Approach................... 49

2.4.5: Risk Metric............................................. 53

2.5: Design Issues in Contingent Valuation Studies................... 54

2.5.1: Assign Baseline Risk....................................... 55

2.5.2: Responded Assessment of Baseline Risk................... $\quad 56$

2.5.3: Communication of Risk Reduction....................... 57

2.5.3.1: Absolute Risk Reduction........................... 57

2.5.3.2: Percentage Risk Reduction....................... 58

2.5.3.3: Risk Reduction as Probability..................... 59

2.6: Stated Preference Studies - Problems and Remedies................ 59

2.7: VSL from Road Safety in Developing Countries.................. 61

2.8: Estimating the VSL in India...................................... 64

2.9: VSL in Public Policy: Road Safety............................. 65

Chapter 3: Background Information of Road Accidents in Delhi................. 68

Chapter 4: Questionnaire Development and Survey Administration................ 74

4.1: The Questionnaire.......................................... 75

4.2: Risk Communication........................................ 78

4.3: Valuation Scenarios........................................ 82

4.4: Format of Valuation Questions............................... 88

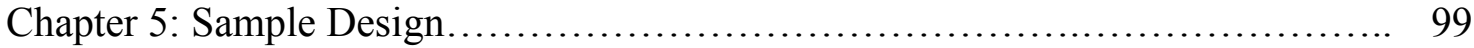

5.1: Sample Selection.............................................. 99

5.2: Mapping and Listing....................................... 101

5.3: Respondent Screening Criteria................................. 103

Chapter 6: The Data........................................................ 107

6.1: Socio-demographics..................................... 107

6.2: Commuting Characteristics..................................... 109

6.3: Perception of Risks and Government Safety Policies............... 110

6.4: Characteristics of Drivers of Motorcycles........................ 113

6.5: Characteristics of Persons with High School Diploma............... 115

Chapter 7: Models of Willingness to Pay, Estimation and Results................ 117

7.1: Graphical Analysis of WTP Responses......................... 120 
7.2: Model of Zero Willingness to Pay............................. 122

7.3: Models of Willingness to Pay................................. 126

7.4: WTP Models with Covariates................................... 129

7.5: Combining the Scenarios.................................... 131

7.6: Implied VSL .......................................... 136

7.7: Comparison with Transferred Values from Other Studies.......... 138

Chapter 8: Summary of Results and Discussion............................... 140

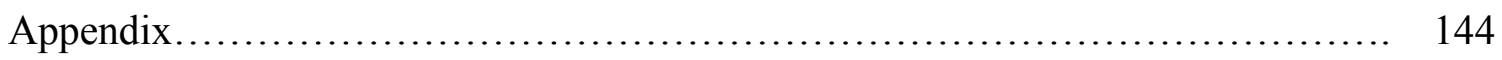

A: Comparison of India's Traffic Crash Rates with Some Other Countries........ 144

B: Sampling Criteria: Number of Census Enumeration Blocks Selected by

Ward.................................................................. 146

C: Location of Delhi, India on the World Map............................ 150

D: Analysis of WTP Responses for the Pedestrian, City and Helmet Scenario..... 151

E: The Questionnaire for Version 1 of the Final Survey....................... 155

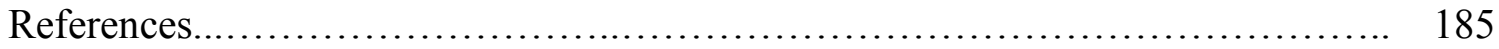




\section{List of Tables}

3.1: Fatalities in Road Accidents in Delhi, India.......................... 71

3.2: Children and Adults Killed in Road Accidents - 2001 ................... 72

3.3: Victim versus Vehicle at Fault for Fatal Accidents - 2001................ 72

3.4: Road Accident Crash Rate by Vehicle at Fault - 2001................... 73

4.1: Details of Questionnaire Development Stages......................... 93

4.2: Details of Each Stage of Questionnaire............................ 94

4.3A: Details of the Valuation Questions in the Focus Groups and Pre-Test....... 95

4.3B: Details of the Valuation Questions in the Pilot Studies and One-On-One Interviews........................................................ 96

4.3C: Details of the Valuation Questions in the Pilot Studies and Final Survey... 97

4.4: Study Design....................................................... 98

6.1: Demographic Profile of the Sample................................... 108

6.2: Commuting Characteristics...................................... 110

6.3: Accident History \& Attitudes towards Personal Risk, Averting Behavior \& Governmental Policies....................................................... 112

6.4: Demographic and Commuting Characteristics, Accident History \& Attitude towards Personal Risk \& Safety Policies of 2-Wheeler Drivers.

6.5: Demographic, Commuting, Accident History \& Attitude towards Personal Risk \& Safety Policies of Persons with at least a High School Diploma...........

7.1: Mean and Median Willingness to Pay and the Value of Statistical Life by Scenarios and Version.

7.2: Mean and Median Willingness to Pay and the Value of Statistical Life by Levels of Risk Reduction.

7.3a: Probit Model for those whose Willingness to Pay is Zero in all Three

Scenarios.

7.3b: Probability of Paying Nothing in all Three Scenarios

7.4a: Mean and Median Willingness to Pay and the Value of Statistical Life by

Scenarios and Risk Reduction...

7.4b: Mean and Median Willingness to Pay and the Value of Statistical Life by

Levels of Risk Reduction.

7.5: Weibull Models with all Scenarios.

7.6: Effect of Education on WTP (Weibull, Interval Based).

7.7: Mean WTP and VSL from all Three Scenarios Based on an Interval Based Weibull Model. 


\section{List of Figures}

2.1: Indifference Curve between Wealth and Mortality Risk.................... 11

2.2: Example of a Choice Set used in Tsuge et al............................. 46

2.3: Risk Communication in Schawb-Christe and Soguel........................ 55

2.4: Example of a Choice Set used in Chilean Road Safety Studies............... 58

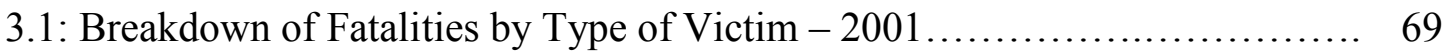

3.2: Vehicles at Fault for Fatal Accidents - 2001 .............................. 71

4.1: Risk Communication Tool - Jar of 100,000 Rice Grains................... 79

4.2: A Rectangular Grid Representing a Risk of 3/10,000 ....................... 81

4.3: A Sample Question (Pedestrian Scenario) from the Choice Experiment

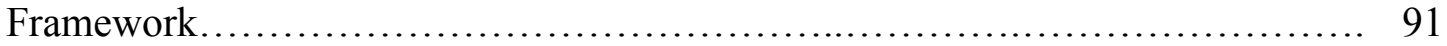

4.4: Payment Card Used in the Final Survey ................................. 92

7.1: Kernel Density Smoothed Distribution of WTP (Versions 1 \& 2) ............ 121

7.2: Kernel Density Smoothed Distribution of WTP (Versions $3 \&$ \&) ............ 121

\section{List of Boxes}

4.1: Contingent Valuation Question in the Final Survey....................... 87

5.1: Screening Criteria for Respondent Selection............................. 105 


\section{CHAPTER 1: INTRODUCTION}

In 2002, roads accidents killed nearly 1.2 million people worldwide. Two-thirds of these deaths occurred in developing countries. The Global Burden of Disease (GBD) (Murray and Lopez, 1996) estimates that road traffic accidents will account for about 2.5 million deaths throughout the world by the year 2020, making them the third leading cause of disability adjusted life years $\left(\mathrm{DALY}^{1}\right)$ in 2020 . Fatality rates are rapidly accelerating in Asia: Between 2000 and 2020, road traffic deaths are expected to increase by $92 \%$ in China and $147 \%$ in India, much faster than in other developing countries.

For governments in developing countries to properly evaluate investments in road safety, it is important to have reliable estimates of the value of lives saved as a result of the policy. Once monetized, the mortality benefits of road traffic improvements can be compared with the cost of the projects. Unfortunately, estimates of the value of reductions in risk of death from road accidents are not currently available for most developing countries. The goal of this dissertation is to estimate the value of mortality risk reduction in one developing country — India.

India, which comprises roughly one-sixth of the world's population, had the second highest number of road traffic fatalities in the world in $2004-7.5 \%$ of the worldwide total. ${ }^{2}$ The number of fatalities per 100,000 people -8.33 in 2004 , is not high by international standards, but has been increasing. Fatality rates per 100,000 people

\footnotetext{
${ }^{1}$ DALY or Disability Adjusted Life Years is an indicator of the time lived with a disability and the time lost due to premature mortality.

${ }^{2}$ China reported the highest number of road accident deaths at 107,077 in 2004 (official government figures). However, it is alleged that the actual road death toll is vastly higher than the one reported by the Chinese Government (WHO, 2005).
} 
increased by about $80 \%$ during the period $1980-1998$. This is in sharp contrast to developed countries where the comparable rates declined considerably for the same period (WHO, 2004). India's rate is low because motorization is low but the fatality rate per 10,000 motor vehicles (12 per 10,000 in 2004) is much higher than the corresponding figure in highly motorized countries like the United States, where it averages around 2 per 10,000 motor vehicles. Furthermore, road traffic deaths in India are expected to rise until 2042 (Kopits and Cropper 2004).

Currently, there exists no estimate of the value of mortality risk reductions in a traffic crash context for any city in India. Some studies have, however, attempted to estimate the total cost of road crashes to society as a percentage of that region's GDP. These studies account for loss of life by either imputing data from insurance payments made to the victims' families or by using the present discounted value of lost income. Chand (2001) estimates that economic loss due to road traffic crashes for the state of Kerala, India is equivalent to one percent of the state's GDP. This figure includes the cost of injuries including minor injuries, loss of output, court related expenses, administrative expenses including police, insurance and visits by relatives and friends as well as a notional value for pain, grief and suffering. Another prominent study (Mohan, 2001) estimates that the cost of road injuries alone in India may be valued at Rs. 322 billion (\$ 7.16 billion) or $3.2 \%$ of India's GDP. Mohan (2001) quotes a figure of Rs. 535,489 in 1999 Rupees used by the Ministry of Surface Transport, Govt. of India for valuing fatalities. $^{3}$

\footnotetext{
${ }^{3}$ This would be equivalent to 75,417 in 2005 PPP dollars. It is based on a study by Tata Consultancy Services in 1999 for the Ministry of Surface Transport, Govt. of India and can be found in: Evaluation of Road Accident Costs - Research Digest (2000). Indian Highways. 28:2, 27-44.
} 
However, it is widely accepted that all of these assessments are a gross underestimate of the true costs since they do not take into account the costs of pain, bereavement, etc. (Mohan, 2002). Clearly, it would be useful to have an estimate of VSL that can be used for benefit cost analysis and guide national transportation policy.

The goal of this research was to conduct a contingent valuation survey in Delhi, India to provide estimates of the value of mortality risk reductions in the context of traffic safety. Given the cost and time needed to undertake such a survey, the national capital territory of Delhi is chosen as a representative case study. I chose the contingent valuation $(\mathrm{CV})$ approach for two reasons. First, revealed preference methods for valuing reductions in risk of death in the context of road safety were not applicable here. Second, the approach is flexible and can cater to the specifics of mortality risks in the road traffic context in Delhi. The questionnaire contained a series of $\mathrm{CV}$ questions framed in realistic scenarios that residents of Delhi face in their day-to-day travel. Specifically, people were asked to trade the risk of dying in a road accident for money. The valuation questions placed the respondents in three different roles as road users - as pedestrians, drivers of two-wheelers ${ }^{4}$ and as regular commuters to their workplace. As a pedestrian, the respondent was asked to make a choice between a lower risk of dying when crossing the road and paying money to use a pedestrian subway which reduced the risk of dying from road accidents to zero. As a commuter, the respondent was asked to choose between living in two cities that differed only in their mortality rates from road accidents as well as annual commute costs. The third valuation question required the respondent to make a

\footnotetext{
${ }^{4}$ Two-wheelers refer to motorized two-wheeled vehicles like motorcycles or scooters. They may be also called motorcycles in some places in this dissertation.
} 
choice between two identical helmets that differed only in price and in the risk reduction afforded to the wearer from dying from a head injury.

I used payment cards to assist the respondents in stating their willingness to pay, for the increased safety provided by the use of the pedestrian subway, the safer city or safer helmet. The communication of the magnitude of risk posed a major challenge in this survey, especially so in a city where the majority of the population is generally less highly educated than in more developed nations. After some initial experimentation with various tools for risk communication, I finally decided to use a grid of 100,000 squares to convey the risks. In modeling the responses to the WTP question, I pay special attention to the relationship between WTP and risk reduction and also examine the effects of age, wealth and education.

I find evidence that Mean Willingness to pay, and thus VSL, is individuated, i.e., it varies with the type of potential beneficiaries - two-wheeler drivers, those who travel for job purposes other than regular commute to and from work, etc. I also found that it varies near-proportionally to the size of risk reduction for individuals who are more educated, especially for those who have completed an undergraduate degree. Younger people and less educated people (without high school diploma) are more likely not to pay anything at all for road safety policies. VSL for the most likely beneficiaries of road safety policies is roughly $\$ 150,000$ (PPP, 2005). This value is about three times lower than the income-adjusted transferred values used by governmental agencies of some developed countries like US and UK or that from a Thailand based study accentuating the need for an original study. 
The remainder of the dissertation is organized into seven chapters. Chapter 2 discusses the key concepts, methodologies and the available literature about valuation of mortality risk. Chapter 3 provides background information about road accidents in Delhi. Chapter 4 provides an account of the various stages of the questionnaire development and survey administration. It describes the survey design, content of every section of the questionnaire including details on the valuation questions and the various methodologies for communication of risk to the respondent. Chapter 5 discusses the sampling methodology. Chapter 6 discusses the sample characteristics. Chapter 7 presents the theoretical framework for the willingness to pay models, estimation procedures used as well as reports the main findings of the study. Chapter 8 summarizes the results from the study and its policy implications as well as provides insights into future directions of research. The Appendix section contains the questionnaire together with visual aids and handouts. It also contains details about the sampling process, information on traffic crash rates across the globe as well as some information about the city of Delhi. 


\section{CHAPTER 2: LITERATURE REVIEW}

In order to conduct benefit-cost analyses, benefits and costs must be both quantifiable in monetary terms for comparability. Most of the benefits of environmental, public health and safety related programs entail reduced morbidity or mortality. In such situations where the benefits consist of human lives saved, an economic value must be assigned to the lives saved. To monetize these benefits, it is necessary to find out how much people value (i.e., are willing to pay for) mortality risk reductions. Whereas the life of an identified individual in the society may be deemed priceless, the value of a statistical human life saved may be assessed by adding individual willingnesses to pay for small reductions in the risk of death, when the risk reductions add to one.

\subsection{Valuation of Changes in Mortality Risk}

The alternative approaches that have been used to value mortality risk reductions may be broadly categorized as the Human Capital Approach and the Willingness to Pay Approach.

\subsubsection{The Human Capital Approach}

According to the Human Capital Approach, the value of life of an individual is the present value of foregone future earnings. This is based on the premise that an individual is worth to the society only as much as he/she would have produced in the remainder of his/her lifetime gross of taxes. According to this approach, the value of a change in mortality risk is the income lost multiplied by the change in risk. However, this 
approach has been criticized because it values livelihood rather than life per se. That is, it places no value on the lives of people who do not produce any marketed output, i.e., retired persons, housewives, etc. There is no consideration of how individuals value the risks to their own life (Mishan, 1971). Due to this shortcoming, this approach has fallen out of favor among academics and policy makers, when other alternatives are available.

The human capital method is also known as the gross output method since it considers gross income lost due to a premature death. An alternative method, known as the net output method, deducts future consumption from future income, thus providing a more conservative estimate. Loss to society according to this method is the individual's net output. Ironically, this may translate into net benefits for the society for persons who do not produce any marketed output (Mishan, 1971).

Other closely related approaches value human life on the basis of court payments, medical costs, implicit public sector values or life insurance (Hills and Jones-Lee, 1983). The life insurance method covers only the expected financial requirements of dependents and hence does not reflect the individual's willingness to pay to increase his own safety. The implicit public sector valuation uses values derived from past safety legislations or public sector investments on road safety. The major drawback for this approach is that it does not measure what individuals would pay to reduce their own risk of dying. Jacobs (1995) quotes examples from studies in the UK that relied on this methodology to place the value of life ranging from $£ 50$ to $£ 20$ million.

The Court award method is based on actual compensations awarded. These are in turn determined using human capital measures and influenced by characteristics such as 
negligent driving, whether the person killed was partly to blame, etc. While the court award method may be deemed appropriate for determining the appropriate value of compensation for fatalities, it is incorrect to use it as the value of prevention of fatalities (Viscusi, 2000).

All the above mentioned methodologies suffer from one similar theoretical weakness - they are not well founded in terms of welfare, in the sense that they are not able to fully capture individuals' marginal rate of substitution between risks and income (Mishan, 1971; Zeckhauser, 1975). This is what the willingness to pay (WTP) approach attempts to measure.

\subsubsection{The Willingness to Pay Approach}

The Willingness to Pay (WTP) approach emphasizes the importance of individual preferences for risk changes. WTP can be defined as the monetary measure of the value of a small reduction in the risk of death. Unlike the human capital approach, which is an ex-post measure, WTP is an ex-ante measure. WTP may be alternatively defined as a compensating surplus measure - as the sum of money that could be taken away from the individual who gains the mortality risk so that the individual is no better off than in the status quo no policy situation (Freeman, 2003).

Suppose an individual's utility can be expressed in terms of W, which represents his wealth and $\mathrm{p}$, which represents the mortality risk in the society he lives in (Dreze, 1962; Jones-Lee, 1974). Let $\mathrm{u}_{\mathrm{a}}(\mathrm{W})$ be the utility conditional on surviving and assume that $\mathrm{u}_{\mathrm{a}}{ }^{\prime}(\mathrm{W})>0$ and $\mathrm{u}_{\mathrm{a}}{ }^{\prime \prime}(\mathrm{W}) \leq 0$ implying that the marginal utility of this individual increases 
with wealth and that he is averse to financial risks. Let $u_{d}(W)^{5}$ be the utility conditional on death and assume that $u_{d}{ }^{\prime}(W) \geq 0$ and $u_{d}{ }^{\prime \prime}(W) \leq 0$. Also assume that $u_{a}(W)>u_{d}(W)$ and $\mathrm{u}_{\mathrm{a}}{ }^{\prime}(\mathrm{W})>\mathrm{u}_{\mathrm{d}}{ }^{\prime}(\mathrm{W})$ at all relevant values of $\mathrm{W}$ implying that the more wealth provides more utility if the individual survives rather than dies. If the baseline mortality risk is $p_{0}$, then expected utility $\mathrm{E}[\mathrm{U}(p, \mathrm{~W})]$ can be expressed as:

$$
\mathrm{E}[\mathrm{U}(p, \mathrm{~W})]_{0}=\left(1-p_{0}\right) \mathrm{u}_{\mathrm{a}}\left(\mathrm{W}_{0}\right)+\mathrm{p}_{0} \mathrm{u}_{\mathrm{d}}\left(\mathrm{W}_{0}\right)
$$

where $\mathrm{W}_{0}$ is the initial wealth level. If mortality risk changes from $p_{0}$ to $\mathrm{p}$, and $\mathrm{q}$ is the amount of wealth required to maintain the expected utility at the same level as before such that expected utility can be written as:

$$
\mathrm{E}[\mathrm{U}(p, \mathrm{~W})]_{0}=(1-p) \mathrm{u}_{\mathrm{a}}\left(\mathrm{W}_{0}-\mathrm{q}\right)+p \mathrm{u}_{\mathrm{d}}\left(\mathrm{W}_{0}-\mathrm{q}\right)
$$

Two kinds of measures may be obtained: willingness to pay (WTP) or willingness to accept (WTA). WTP measures the individual's willingness to pay an amount of money for a stated mortality risk reduction whereas WTA measures the individual's willingness to accept an amount of money as compensation for an increase in mortality risk. If $p<p_{0}$ i.e., if mortality risk decreases, then $\mathrm{q}>0$ and we term it willingness to pay (WTP) which is a compensating variation measure. In other words, it is the maximum monetary payment that would ensure that the individual's well being with a small mortality risk reduction is the same as his well being without any mortality risk reduction. If $p>p_{0}$ i.e., if mortality risk increases, then $\mathrm{q}<0$ and we term it willingness to accept (WTA) which

\footnotetext{
${ }^{5}$ The utility function at death includes bequests.
} 
is an equivalent variation measure. Both these measures - WTP and WTA - are used in the calculation of the Value of Statistical Life (VSL), which is defined below.

\subsubsection{The Value of a Statistical Life (VSL)}

If we vary $p$ marginally around $p_{0}$ holding expected utility constant, then we obtain the marginal rate of substitution between $p$ and wealth:

$$
V S L_{0}=-\left.\frac{d q}{d p}\right|_{p-p_{0}}=\frac{u_{a}\left(W_{0}\right)-u_{d}\left(W_{0}\right)}{p_{0} u_{d}^{\prime}\left(W_{0}\right)+\left(1-p_{0}\right) u_{a}^{\prime}\left(W_{0}\right)}
$$

Equation 2.3 says that the VSL is the difference in utilities between survival and death divided by the expected marginal utility of wealth. Given our assumptions, VSL is always positive and increases with baseline risk (Jones-Lee, 1974; Eeckhoudt and Hammitt, 2001). In other words, VSL is the rate at which people are willing to trade off income for a specified risk reduction. Figure 2.1 below illustrates the indifference curve between individual wealth $(\mathrm{W})$ and mortality risk (p).

Using equation 2.3 we can alternatively define the Value of Statistical Life as the Marginal Willingness to Pay (MWTP) to reduce the risk of death:

$$
\mathrm{VSL}=\partial \mathrm{q} / \partial \mathrm{p}=\partial \mathrm{WTP} / \partial \mathrm{p}
$$

VSL may vary across individuals, since it depends on $\mathrm{W}$ and $\mathrm{p}$, and on the shape of the utility function. 


\section{FIGURE 2.1: INDIFFERENCE CURVE BETWEEN WEALTH AND MORTALITY RISK}

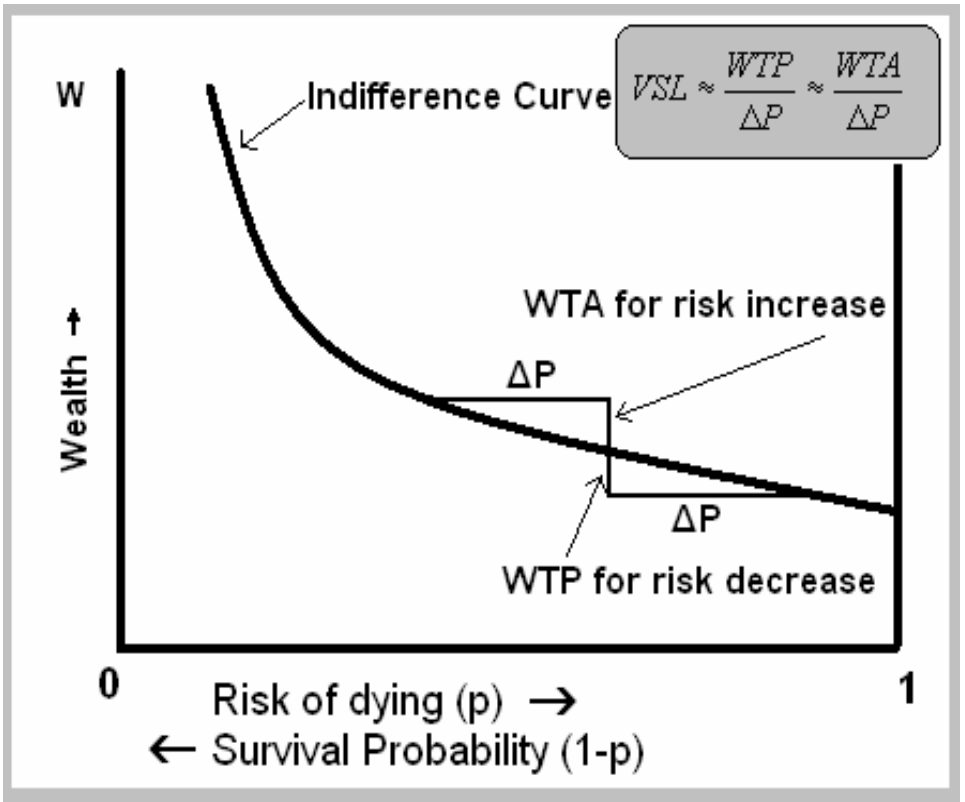

Equivalently, the Value of a Statistical Life (VSL) is the economic value of preventing one statistical death in a given population. A statistical death is the reduction in the statistical frequency of deaths by one life (Schelling, 1968). Thus, the term VSL defines the value, not of a particular life, but of safety measures that reduce the statistically expected number of accidental fatalities by one. ${ }^{6}$ This concept is an essential tool for computing the mortality benefits of environmental, health and safety policies, where the total benefit to society is the product of number of lives saved multiplied by VSL per life saved. Under reasonable assumptions, VSL can be shown to exceed the value of foregone earnings (Bergstrom, 1982).

An alternative but equivalent way of illustrating the concept of VSL is explained by the following example. If new traffic measures induce reductions in road fatalities of

\footnotetext{
${ }^{6}$ The VSL does not measure the value of an identified life, rather the value of a statistical life.
} 
$10^{-5}$ for each of 100,000 persons in a population, they will save one statistical life. If each of these people is willing to pay $\$ 10$ for the $10^{-5}$ risk reduction then the value of a statistical life (VSL) is the sum of their individual willingnesses to pay divided by the number of lives saved. In this case, VSL is $\$ 1,000,000$, which is the value the society places on a life saved. In other words, VSL is the sum of societal willingness to pay for $n$ individuals at risk for reducing risk uniformly by $1 / n$, which aggregates to one statistical life saved.

\section{2 Empirical Estimation of the Value of a Statistical Life}

Since mortality risk reductions are normally not bought and sold in markets, it is difficult to place a value on them. Economists have developed methodologies to infer these values. These non-market valuation methodologies can be grouped into two broad categories - revealed preference methods and stated preference methods. Revealed preference methodologies infer the willingness to pay for risk reductions indirectly from observed market transactions. For example, for an individual who just purchased a car, its price reflects his/her willingness to pay for the safety that the car provides relative to another identical car without the same safety features. ${ }^{7}$ In contrast, stated preference methodologies elicit WTP for risk reductions directly by asking the respondent how much he would pay. For example, a contingent valuation study would ask an individual how much extra he/she is willing to pay for a car that is X percent safer than an otherwise identical but less safe car.

\footnotetext{
${ }^{7}$ Since in reality it may be difficult to find data on identical cars bought with or without the safety features, one controls statistically for other factors that affect the purchase of a car such as the brand, model, color and seating capacity.
} 


\subsubsection{Revealed Preference Approach}

The revealed preference approach assumes that the value of a small mortality risk reduction can be inferred from observable behavior. Examples include choice of automobile type, purchase and use of safety equipment such as seat belts or travel speed (Blomquist, 2004). The two most common revealed preference approaches are the averting behavior approach and the hedonic pricing method. Averting behavior models infer the value of mortality risk reductions from the time or money people spend on selfprotecting and risk averting activities. For example, the voluntary purchase of products such as airbags, seatbelts, helmets, smoke detectors or fire alarms when these products are not required by law indirectly reveals the value people place on the risk reduction that obtained from their usage. The hedonic pricing method looks at the value that people place on the attributes of a good when mortality risk is considered one of the attributes.

\subsubsection{Averting Behavior Studies}

Averting behavior studies examine the time spent by an individual in activities that increase safety, or the amount of money spent on items that reduce risk, to estimate WTP for a reduction in the risk of death. For example, Blomquist (1979) uses a probit model explaining whether a driver buckles up when driving to infer the VSL. Jenkins et al. (2001) examine the use of helmets when riding a bicycle. In theory, consumer choices of risk averting behaviors should equate the marginal benefits and marginal costs of the risk reductions (Blomquist, 2004).

Blomquist $(1979,1991)$ focuses on the decision to wear a seat belt. He uses a multinomial logit model of the decision to always, sometimes or never wear a seat belt as 
a function of the chooser's income, number of children, education, number of miles driven, or the presence of an airbag. These models are however limited only to examining the behavioral responses to wearing seat belts, the risk reductions from which may not be well understood (Viscusi, 1995). However, this study is critical in pointing out that in addition to the economic cost of the seat belt, which is directly observable, safety features also have a time cost which is not directly observable.

Blomquist, Miller and Levy (1996) use the Nationwide Personal Transportation Study (NPTS) data to estimate the VSL from seat belt use, helmet use and child safety seat use. They use a net benefit equations similar to Blomquist (1991). The study obtains price information and bases estimates of risk reduction solely on implicit values of time and on estimates of monetized disutility drawn from various other sources. These define the three methodologies they use, which vary according to how time and disutility costs are incorporated. VSL for the seat belt use varies from $\$ 1.69$ million to $\$ 7.80$ million in 1991 dollars. For child safety seat use, the VSL ranges from $\$ 2.89$ million and $\$ 5.15$ million in 1991 dollars. The VSL is $\$ 1.33$ million in 1991 dollars for helmet use.

Carlin and Sandy (1991) collected data on mothers' decisions on car seat usage from ten cities in Indiana and estimated a VSL for a child of \$ 0.42 million 1985 dollars. Jenkins, Owens and Wiggins (2001) calculate the VSL for adults and children using data on the purchase of bicycle safety helmets. They use a lower end price for helmets with same safety levels since the higher priced helmet does not provide any further protection. Children's VSL is estimated by parental willingness to pay to reduce their child's risk. Depending on the assumptions, the authors find an implied VSL in the range of $\$ 1.1$ million to $\$ 2.7$ million. Interestingly, in this study the VSL for children is lower (\$2.9 
million in the 5-9 age group and $\$ 2.8$ million in the 10-14 age group) than for adults (\$4.3 million). In a review of 20 averting behavior consumer studies from 1990, Blomquist (2004) found that VSL for adults ranged from $\$ 1.7$ to 7.2 million in 2000 dollars.

Ghosh, Lees and Seal (1975) used observable speeds on British motorways to estimate the value of life where the tradeoff involves time saved versus increased risk of death associated with the higher speed. Individual choice of highway speed, vehicle miles/month/mile of motorway, hours of daily average sunshine for a month (weather), and number of casualties were some of the variables utilized in the model. Two critical assumptions were: that drivers understood the incremental mortality risk associated with increased speeds and that the opportunity cost of time was equal to worker's wage rate. The second assumption is questionable since some drivers may have been driving just for the joy of driving in which case their opportunity cost may have been lower and some drivers may have been caused disutility by traffic congestion in which case their opportunity cost may have been higher. The Value of Life from a motorway fatality (VSL) from this study was $£ 94,000$ when the value of time is $£ 1.00$ an hour, the price of petrol is $35 \mathrm{p}$ a gallon and speed is assumed to be optimal at its actual average level of $58.8 \mathrm{mph}$. This is equivalent to $\$ 1.1$ million in 2002 dollars (Blomquist, 2004). The authors note that if the value of time is decreased, the implied Value of life becomes 0 at $63 p$ per hour and negative for values of time below that.

A similar study was carried out recently by Ashenfelter and Greenstone (2004). The objective of the study was to estimate how state agencies trade wealth for risk of 
death using state mandated speed limits on rural interstate roads. ${ }^{8}$ VSL for a median driver in state $i$ is assumed to be a function of observable $\left(\mathrm{X}_{\mathrm{i}}\right)$ and unobservable factors $\left(\varepsilon_{i}{ }^{\prime}\right)$

(2.5) $\operatorname{VSL}_{\mathrm{i}}^{*}=\alpha^{\prime}+\beta^{\prime} \mathrm{X}_{\mathrm{i}}+\varepsilon_{\mathrm{i}}^{\prime}$

Consider $\mathrm{VSL}_{\mathrm{i}}$ as the monetary value of the extra time saved per marginal fatality and $\mathrm{VSL}_{\mathrm{i}}{ }^{*}$ as the rate of substitution between the monetary travel costs and fatalities. Assume that for the median driver the optimal speed limit would balance the decreased cost of a mile traveled against his/her increased fatality risk. A higher speed limit will be adopted if $\mathrm{VSL}_{\mathrm{i}}>\mathrm{VSL}_{\mathrm{i}}{ }^{*}$, since the time costs saved by the higher speeds that result from the higher speed limit will be greater per fatality than the value of the median statistical life, $\mathrm{VSL}_{\mathrm{i}}{ }^{*}$. The probability that the higher speed limit is adopted is thus:

$$
\operatorname{Pr}(\text { Adoption })=\operatorname{Pr}\left(\mathrm{VSL}_{\mathrm{i}}>\mathrm{VSL}_{\mathrm{i}}^{*}\right)=\operatorname{Pr}\left(\varepsilon_{\mathrm{i}}-\varepsilon_{\mathrm{i}}{ }^{\prime}<\alpha-\alpha^{\prime}+\beta Z_{\mathrm{i}}-\beta^{\prime} \mathrm{X}_{\mathrm{i}}\right)
$$

where $\sigma=\sigma_{\varepsilon-\varepsilon^{\prime}}$ is $\left(\operatorname{var}\left(\varepsilon-\varepsilon^{\prime}\right)\right)^{1 / 2}$ and $\mathrm{F}[\bullet]$ is the cumulative unit normal distribution. $\mathrm{Z}_{\mathrm{i}}$ is a vector of observable factors that influence the costs per fatality due to an increase in the speed limit. It is apparent that the average value of VSL amongst adopters, $\mathrm{E}(\mathrm{VSL} \mid$ Adoption $)=\mathrm{E}(\mathrm{VSL} \mid \mathrm{VSL}>\mathrm{VSL} *)$, must be at least as great as $\mathrm{E}\left(\mathrm{VSL}^{*}\right)$, the unconditional average value of a statistical life among both adopters and non-adopters. Assuming that $\varepsilon_{\mathrm{i}}$ and $\varepsilon_{\mathrm{i}}^{\prime}$ are joint normally distributed, equation 2.6 can be estimated by the probit function:

$$
\operatorname{Pr}(\text { Adoption })=F\left[\left(\alpha-\alpha^{\prime}+\beta Z_{i}-\beta^{\prime} X_{i}\right) / \sigma\right]
$$

\footnotetext{
${ }^{8}$ They use it to study the effect of speed limits that were raised from $55 \mathrm{mph}$ to $65 \mathrm{mph}$ in 1987.
} 
In particular, estimates of $\alpha^{\prime}$ and $\beta^{\prime}$ can be used to derive an estimate of $\mathrm{VSL}^{*}$, the mean value of a statistical life in equation 2.5. Using the derivation above, the authors note that a monetary measure of value of time saved per fatality only serves as an upper bound for the VSL and is not a true VSL. ${ }^{9}$ With data from the 21 states that adopted this measure, they estimate that 125,000 hours per life lost were saved as a result of increased speed. This translates to a VSL of $\$ 1.54$ million.

Averting behavior studies have four major limitations plague this approach. First, they assume that individuals perfectly know both their baseline risk of dying and the risk reduction afforded by certain products or risk-reducing activities (Ball et al., 1997). Second, the amount of safety from which WTP is inferred may be limited by local market choices. For example, suppose a person wanted to buy a safer $\$ 900$ helmet but only an $\$ 800$ one was available Third, these studies capture the willingness to pay only of individuals or households who purchase the good. This may be problematic if a large proportion of households do not purchase the good. Fourth, certain assumptions in these studies can lead to biased estimates. For example, the time required to wear a seatbelt may not be the only factor determining its use. There is also an associated discomfort that discourages some people from using it. Therefore, not accounting for the latter can lead to an underestimation of the VSL (Fisher et al., 1989). Moreover, Viscusi (1993) contends that averting behavior studies do not provide information about the consumers' total willingness to pay for safety. This is because with such discrete decisions consumers may not be pushed to the point where the marginal cost of greater safety equals its

\footnotetext{
${ }^{9}$ Since states that adopted higher speed limits valued the time saved more than the fatalities incurred.
} 
marginal value. Thus he argues that the implied estimates from these studies are a lower bound of the value of life.

\subsubsection{Hedonic Price Function}

A typical hedonic price function measures how the price of a good varies with its attributes, including mortality risk. There are several ways one can utilize an hedonic price function to elicit the marginal willingness to pay for a risk reduction. One technique is to use labor market data to study occupational mortality risks. These compensating wage studies are based on the premise that workers must be offered higher wages for them to accept jobs with greater risks of dying, and that employers are willing to pay higher wage to avoid having to install safety equipment in the workplace.

The compensating wage literature has assessed wage-risk tradeoffs in a variety of situations. While some studies focus on the entire workforce (Thaler and Rosen, 1975; Viscusi, 1981; Moore and Viscusi, 1988), others have focused on a sub-sample of the workforce such as blue-collar workers (Dorman and Hagstrom, 1998; Fairris, 1989; Shanmugam, 1997; Shanmugam, 2001), union workers (Dillingham and Smith, 1984; Madheswaran et al., 2003) or petrochemical workers (Liu and Hammitt, 1999. Viscusi and Aldy (2003) provide an exhaustive review of the international compensating wage literature. They conclude that credible estimates of the VSL lie in the range of $\$ 4$ million to $\$ 9$ million (2000 dollar). Viscusi (2004), however, points out that these estimates can vary significantly across industries, occupations and individual characteristics.

Cropper and Oates (1992) point out three major deficiencies of hedonic wage analyses. First, the results are valid if and only if workers have full information about the 
mortality and injury risks that their jobs entail. Second, compensating wage premiums may not be observed in all industries. Third, measures of job risk used in the analysis should reflect workers' own perceptions of their job risks. Black and Kniesner (2003) find that the job risk measures in many wage equation studies are affected by measurement error probably of a non-classical nature, and most estimates of compensating differentials are not robust to even minor changes in specification. Kniesner and Viscusi (2005) point out that omitted variables in a standard wage equation model render the VSL estimates obtained from them too low.

An alternative hedonic pricing approach for estimating the VSL is to relate the price of a product to its attributes, ${ }^{10}$ including safety. Atkinson and Halvorsen (1990) regress the price of cars on car attributes, such as car size, model type, fuel efficiency, luxury index, and the risk of dying in an accident to find the implicit marginal price of risk. The standard hedonic car-pricing model is expressed as:

$$
\mathrm{C}=\alpha+\beta \mathrm{P}+\delta \mathrm{X}+\varepsilon
$$

where $\mathrm{C}=$ price of the automobile model, $\mathrm{P}=$ inherent risk of a fatal accident associated with the automobile model, $\mathrm{X}=\mathrm{a}$ vector of its other performance characteristics

For practical purposes a modified version of the above model is used since data are available only for the actual accident rate, $\mathrm{R}$, associated with a particular automobile model. This fatal accident rate $\mathrm{R}$ is a function of both $\mathrm{P}$, inherent risk and a vector of characteristics, $D$, of the drivers involved in the fatal accidents, where $R=g(P, D)$.

\footnotetext{
${ }^{10}$ Some researchers classify hedonic models that involve data from a marketed commodity like the price of a car, helmet, etc. as consumer market studies.
} 
Assuming $\mathrm{R}$ is monotonic in $\mathrm{P}$, the inherent risk can be implicitly measured by the inverse function $\mathrm{P}=\mathrm{g}^{-1}(\mathrm{R}, \mathrm{D})$. Substituting for $\mathrm{P}$ in equation 2.9 we obtain the modified model:

$$
\mathrm{C}=\alpha+\beta \mathrm{R}+\gamma \mathrm{D}+\delta \mathrm{X}+\varepsilon
$$

where $\mathrm{C}, \mathrm{P}$ and $\mathrm{X}$ are same as defined in equation (2.9), and $\mathrm{D}$ is a vector of driver characteristics that also affect the fatality rate. This model can now be estimated empirically. Atkinson and Halvorsen (1990) obtain a VSL of \$3.36 million in 1986 dollars using the data for 112 models of new 1978 automobiles.

Dreyfus and Viscusi (1995) use an extended version of the hedonic car-pricing model. Using a dataset of almost 3000 households from the U.S. Department of Energy Residential Transportation Consumption Survey, they regress the log of automobile price on discounted expected life years lost, discounted injury and discounted operating costs along with the attributes of a car and owner characteristics. They obtain an implicit value of life that ranges from $\$ 2.6$ million to $\$ 3.7$ million. Significant price effects are observed for auto injury risks and fuel efficiency. The estimated rate of time preference ranges from 11 to 17 percent according to the study.

The studies above considered safety as a personal decision. Some other studies have considered safety as family decisions and estimate VSL for children as well as adults. Mount, Weng, Schulze and Chestnut (2000) estimate a hedonic model of automobile fuel efficiency. In their model, automobile safety is considered as a family public good thus the marginal cost of purchasing and operating a safer automobile equals 
the usage weighted sum of VSL of family members. The authors estimate the VSL for adults at $\$ 6.34$ million, for children at $\$ 6.47$ million and for seniors at $\$ 4.59$ million.

\subsubsection{Other Revealed Preference Approaches}

One of the earliest studies to estimate the Value of Life in the road safety framework is Melinek (1972) for the Department of Fire Research in the United Kingdom. His model computes the VSL as the ratio of driving time saved by speeding to the increase in road traffic fatalities. Thus, for drivers, the Value of Life is computed as:

$$
V_{d}=\frac{S}{I}
$$

where $V_{d}=$ value of life for drivers,

$\mathrm{S}=$ value of driving time saved, and

$\mathrm{I}=$ increase in number of driver deaths

$$
\text { If } \quad S=\frac{0.01 s v}{A} \quad \text { and } \quad \mathrm{I}=0.03 \mathrm{n}_{\mathrm{d}} \quad \text { then } \quad V_{d}=\frac{s v}{3 A n_{d}}
$$

where $\mathrm{s}=$ distance traveled $\left(3.5 \times 10^{11}\right.$ passenger $\mathrm{km}$ per annum), $\mathrm{v}=$ value on unit time saved (23 $\mathrm{p} /$ hour $)$, $\mathrm{A}=$ average speed $(50 \mathrm{~km} / \mathrm{hr})$, and $\mathrm{n}_{\mathrm{d}}=$ number of road accident deaths ( 7300 per annum)

For estimating the value of life for pedestrians, the author uses the case of a pedestrian subway and the Value of Life is:

$$
V_{p}=\frac{S}{P}
$$

where $V_{p}=$ value of life for pedestrians,

$\mathrm{S}=$ value of time saved, and

$\mathrm{P}=$ probability of a fatal accident as a pedestrian 
If $\mathrm{S}=\mathrm{vt}_{\mathrm{c}} \quad$ and $\quad \mathrm{P}=\mathrm{p}_{\mathrm{a}} \mathrm{p}_{\mathrm{d}}$ then $\quad V_{p}=\frac{v t_{c}}{3 p_{a} p_{d}}$

where $\mathrm{v}=$ value on unit time saved (23 $\mathrm{p}$ /hour),

$\mathrm{t}_{\mathrm{c}}=$ extra time people are willing to spend to avoid risk from road crossing $(16.5 \mathrm{sec})$,

$\mathrm{p}_{\mathrm{a}}=$ probability of an accident from crossing the road $\left(3.5 \times 10^{-7}\right)$, and

$\mathrm{p}_{\mathrm{d}}=$ probability of these accidents being fatal $(0.035)$

Using the formulae in equations 2.11 and 2.12, yields a Value of Life for pedestrians of $£ 86,500$ and for drivers of $£ 73,500$.

\subsubsection{Limitations of the Revealed Preference Approach}

Viscusi (1993) points out two major limitations of revealed preference studies. First, these studies rely on the assumption that individuals know perfectly both their baseline risk of dying and the risk reduction afforded by risk-reducing products or activities and make rational decisions. Second, using market behavior restricts researchers to a narrow set of attributes that can be studied. Another limitation of revealed preference studies is that they cannot be used in situations where there is no observable market data. For example, they cannot be used to evaluate people's preferences towards public policies that reduce mortality.

\subsubsection{Stated Preference Approach}

Unlike the revealed preference approach, the stated preference approach involves asking a sample of individuals directly about their willingness to pay - or required compensation - for hypothetical changes in their risk of dying (Jones-Lee, 1989). In the literature, stated preference studies have been conducted for various types of mortality 
risks such as those from diseases, employment, natural disasters, environmental pollution, etc. Studies have also elicited the value of mortality risks in the abstract without specifying a cause of death.

The most commonly used stated preference approach is the contingent valuation method (CVM) in which individuals are asked how much they are willing to pay for a hypothetical reduction in their mortality risk under conditions specified in a scenario. An alternative to this methodology is to confront the respondents with two or more choices where monetary expenditure associated with corresponding risk levels is presented. ${ }^{11}$ The analyst then deduces the respondent's risk valuation based on the attributes of the chosen alternative. This is known as conjoint choice analysis, a technique that is frequently used in transportation research and environmental economics.

\subsubsection{Contingent Valuation Method (CVM)}

Contingent valuation (CV) is a survey-based methodology for eliciting values people place on goods, services and amenities (Boyle, 2003). This methodology, initially proposed by Ciriacy-Wantrup (1947) and applied first by Davis (1963), asks people to directly value goods for which markets do not exist, and for which, demand is unobservable. Valuation questions in a CV survey are contingent on hypothetical scenarios. In this section, I will focus only on the CV studies that have valued reductions in small mortality risks to estimate the VSL.

Contingent valuation studies in the literature have valued various kinds of mortality risks. Alberini et al. (2004) value reductions in mortality risks from all causes.

\footnotetext{
${ }^{11}$ Attributes other than risk of dying and costs may also be varied using this technique.
} 
There are studies that estimate WTP for reduction in mortality risks from accidents: e.g. WTP to avoid fatalities in traffic accidents (Persson et al., 2001; Johanesson et al., 1996; Jones-Lee et al., 1995) or tor reduced risk of dying in airplane (Savage, 1993; Carlsson et al., 2004) or underground rail accidents (Jones-Lee and Loomes, 1995).

Others evaluate WTP to reduce the risk of dying on the job (Gerking et al., 1988; Gegax et al. 1991), or to reduce risk of dying from a domestic fire (Savage, 1993; Rowlatt et al., 1998), or from gun violence (Ludwig and Cook, 2001. Finally, other examples include specific risks from fatal/chronic diseases; for example, WTP to reduce trihalomethanes in public drinking water systems that will reduce chances of death due to cancer (Carson \& Mitchell, 2006), WTP for the reduction in risk of dying from air pollution related diseases (Hammitt and Liu, 2004; Chilton et al., 2004), from pneumonia (Morris and Hammit, 2001), cardiovascular diseases (Alberini and Chiabai, 2005), skin cancer due to exposure to UV rays (Dickie and Gerking, 1996; Bateman and Brouwer, 2005), radiation induced cancers (Ami and Leblanc, 2000).

There are various types of elicitation formats that are used in CV studies-openended, dichotomous choice, payment card or bidding game. These are discussed in detail in section 2.4. Design issues are discussed in section 2.5 and advantages and limitations are discussed in sections 2.2.2.4 and 2.6, respectively.

\subsubsection{Conjoint Analysis}

As mentioned before, stated preference studies may be conducted with the aid of conjoint analysis techniques. Here, the individual is offered choice between a pair of 
alternatives or among a set of options from which the analyst deduces his/her risk valuation. The following discussion follows Bateman et al. (2002) which lists four different approaches to performing a conjoint analysis—choice experiments, contingent ranking, contingent rating and paired comparisons.

The most commonly used technique is the choice experiment (CE). Conventional choice experiments for mortality risk valuation present choice sets where at least two of the attributes that are varied are the risk of dying and cost. For example, the respondent is asked to choose between buying a $\$ 20$ bicycle helmet that reduces the risk of dying in a bicycle accident by $1 / 1,000$ or a $\$ 50$ bicycle helmet that reduces the risk of dying in a bicycle accident by $5 / 1,000$. In a contingent ranking experiment, a set of scenarios (three or more) with varying attribute levels are provided to the respondents who are asked to rank them in order of preference. Respondents may also sometimes be asked to rate the set of scenarios provided to them on a scale. This is known as a contingent rating experiment.

Conjoint analysis in general and CE in particular, has two major advantages over the CVM method. First, experience suggests that having to tradeoff attributes and compare alternatives tends to reduce outright rejection of the scenario, a phenomenon sometimes seen in CV studies. Second, CE choices are designed to reflect real-life choices and are thus easier for respondents to make compared to valuing a risk reduction (Bateman et al., 2002).

Similar to the case of CV studies, welfare estimates obtained from the CE method are highly sensitive to the study design — to the choice of attributes, their levels, and the 
manner in which they are presented to the respondents (Bateman et al., 2002). Although, using Monte-Carlo simulations, Lusk and Bailey (2005) observe that a large sample size can substitute for poor experimental design, Bateman et al. (2005) find that introduction of alternatives that are irrelevant ${ }^{12}$ in choice experiments produces biased estimates. Choice or rank complexity also poses problems for respondents (Swait and Adamowicz, 1996). Also it is more difficult for CE to derive values for a sequence of elements implemented by policy or project (Bateman, et al., 2002). The total value of changes in the provision of a good is found to be higher when questions are posed in a conjoint analysis format as compared to the CV format: Adamowicz et al, 1998; Hanley et al., 1998, 2003; Cameron et al., 2002; Foster and Mourato, 2003. Mackenzie (1993), Adamowicz et al. (1998) and Hanley et al. (1998) find that welfare estimates from conjoint analysis techniques are greater than those from contingent valuation. ${ }^{13}$ By contrast, Boyle et al. (2001) finds that conjoint analysis produces low welfare measures and large confidence intervals than $\mathrm{CV}$. It is still debatable which of the stated preference approaches is superior in eliciting values for mortality risk. Given the mixed evidence about conjoint analysis techniques in non-market valuation and even more so in the case of mortality valuation, it may be more appropriate to use a CV approach and obtain an answer directly rather than indirectly, especially if people have a good sense of what they are valuing.

\footnotetext{
${ }^{12}$ Bateman, Munro and Poe term this as decoy effects.

13 Their econometric analysis has been criticized as flawed since the underlying indirect utility specifications that they compare for the two sets are different (see Scarpa, 2000).
} 


\subsubsection{Advantages of Stated Preference Studies}

One major advantage of a stated preference approach is that it is flexible and allows for a survey design with as much variation in each attribute is feasible. Thus multiple changes in the levels of risk reduction can be studied in contrast to the revealed preference method where one has to deal with available market data (Bateman et al., 2002). Also, since there is little price variation in the real world, one can devise experiments with sufficiently different prices to allow for more precise estimation. By contrast, market data tend to be limited in the range of variation of features and attributes of products. Stated preference also allows the estimation of models using levels of attributes that do not currently exist thus providing an advantage over revealed preference methods (Freeman, 2003).

\subsubsection{Benefit Transfer Approach}

Lacking adequate primary data, researchers sometimes apply techniques that transfer results from one study site to another. This technique, known as the benefit transfer approach, estimates values for a policy site based on single or multiple studies in other sites. The main advantage of this approach is that it can save the time and money that are involved in conducting a new study in the policy site. The USEPA has used benefit transfers to evaluate many of its policies since the 1980s (Bergstrom, 1996). Environmental Canada has created an online database to facilitate conducting benefit transfers known as the Environmental Valuation Reference Inventory (EVRI). 
In general, transfer values may be estimated in a variety of ways. The simplest is the Value Transfer Approach. This can be done in two ways - unadjusted and adjusted. The unadjusted value transfer is the simplest of all approaches. It applies the value obtained from the study site to the policy site without any adjustments. This may be appropriate only when the context is similar and the socio-economic characteristics, physical characteristics and the market conditions between the study and policy sites are similar (Bateman, Nishikawa and Brouwer, 1999). However, rarely do conditions exist that allow unadjusted value transfer. This necessitates the need to adjust the transfer values using some suitable index.

The most commonly used formula for the adjusted value transfer modifies the value from the study site by adjusting for differences in the populations of beneficiaries. One such adjustment factor that is commonly used is per capita income. Thus, WTP at the policy site can be estimated using the formula in equation 2.14 :

$$
\mathrm{WTP}_{j}=\mathrm{WTP}_{i}\left(\mathrm{Y}_{j} / Y_{i}\right)^{e}
$$

where ' $\mathrm{Y}$ ' is the income per capita in the study (i) and policy (j) sites respectively and ' $e$ ' is the income elasticity of WTP. In practice, income elasticity is assumed to be equal to 1 when transferring estimates between two countries (ADB, 1996; Simon et al., 1999). Flores and Carson (1997) make a distinction between the income elasticity for WTP of an environmental amenity and the income elasticity of demand - the former looks at how WTP for a fixed amount of a good changes when income changes.

Sometimes, instead of unit values, confidence intervals are used for value transfers (Alberini et al., 1997). In other cases, researchers have transferred results from a 
sub-sample of the original study site because the policy site characteristics are similar to a sub-sample rather than to the entire study site. Subdividing samples however raises another issue - the confidence bounds around the original estimates and transferred values are larger (holding the confidence level the same) because of smaller sample sizes and hence produce larger standard errors (Bateman et al., 2002).

A more rigorous approach — the benefit function transfer approach -- also known as the model transfer approach, involves estimating a function based on data from existing studies. An estimate of WTP can be predicted for situations where studies cannot be conducted easily by inserting the known characteristics into the benefit transfer function (Bateman et al., 2002). Data from relevant studies are pooled and a combined model is estimated. This is known as the benefit transfer function. A typical benefit function looks like:

$$
W T P_{j}=\beta_{i}^{\prime} \bar{X}_{j}
$$

where WTP at policy site $\mathrm{j}$ can be estimated by inserting the average values of the variables from site $j$ in the estimated equation. The benefit function transfer approach accounts for variation only in sample characteristics and not statistical parameters.

Meta-analyses synthesize the most carefully done ones to explain differences in the estimates and obtain a range of findings that may be more acceptable than using results from any single study. In a meta regression, parameters are identified that cause differing results in the selected studies and which are used as explanatory variables (Bateman et al., 2002). In the case of VSL, one has to be careful in combining studies since different assumptions about VSL in earlier studies can produce significant changes 
in recommended values. Mrozek and Taylor (2002) and Viscusi and Aldy (2003) provide estimates for the range of VSL by selecting and comparing wage-risk studies in a metaanalytic framework.

There is considerable ambiguity over the validity of each of these approaches to best represent a real study. The benefit transfer function may be appropriate if applied to situations where conditions are similar, e.g. it may yield satisfactory results for the VSL if a benefit transfer function obtained in one developed country is applied to another. However, evidence suggests that VSL depends on the context in which it is assessed, such as road safety or health or wage-risk (Miller, 2000; Hammitt, 2000). Thus, VSL from a benefit transfer function for workplace safety in a developed country may be inappropriate for computing VSL in the road safety context, or for computing VSL in the workplace context in developing countries where the situation is very different. ${ }^{14}$

In the context of road safety, I am aware of three meta-analyses that rely on earlier studies to produce a single measure of the VSL. Elvik (1995) estimates the mean and median values of statistical life related to road and occupational safety. He uses VSL estimates derived from studies using either stated and/or revealed preference methods. His main conclusions are that the mean VSL for occupational safety is higher than for transport safety; poorly designed stated preference studies result in higher estimates than more carefully designed studies; estimates of studies with high validity — those studies with tests of rationality or risk perceptions and those that use individual data - lead to lower valuations and lower risk levels result in higher VSL estimates.

\footnotetext{
${ }^{14}$ Ready et al. (2004) however finds that context effects are not significant.
} 
Miller (2000) combined 68 studies of road and occupational risks as well as of other fatal risks from 13 countries to obtain a value of statistical life that is strongly dependent on income levels. The VSL estimates were on an average 120 times annual per capita income. The income elasticity of these estimates across countries ranged from 0.85 to 1.00 . Studies using both stated and revealed preference methodologies were included. He also estimated a transfer function that could be used to predict estimates for any country given per capita GDP. The estimate of the VSL for the US ranged between $\$ 3.3$ million and \$4.5 million in 1995 dollars.

DeBlaeij et al. (2003) combine studies conducted exclusively in the context of road safety since most studies in this area value risks that are typically lower than those in other categories such as occupational hazards. Thus combining the results from these studies with others may not be a suitable strategy. The authors find that initial risk levels have significant impacts on the VSL and thus cannot be disregarded when predicting values. Also, they determine income elasticity in the context of road safety to be 1.33 . Significant differences are found with respect to the choice of preference revelation method; i.e., revealed preference studies led to lower estimates than the stated preference studies. Private good framing produces higher estimates than public good framing. Payment vehicle, risk elicitation method, and type of safety enhancing measure also affected the estimates.

\subsubsection{VSL in Road Safety}

As discussed above, the VSL in the context of road safety has been estimated using both revealed preference and stated preference approaches. A review of the 
literature shows that most of the early studies used revealed preference techniques whereas most of the recent studies use stated preference techniques. Although various approaches have been proposed to estimate the VSL, all of them rely on the assumption that people understand the risk reduction afforded by certain behaviors and products, or that they understand and accept the risks communicated to them in stated preference studies. This has been questioned for very small risks and risk changes (Tversky and Kahnemann, 1974; Fischhoff, 1990; Viscusi, 1993). It is also assumed that people have very well defined preferences for risk and income tradeoffs. The changes in risk levels are sometimes so small that this tradeoff becomes very difficult, if not impossible, to make (Hauer, 1994). Nevertheless, numerous estimates for VSL in road safety do exist. The magnitudes vary widely from less than USD 400,000 to USD 30 million in 1996 dollars (deBlaeij, 2003).

\section{3 Factors Influencing WTP and Hence the VSL}

In theory, WTP for mortality risks is influenced by initial wealth and initial risk (section 2.2.1). This theoretical foundation rests on the premise that individuals have an adequate perception of the risks undertaken and have the ability to make rational decisions (Jones-Lee, 1989). Psychologists have identified several ways in which people distinguish risks - knowledge, timing, suffering, possible disaster, newness, voluntariness, and control (Slovic, Fischhoff and Lichtenstein, 1979). These factors have been studied by economists to ascertain whether they have any influence on WTP values. Specifically, studies have investigated whether WTP measures for small mortality risk reductions are influenced by the size of risk reduction, baseline risk, perception of risk 
(voluntariness and controllability), timing (latency), and the context in which the risk reduction is applied (e.g. as a private versus a public good).

\subsubsection{Size of Risk Reduction}

One major challenge often faced in contingent valuation studies is that WTPs are insensitive to the size of risk reduction. Economic theory expects the values individuals place on risk reductions to be sensitive to their size. This criterion is often validated using a scope test. The scope test examines whether WTP values increase monotonically with the size of risk reduction. The weak criterion of this test requires WTP to increase with the size of risk reduction valued, whereas the strong criterion requires WTP to increase in proportion to the size of the risk reduction (Hammitt and Graham, 1999). When the scope test is examined within the same sample it is called an internal scope test, i.e., it tests whether the same respondent valued a larger risk reduction more than a smaller one. In contrast, an external scope test examines the scope effect between samples, i.e., it tests whether different respondents placed higher values on a larger risk reduction for the same set of conditions (Hammitt and Graham, 1999).

Beattie et al. (1998) study minor, temporary, permanent and fatal risks from traffic accidents in UK. They try to make the small changes in risk more intuitive by using frequencies of occurrence rather than probabilities. Thus, respondents are asked about their WTP for a road safety program that prevents a number of deaths in a specified

area. Unfortunately, the results show that persistent insensitivity to scale and scope remain, and point to vulnerability from framing effects. 
Based on empirical evidence, researchers have recommended providing information to respondents on risks and costs for alternative goods and services on the market, in order to improve their ability to make rational decisions on hypothetical markets. Using two CV studies from Sweden, Norinder, Hjalte and Persson (2001) find that when the respondents have a reference point, i.e., when the same respondent valuesseveral sizes of risk reductions, WTP is internally sensitive to scope. Preference uncertainty can give rise to hypothetical and scale biases. Corso, Hammit and Graham (2001) find that different kinds of visual aids can be used to reduce this bias.

Rizzi and Ortuzar (2003) apply a different approach to tackle the problem of insensitivity to scope. These authors assert that people do not perceive risks in terms of objective probabilities but rather in terms of actual number of accidents or fatalities. On the basis of that rationale, the absolute number of accidents in a day (averaged on a yearly basis) with at least one fatality is chosen as the proxy variable for risk. ${ }^{15}$ This article details the results from three surveys that used the stated choice framework and contained similar statistical designs - two interurban surveys by Rizzi and Ortuzar and one urban survey by Iragüen and Ortúzar. Respondents were told that they would be driving a car on a specified route and that they would have to pay a toll and travel at a specified time. In each of the questions, respondents were given two choice scenarios with three varying attributes - time of the accident, toll, and number of accidents with at least one fatality. Nine choice questions were presented in each survey. The authors

\footnotetext{
${ }^{15}$ They reported 12 accidents with at least 1 fatality occurring daily on the Santiago-Valparaíso route using the 1996-97 data.
} 
found that the subjective value of accident reductions (SVAR) ${ }^{16}$ and the value of risk reduction $(\mathrm{VRR})^{17}$ was greater for the riskier scenario. If the value of risk reduction (VRR) is considered identical in the first two samples (interurban studies), then VRR is obtained as USD 759, 837. VRR for the third urban survey is USD 290,009. Using data from three surveys, the authors find that VRR increases with the size of the risk reduction. Thus, by using a proxy variable for mortality risk, they obtain sensitivity of WTP to the risk reduction.

As mentioned earlier, a stronger scope criterion requires that estimated willingness-to-pay be proportional to the size of the risk reduction (Hammitt, 2000). This is a critical assumption that is applied in the calculation of VSL that most empirical studies fail to substantiate. Even though for small risk changes WTP is expected to vary proportionally to the size of risk change, empirically it has not always been found to vary proportionally with the size of risk change (Carson \& Mitchell, 2006; Alberini et al., 2000; Corso et al., 2001; Andersson, 2005; Viscusi \& Zeckhauser, 2005). One may argue that the proportionality test is irrelevant if respondents experience diminishing marginal utility in the risk reduction, i.e., if willingness-to-pay is nonlinear with respect to the size of the risk reduction. In a study of willingness-to-pay for reductions in the risk of being exposed to trihalomethanes, Carson and Mitchell (2000) find evidence to support the hypothesis that willingness-to-pay is non-linear in the risk reduction.

\footnotetext{
${ }^{16}$ Similar to WTP, except it is the value for reduction in the number of fatal accidents and not risk as a probability.

${ }^{17}$ Same as VSL. It is the value of avoiding one expected death in a population (Jones-Lee, 1994).
} 
Corso, Hammitt and Graham (2001) used a phone-mail-phone survey to investigate the effects of visual aids on the sensitivity of WTP responses to mortality risk reductions in the context of automobile crashes. They tested three kinds of visual aids: two types of risk ladders, multicolored logarithmic and linear scales and a grid with an array of dots. There was a fourth scenario where the respondents were not provided any visual aids. Respondents were told their initial and final risk levels if they chose to purchase an optional side-airbag on the next vehicle they purchase. WTP was elicited using double-bounded dichotomous-choice question format with an increase in annual car payments over a five-year period. There were eight versions of the questionnaire (4 visual aids $\times 2$ baseline risk levels). The results indicated important differences in effect of alternative visual aids on the sensitivity of estimated WTP to magnitude of mortality risk reduction. For the sub-sample that received no visual aid there was no statistically significant relationship between WTP and magnitude of risk reduction. For sub-samples that received visual aid there was a statistically significant relationship between WTP and the magnitude of risk reduction. The dots (grid) yielded results consistent with economic theory, i.e., statistically significant sensitivity to magnitude (single and double bounded). The logarithmic scale yielded results that were not statistically significantly different from theory. Only estimates using the logarithmic scale or array of dots were consistent with proportionality between WTP and the risk reduction.

Dubourg, Jones-Lee and Loomes (1997) conducted an in-person survey in the UK in which respondents were asked a variety of questions about a safety feature to be installed in cars. The respondents were shown injury/health cards and then asked to rank 10 injury/ health states based on information provided in the cards. The respondents were 
subsequently asked to locate them on a visual analog scale calibrated from 100 (best) to 0 (worst). The annual risk of each category on a scale of 100,000 was presented in the form of a grid. There were two versions of the questionnaire and the study was conducted in three stages. In Stage I, version 1 asked for a lump sum payment for the stated risk reduction whereas version 2 asked for an annual payment (renewable) for the safety feature to be installed in the car. There were 5 WTP and 2 WTA questions in the injury categories. Additional safety features reduced baseline risk by $50 \%$ in each of the categories. In each sample, half the respondents began each question with £25 displayed while the other half were initially shown $£ 75$. Three possible responses were elicited: definitely yes, definitely no and not sure. Value elicitation was conducted via an iterative bidding procedure using a plain white disc in which a small window was cut to reveal a single number at a time. Depending on the response, the interviewer rotated the back of the disc and changed the sums until two points had been determined: the largest amount the respondent would definitely pay and the smallest amount the respondent would definitely not pay. The interviewer then asked for a single amount between these upper and lower bounds that was the respondent's best estimate of what he would most likely pay.

The objective of Stage 2 of this study was to examine sensitivity of responses to different magnitudes of risk reduction. The same cards as in Stage 1 were shown but with much shorter questionnaires that focused only on WTP/WTA annual payments/ savings. There were four variants of the questionnaire with same baseline risks as in stage 1 but only two sub-samples were given same risk reduction as in stage 1; the other two were given different risk reductions. Payment cards instead of numbered discs wereused with 
payments ranging from $£ 0$ to $£ 500$. Strong starting point biases and strong range effects were experienced in Stages 1 and 2 respectively. In both stages, lack of sensitivity to severity of injuries as well as to the magnitude of risk reduction was observed. In the third stage the questionnaire was identical to the one presented to group $\mathrm{C}$ of stage 2, with an additional question regarding injury category S's risk reduction (12/100,000 risk reduction question in addition to the original 4/100,000 risk reduction). A single payment card with values ranging from $£ 0$ to $£ 500$ was used in this stage. The embedding effect was eliminated in this stage as well as insensitivity removed in at least three-fourths of the cases. The results from the study are provided to the UK Dept. for Transportation with a value for reductions in risk of serious non-fatal road injuries relative to fatality risk.

\subsubsection{Timing of Risk}

Mortality risks may be broadly classified into two categories - acute and chronic. Acute risks are those risks that cause premature death immediately on exposure like accidents, inhalation of toxic fumes, etc. Chronic risks are those where premature death occurs in the form of reduced life expectancy due to long-term exposure to the risk factor. Chronic risks cause illness for some period of time before death occurs. Examples include skin cancer risks due to exposure to UV rays or asthma due to exposure to air pollutants. Latent risks are those where there is a latency period between exposure and impact, i.e., premature death occurs in the future. For instance, exposure to asbestos may lead to mesothelioma and premature death many years after the exposure in healthy young individuals. Another example would be death from lung cancer due to prolonged 
smoking. Johannesson et al. (1997), Krupnick et al. (1999), Alberini et al. (2001), Markandya et al. (2004), Chilton et al. (2004) and Hammitt and Liu (2004) find that people are willing to pay higher amounts for reducing immediate (acute) risks than latent ones.

\subsubsection{Perception of Risk}

Risk perception can influence the value individuals place on risk reduction. Individuals may perceive some risks as being unavoidable, others as being under their control (voluntary risks) and others as being imposed upon them (involuntary). The voluntary-involuntary distinction is linked to feelings of responsibility. Risks for which individuals hold themselves responsible tend to be valued lower than risks for which individuals hold others responsible or risks over which individuals have no control. Voluntariness can be linked to controllability.

In the literature, WTP may vary according to the voluntariness and controllability of the risk (Jones-Lee et al., 1985; Jones-Lee \& Loomes, 1995; Viscusi \& Zeckhauser, 2005). On the other hand, in a recent comparative study for mortality risk reduction of road accidents and air pollution in Thailand, perception of risk type was found to have negligible impact on WTP (Vassanadumrongdee and Matsuoka, 2005).

Context effects are the result of people's perceptions of and attitudes towards the context or circumstances in which accidents happen and may influence their WTP. For example, reducing risk of death on the London Underground attracted a $50 \%$ premium 
over reducing fatality risk on the road (Jones-Lee and Loomes, 1995). ${ }^{18}$ The study examined both scale and context effects. The scenarios offered for the scale effects were whether people would choose 25-30 deaths in a single underground accident or 25-30 deaths in separate underground accidents. A $51 \%$ premium was placed on large-scale underground accident prevention primarily because of its involuntary nature. The context premium was significant but the scale premium was not. The authors recommended increasing the VSL for an underground accident to 1.5 times the figures for above ground road or rail safety.

Beattie et al. (1998) observed that WTP-based values of safety are not universally transferable and that people's ex-ante willingness to pay to reduce risk will instead tend to vary with their perceptions of and attitudes towards the characteristics of different hazards; for example whether the hazard is seen to be voluntarily assumed, under the potential victims' own control, or their own responsibility, well-understood (Slovic et al., 1985). Economic theory assumes that people's preferences are stable; however, empirical evidence suggests otherwise. Research suggests that people's risk perceptions systematically respond to information. Thus the content and framing of information in CV studies can influence respondents' risk perceptions, and both stated and actual behavior.

It is often argued that the proportionality criterion in $\mathrm{CV}$ studies is probably not achieved because individuals base their valuations not just on the risks given in the survey but also on their prior experiences and beliefs (Viscusi, 1989; Hakes and Viscusi, 1997; Hammitt and Graham, 1999). These subjective evaluations of risks by individuals

\footnotetext{
${ }^{18}$ These figures may be of significance after the recent bombings in London last year in July.
} 
imply that they act as Bayesian decision makers whose posterior probabilities are a function of prior beliefs and survey information. This model is dealt in greater detail later in Chapter 7.

\subsubsection{Private versus Public Risk Reduction}

Risk reductions for traffic fatalities can be delivered in two possible ways: through a public program, or as a private risk reduction (Johannesson et al., 1996; Romer et al., 1998; Hultkrantz et al., 2006). The choice between the two depends on the purpose for which the study is conducted, as well as on practical considerations. It may seem straightforward to base the valuation exercise on a public program that reduces the risk of dying. However, two extreme types of behavior might stimulate responses in this situation: (1) altruistic considerations, and (2) free riding. Altruistic behavior may be either paternalistic or non-paternalistic. The corresponding value of a statistical life depends closely on the type of altruism exhibited (Jones-Lee, 1991). ${ }^{19}$ These complexities have led to researchers focusing on private risk reductions, which usually involve the purchase of a safety device or a medical intervention to bring about the risk reduction. Instruments for private risk reductions may however carry side effects that may lead to scenario rejection.

\footnotetext{
19 "It is appropriate to include the full amount of people's willingness to pay for others' safety in the definition of VSL if and only if altruism is exclusively safety-focused in the sense that, while $i$ may be concerned and hence willing to pay for $j$ 's safety, he or she is completely indifferent to the other determinants of $j$ 's wellbeing," Jones-Lee (1991). The value of statistical life varies in a simple and systematic manner, increasing as one gets nearer to safety-focused altruism and decreasing as one approaches the wealth focused form. Bergstrom (1982) and Jones-Lee (1992) show that for cases of pure altruism and pure paternalism, VSL should be set equal to the value that emerges from pure self-interest.
} 
Based on the Jones-Lee (1991) model, Johannesson et al. (1996) attempts to investigate VSL when road safety is presented as a private good versus a public good. The telephone survey was administered to individuals aged 16 and above who owned a car. Respondents were informed about the absolute number of traffic deaths in the population. One group of respondents was offered a safety device to be installed in their cars that would reduce the risk of dying in a traffic accident for all travelers in the car by 'half'. This safety equipment had to be installed each year to work. The other group was offered a public safety program (improved road quality ${ }^{20}$ ) in the form of increased car taxes. This would reduce traffic mortality risk by $50 \%$ for all road users. Each group was presented with bids and follow up questions to confirm the confidence in their responses. WTP for the private safety device ranged from SEK 4700 using standard estimation ${ }^{21}$ to SEK 2400 using conservative estimation higher than the WTP for the public safety program, which ranged from SEK 3900 using standard estimation to SEK 1300 using conservative estimation. For the conservative (standard) estimation, the WTP for private safety measure is (not) significantly higher than the WTP for the public safety measure. VSL varies between SEK 30 million ( $\$ 4.5$ million) and SEK 59 million ( $\$ 8.9$ million) for private risk reduction. VSL varies between SEK 17 million (\$4.5 million) and SEK 49 million (\$7.4 million) for public risk reduction.

Persson et al. (2001), in a mail survey in Sweden, used a private risk reduction, describing a hypothetical safety device that would reduce risk for one year only and would be worn by the car driver or passenger. Respondents were asked to purchase the

\footnotetext{
${ }^{20}$ Examples were provided as straightened out bends, build safer crossings and increased supervision of traffic.

21 Standard estimation involved all responses, whereas conservative estimation involved bids of respondents who strongly confirmed their choices in the follow-up question.
} 
safety device after being told the average risk of dying in a traffic accident for a person of their age and gender. They were then asked their own perceived baseline risk considering their frequency of travel, distance traveled, choice of transportation mode and how safely they drive. The risk change was expressed as a percentage $(10,50$, or 99 percent) of the baseline risk. WTP was regressed on baseline risk, the risk change, and individual characteristics; however, both baseline risk and risk changes are likely to be endogenous. Results supported an inverted-U shaped relationship between WTP and age. ${ }^{22}$ A positive relationship was observed between WTP and income and WTP and the size of the risk reduction. The VSL ranged from 30.38 million SEK (\$3.59 million USD) for a $1.8 / 100,000$ mortality risk reduction to 24.01 million SEK ( $\$ 2.84$ million USD) for a 2.4/100,000 mortality risk reduction to 13.17 million SEK ( $\$ 1.56$ million) for a $5 / 100,000$ mortality risk reduction..

\subsubsection{Individual Characteristics}

As expected, WTP may vary with individual characteristics such as income (Gerking et al., 1988; Flores and Carson, 1997; Bloom and Sevilla, 2004; Alberini et al., 2006) and age (Shepard and Zeckhauser, 1984; Jones-Lee et al., 1985; Cropper and Sussman, 1990; Krupnick, et al., 2002; Hersch and Viscusi, 2005). There is also some limited evidence about the effect of health status on WTP (Johannesson and Johansson, 1996; Alberini et al., 2004; Smith, 2004; Jones-Lee and Loomes, 2004; Alberini and Chiabai, 2005) etc.

${ }^{22}$ Estimated coefficients for age and [age-mean age $]^{2}$ are found negative. 


\subsubsection{Context}

Dionne and Lanoie (2004) suggest that the VSL for transportation risks may differ from the VSL in other contexts because the nature of the deaths may differ. Empirical estimates of VSL often confirm that it varies by context (Viscusi and Aldy, 2004; deBlaeij, 2003). If WTP does vary with context, then transfers between studies conducted in different contexts are invalid (Dionne and Lanoie, 2004). Most empirical studies in the literature indicate significant contextual effects.

Savage (1993) in a telephone survey asked 1,027 adults about their perceptions of four risks: commercial airplane accidents, household fires, automobile accidents and stomach cancer, and also asked respondents to value changes in these risks. The author found that WTP increased with the dread of the risk but declined with degree of knowledge people have about the risk they are exposed to. Although this study provided WTP estimates for these four risks, it did not measure individual WTP to reduce own risk. No information about baseline risk and the magnitude of risk reduction were specified in the survey. Results indicated that WTP to avoid stomach cancer was substantially higher than WTP to avoid road accidents, air accidents and deaths from domestic fires.

Similarly, Chilton et al. (2002) estimated the VSL in four contexts: railways, domestic fires and fires in public places, as well as for road accidents. Respondents were introduced to the four hazard contexts and further informed that money was available to fund one public program to reduce deaths. They were given choices between preventing 10 deaths from Cause $\mathrm{X}$ versus preventing 10 deaths from Cause $\mathrm{Y}$. The indifference 
points were determined by asking how many extra deaths must be prevented from the cause of death not chosen above to be indifferent between the two policies. Results indicated a clear and statistically significant upward shift in the priority given to the rail safety program in the 2000 study relative to the 1998 study; however preference for fire safety (public and private) both decreased from 1998 to 2000. However, none of the typical risk characteristics (e.g., dread, expert-knowledge, voluntariness and controllability) was significant, only personal exposure and household benefits were significant. The authors cautioned that the indifference points may have been influenced by respondents' misconceptions of baseline risks.

Carlsson et al. (2004) compared the VSL based on preventing fatal risk in an airplane versus a taxi in a survey of Swedish respondents. I $n$ both cases the risks are beyond the control of the respondent. In the road accident scenario, the respondent is asked to imagine that he is traveling alone on a taxi ride from his/her home to a train station or a restaurant or an airport and must choose between two taxis that vary in risk of death because one is equipped with an advanced safety system. In the airline scenario, the respondent is asked to imagine flying alone for a week's vacation to Amsterdam from the airport closest to home. The choice is between two airlines that are identical in all respects except the risk of a fatal accident. The results suggest that WTP is significantly higher for flying than in a taxi. This may indicate that individuals are willing to pay a premium for risks that are perceived as more uncontrollable than others.

Tsuge, Kishimoto and Takeuchi (2005) compare WTP to reduce risks from road accidents, cancer and heart disease using a choice experiment approach. The respondents are asked to choose between two hypothetical commodities that reduce mortality risk and 
differ with respect to price, effective type of risk, amount of the risk reduction, and latency period. Voluntariness, controllability, dread and knowledge about the risk are considered. A typical choice set is displayed in Figure 2.2:

FIGURE 2.2: EXAMPLE OF A CHOICE SET USED IN TSUGE ET AL. (2005)

\begin{tabular}{|c|c|c|c|}
\hline & 1 & 2 & 3 \\
\hline $\begin{array}{l}\text { Price } \\
\text { (for } 10 \text { years) }\end{array}$ & 80,000 Yen & 850,000 Yen & \multirow{4}{*}{$\begin{array}{l}\text { I do not wish to } \\
\text { purchase } \\
\text { either }\end{array}$} \\
\hline $\begin{array}{l}\text { Risk Reduction } \\
\text { (for } 10 \text { years) }\end{array}$ & $1 / 10,000$ & $10 / 10,000$ & \\
\hline Risk Type & Accident & Disease (Cancer) & \\
\hline Effect Starts & 5 Years Later & 10 Years Later & \\
\hline
\end{tabular}

The estimated discount rate was $20 \%$ indicating that individuals exhibited a strong preference for risk reductions of an immediate nature than for future risk reductions. Population characteristics were more significant than risk characteristics in affecting the VSL. The VSL for reducing the risk of death from both traffic accidents and heart disease was found to be higher than that for reducing cancer risks.

\subsection{Eliciting WTP in CV Studies}

A variety of response formats are used to elicit the WTP in CV studies. The most common formats are the open-ended approach, payment card approach and the dichotomous choice approach. Of these, the latter is the most widely used (Boyle, 2003). Below is a brief description of a few of the elicitation formats that have been used in the CV literature. 


\subsubsection{Open-Ended}

An open-ended format poses the question directly in a very straightforward manner to the respondent (e.g. how much money are you willing to pay for a reduction of $\mathrm{X}$ to your risk of dying from a road accident?). There can be no anchoring biases using this format. Nevertheless, theoretically, open-ended responses are not considered incentive compatible (Boyle, 2003). Moreover, they suffer from potentially large nonresponse rates, protest answers, zero bids and outliers which may all lead to unreliable responses (Mitchell and Carson, 1989). Very few road safety studies have elicited WTP values through open-ended questions. One such study is Desaigues and Rabl (1995) where French subjects were asked to elicit their WTP for reduction in the number of road accident fatalities (as an absolute number) given the total number of fatalities in France.

\subsubsection{Dichotomous Choice}

In the closed-ended format, valuation questions can be posed in variety of ways, all of which provide pre-specified response options from which the respondent selects the appropriate one (Boyle, 2003). The simplest is the take-it or leave-it format (e.g., are you willing to pay $\$ Y$ for an $\mathrm{X}$ reduction in your risk of dying from road accident? Yes or No). There may be consecutive multiple bids conditional on the responses used in the bounded format. Sometimes these also follow a bidding pattern where a series of bids are offered until the maximum willingness to pay is acquired. A more complex formulation provides more specific choices to these questions like "definitely yes," "probably yes," "not sure," "probably no," and "definitely no." These are together classified as what is 
known as the dichotomous choice format. A few studies in the road safety valuation literature have also employed this elicitation format (Scarpa et al., 2001).

Although this format has been shown to have some theoretically incentive compatible desirable properties when framed as a referendum vote (Hoehn and Randall, 1987), it suffers from anchoring, yea-saying problems and the voting as a good citizen

phenomenon. The dichotomous choice approach has been shown to yield significantly higher welfare estimates than the payment card approach (Ryan et al., 2004; Donaldson, 1999). This has led to significant concerns in the CVM literature over the prospects of 'yea-saying' behavior. However two studies indicate that this may not be so: Boyle et al. (1996) and Ready et al. (2001) find no significant differences between dichotomouschoice and open-ended responses.

\subsubsection{Payment card}

Specially designed payment cards that provide a range of possible values are often used in this framework to ease the respondent's task. Payment cards provide the respondents with an ordered set of values. Stated values from a payment card usually indicate an interval within which the respondent's true valuation lies. This is based on the assumption that WTP is greater than the amount selected from the payment card but less than the next highest amount listed on the card. Using OLS to evaluate the mid-point values of these intervals provides potentially biased parameter estimates and misleading inferences as compared to efficient maximum likelihood estimation using the entire interval (Cameron and Huppert, 1989). 
Owing to its ease for the respondent, this approach has become the next most popular method after dichotomous choice (Jones-Lee, 1989; Beattie et al., 1998; Reaves, 1999; Brox et al., 2005). However, like the dichotomous choice method, it may be subject to anchoring biases - starting point and mid-point. While the mid-point bias can be eliminated by specially designing the array so that there is no middle value, the starting point remains a concern, at least theoretically.

\subsubsection{Standard Gamble and Chained Approach}

Researchers have also experimented with standard gambling approaches in order to elicit more reliable estimates of WTP. Standard gamble formats typically ask respondents to trade off the certainty of being in an intermediate health state for the remaining life expectancy with a 'treatment' that offers a chance of regaining full health for the remaining life expectancy but also entails a risk of immediate death. The probabilities of success and failure are both provided to the respondent.

Jones-Lee, Loomes and Philips (1995) compare the contingent valuation approach with a standard gamble approach for four non-fatal injury risk reductions. Two samples were considered that were both similar in age, gender, car ownership and social class. One of the samples was presented with a contingent valuation scenario where risks were presented on a grid and asked their willingness to pay for a stated risk reduction using a safety device. Six risk reduction scenarios were considered for this sample. The other sample was offered the risk reduction scenarios in a standard gamble format. The respondents in this sample were asked to choose between the two scenarios as described below: 


\section{(1) Health State R 'FOR CERTAIN' or (2) Health state J if Treatment SUCCEEDS Health state $\mathrm{K}$ if Treatment FAILS}

with corresponding probabilities for success and failure that varied from 10 percent to 99 percent. The CV estimates were remarkably higher than SG estimates and the disparity increased with the size of the risk reduction. The authors believed that SG estimates were more reliable for policy purposes. WTP values were $£ 70,000$ for the prevention of serious non-fatal injuries in 1990 prices.

Similarly, Guria et al. (2003) compare conjoint choice with the standard gamble approach using a survey based on mortality and non-fatal injury risk reduction in traffic accidents in New Zealand. Since the questionnaire was partly administered using a computer, respondents were randomly assigned either the matching question or standard gamble framework. In the matching question or contingent choice framework, respondents were asked to choose between minor injuries with greater risk reduction versus temporary injuries with smaller risk reduction, both of which cost the same. In the standard gamble framework, respondents were given a choice between two alternative clinical treatments ${ }^{23}$ after an accident with different sets of probabilities for recovery in a standard gambling format.

Koyama and Takeuchi (2004) estimated WTP by using the weight of road injuries against fatalities based on Japanese people's preferences elicited by a standard gamble approach. Respondents were asked to evaluate the weight of the medical treatment for an automobile injury in a standard gamble format from both a private viewpoint and a social

\footnotetext{
${ }^{23}$ The question was very similar to the one asked in Jones-Lee et al. (1995).
} 
viewpoint, i.e., as a third party, using a mail-in survey ${ }^{24}$. No questions to test the probability comprehension abilities of the respondents were included. Two types of injury classifications were used. Respondents were asked to suppose that they had met with a road accident. They could either choose to undergo the usual treatment, whose consequences were described in the card, or choose to undergo a new treatment with probabilities of either restoring back their normal health state if successful or dying if unsuccessful. A column of chances of success ranging from 99/100 to 10/100 were displayed and respondents had to circle the point beyond which they were confident that they would choose to have the risky treatment and the point where they were confident that they would definitely reject the new treatment. Respondents were also asked to indicate the point at which their accept/reject decision was finely balanced. Only the physical and mental pain as well as inconvenience from injury was to be accounted for. No treatment costs or lost income were to be considered in making the choices. For the social viewpoint, respondents were asked to imagine that this choice was to be made for someone else, as a doctor or medical counselor. Their estimates indicate that the human cost of fatalities and injuries when estimated using people's preferences are significantly higher than if computed as the sum of lost income and medical costs.

When immediate death is used as the treatment failure outcome, a possible problem with the standard gamble is that many people may not be willing to accept any chance of treatment failure when minor or temporary states of poor health are valued ${ }^{25}$. In these circumstances, the basic reference standard gamble may be insufficiently sensitive

\footnotetext{
${ }^{24}$ Survey design similar to Jones-Lee et al. (1993 \& 1995).

${ }^{25}$ For example, if a respondent has (or is being asked to assume that she has) a slight limp, she may not be willing to accept a treatment that entails any chance of immediate death.
} 
to capture true underlying preferences. One possible way of overcoming the problem of insensitivity in the standard gamble is by indirectly linking — or 'chaining' - minor or temporary health states to death (Jones-Lee et al., 1995). Thus, when valuing a minor or temporary health state, a non-fatal health outcome that is considered more severe than the intermediate health state that is being valued could be used instead of immediate death as the treatment failure outcome. For example, if a slight limp is the health state being valued, the treatment failure outcome could be the loss of the leg. The value of the loss of the leg could then be chained from a further gamble where the loss of a leg is valued using a treatment that offers a chance of full health or immediate death. The chaining approach also exhibits a potential to attenuate biases owing to less marked embedding effects that exist in most other direct contingent valuation questions. A drawback of this approach is that biases at any stage during the process may become intensified when combined with other links in the chain (Jones-Lee and Loomes, 2004).

Carthy et al. (1999) estimate a VSL for road risks using a chained approach that first elicits the WTP for the certainty of a complete cure from an easily imaginable 'slight injury' from a road accident and the WTA compensation for the certainty of sustaining the same injury and then uses 'standard gamble' questions to link this scenario to others entailing a range of more serious consequences, up to and including premature death. There were six questions that were posed to the respondents in the following order: WTA for 2 weeks hospitalization with full recovery after 18 months, WTA for 2-3 days hospitalization with full recovery after 3-4 months, WTP for the above two questions, respectively, and a standard gamble for 2 weeks hospitalization in which treatment failure could result in death and standard gamble for 2-3 days hospitalization in which treatment 
failure could result in hospitalization and prognosis for the first (severe) injury. The authors recommend a VSL figure of $£ 1$ million for road policy appraisals in UK with confidence, considering the robustness of the $\mathrm{CV} / \mathrm{SG}$ chained approach that they employed in the study.

\subsubsection{Risk Metric}

Viscusi et al. (1991) initiated a novel approach to elicit preferences for various mortality risks. Known as a risk metric, it eliminates the need for monetary attributes and interprets risk preferences through indicated choices. Unlike risk-dollar tradeoffs, the budget constraints of the respondents are not a factor, thus giving the researcher freedom to vary risk attributes.

In a comparison of automobile fatality risk with chronic bronchitis risk, Viscusi (1995) uses a risk metric in an interactive computer based survey. The implications of the disease were explained to the respondents. Individuals were presented with tradeoffs between death in an automobile accident versus chronic bronchitis, nerve disease, morbidity component of curable lymph cancer, curable lymph cancer and terminal lymph cancer. They were then asked whether they would choose to relocate to an area with greater chance of dying from chronic bronchitis $(75 / 100,000)$ and lower automobile fatality rate $(15 / 100,000)$ versus lower chance of dying from chronic bronchitis $(55 / 100,000)$ and higher automobile fatality rate $(19 / 100,000)$. The probabilities shown above were changed until the respondent was indifferent between the two cities. Results indicated that the utility of living with chronic bronchitis was considered equivalent to 
0.68 if the utility of living in good health. Thus, the value associated with a case of chronic bronchitis was determined to be 0.32 times the VSL.

In a similar study Viscusi, Magat and Huber (1991) elicited risk-dollar as well as risk-risk tradeoffs. Specifically, respondents were asked to choose between cities with different risks of chronic bronchitis and different costs of living, as well as choosing between cities with different risks of chronic bronchitis and risks of dying in an auto accident. The resulting rates of trade-off for chronic bronchitis and automobile fatality risks revealed that the risk of a chronic bronchitis case was worth $32 \%$ of the risk of death in an auto accident, as measured by the median trade-off rate. When the risk reduction for chronic bronchitis was compared to a cost of living increase, the median value of a case of chronic bronchitis was $\$ 457,000$. The comparison between automobile fatality risk reductions and cost of living increases yielded a median rate of trade-off of $\$ 2.29$ million.

\subsection{Design Issues in Contingent Valuation Studies}

Theoretically, WTP measures and the implied VSL from them are heavily dependent on individuals' understanding of risks and on their ability to make rational decisions (Jones-Lee, 1989). Psychologists have often alleged that people do not accurately perceive small risk changes (Fischhoff, 1990). To improve the understanding of small risks, researchers have experimented with a variety of ways of communicating small risk changes effectively to respondents. This section discusses a few of these methods. 


\subsubsection{Assign baseline risk}

In surveys it is usual to inform the respondent what his initial risks are prior to the risk reduction he is expected to value (Bateman et al., 2002; Alberini, 2004; Melhuish, 2005). In a study in a province of Switzerland, Schwab Christe and Soguel (1996) estimated WTP measures that included the pain, suffering and bereavement of road accident victims or their relatives. Thus, WTP was estimated in two contexts- for the victims and for the relatives. Six injury categories were shown with their associated risks (from no hospitalization $2 / 1000$ risk to death $1.4 / 10000$ risk) initially. However the valuation questions pertained to only 4 of those categories. Subjects were first asked to rank the various injury categories and death. Since the pilot revealed that people found it hard to understand the concept of risk and the grid methodology proved unsatisfactory, risk was depicted pictorially as a lottery with victims being pulled out of a hat (as depicted in Figure 2.3).

FIGURE 2.3: RISK COMMUNICATION IN SCHWAB-CHRISTE AND SOGUEL

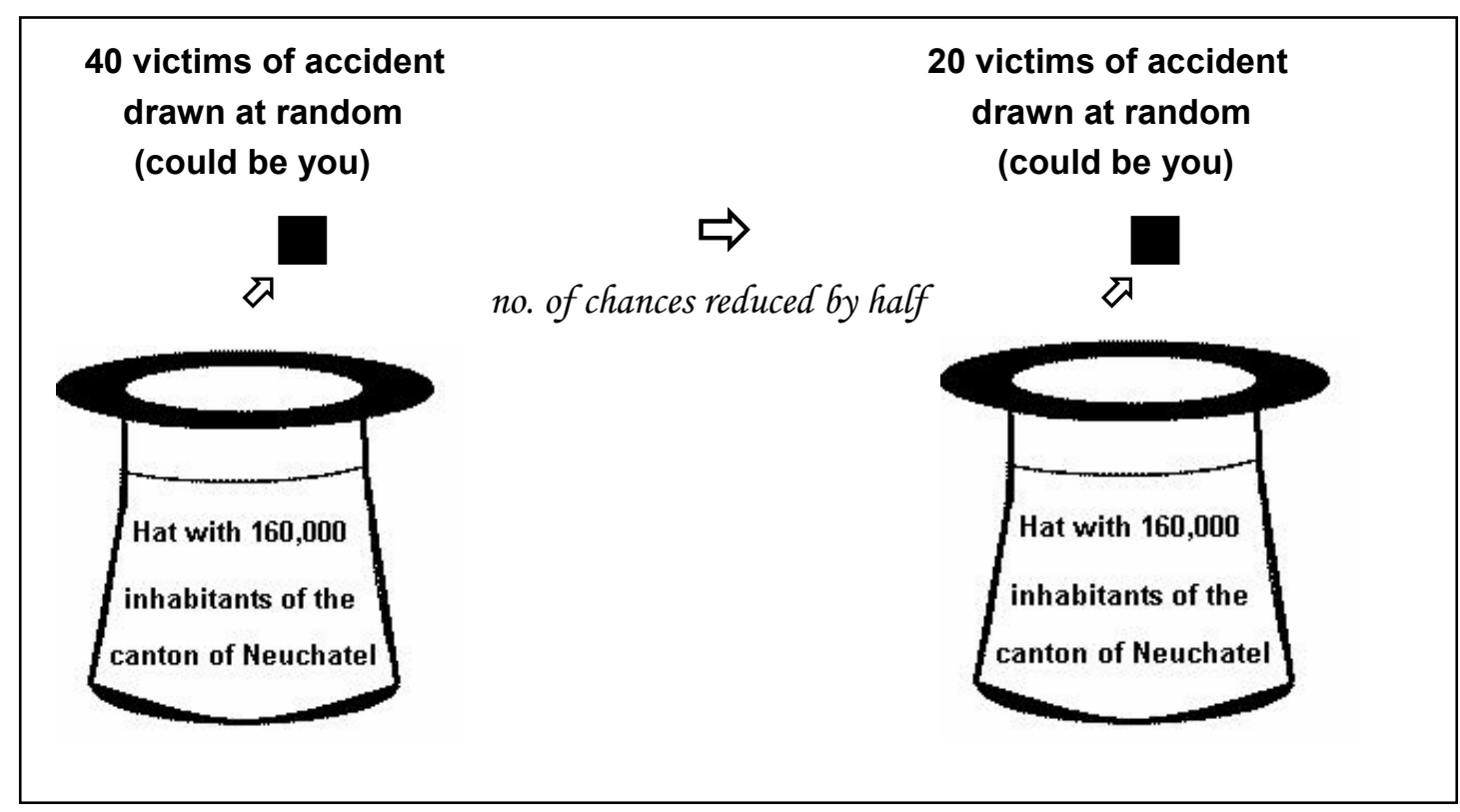


Respondents were offered an option to rent a safety device (hypothetically) for one year that would reduce the chances of being the victim in a corresponding injury category by half. A payment card was shown that included amounts from SFr 0 to SFr 3000 scaled logarithmically. Respondents were asked to put a tick $(\checkmark)$ next to each amount they would surely pay, a cross $(\times)$ next to each amount they would surely not pay and an asterisk $(*)$ next to the best estimate of the maximum WTP for that particular risk reduction. A VSL of SFr 1.7 million was estimated based on the results of this survey. Values were slightly higher in case of severe and permanent disability. All other injury categories were assessed to be less serious than death and permanent disability and thus values associated with them decreased gradually to a point where an injury involving no hospitalization was valued at SFr 11,000.

\subsubsection{Respondent Assessment of Baseline Risk}

Some researchers let respondents assess their own baseline risks (Gerking et al., 1988; Persson et al., 2001). For example, in a mail survey in Sweden, Persson et al. (2001) first asked the respondents to indicate their own baseline risks on a scale of 0 to 100,000 . Thereafter they were asked to value a specified percentage risk reduction from the baseline risk level they stated. While this approach helps in obtaining individuals' subjective evaluation of their own risks, it does not eliminate other problems; e.g., whether the respondent correctly understood his risks. 


\subsubsection{Communication of Risk Reduction}

Whether the baseline risk is presented by the researcher or the respondent is asked to assess it himself, a major challenge with all stated preference studies is the communication of risk reductions. Most studies present mortality risk reduction either as probabilities (e.g. $3 / 10,000$ ) or in percentage terms (e.g. $20 \%$ of $15 / 10,000$ ) with respect to a baseline risk stated to the respondent (Persson, 2001). Sometimes reductions in numbers (Johannesson et al., 1996) of deaths are used because people have difficutly dealing with probabilities. This may be influenced by media reports, which present accidents as absolute numbers (Rizzi and Ortuzar, 2003). Each technique has its own merits and demerits which are discussed below.

\subsubsection{Absolute risk reduction}

Some analysts believe that people understand risks in terms of absolute numbers rather than as probabilities. Using a telephone survey, Johannesson et al. (1996) used absolute numbers of accidents to communicate risk. Respondents in the survey were told the total number of annual road accident deaths in Sweden. They were then asked to evaluate either a private or public risk reduction. In the case of private risk reduction, people were asked to state whether they would pay SEK " $X$ " for a safety device to be installed in their cars that would work for a year and cut all passengers' risks by half. For the public risk reduction, people were asked if they would pay SEK " $\mathrm{X}$ " for road improvements that would reduce traffic mortality by $50 \%$ for all road users.

Similarly, Ortuzar et al. (2000), Rizzi and Ortuzar (2003) and Hojman, Ortuzar and Rizzi (2005) portray risks in terms of absolute number of fatal accidents involving at 
least one victim. These studies, conducted in Chile ask people to choose between two routes with varying attributes. A standard choice set is displayed in Figure 2.4:

FIGURE 2.4: EXAMPLE OF A CHOICE SET USED IN CHILEAN ROAD SAFETY STUDIES

\begin{tabular}{|l|c|c|}
\hline & Route A & Route B \\
\hline Toll (\$) & A1 & B1 \\
\hline Accidents (absolute no. daily with at least one fatality) & A2 & B2 \\
\hline Time Taken ( Hour: min.) & A3 & B3 \\
\hline
\end{tabular}

The numbers per se are not important. What is important is how they are calculated using absolute numbers of accidents. The fundamental problem in using absolute numbers for risk communication is that it is highly sensitive to individuals' risk perceptions. Since respondents have not been asked to state the risk reduction in terms of probability, the perception of the probability may differ from what the researcher assumes for his calculations. For example, person A may be valuing a risk of 5/1000, person B may be valuing 5/10,000 and person $\mathrm{C}$ may be valuing $5 / 100,000$. The researcher does not observe which risk each individual is valuing. In addition, reductions in absolute numbers may sound larger than reductions in probabilities. ${ }^{26}$ Eliciting WTP for reductions in absolute number of deaths when the respondent is unaware of the chance of dying is inappropriate for calculating the VSL.

\subsubsection{Percentage risk reduction}

Some researchers ask respondents to value a specified percentage risk reduction, given a baseline risk (Persson et al., 2001; Melhuish et al., 2005). Persson et al. (2001)

\footnotetext{
26 A reduction of 300 deaths annually may sound bigger than an annual reduction in risk of dying by $300 / 100,000$.
} 
for example asked the respondents to first assess their risk of dying from road accidents in Sweden. Thereafter, they were asked of their WTP for a 50\% reduction in the risk of dying. One fundamental problem with percentage risk reductions is that given the small baseline risks of traffic accidents, many respondents may not accurately perceive the magnitude of the reductions they are valuing.

\subsubsection{Risk Reduction as Probability}

This is by far the most commonly used form of communicating reductions in mortality risk. It asks the respondent to value the risk of dying based on its magnitude expressed as probability. For example, Corso et al. (2001) asked respondents what they would pay for a side impact automobile airbag that reduced the risk of dying in a traffic accident by $5 / 100,000$. Theoretically, it is consistent with the model derived in Section 2.1 (Hammitt, 2000). Respondents are clearly told the good that they are valuing. As long as respondents have a clear understanding of risks as probabilities and are rational decision makers, this approach can yield good estimates of WTP.

\section{6 Stated Preference Studies- Problems and Remedies}

The literature discusses whether stated preference studies may be subject to certain biases such as starting point bias, strategic bias, hypothetical bias, embedding bias and information bias. Many of these biases may be alleviated or eliminated using properly designed survey techniques (Mitchell and Carson, 1989; NOAA Panel ReportArrow et al, 1993). Starting point bias refers to respondents being inclined towards the

first price being offered by the researcher. Different techniques or models to control 
theses anomalies have been suggested (Cameron and Quiggin, 1994; Alberini et al., 1997; DeShazo, 2002; and Flachaire and Hollard, 2006). Similarly a middle-point bias has been reported in some cases when a payment card is used. This can be eliminated by designing payment cards that do not have a specific value in the middle.

Strategic bias refers to the respondent understating or overstating his response for strategic reasons. This is often observed when WTA is elicited. Suggestions for controlling strategic bias include elimination of any incentive for strategic behavior and thus offering respondents a real choice to be taken seriously (Carson, Flores and Meade, 2001). Some researchers allege information bias as the reason for higher WTPs when more information is provided to the respondent about the risk involved. Hypothetical bias refers to the responses being purely hypothetical since the good in question is not actually provided Framing questions in a realistic way, reminding people of their budget constraints or using experimental techniques have been proposed to control this type of a bias (Loomis et al., 1996; Cummings and Taylor, 1999). The embedding or part-whole bias occurs when the respondent may provide an answer for a broader category of goods than what is asked for in the questionnaire (e.g., the questionnaire may be asking for WTP for cleaning a specific portion of a lake in the area but the respondent gives an answer for improving the entire lake). 


\subsection{VSL from Road Safety in Developing Countries}

Most stated preference studies in the context of road safety have been conducted in the developed countries. ${ }^{27}$ Thus, even though mortality risks from road accidents are often higher and are expected to be rising for developing countries, there have been relatively extremely few valuation studies conducted in developing countries. Most of the estimates of the value of fatal accidents in developing countries use the gross capital output or the human capital approach. The Asian Development Bank sponsored Arrive Alive Regional Road Costing Studies to provide estimates for nine developing Asian countries. In only one case was a stated preference method used. The only developing countries in which stated preference studies have been conducted are Chile, Malaysia and Thailand.

Ortuzar, Cifuentes and Williams (2000) provide the earliest stated preference estimates of the benefits of reduced mortality from road accidents in a developing country. In this study they compare mortality risks from pollution related causes versus road accidents. The respondents are introduced to gender-specific baseline risks using a grid of 1000 squares. Since the respondents for this study consist of academic and nonacademic university staff, there was no problem with probability comprehension. The pollution related mortality risk study was adapted from Krupnick et al. $(1999,2002)$ and was conducted as an in-person survey. The road accident mortality risk survey was a mail survey where the risks were presented as the absolute number of accidents with at least

\footnotetext{
${ }^{27}$ A review of the literature shows that there exist only three developing countries where stated preference studies for reducing road risks have been performed. These are Malaysia (1 study), Thailand (1 study) and Chile (3 studies). However, numerous studies exist for the developed countries like the US, UK, Sweden, Norway, New Zealand, and Japan.
} 
one fatality. Respondents were asked to choose between two alternative routes from Santiago to Valparaiso that differed in their tolls, driving times and number of fatal road accidents. Each respondent was asked nine such questions. A major shortcoming of this study is that the sample size is extremely small ${ }^{28}$ and is a convenience sample.

In an Asian Development Bank ${ }^{29}$ sponsored study for assessing the costs of road traffic accidents in selected countries in Asia, Melhuish et al. (2005) conduct a contingent valuation survey in peninsular Malaysia using the same framework as Jones-Lee et al. (1985 and 1993). The baseline risk was communicated in the form of a grid of 100,000 squares on an A4 sized sheet. ${ }^{30}$ Interviewees were asked to imagine that they were taking an excursion bus tour that cost $\mathrm{RM}^{31} 300$ and had a chance of dying $10 / 100,000$ on this bus trip. They were then asked if they were willing to pay an extra RM 50 to travel on a safer bus where the risk of dying during the trip would be $5 / 100,000$. Based on whether respondents answered "yes" or "no" to the first bid question, they were shown payment cards and asked their maximum willingness to pay for the stated risk reduction. A second question introduced another bus with $8 / 100,000$ risk of dying asked whether they were willing to pay RM50 to travel on it, followed by similar question to elicit maximum

\footnotetext{
${ }^{28}$ For the air pollution study, the sample size is 94 . In the road accident case the sample size of 118 respondents becomes a cross-sectional dataset of 1062 entries since each individual is asked 9 choice questions.

${ }^{29}$ The Arrive-Alive Regional Road Safety Strategy and Action Plan program of the Asian Development Bank and Association of Southeast Asian Nations (ADB-ASEAN) sponsored accident-costing studies for Brunei, Cambodia, Indonesia, Laos, Malaysia, Myanmar, Philippines, Singapore, Thailand and Vietnam in 2003-2004. Mortality benefits for all countries, except Malaysia, were mostly assessed using the gross output or public sector valuation methods.

${ }^{30}$ It seems surprising how they fitted a grid of 100,000 equally sized squares with the gridlines being shown on an A4 sized sheet (see Chapter 3 on a sample grid of 10,000 squares). Besides, even if they concealed the gridlines, the risk levels which were 5/100,000, 8/100,000 and 10/100,000, respectively, would be too tiny to be visible clearly.

${ }^{31}$ Malaysian Ringgit
} 
WTP. The order of these two valuation questions was varied across samples. Results indicated that the respondents were not sensitive to the different levels of risk reduction. Based on the results the authors recommend a VSL of RM 1.2 million (USD 755,000) for Malaysians.

One major drawback common to all the three studies is that none truly reflects typical road traffic risks in their respective countries. Melhuish et al. (2005) estimates VSL using a bus passenger scenario. However less than 1 percent of the victims of road accidents in Malaysia are bus passengers. In Bangkok only 25 percent of travel is by car, taxi or motorcycle (Willett et al., 2006). The rest uses public transportation or nonmotorized transport. Thus, the car safety feature scenario is not an appropriate indicator of traffic risks for the entire population of Bangkok. In both Malaysia and Thailand (or Bangkok) motorcyclists seem to bear the brunt of road accidents; and as in India (or Delhi) men in the age group 18-40 are the most vulnerable. Therefore scenarios involving greater safety for motorcyclists would be more appropriate. Ortuzar et al. admit that car ownership in Santiago is only 15 cars per 100 people and is highly correlated with income. Moreover, less than 10 percent of all road deaths in Chile are motor vehicle occupants. ${ }^{32}$ As in other developing countries pedestrians constitute the majority of traffic deaths in Chile. Thus any mortality valuation survey from road accidents in Chile should involve pedestrians.

\footnotetext{
${ }^{32}$ Source: World Health Organization
} 


\subsection{Estimating the VSL in India}

So far there have been very few attempts to estimate the VSL for India. One study, Simon et al.(1999) uses compensating wage differentials and obtains VSL values that are higher relative to per capita income than those for a similar study for the United States. Bussolo and O'Connor (2001) estimate a transferred VSL for India in the context of air quality improvements. Using the estimates from Simon et al. (1999) and Brandon and Homman (1995) and making suitable adjustments, ${ }^{33}$ they estimate the VSL for India at $\$ 273,000$ for the year 1995 .

Shanmugam (1997) uses a hedonic wage equation for computing the VSL of Indian workers. Madheswaran et al. (2003) examine the role of trade unions in influencing the wage-risk tradeoffs. They obtain a VSL of Rs. 15.55 million (USD 338,000 ) for union sector workers and Rs. 5.49 million (USD 1,190,000) for non-union sector workers. Their results are lower than those of developed nations, which typically range between $\$ 3$ million to $\$ 7$ million. While the VSL from these studies could be transferred to the transport context, it is important to investigate whether the value of road safety differs from the value of workplace safety.

All studies in India so far have focused on wage-risk tradeoffs. These figures could be transferred to the road safety context, but doing so implies that we assume that the tradeoffs between risk and income observed in labor markets is the same as in other contexts, such as environmental policy or transportation safety. However, there is no particular reason to believe that the VSL observed in labor markets should be the VSL

\footnotetext{
${ }^{33}$ This estimate is the average value from the two studies obtained after adjusting for relative PPP incomes and using income elasticity as 0.5 .
} 
used to estimate the mortality benefits of transportation safety policies (Viscusi, 1995). At a minimum, one must first estimate VSL in the transportation context separately. Even within the transportation context, the VSL for mortality risk reduction in aviation may differ from that of road transport simply because the attributes and factors that affect behavioral responses to WTP are different in both cases (Carlsson et al., 2004).

There has been no study to estimate the VSL from reductions in traffic crashes in India. It is, in general, very difficult to obtain road traffic accident data in India. Even a simple hedonic model that infers value of road safety from the price of a car cannot be attempted for three reasons. First, computerization of road accident data began only recently in Delhi, and therefore no data exist on the rate of car accident fatalities by make and model of car. Second, many cars are not driven by their owners or a family member, but by friends or hired chauffeurs. Moreover, it is widely believed that many car purchasing transactions are unrecorded since they are bought with evaded tax money, thus making it harder to obtain data on car purchase through official statistics. Third, and even more important, car drivers and passengers account for only $5 \%$ of road fatalities in Delhi, suggesting that mortality risk from a car accident may not play a significant role in the purchase decision of a car.

\subsection{VSL in Public Policy: Road Safety}

Of late, the governments of many developed countries like the US, the UK and Canada use estimates of VSL from stated as well as revealed preference studies to evaluate the benefits of environmental, health and safety rules (Viscusi and Aldy, 2003). Specifically, in the road safety context, the Value of a Statistical Life is a valuable 
measure for the cost-benefit assessment of road infrastructure investments, road maintenance planning and for decisions involving traffic control such as enforcing speed limits. It is an essential tool that governments of many countries now use as an indicator of human mortality benefit for policy purposes. Departments of Transportation of some developed countries have commissioned studies to estimate the VSL for such purposes. These are the governments of United Kingdom, United States, Sweden, New Zealand and Norway.

The Department for Transport for the UK (DfT) began using the willingness to pay approach to evaluate the value of road accident fatalities ${ }^{34}$ in 1988. In 1994, the methodology for the valuation of non-fatal accidents in UK was also revised and made comparable to the procedure used for valuing road traffic fatalities. For the year 2004, the VSL for the UK is pegged at $\$ 1.57$ million. $^{35}$

Until 1991, the Ministry of Transport in New Zealand used the human capital approach to value the average life lost in road traffic accidents. In 1989, in response to political pressure, the Ministry conducted a national travel survey including a contingent valuation module to estimate the public's willingness to pay to reduce transport risk. The results provided a value of statistical life to be used in transport appraisals of NZ\$2 million in 1991 prices.

The Swedish National Road Administration (SNRA) adopted the willingness to pay approach for estimating the benefits of safety improvements in the early 1990s. In

\footnotetext{
${ }^{34}$ The methodology adopted by DfT is explained in Hopkin, J M and Simpson, H (1995) Valuation of Road Accidents. TRL Research Report 163, Transport Research Laboratory, Crowthorne.

${ }^{35}$ Source: Highways Economic Note No. 1, Department for Transportation, United Kingdom, 2004.
} 
2002, they adopted a VSL of SEK 16.3 million in 2001 prices. The Department of Transportation (DOT) of the United States currently uses a value of statistical life that is the result of a combined analysis of both stated and revealed preference studies (US Department of Transportation, 1993 and 2002). DOT periodically revises its estimate of the VSL using results obtained from newer studies, and adjusts it using the GDP implicit price deflator to reflect inflation. Currently, the VSL in the US is established as $\$ 3$ million for purposes of cost-benefit analyses of transportation policies. 


\section{CHAPTER 3: BACKGROUND INFORMATION ON ROAD ACCIDENTS IN DELHI}

Over the last three decades, the state of Delhi, India has experienced a nine-fold increase in the number of motor vehicles. This has led not only to a dramatic increase in vehicular pollution, ${ }^{36}$ but also to road accidents. According to a report released by the Delhi Police Authority, the increase in accidents has been proportional to the growth in the number of vehicles. About 2000 people are killed in traffic accidents each year in Delhi. Thus, Delhi, which accounts for nearly $1.3 \%$ of the country's population, experiences $2.2 \%$ of its traffic fatalities. This implies a death rate of 14 in 100,000 people, which is roughly the same as the United States. When focusing on deaths normalized by the number of vehicles, however, Delhi's rate is 6 in 10,000 motor vehicles, more than three times the US figure. In contrast to developed countries, where car drivers are at high risk, most of the victims in the developing countries are pedestrians, bicyclists, motorcyclists or passengers (WHO, 2004). In Delhi, ${ }^{37}$ pedestrians $^{38}$ followed by two-wheeler drivers and riders, and bicyclists (see Figure 3.1) account for three-fourths of the total victims of road accidents. Car occupants account for only about 2 per cent of the deaths due to road accidents in Delhi.

\footnotetext{
${ }^{36}$ According to World Health Organization, Delhi ranked as the fourth most polluted city in the world in 1999 in terms of Suspended Particulate Matter (SPM). About 70\% of the emissions were attributable to motor vehicles.

${ }^{37}$ The city or state of Delhi may be used interchangeably in this document to imply the National Capital Territory of Delhi- the case study of this research project. For details about the geographical scope of the case study, please see Appendix.

${ }^{38}$ This is based on the figures for 2001, but the trend is similar in preceding years. Pedestrians in Delhi also accounted for $38.71 \%$ of total injuries due to road accidents in Delhi.
} 
FIGURE 3.1: BREAKDOWN OF FATALITIES BY TYPE OF VICTIM- 2001

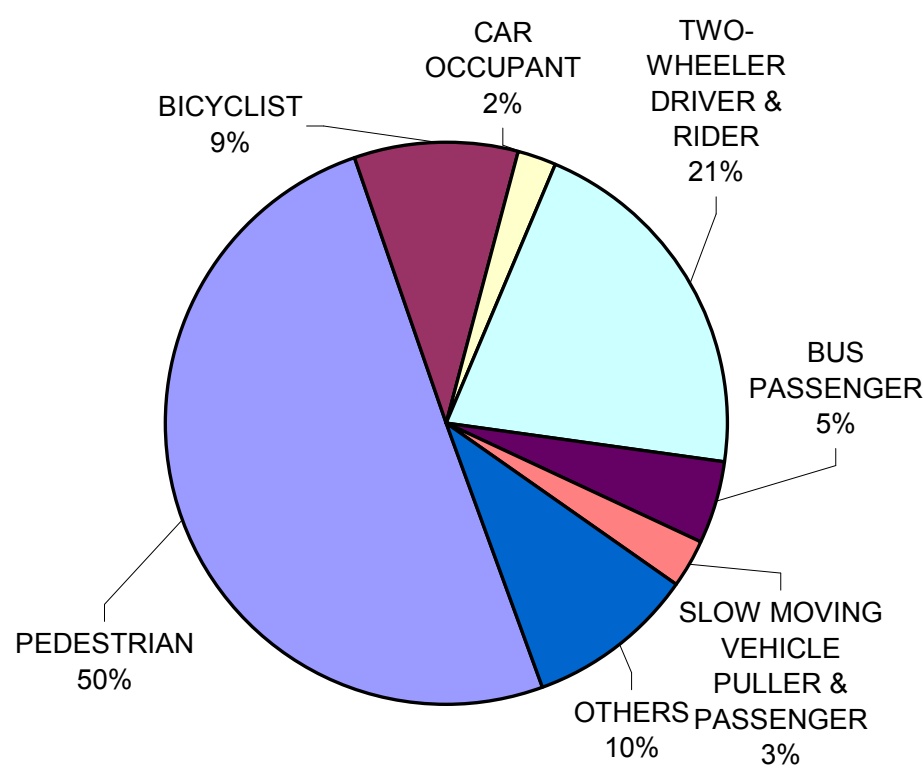

Source: Traffic Accidents in Delhi, Delhi Traffic Police, 2002

The diversity of road traffic is likely to be a causal factor in traffic crashes in Delhi. Modes of transport traveling at different speeds occupy the same road: For example, bicycles, cycle rickshaws (non-motorized tricycles carrying one to three passengers for short distances), tempos (small trucks), motorized two-wheelers (scooters and motorcycles), three-wheeler autorickshaws (motorized three-wheeled open door vehicles that are a cheaper alternative to taxis), horse carts, bullock carts, small hand carts, public and private buses, double-decker buses, minibuses, vans, tractors, big trucks, cars of many makes and models all travel together on the same roads along with millions of the city's pedestrians.

Table 3.1 shows the number of fatalities from road accidents in Delhi in the last ten years. In the year 2000 there were 2014 road fatalities or an average of 5.5 fatalities per day. In 2004 this declined to 1832 fatalities. Adult males experienced the highest 
death rate from road accidents: Table 3.2 shows that the rate of fatalities for 2001 was 37 per 100,000 adult males but only 4 per 100,000 adult females. Buses and other heavy vehicles have been responsible for roughly half the road deaths (Table 3.3, Figure 3.2). Buses, followed by heavy vehicles have the highest crash rate in terms of 10,000 vehicles registered (Table 3.4). Therefore, in recent years the Delhi Traffic Police have been making efforts to improve the system and reduce the number of fatalities. Indeed, the most recent figures (Table 3.1) show that road fatalities have decreased slightly but are still very high compared to the crash rates in most other countries.

In Delhi, $60-65 \%$ of people use public transportation. In 2001, buses comprised only about 1.3 percent (roughly 46,000 ) of the total 3.6 million registered motor vehicles, whereas private vehicles accounted for the rest (about 3.1 million vehicles). About two thirds of the private vehicles are two-wheelers (motorcycles or scooters). However, as noted earlier, the majority of road accident victims are either pedestrians or drivers of private vehicles, mainly two-wheelers and not passengers of the public transport system. Hence, any policy that reduces societal risks from road accidents must pay special attention to these vulnerable road users. Thus, a credible measure of private willingness to pay for reductions in risk of death must place respondents in the roles of pedestrians and two-wheeler drivers. These are, indeed, the two types of risks that my Delhi survey asks respondents to value. 
TABLE 3.1: FATALITIES IN ROAD ACCIDENTS IN DELHI, INDIA

\begin{tabular}{|c|c|c|c|}
\hline Year & No. of Fatalities & No. Injured & No. of Accidents \\
\hline $\mathbf{1 9 9 5}$ & 2070 & 9805 & 10138 \\
$\mathbf{1 9 9 6}$ & 2361 & 10288 & 11315 \\
$\mathbf{1 9 9 7}$ & 2342 & 10700 & 10957 \\
$\mathbf{1 9 9 8}$ & 2182 & 8905 & 10211 \\
$\mathbf{1 9 9 9}$ & 2045 & 8607 & 9909 \\
$\mathbf{2 0 0 0}$ & 2014 & 8746 & 10245 \\
$\mathbf{2 0 0 1}$ & 1842 & 8449 & 9344 \\
$\mathbf{2 0 0 2}$ & 1696 & 7929 & 8699 \\
$\mathbf{2 0 0 3}$ & 1841 & 7829 & 8864 \\
$\mathbf{2 0 0 4}$ & 1832 & N.A. & 9083 \\
\hline
\end{tabular}

Source: Traffic Accidents in Delhi, Delhi Traffic Police, 2002

FIGURE 3.2: VEHICLES AT FAULT FOR FATAL ACCIDENTS- 2001

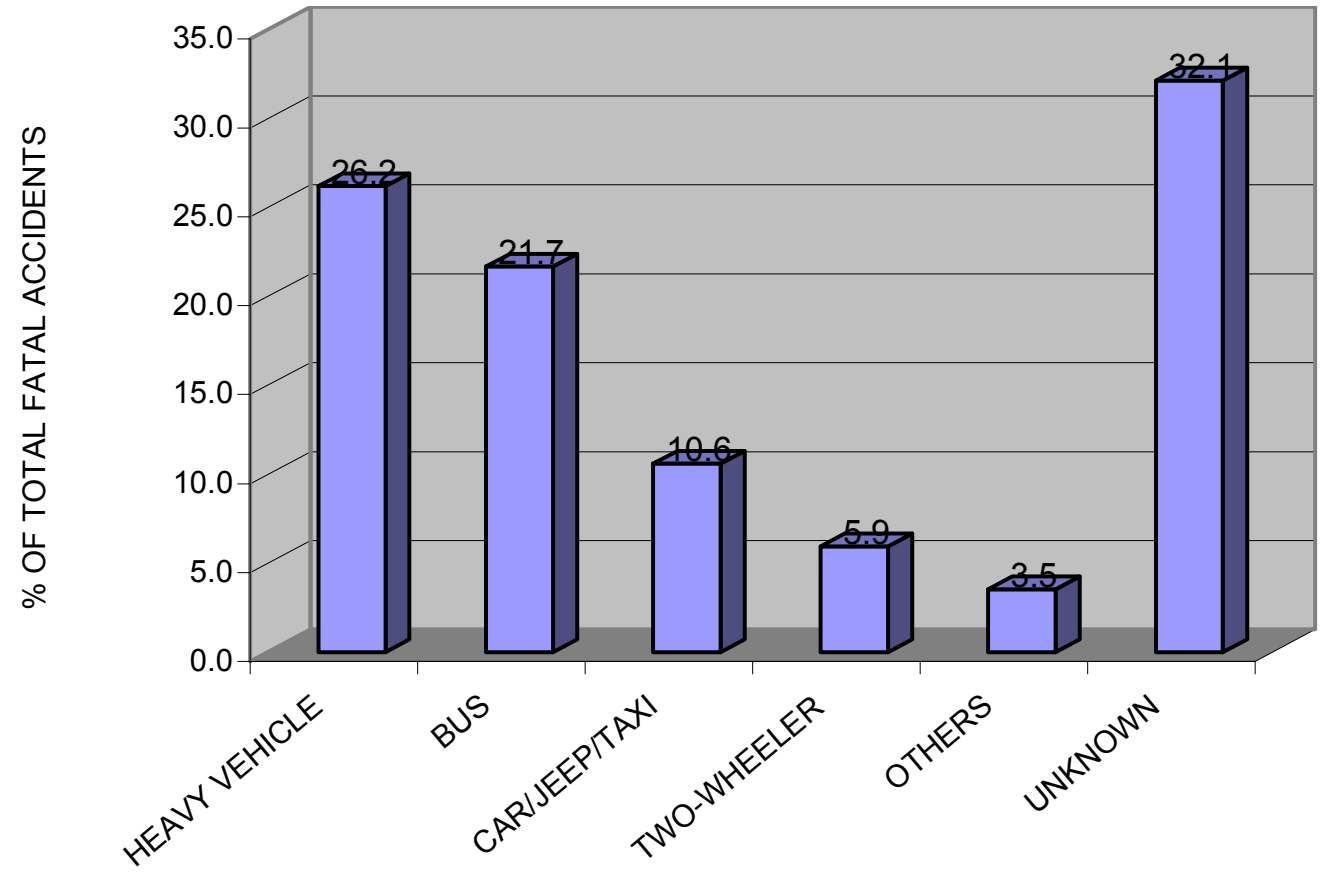

Source: Traffic Accidents in Delhi, Delhi Traffic Police, 2002 
TABLE 3.2: CHILDREN \& ADULTS KILLED IN ROAD ACCIDENTS - 2001

\begin{tabular}{|c|c|c|c|c|c|c|c|}
\hline \multirow{2}{*}{ Year 2001 } & \multicolumn{3}{|c|}{ Children } & \multicolumn{3}{c|}{ Adults } & Total \\
\cline { 2 - 8 } & Boys & Girls & Total & Male & Female & Total & \\
\hline $\begin{array}{c}\text { No. of Fatalities } \\
\begin{array}{c}\text { Urban Population } \\
\text { (Million) }\end{array}\end{array}$ & 2.68 & 30 & 98 & 1615 & 129 & 1744 & 1842 \\
$\begin{array}{c}\text { Fatalities/ 100,000 } \\
\text { Population }\end{array}$ & 2.54 & 1.32 & 1.98 & 36.61 & 3.64 & 21.92 & 14.27 \\
\hline
\end{tabular}

Source: Traffic Accidents in Delhi, Delhi Traffic Police, 2002 and Census of India, 2001

TABLE 3.3: VICTIM V/S VEHICLE AT FAULT FOR FATAL ACCIDENTS - 2001

(No. of accidents)

\begin{tabular}{|c|c|c|c|c|c|c|c|}
\hline \multirow[b]{2}{*}{ VICTIM } & \multicolumn{7}{|c|}{ VEHICLE AT FAULT } \\
\hline & $\begin{array}{c}\text { HEAVY } \\
\text { VEHICLE }\end{array}$ & BUS & $\begin{array}{l}\mathrm{CAR} / \\
\mathrm{JEEP} / \\
\mathrm{TAXI}\end{array}$ & $\begin{array}{c}\text { TWO- } \\
\text { WHEELER }\end{array}$ & UNKNOWN & OTHERS & TOTAL \\
\hline$C A R$ & 12 & 9 & 8 & $\mathbf{0}$ & 7 & 2 & 38 \\
\hline BUS & 1 & 7 & 0 & 0 & 2 & 3 & 13 \\
\hline BICYCLE & 75 & 40 & 13 & 11 & 19 & 13 & 171 \\
\hline $\begin{array}{l}\text { CYCLE } \\
\text { RICKSHAW }\end{array}$ & 15 & 12 & 7 & 5 & 6 & 3 & 48 \\
\hline $\begin{array}{l}\text { HEAVY } \\
\text { VEHICLE }\end{array}$ & 28 & 4 & 2 & $\mathbf{0}$ & 4 & 1 & 39 \\
\hline $\begin{array}{l}\text { TWO- } \\
\text { WHEELER }\end{array}$ & 126 & 74 & 40 & 11 & 106 & 10 & 367 \\
\hline PASSENGER & 18 & 77 & 1 & 2 & 3 & 7 & 108 \\
\hline PEDESTRIAN & 161 & 150 & 102 & 59 & 416 & 19 & 907 \\
\hline OTHERS & 27 & 10 & 14 & 17 & 5 & 4 & 77 \\
\hline TOTAL & 463 & 383 & 187 & 105 & 568 & 62 & 1768 \\
\hline
\end{tabular}

Source: Traffic Accidents in Delhi, Delhi Traffic Police, 2002 
TABLE 3.4: ROAD ACCIDENT CRASH RATE BY VEHICLE AT FAULT - 2001

\begin{tabular}{|l|c|c|c|c|c|}
\hline $\begin{array}{l}\text { TYPE OF } \\
\text { VEHICLE }\end{array}$ & $\begin{array}{c}\text { HEAVY } \\
\text { VEHICLE }\end{array}$ & BUS & $\begin{array}{c}\text { CAR/JEEP/ } \\
\text { TAXI }\end{array}$ & $\begin{array}{c}\text { TWO- } \\
\text { WHEELER }\end{array}$ & TOTAL \\
\hline $\begin{array}{l}\text { No. of accidents } \\
\text { caused by }\end{array}$ & 463 & 383 & 187 & 105 & 1,768 \\
$\begin{array}{l}\text { No. of registered } \\
\text { vehicles }\end{array}$ & 162,289 & 46,033 & 984,093 & $2,291,906$ & $3,589,748$ \\
$\begin{array}{l}\text { Accidents/ 10,000 } \\
\text { vehicle }\end{array}$ & 28.53 & 83.20 & 1.90 & 0.46 & 4.93 \\
\hline
\end{tabular}

Source: Traffic Accidents in Delhi, Delhi Traffic Police, 2002 


\section{CHAPTER 4: QUESTIONNAIRE DEVELOPMENT AND SURVEY ADMINISTRATION}

In this chapter I describe the various stages of the development of my survey instrument: a series of focus groups and one-on-one interviews, followed by a pretest, and four pilot studies that deployed an interim questionnaire before the final survey was finalized. The process is summarized in Table 4.1 .

I deemed it essential that that the survey include: (i) extensive questions about the respondent's commute and use of public roadways, (ii) the respondent's experience with accidents and transportation safety features, (iii) a probability tutorial, (iv) background information about road traffic risks, (v) willingness to pay questions, (vi) opinions about own exposure to road traffic risks and about the effectiveness of governmental traffic safety initiatives in reducing road risks, and (vii) demographic characteristics. In each testing stage special attention was paid to the time taken to complete the survey, the ease of answering each question and of using the survey materials on the part of the interviewers, such as the show-cards or the visual aids to represent risks.

I decided to administer the questionnaire using an in-person interview. This is by far the most common means of survey data collection in India. The use of visual aids to help the respondent understand the concept of probability as well as the magnitudes of risks precluded any other survey administration mode. ${ }^{39}$ Other advantages are that the interviewer can assess whether the respondents have fully understood risks when they are giving their responses. Interviewers are also able to cover a wide cross section of the

\footnotetext{
${ }^{39}$ Telephone surveys and mail surveys were therefore ruled out. In my case, mail surveys would not permit the use of screening criteria for identifying respondents. Alternatively, a telephone survey would exclude two-thirds of the households since only 35 percent of the households in Delhi have telephones.
} 
population. The main disadvantage of this approach is its time and cost. I engaged the services of a professional marketing firm to help administer the interviews. Interviewers and their supervisors were first trained thoroughly for 2-3 days. After training, the interviewers practiced mock interviews in my presence. I accompanied each interviewer for practice interviews before the survey was launched. In addition, the survey firm and I conducted random validation checks to ensure quality control. The interviews were conducted in two languages — English and Hindi. ${ }^{40}$

\subsection{The Questionnaire}

The questionnaire for the final survey (see Appendix) consisted of six sections. The first section asked extensive questions about the respondent's commute. Details were collected about the daily trip from home to workplace were collected. The respondent was asked to describe one complete trip from the time he left home to the time he reached the workplace, including the costs incurred, the modes of transportation used and any waiting time involved. To get a sense of the value of time, I asked how much the respondent would pay to reduce commute time from home to workplace by 10 minutes each day. This question was asked of persons with commuting time greater than 20 minutes.

The second section involved a brief tutorial about probability concepts. This was necessary since the $\mathrm{CV}$ questions that would be asked later relied on an understanding of

\footnotetext{
${ }^{40}$ Hindi is the primary language for the majority of the residents of Delhi. It is also the national language of India. However, since Delhi is a cosmopolitan city with many residents from parts of India where Hindi is not the primary language, the survey was also administered in English. Back translations were also done to ensure that the content in both language versions was identical.
} 
probability. I revised this section numerous times in response to what I learned at different stages of questionnaire development and testing. The tutorial was made more succinct after the pre-test in order to reduce the time needed to complete the interview (see Table 4.2).

The third section informed the respondent about the risk of dying from traffic accidents in Delhi using a grid of 100,000 squares (see Section 3.2). In the initial drafts of the questionnaire, the annual average baseline risk was presented for the entire population. However, since my target population was adult commuters, for whom the risks are higher, I decided to present the respondents with risk levels that reflected this. Annual risk levels from dying in a traffic accident vary dramatically by gender: for adult men the risks are roughly $37 / 100,000$ whereas for adult women the risks are 4/100,000. Since the risks for women are negligible, I decided not to present the traffic risks separately by gender. Thus the combined risk for all adults, roughly $21 / 100,000$, was presented to the respondents in later drafts of the questionnaire and in the final survey. Respondents were also told of their risk as pedestrians, which is roughly half of the total risk from road accidents. Subsequently, they were informed about the factors that could influence their own risks. Finally, the respondents were tested for their understanding of these concepts through the use of a grid with 100,000 squares.

The fourth section of the survey included three contingent valuation questions, which are described in detail in Section 4.3. The fifth section asked respondents how they compared their own risks of dying with those of other people in various situations — as a pedestrian, a driver and a passenger. It also elicited opinions on the effectiveness of government policies aimed at reducing their risk of dying in road accidents. For example, 
respondents were asked to rate on a scale from 1 to 5 of the effectiveness of introducing separate lanes for slower traffic like bicycles and cycle rickshaws in reducing their own risks of dying in a road accident. In earlier drafts of the questionnaire, I had included a number of debriefing questions that I subsequently removed from the later drafts for various reasons. For example, almost everybody answered that they thought about their income and expenses when answering the contingent valuation (CV) questions. Thus this question was removed to save interview time. A question that asked the respondent whether he had considered the risk of injury ${ }^{41}$ when answering the CV questions tended to create confusion and was also removed. ${ }^{42}$

The sixth and last section included various questions about the personal characteristics of the respondent and his household like age of all household members, personal and household income, whether breadwinner for the household, education, marital status, family size, etc. I believe that a person's past experience with a road accident, especially if recent, whether personal or to someone closely related can have an impact in the attitude of that person towards road safety. Thus, I also included some detailed questions about the respondent's past accident history, if any, including severity, duration of recovery, how long ago occurred, etc. and/or knowledge of road accidents experienced by other family members. These questions were placed at the send of the questionnaire in this last section, after the valuation questions, to avoid biasing the

\footnotetext{
${ }^{41}$ It is acknowledged that when asked about road traffic accidents, attention may also be devoted to the risk of injuries, however the scope of this survey did not allow me to focus on that aspect. In the literature, studies that dealt with road traffic injuries followed a different approach (see Chapter 2).

${ }^{42}$ During focus groups, one-on-one interviews and whenever I observed an actual at-home interview, I witnessed this question to elicit a negative response by most of the respondents when correctly asked. However, initially when asked, many of the respondents who answered in the affirmative actually misinterpreted the question by thinking it meant whether they thought accidents could cause injuries too.
} 
respondent on matters related to road traffic safety. Questions about household motor vehicle ownership, maintenance and costs, monthly transportation costs from all modes, etc. were also included. Finally, there were attitudinal questions that elicited the respondent's risk taking behavior like whether he straps the helmet when wearing (if applicable) or uses the seatbelt when sitting on the front seat of a car, whether has life insurance, etc.

\subsection{Risk Communication}

The validity of $\mathrm{CV}$ responses are judged by their sensitivity to factors that are expected to influence WTP such as income and the quantity of the good offered (Mitchell and Carson, 1989). When the good to be valued is a small reduction in the risk of death, its communication becomes crucial in determining valid responses. In an experiment to test the effectiveness of various visual aids Corso, Hammitt and Graham (2001) find that the use of visual aids to demonstrate probability in contingent valuation studies improves validity as compared to a situation where no visual aids are used.

In the early drafts of my questionnaire, I experimented with a new visual aid to demonstrate the probability of dying. This tool was a jar of 100,000 rice grains. Respondents were shown risk levels using black rice grains. The interviewer replaced the appropriate number of white rice grains with black grains to demonstrate the chance of dying. This procedure was repeated for every CV question. For convenience, the black grains were placed in small, transparent plastic pouches. The respondent was asked to imagine that each white rice grain represented a person who is alive and black rice grain 
represented a dead person. For example, to demonstrate the probability of an adult dying as a pedestrian in road traffic accidents in Delhi, the interviewer inserted a bag of 11 black rice grains in a jar of 99,989 white grains. Ideally, if these black grains could be scattered in the jar, they would be a perfect representation of the traffic risks and of their randomness. However, if they were scattered inside the jar then they would have been harder to see.

\section{FIGURE 4.1: RISK COMMUNICATION TOOL- JAR OF 100,000 RICE GRAINS}

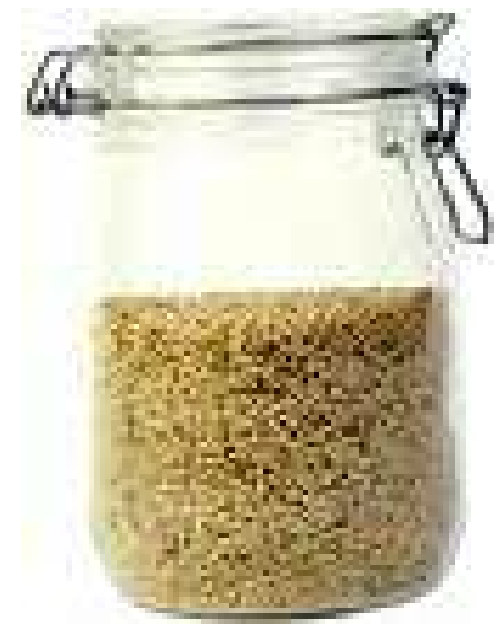

JAR OF RICE

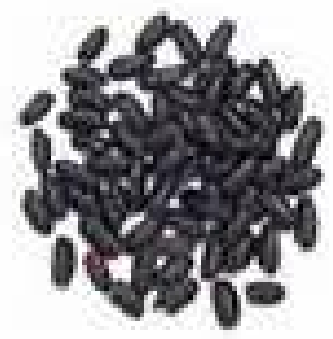

BLACK GRAINS OF RICE

Thus, innovative and intuitive as this approach might have been, it proved impractical: the interviewer had to remove the pouch of black grains from the jar before the demonstration for the next question. This was both cumbersome and time consuming for the interviewers. Moreover, each jar weighed roughly 2 kilos and extracting the black grains was difficult and awkward. These problems became apparent in the focus groups and the first two pilot studies. For this reason I decided to switch to presenting the 
probability of dying using a grid of 100,000 squares. Success in one-on-one interviews and Pilot Study 3 led me to believe this methodology worked well.

The method of using a grid of squares to demonstrate risk of dying has been used in many recent mortality risk studies conducted in developed countries. In a review of the literature to examine the methods of communicating small risks such as those from cancer, Lipikus and Hollands (1999) report that the grid and risk ladder have proved to be most effective in helping study participants understand the risks. Corso, Hammitt and Graham (2001) find that the grid and logarithmic scale are the best suited visual aids to demonstrate probability and that using them resulted in WTP that was near-proportional to the size of risk reduction.

I experimented with squares of various sizes for my grid. The smallest-sized square that was easily discernable by the naked eye was $1 \mathrm{~mm}$ by $1 \mathrm{~mm}$. Since I wanted to express risks as $\mathrm{X}$ in 100,000, the smallest grid that would represent this was of $400 \mathrm{~mm}$ by $250 \mathrm{~mm}$ (or $40 \mathrm{~cm}$ X $25 \mathrm{~cm}$ ) rectangular grid. Risk levels were represented as red squares. For example, a $7 / 100,000$ risk of dying was represented as 7 red squares and 999,993 white squares in a rectangular grid of 100,000 squares.

The respondent was asked to imagine that each white square represented a person who is alive and each red square represented a dead person. Ideally, I would have liked to scatter the red squares on the grid to convey the randomness of the risk, but doing so would not have given the respondent a good sense of the size of the risks. ${ }^{43}$ Thus, I

${ }^{43}$ Since my survey respondents were working people, the survey was mostly conducted on weekday evenings and nights. Clustering the red squares ensured that the red squares were noticeable even during late evenings in case the interviewer was standing outside the respondent's home and/or in a dimly lit environment. 
clustered the red squares in the center of the grid. Figure 4.2 shows a rectangular grid of 10,000 squares. The actual grid used in the survey was 10 times larger. The three red squares in Figure 4.2 represent a risk level of 3/10,000, which is equivalent to $30 / 100,000$, the highest level of risk reduction in any valuation question across all versions in the final survey.

FIGURE 4.2: A RECTANGULAR GRID REPRESENTING A RISK OF 3 / 10,000 (THE GRID IN THE SURVEY WAS 10 TIMES LARGER WITH 100,000 SQUARES)

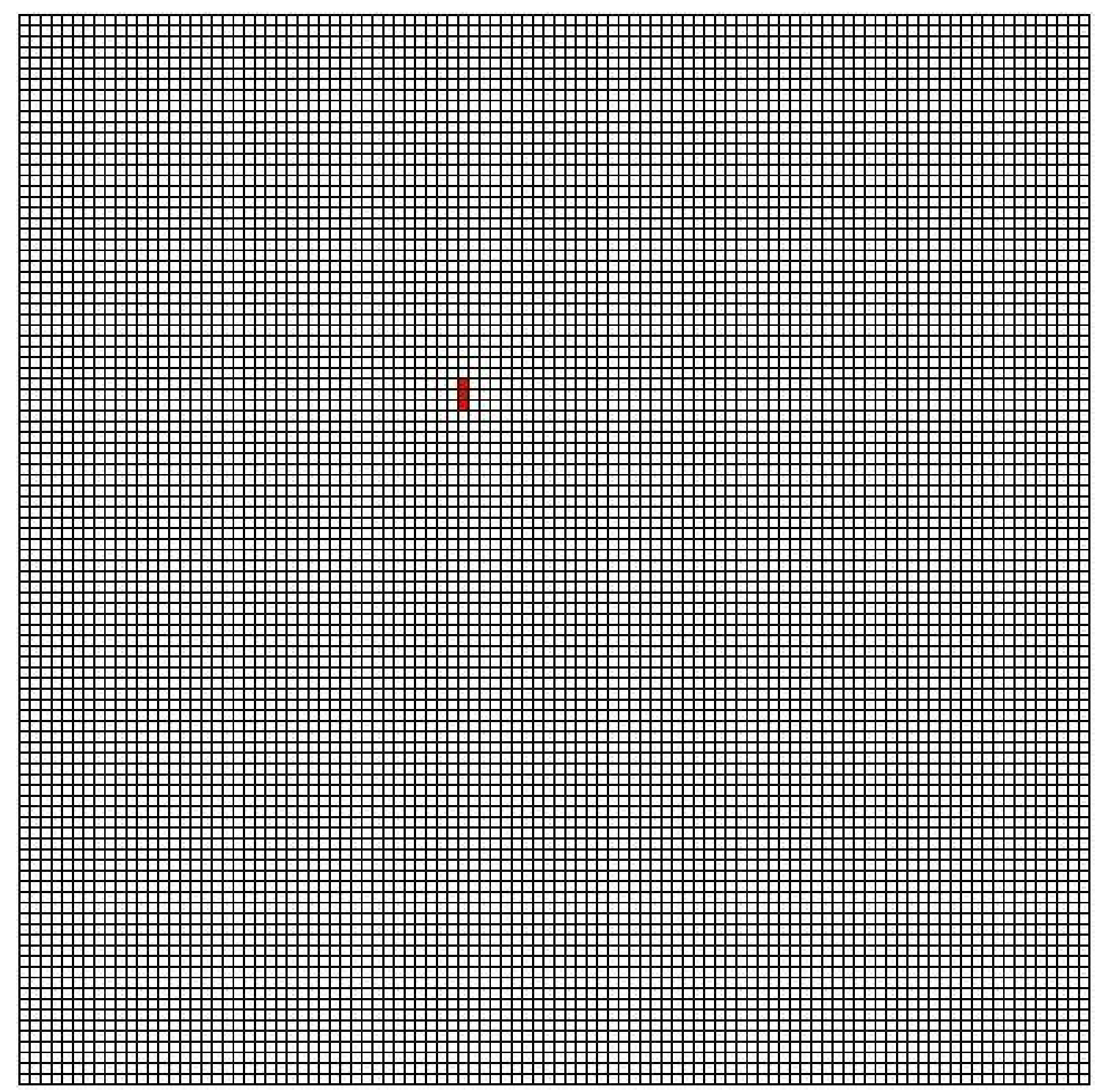




\subsection{Valuation Scenarios}

One major criticism of the CV methodology is the hypothetical nature of the payment questions. It is alleged that since the questions are hypothetical, the responses will also be hypothetical and thus not indicative of what people would truly pay. To minimize this concern, $\mathrm{CV}$ questions were devised to be as realistic and easy to grasp as possible. Moreover, each of the scenarios elicited willingness to pay for a private risk reduction. These were then tested for their acceptability in a series of focus groups, oneon-ones and pilots before the finalizing the questionnaire. Tables 4.3A, 4.3B and 4.3C describe the development of the $\mathrm{CV}$ questions through the various stages of questionnaire development.

Pedestrians are the largest category of road accident victims in Delhi as well as the rest of India (see Figure 3.1 in Chapter 3). It was therefore essential to elicit WTP for pedestrian safety. The next highest category of road accident victims are two-wheeler drivers, which prompted me to create a scenario involving safety for a two-wheeler driver.

Early drafts of the questionnaire cast the valuation questions in a choice experiment framework. The three basic scenarios involved were the use of a pedestrian subway (pedestrian), wearing of a helmet for the driver of a two-wheeler vehicle (driver) and choice between buses for a bus passenger. Three types of tradeoffs were used — risk versus money, risk versus time and time versus money with the intent of chaining them to ultimately place a monetary value on risk reduction (see Carthy et al., 1999). Each 
respondent was asked to evaluate all three tradeoffs, but the money, risk reduction and time attributes were varied across respondents (Table 4.3A).

During the first six focus groups (Table 4.3A), I experimented with a scenario focusing on bus passengers as in Jones-Lee et al (1985). Inclusion of this scenario would have given me the opportunity to evaluate the respondent's choices in all three roles — as a pedestrian, as a driver and as a passenger. In one of the versions of the questionnaire, the bus scenario also involved two additional questions. The first question involved a risk versus money tradeoff between two alternative bus routes. Depending on what option the respondent chose in the question, there were follow-up questions that elicited maximum willingness to pay in a dichotomous choice setup. A final question offered the respondent three choice alternatives one of which could be considered to elicit WTA for an increase in risk.

Unfortunately, it became clear that people were unwilling to make the time versus risk tradeoff, except in the pedestrian context. These tradeoffs were therefore dropped in the second set of focus groups. As mentioned earlier, all the three scenarios described above elicit private willingness to pay values. In the second set of focus groups, I tested two additional questions. One of them involved asking the WTP for a reduction of X deaths in Delhi each year to elicit willingness to pay values in a public program context. Another question asked respondents whether they thought road accidents or air pollution were responsible for more deaths in Delhi. Most of the respondents chose road accidents.

After the second set of focus groups, I opted for dropping the bus passenger scenario after the focus groups because bus riders account for less than one percent of 
road deaths in Delhi. I replaced it with a location choice question similar to that in Viscusi, Magat and Huber (1996). Specifically, I asked respondents to choose between two identical cities - City A and City B - that differed only in annual commute cost and risk of death from road accidents. This scenario was tested during the pretest that followed the ten focus groups.

The pedestrian subway scenario that involved a tradeoff between risk and time was reintroduced in the pretest. In Pilot1 and Pilot2, the same set of valuation questions were included as in the pretest. Baseline risk levels and the implied risk reductions when choosing the safer option were varied across respondents.

As mentioned earlier, after the first two pilot studies the risk communication tool was changed from the jar of rice grains to a rectangular grid of 100,000 squares, which resulted in a shorter survey that was easier for the interviewers to administer. Twelve one-on-one interviews and Pilot3 were designed to test the grid as a tool for demonstrating probability. Another CV question was also introduced in these stages. This question elicited in an open-ended format the WTP for a reduction of 10 minutes in daily commute time for respondents whose commute was greater than 20 minutes. Since the question involved the respondent's daily commute, it was asked in the first section of the survey after the respondent gave an account of his commute.

The question about willingness to pay for a reduction in the absolute number of road accident deaths in New Delhi was removed in the subsequent drafts (Pilot 4 and the final survey) of the questionnaire for two reasons. First, no sensitivity of WTP to the number of absolute deaths in the pilot studies was observed (e.g., the mean WTP was 
virtually the same for a reduction of 50 deaths as for a reduction of 200 deaths). Second, presenting the risk in terms of absolute number of deaths does not give an indication of the true probability of dying to respondents unless they know exactly the reference population. Another question that was subsequently removed after the Pilot4 stage was the time versus risk tradeoff in the pedestrian scenario. This question was excluded since it did not elicit credible answers ${ }^{44}$ during the pilot studies. In the choice experiment framework, the majority of the respondents chose the option to spend the extra time to walk to the pedestrian subway to eliminate the risk of dying while crossing the road. However, the proportion of respondents who chose the safer option did not vary much with the time it took to walk to the subway. Thus, I concluded that this question did not represent a plausible scenario and decided to exclude it from the final survey.

The final survey was comprised of four valuation questions. The principal reason why the number of questions was reduced to four was to reduce respondent burden and survey time. The first of the four CV questions in the final survey asked the daily WTP for a 10 minutes reduction in commute time from home to workplace. This question was asked in an open-ended format with no payment cards and was asked at the end of commuting pattern questions in section A of the survey. The next three valuation questions were included in section D and were accompanied by grids, show cards and payment cards.

For the first question in section $\mathrm{D}$, the respondent was supposed to imagine that he would have to cross the street in front of his/her workplace. Crossing the street each

\footnotetext{
${ }^{44}$ There were instances of respondents indicating that they would walk an extra 30 minutes each way to use the pedestrian subway to reduce the risk of dying.
} 
workday would imply an X/100,000 annual risk of dying as a pedestrian. Alternatively, a toll pedestrian subway could be used by buying an annual pass for Rs.WTP, which would reduce the risk of dying to $0 / 100,000$. The respondent was then asked about his willingness to pay for using that pedestrian subway for one year that would reduce the risk of dying from $\mathrm{X} / 100,000$ (if he crossed the road directly) to $0 / 100,000$.

The second WTP question asked the individual to consider two cities that are identical in all aspects except for road accident fatality rate and cost of commuting. The respondent is asked how much more he would be willing to pay to live in the safer of the two cities. A baseline commute cost was provided to respondents which varied with the version of the questionnaire assigned. Respondents given versions 1 and 3 were told that their baseline annual commute cost was Rs. 2400, whereas those given versions 2 and 4 were told it was Rs. 4800 . These baseline values were based on average commuting costs obtained during the focus groups and pilot studies and were found to have no influence on the WTP amounts stated by the respondents (see Chapter 6).

In the third and last question (which is worded slightly differently for people who do not drive a two-wheeler), respondents were asked how much extra they would pay for a helmet that would last exactly 3 years but would provide greater safety than a Rs. 300 helmet. Respondents were asked to assume that the helmet they already use was ready to be replaced. Helmets are normally available for purchase in the market from Rs. 100 to Rs. 2000. The Rs.300 baseline value for a helmet was the average price reported in focus group discussions and one-on-ones. 


\section{BOX 4.1: CONTINGENT VALUATION QUESTIONS IN THE FINAL SURVEY}

\section{D1: PEDESTRIAN SCENARIO}

Suppose that to get to work in the morning you have to cross a very busy street in front of your workplace/ office. You need to cross that street 240 days in a year. You have two options available to you for crossing the busy street in the morning. You can cross the street right away, dodging speeding traffic, with a chance of ' $15 / 100,000$ ' each year of dying in an accident on that street. If you choose this option you will not be spending any money for crossing the road (cost Rs. 0 ). Or, you can cross the street using the pedestrian subway with a chance ' $0 / 100,000$ ' each year of dying in an accident on this street. However, to use this new pedestrian subway you must buy a pass that is valid for a year. Please note that this pass can be used only for this subway and cannot be transferred or sold to another person.

What is the maximum amount of money you would be willing to spend every year to use the pedestrian subway in order to reduce your chance of dying in a road accident from $15 / 100,000$ to $0 / 100,000$ ? (Please remember if you spend more money each year for your safety, you will have less money available for food, clothing, etc.). To help you answer this question, here is a card with several possible values. Which of them is closest to the maximum amount you would spend to get a pass for the pedestrian subway? (Please feel free to suggest any other value too that is not mentioned in this card.)

\section{D2: CITY A V/S CITY B SCENARIO}

Suppose that there are two cities. The two cities are identical in all respects except the chance of dying from road accidents and transportation costs. Assume that you live the same distance away from your workplace/ office in either of these two cities. In City A the cost of commuting to and from work is $2400 \mathrm{Rs}$. a year. Your chance of dying while commuting to and from work is $35 / 100,000$ each year.. In City $B$ your chance of dying while commuting to and from work is $\underline{5 / 100,000}$ a year.

How much extra money would you be willing to spend every year in transportation costs to live in the safer city in order to reduce your chance of dying in a road accident from $35 / 100,000$ to $5 / 100,000$ ? (Please remember if you spend more money each year for your safety, you will have less money available for food, clothing, etc.). To help you answer this question, here is a card with several possible values. Which of them is closest to the maximum amount you would spend to get a pass for the pedestrian subway? (Please feel free to suggest any other value too that is not mentioned in this card.)

\section{D4 or D5: HELMET SCENARIO}

Suppose it is time to replace the two-wheeler helmet that you wear. Imagine that you are shown two helmets that look exactly identical but differ in price and quality. Please note that both helmets last for three years. Assume that you will be the only person wearing this helmet. You can buy Helmet 1 that lasts for three years and costs Rs. 300. If you wear this helmet, your chances of dying due to a head injury in a two-wheeler accident are $\underline{\mathbf{3 0 / 1 0 0 , 0 0 0}}$ during the three years that the helmet will last. Or, you can buy Helmet 2 that also lasts for three years. Wearing this helmet will reduce your chance of dying due to a head injury in a two-wheeler accident to $\underline{6 / 100,000}$ during the three years that the helmet will last.

How much extra money are you willing to spend for Helmet 2 in order to reduce your chances of dying from head injury in a two-wheeler accident from $\underline{30 / 100,000}$ to $6 / 100,000$ during the three years that you would wear the helmet? (Please remember if you spend more money each year for your safety, you will have less money available for food, clothing, etc.). To help you answer this question, here is a card with several possible values. Which is the closest to the maximum extra amount of money you would spend for Helmet 2? 
Respondents were reminded after every question that if they decided to spend more money on safety then they would have less money to spend on other things (i.e., the respondents were reminded of their budget constraint). The wording of the three WTP questions for Version 1 is presented in Box 4.1.

An equal number of interviews were carried out using each version. The versions differed in the risk reduction levels offered for valuation in each scenario as well as the baseline commute cost in the City A versus City B question. The baseline risks and risk reductions were thus varied across and within the respondents. Table 4.4 shows the study design across the various versions of the questionnaire for the final survey.

Versions 1 and 2 contained identical risk reductions as did Versions 3 and 4. The Helmet question involved risk reductions and payments that lasted for a period of three years instead of annual risk reductions and payments as in the case of the other two questions. This question was asked last so the respondent would not be confused about the timing of the payment. Each version of the questionnaire was asked of equal number of respondents in each geographical section of the city. These are all discussed in greater detail in Chapter 5.

\subsection{Format of Valuation Questions}

As mentioned in Chapter 2, stated preference studies can use many approaches to elicit the value an individual places on a good. Payment questions can be posed in an open-ended format, using a payment card or in the dichotomous choice format, etc. (Bateman et al., 2002). In early drafts of the questionnaire, I cast all CV questions in the 
choice experiment format, except for one, which was formulated as an open-ended question.

The valuation questions in these early stages (Focus groups, Pilot1, Pilot2 and Pilot3) asked the respondents to make choices between two options for which two attributes were varied. One of these attributes was the probability of dying while the other was either the money cost (Rupees) or time cost (minutes). Pictorial representations of both choice options accompanied the narration of the question wherever applicable. Figure 4.3 shows a sample question in the choice experiment format that was used in one of the pilot studies. The respondent was first read the scenario, and then presented with each alternative along with the illustration and a demonstration of the risk of dying using the grains of rice. ${ }^{45}$ For example, in valuation question D1 of version 1 of the questionnaire for the Pilot2 study, the respondent was shown 13 grains of black rice in a jar of 99,987 grains of white rice. After the demonstration the respondent was shown a card (Card number 5 for this question) that summarized the two options before finally being asked to choose between them. The questionnaire versions varied only in the attribute levels — baseline risk, size of risk reduction, time and money cost — offered in the choice sets.

Unfortunately, during Pilot1 and Pilot2, I found that a high percentage (as high as 95\%) of respondents selected the safer and higher-cost option as their choice regardless of the price. In a subsequent pilot study, Pilot3, I decided to include open-ended followup questions after every valuation question that asked the respondents their maximum

\footnotetext{
${ }^{45}$ The reader is reminded that in the focus groups, pre-test, Pilot1 and Pilot2, the risk communication tool was the rice jar.
} 
willingness to pay for the safer alternative. The objective of including these follow-up questions was to find out whether the choice for the safer alternative was indeed a legitimate response. I found contradictions between the option chosen from the choice experiment and the follow up question in many cases (this occurred in $38 \%$ for the pedestrian subway risk-time tradeoff scenario and $54 \%$ for the pedestrian subway riskmoney tradeoff scenario).

This led me to rephrase all valuations questions in an open-ended format. To facilitate the respondent's task I decided to use a payment card. The payment card lets the respondent choose a value from an array of possible amounts. I also allowed the respondent to state a value not displayed in the payment card.

One possible criticism of the payment card approach is that it can be subject to anchoring biases, i.e., the responses may be influenced by the starting values or the middle value in the array (Boyle, 2003). Thus, in Pilot4 I experimented with two types of payment cards to test for anchoring biases. Two payment cards with differing starting points were designed to investigate whether these biases could occur. These two payment cards were devised so that there was no single middle value in them, i.e., they had a total of 24 values presented as a matrix of 4 rows and 6 columns. They differed in the starting value: one had a starting value of Rupees 0 and the other had Rupees 5. Each payment card ranged from either Rupees 0 or Rupees 5 to Rupees 3,000. There were total of 23 different possible payment amounts plus the option for the respondents to state a value greater than Rupees 3,000 (or any value not shown in the payment card). 
FIGURE 4.3: A SAMPLE QUESTION (PEDESTRIAN SCENARIO) FROM THE CHOICE EXPERIMENT FRAMEWORK

D1) Suppose, to get to work in the morning you have to cross a very busy street in front of your workplace/ office. You would thus need to cross that street every workday ( 240 days in a year). You have to go to work $\mathbf{2 4 0}$ days in a year. You have two options available to you for crossing the busy street in the morning:

\begin{tabular}{|c|c|}
\hline Option 1 & Option 2 \\
\hline $\begin{array}{l}\text { You can cross the street right away, } \\
\text { juggling your way across speeding } \\
\text { traffic, with a chance of } 13 / 100,000 \text { in a } \\
\text { year of getting fatally injured from an } \\
\text { accident. If you choose this option you } \\
\text { will be spending } 1 \text { minute daily for } \\
\text { crossing the road (4hours in a year). }\end{array}$ & $\begin{array}{l}\text { You can walk down } 200 \text { metres to the } \\
\text { pedestrian subway, with a chance of } \\
0 / 100,000 \text { in a year of getting fatally } \\
\text { injured from an accident. If you choose } \\
\text { this option you will be spending } 7 \\
\text { minutes daily for crossing the road } \\
\text { (28 hours in a year). }\end{array}$ \\
\hline You are here & $\begin{array}{l}\text { are here } \\
3 \text { minutes }\end{array}$ \\
\hline 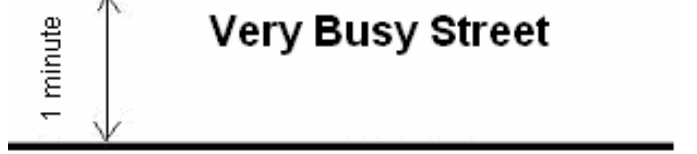 & 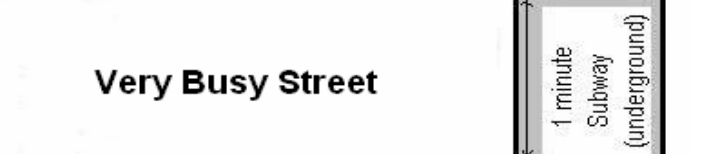 \\
\hline & 3 minutes \\
\hline
\end{tabular}

Card \# 5: QUESTION D1

\begin{tabular}{|c|c|c|}
\hline & OPTION 1 & OPTION 2 \\
\hline Cross street right away. & $\begin{array}{c}\text { Walk to Subway I, 200 meters from } \\
\text { the place where you want to } \\
\text { cross the road. }\end{array}$ \\
$\begin{array}{c}\text { Chance of } \\
\text { Death }\end{array}$ & $13 / 100,000$ & $0 / 100,000$ \\
Time Spent & $\begin{array}{c}1 \text { minute daily } \\
4 \text { hours/ year }\end{array}$ & $\begin{array}{c}7 \text { minutes daily }= \\
28 \text { hours/ year }\end{array}$ \\
\hline
\end{tabular}

Which option would you choose- Option 1 or Option 2?

\begin{tabular}{|l|l|l|}
\hline 1 & Option 1 & \\
\hline 2 & Option 2 & \\
\hline
\end{tabular}


FIGURE 4.4: PAYMENT CARD USED IN THE FINAL SURVEY

\begin{tabular}{|c|c|c|c|c|c|}
\hline What is & $\begin{array}{l}\text { d No. } \\
\text { aximu } \\
\text { pedes }\end{array}$ & $\begin{array}{l}\text { YMEI } \\
\text { unt of } \\
\text { ubwa } \\
\end{array}$ & $\begin{array}{l}\text { IRD FC } \\
\text { y you r } \\
\text { our wa } \\
\end{array}$ & $\begin{array}{l}\text { ESTI } \\
\text { spend- } \\
\text { ork ea }\end{array}$ & $\begin{array}{l}\text { er a year-to } \\
\text { a? }\end{array}$ \\
\hline & & & & & \\
\hline 0 & 5 & 10 & 15 & 20 & 40 \\
\hline 50 & 75 & 100 & 125 & 150 & 200 \\
\hline 250 & 300 & 350 & 400 & 500 & 600 \\
\hline 800 & 1000 & 1500 & 2000 & 3000 & $\begin{array}{c}\text { More than } \\
\mathbf{3 0 0 0}\end{array}$ \\
\hline & & & & & \\
\hline & An & amou & t ment & above) & \\
\hline
\end{tabular}

No anchoring effects or starting point biases were observed in Pilot4 in the sense that mean WTP and the distribution of WTP was roughly similar by using either of the two payment cards. Thus for the final survey, I decided to use only one version of the payment card, the one where payments ranged from Rupees 0 to Rupees 3,000. These range of values ensured that my range of VSLs that could be elicited varied from PPP $\$ 0$ to about PPP $\$ 1.14$ million. ${ }^{46}$ This range seems reasonable given the estimates computed by other studies in developing and developed countries. Figure 4.4 shows the payment card that was used for question D1 in the final survey. This payment card was chosen from the two versions that were tested because I wanted the give the respondent the

\footnotetext{
${ }^{46}$ VSL would be greater than $\$ 1.14$ million (2005 PPP) for people who elicit values greater than Rs. 3000 .
} 
option to pay nothing for increased safety if he so desired. Also, it included in its range of values the amounts that were presented in the other card used in Pilot4.

TABLE 4.1: DETAILS OF QUESTIONNAIRE DEVELOPMENT STAGES

\begin{tabular}{|c|c|c|c|c|c|}
\hline & $\begin{array}{c}\text { Date } \\
\text { Conducted }\end{array}$ & Sample Size & $\begin{array}{l}\text { Format of } \\
\text { CV } \\
\text { Questions }\end{array}$ & $\begin{array}{c}\text { Number of } \\
\text { Versions of the } \\
\text { Questionnaire }\end{array}$ & $\begin{array}{c}\text { Number of } \\
\text { CV } \\
\text { Questions }\end{array}$ \\
\hline $\begin{array}{l}\text { Focus Groups- } \\
\text { Set } 1\end{array}$ & January 2005 & $\begin{array}{l}6 \text { focus groups } \\
\text { with } 8 \text { to } 12 \\
\text { participants in } \\
\text { each group }\end{array}$ & $\begin{array}{c}\text { Choice } \\
\text { Experiment }\end{array}$ & 3 & 3 to 6 \\
\hline $\begin{array}{l}\text { Focus Groups- } \\
\text { Set } 2\end{array}$ & January 2005 & $\begin{array}{l}4 \text { focus groups } \\
\text { with } 8 \text { to } 12 \\
\text { participants in } \\
\text { each group }\end{array}$ & $\begin{array}{c}\text { Choice } \\
\text { Experiment }\end{array}$ & 1 & 5 \\
\hline Pre-test & March 2005 & $N=37$ & $\begin{array}{c}\text { Choice } \\
\text { Experiment }\end{array}$ & 1 & 5 \\
\hline Pilot1 & April 2005 & $N=200$ & $\begin{array}{c}\text { Choice } \\
\text { Experiment }\end{array}$ & 4 & 5 \\
\hline Pilot2 & May 2005 & $N=650$ & $\begin{array}{c}\text { Choice } \\
\text { Experiment }\end{array}$ & 12 & 5 \\
\hline $\begin{array}{l}\text { One-on-One } \\
\text { Interviews }\end{array}$ & July 2005 & $\mathrm{~N}=12$ & $\begin{array}{c}\text { Choice } \\
\text { Experiment }\end{array}$ & 2 & 6 \\
\hline Pilot3 & July 2005 & $\mathrm{~N}=212$ & $\begin{array}{c}\text { Choice } \\
\text { Experiment }\end{array}$ & 4 & 6 \\
\hline Pilot4 & August 2005 & $N=200$ & Open-ended & 4 & 4 \\
\hline Final Survey & $\begin{array}{l}\text { October to } \\
\text { December } \\
2005\end{array}$ & $N=1200$ & Open-ended & 4 & 3 \\
\hline
\end{tabular}




\section{TABLE 4.2: DETAILS OF EACH STAGE OF QUESTIONNAIRE}

\begin{tabular}{|c|c|c|}
\hline & Purpose & Outcome \\
\hline $\begin{array}{l}\text { Focus } \\
\text { Groups- } \\
\text { Set } 1\end{array}$ & $\begin{array}{l}\text { Testing the acceptability of the } \\
\text { scenarios presented in the CV } \\
\text { questions. Testing whether jar of rice } \\
\text { grains effective for risk communication, } \\
\text { whether the show cards were effective } \\
\text { or not, checking for a range of the price } \\
\text { of helmets available, testing whether } \\
\text { annual payments are acceptable. }\end{array}$ & $\begin{array}{l}\text { Jar of rice grains well understood. Price } \\
\text { of a helmet varied from Rs. } 100-2000 \text {. } \\
\text { Most people were curious about the } \\
\text { payment vehicle. Annual payments } \\
\text { were acceptable. The show cards were } \\
\text { effective. However, the prospect of a } \\
\text { helmet lasting for only "one" year was } \\
\text { not very convincing to the participants. }\end{array}$ \\
\hline $\begin{array}{l}\text { Focus } \\
\text { Groups- } \\
\text { Set } 2\end{array}$ & $\begin{array}{l}\text { To find out people's views about road } \\
\text { safety, what they are willing to give up } \\
\text { for increased safety, and how small a } \\
\text { risk reduction they will pay for. } \\
\text { Assessing people's perception of the } \\
\text { risks in the city and their personal risks } \\
\text { in their opinion. Finding out opinion } \\
\text { about certain governmental policies. } \\
\text { Also comparing perceptions about } \\
\text { other health risks. }\end{array}$ & $\begin{array}{l}\text { The perception held by most } \\
\text { participants was that the fatality rates } \\
\text { were much higher than those presented } \\
\text { in the official documents. There was a } \\
\text { general mistrust about the government } \\
\text { so additional tax as a payment vehicle } \\
\text { was not acceptable. Most people were } \\
\text { of the opinion that road accidents killed } \\
\text { more people than air pollution. }\end{array}$ \\
\hline Pre-test & $\begin{array}{l}\text { Testing average time taken to complete } \\
\text { the survey, ease of answering } \\
\text { questions, whether jar of grains } \\
\text { effective in risk communication. }\end{array}$ & $\begin{array}{l}\text { Average time was anywhere between } \\
45 \text { minutes to } 1 \text { hour. Jars of rice grains } \\
\text { effective in communicating risk but } \\
\text { required a lot of time and effort to } \\
\text { demonstrate with every question. }\end{array}$ \\
\hline Pilot1 & $\begin{array}{l}\text { Testing the new set of scenarios for } \\
\text { their credibility amongst various strata } \\
\text { of population- by income, age, } \\
\text { education etc. }\end{array}$ & $\begin{array}{l}\text { Helmet most acceptable scenario } \\
\text { followed by city and then pedestrian } \\
\text { subway. Open-ended WTP question for } \\
\text { a reduction of } X \text { (absolute) number of } \\
\text { road deaths was challenged by the } \\
\text { respondents. }\end{array}$ \\
\hline Pilot2 & $\begin{array}{l}\text { Testing whether the magnitudes of the } \\
\text { risk levels had an impact on the value } \\
\text { people placed for their safety. }\end{array}$ & $\begin{array}{l}\text { Percentage of people choosing the } \\
\text { safer option relatively insensitive to the } \\
\text { level of risk reduction. }\end{array}$ \\
\hline $\begin{array}{l}\text { One-on-One } \\
\text { Interviews }\end{array}$ & $\begin{array}{l}\text { Testing grid with squares as a tool to } \\
\text { communicate probability. }\end{array}$ & $\begin{array}{l}\text { The grid worked as an effective tool for } \\
\text { risk communication. }\end{array}$ \\
\hline Pilot3 & $\begin{array}{l}\text { Testing grid with squares as a tool to } \\
\text { communicate probability. }\end{array}$ & $\begin{array}{l}\text { While the grid worked as an effective } \\
\text { toll for communicating the magnitudes } \\
\text { of the risks, there was still a high } \\
\text { percentage of yea saying (for the safer } \\
\text { options) irrespective of the magnitude of } \\
\text { the risk reduction. About half the } \\
\text { respondents who chose the safer option } \\
\text { contradicted themselves in the follow-up } \\
\text { question. }\end{array}$ \\
\hline Pilot4 & $\begin{array}{l}\text { Testing for anchoring effects with } \\
\text { payment cards. }\end{array}$ & No evidence of anchoring effects! \\
\hline Final Survey & N.A. & N.A. \\
\hline
\end{tabular}


TABLE 4.3A: DETAILS OF THE VALUATION QUESTIONS IN THE FOCUS GROUPS AND PRE-TEST

\begin{tabular}{|c|c|c|c|c|}
\hline & $\begin{array}{c}\text { Number of } \\
\text { CV } \\
\text { Questions }\end{array}$ & Details of the CV Questions & $\begin{array}{c}\text { Survey } \\
\text { Instrument }\end{array}$ & $\begin{array}{c}\text { Modifications Based on Results in } \\
\text { the Preceding Stage }\end{array}$ \\
\hline $\begin{array}{l}\text { Focus } \\
\text { Groups- } \\
\text { Set } 1\end{array}$ & 3 to 6 & 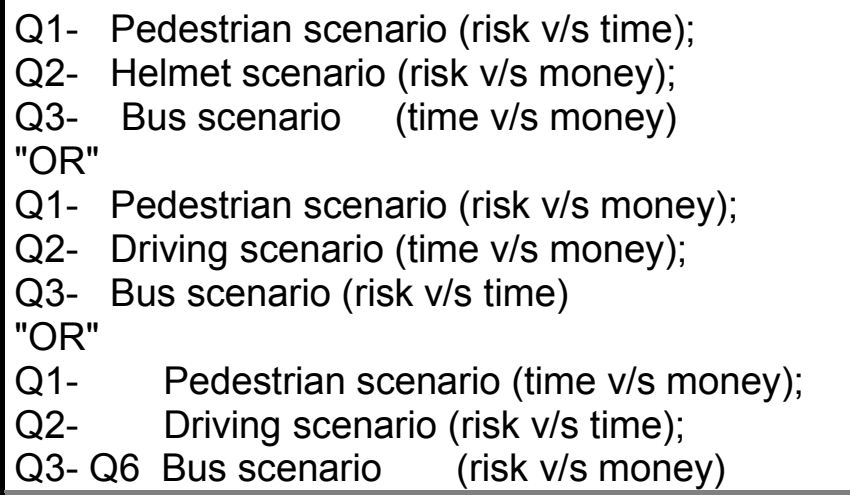 & $\begin{array}{l}\text { Jar with } \\
\text { rice grains }\end{array}$ & N.A. \\
\hline $\begin{array}{l}\text { Focus } \\
\text { Groups- } \\
\text { Set } 2\end{array}$ & 5 & 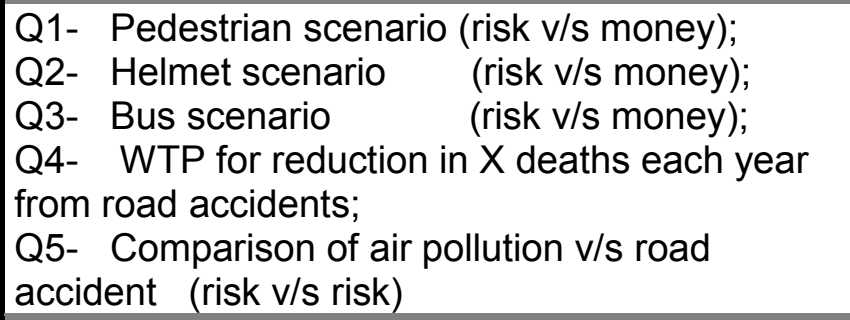 & $\begin{array}{l}\text { Jar with } \\
\text { rice grains }\end{array}$ & $\begin{array}{l}\text { Generic questions about people's } \\
\text { perceptions about risks. WTP in } \\
\text { these scenarios elicited by } \\
\text { varying the levels of risk or time } \\
\text { to ascertain values provided in } \\
\text { the safer options. }\end{array}$ \\
\hline Pre-test & 5 & $\begin{array}{l}\text { Q1- Pedestrian scenario (risk v/s time); } \\
\text { Q2- Pedestrian scenario (risk v/s money); } \\
\text { Q3- Helmet scenario (risk v/s money); } \\
\text { Q4- City scenario (risk v/s money) } \\
\text { Q5- WTP for reduction in X deaths each year } \\
\text { from road accidents }\end{array}$ & $\begin{array}{l}\text { Jar with } \\
\text { rice grains }\end{array}$ & $\begin{array}{l}\text { Bus scenario questions dropped } \\
\text { and city scenario introduced. } \\
\text { Risks and payment in helmet } \\
\text { scenario changed from one year } \\
\text { to three years. }\end{array}$ \\
\hline
\end{tabular}


TABLE 4.3B: DETAILS OF VALUATION QUESTIONS IN THE PILOT STUDIES \& ONE-ON-ONE INTERVIEWS

\begin{tabular}{|c|c|c|c|c|}
\hline & $\begin{array}{c}\text { Number of } \\
\text { CV } \\
\text { Questions }\end{array}$ & Details of the CV Questions & $\begin{array}{c}\text { Survey } \\
\text { Instrument }\end{array}$ & $\begin{array}{c}\text { Modifications Based on Results in } \\
\text { the Preceding Stage }\end{array}$ \\
\hline Pilot1 & 5 & $\begin{array}{l}\text { Q1- Pedestrian scenario (risk v/s time); } \\
\text { Q2- Pedestrian scenario (risk v/s money); } \\
\text { Q3- Helmet scenario (risk v/s money); } \\
\text { Q4- City scenario (risk v/s money) } \\
\text { Q5- WTP for reduction in X deaths each year } \\
\text { from road accidents }\end{array}$ & $\begin{array}{l}\text { Jar with } \\
\text { rice grains }\end{array}$ & $\begin{array}{l}\text { Some text and material reduced } \\
\text { in sections on probability tutorial } \\
\text { and information about baseline } \\
\text { risks to reduce interview time. } \\
\text { Some questions in the debriefing } \\
\text { section removed to reduce } \\
\text { interview time. }\end{array}$ \\
\hline Pilot2 & 5 & $\begin{array}{l}\text { Q1- Pedestrian scenario (risk v/s time); } \\
\text { Q2- Pedestrian scenario (risk v/s money); } \\
\text { Q3- Helmet scenario (risk v/s money); } \\
\text { Q4- City scenario (risk v/s money); } \\
\text { Q5- WTP for reduction in X deaths each } \\
\text { year from road accidents }\end{array}$ & $\begin{array}{l}\text { Jar with } \\
\text { rice grains }\end{array}$ & $\begin{array}{l}\text { Scenario descriptions made } \\
\text { more concise. Questions about } \\
\text { accident history moved after the } \\
\text { section on CV questions. }\end{array}$ \\
\hline $\begin{array}{l}\text { One-on-One } \\
\text { Interviews }\end{array}$ & 6 & $\begin{array}{l}\text { Q1- Pedestrian scenario (risk v/s time); } \\
\text { Q2- Pedestrian scenario (risk v/s money); } \\
\text { Q3- } \text { City scenario (risk v/s money); } \\
\text { Q4- Helmet scenario (risk v/s money); } \\
\text { Q5- WTP for reduction in X deaths each } \\
\text { year from road accidents; } \\
\text { Q6- WTP for } 10 \text { minutes reduction in daily } \\
\text { commute from home to workplace }\end{array}$ & Grid & $\begin{array}{l}\text { Introduction of a grid of } 100,000 \\
\text { squares to communicate } \\
\text { probabilities. Jar of rice grains for } \\
\text { this purpose discontinued. Some } \\
\text { text and material reduced in } \\
\text { sections on probability tutorial } \\
\text { and information about baseline } \\
\text { risks to reduce interview time. }\end{array}$ \\
\hline
\end{tabular}


TABLE 4.3C: DETAILS OF THE VALUATION QUESTIONS IN THE PILOT STUDIES AND FINAL SURVEY

\begin{tabular}{|c|c|c|c|c|}
\hline & $\begin{array}{c}\text { Number of } \\
\text { CV } \\
\text { Questions }\end{array}$ & Details of the CV Questions & \begin{tabular}{c|} 
Survey \\
Instrument
\end{tabular} & $\begin{array}{l}\text { Modifications Based on Results in } \\
\text { the Preceding Stage }\end{array}$ \\
\hline Pilot3 & 6 & $\begin{array}{l}\text { Q1- Pedestrian scenario (risk v/s time); } \\
\text { Q2- Pedestrian scenario (risk v/s money); } \\
\text { Q3- City scenario (risk v/s money); } \\
\text { Q4- Helmet scenario (risk v/s money); } \\
\text { Q5- WTP for reduction in X deaths each } \\
\text { year from road accidents; } \\
\text { Q6- WTP for } 10 \text { minutes reduction in } \\
\text { daily commute from home to workplace }\end{array}$ & Grid & $\begin{array}{l}\text { Consistency check questions } \\
\text { added after each CV question to } \\
\text { verify whether the WTP } \\
\text { responses were genuine. }\end{array}$ \\
\hline Pilot4 & 5 & $\begin{array}{l}\text { Q1- WTP for } 10 \text { minutes reduction in daily } \\
\text { commute from home to workplace; } \\
\text { Q2- Pedestrian scenario (risk v/s time); } \\
\text { Q3- Pedestrian scenario (risk v/s money); } \\
\text { Q4- City scenario (risk v/s money); } \\
\text { Q5- Helmet scenario (risk v/s money) }\end{array}$ & Grid & $\begin{array}{l}\text { Introduction of open-ended format } \\
\text { for the CV questions (choice } \\
\text { experiment } \\
\text { discontinued). Introduction of } \\
\text { payment cards. }\end{array}$ \\
\hline Final Survey & 4 & $\begin{array}{l}\text { Q1- WTP for } 10 \text { minutes reduction in daily } \\
\text { commute from home to workplace; } \\
\text { Q2- Pedestrian scenario (risk v/s money); } \\
\text { Q3- City scenario (risk v/s money); } \\
\text { Q4- Helmet scenario (risk v/s money) }\end{array}$ & Grid & $\begin{array}{l}\text { Same payment card, one that } \\
\text { contained an option of choosing } \\
\text { Rs. } 0 \text { to values greater than Rs. } \\
3000 \text { used for all CV questions. } \\
\text { Removal of the pedestrian } \\
\text { subway question that involved risk } \\
\text { versus time tradeoff. }\end{array}$ \\
\hline
\end{tabular}


TABLE 4.4: STUDY DESIGN

\begin{tabular}{|c|c|c|c|c|c|}
\hline Scenario & Version & $\begin{array}{c}\text { Initial } \\
\text { Annual } \\
\text { Risk }\end{array}$ & $\begin{array}{c}\text { Annual Risk } \\
\text { after the } \\
\text { Risk Reduction }\end{array}$ & $\Delta$ Risk & $\begin{array}{c}\text { Baseline } \\
\text { Cost } \\
\text { Provided } \\
\end{array}$ \\
\hline \multirow{4}{*}{ Pedestrian } & 1 & $15 / 100,000$ & $0 / 100,000$ & $15 / 100,000$ & Rs. 0/yr. \\
\hline & 2 & $15 / 100,000$ & $0 / 100,000$ & $15 / 100,000$ & Rs. 0/yr. \\
\hline & 3 & $7 / 100,000$ & $0 / 100,000$ & $7 / 100,000$ & Rs. 0/yr. \\
\hline & 4 & $7 / 100,000$ & $0 / 100,000$ & $7 / 100,000$ & Rs. 0/yr. \\
\hline \multirow{4}{*}{$\begin{array}{l}\text { City A } \\
\text { versus } \\
\text { City B }\end{array}$} & 1 & $35 / 100,000$ & $5 / 100,000$ & $30 / 100,000$ & Rs. $2400 / y r$ \\
\hline & 2 & $35 / 100,000$ & $5 / 100,000$ & $30 / 100,000$ & Rs. $4800 / \mathrm{yr}$ \\
\hline & 3 & $20 / 100,000$ & $5 / 100,000$ & $15 / 100,000$ & Rs. $2400 / y r$ \\
\hline & 4 & $20 / 100,000$ & $5 / 100,000$ & $15 / 100,000$ & Rs. $4800 / y r$ \\
\hline \multirow{4}{*}{ Helmet* } & 1 & $10 / 100,000$ & $2 / 100,000$ & $8 / 100,000$ & Rs. 300 \\
\hline & 2 & $10 / 100,000$ & $2 / 100,000$ & $8 / 100,000$ & Rs. 300 \\
\hline & 3 & $6 / 100,000$ & $2 / 100,000$ & $4 / 100,000$ & Rs. 300 \\
\hline & 4 & $6 / 100,000$ & $2 / 100,000$ & $4 / 100,000$ & Rs. 300 \\
\hline
\end{tabular}

*: The risk levels and the baseline costs were presented as three times the ones shown here since they were specified over three years. For example, in Versions 1 and 2, the initial risk level was $30 / 100,000$ and after a risk reduction of 24/100,000 the final risk was $6 / 100,000$. Thus the WTP values elicited from this question were also for a period of three years. 


\section{CHAPTER 5: SAMPLE DESIGN}

One objective of this study was to create a sample that would be as representative as possible of the population of Delhi, hence population-weighted data from the 2001 Census of India were used to draw the sample. The 2001 Census recorded the total population of Delhi State in 2001 as 13.78 million persons, of which 12.9 million were classified as urban and the remainder as rural. The Census for Delhi divides the city geographically into 134 Wards, 132 of which are considered urban. My attention for this survey was restricted to the 132 urban Wards, where most commuting is likely to occur.

The 132 urban Wards are divided into 21474 Census Enumeration Blocks (hereafter referred to as EB). Enumeration Blocks are also called Primary Sampling Units (PSU). The population in the EBs in urban Wards ranged from 5 to $2138.400 \mathrm{EBs}^{47}$ were selected from among the 132 wards, in proportion to ward population. Three households were selected from each EB using a systematic sampling procedure.

\subsection{Sample Selection}

Specifically, a two-stage sample design was followed: selection of EBs followed by selection of households. All 132 Wards were included in the survey to ensure full geographical coverage. In the first stage, 400 EBs were selected from the 132 Wards

\footnotetext{
${ }^{47}$ For national security concerns, the Census officials do not provide maps of enumeration blocks that comprise of the armed forces barracks. Thus, if selected, these EBs were replaced with others from the same Ward with similar population levels.
} 
using probability proportional to size (PPS) cluster sampling methods ${ }^{48}$ i.e., the number of EBs to be selected from each Ward $\left(n_{i}\right)$ was a function of the ratio of the population of the Ward to total urban population. The PPS method required the following steps:

i. Count the number of EBs belonging to a particular Ward $i, N_{i}$.

ii. Determine the number of EBs required to be sampled from the Ward, $n_{i}$. This is computed using the formula:

$$
n_{i}=\frac{P_{i}}{\sum_{j=1}^{132} P_{j}} \times 400 \text { where } P_{i} \text { is the total population of Ward } I
$$

Accordingly, the number of EBs selected in each Ward ranged from 1 to 8 . For example, 0.50 percent of the Delhi's urban population resided in Ward number 100. Thus, 0.50 percent of the $400 \mathrm{EBs}$ to be selected, which is $2 \mathrm{EBs}$, were selected from this Ward.

iii. Determine the sampling interval $\left(k_{i}\right)$ for each Ward, which can be computed as the total number of EBs in that Ward, $N_{i}$, divided by the number of EBs required to be sampled, $n_{i}$.

iv. Arrange all the EBs of a Ward in ascending order of their population. This ensures equal probability of selecting EBs that are highly populated as well as those that are less populated. In reality, this procedure is equivalent to selecting

\footnotetext{
${ }^{48}$ PPS is a commonly used sampling technique for governmental and business surveys. Examples include the National Family and Health Survey of India, Current Population Survey of the US Bureau of the Census, World Bank's Living Standard Measurement Survey among others. (NFHS, 2005; US Census Bureau, Current Population Survey, 2003; World Bank). There are numerous alternative approaches for selecting a fixed sample using the PPS sampling method. The popularity of this method stems from the fact that it allows the usage of smaller sample sizes that are simpler and less costly to administer without compromising on most potential sources of bias (Ernst, 2003).
} 
EBs with concentration of higher income groups, middle income groups and lower income groups with equal odds since population density is typically related to income levels.

v. Sort the EBs belonging to a particular ward in ascending order according to their Ward number.

vi. Choose a random integer between 1 and $k_{1}$ as the first selection and every $k_{1}^{\text {th }}$ EB from that consequently, until a total of $n_{l}$ EBs is obtained. Then add $k_{2}$ from the last selection in Ward 1 until $n_{2}$ EBs are obtained. Continue this process till the $400^{\text {th }}$ EB is selected from Ward $1344^{49}$

\subsection{Mapping and Listing}

To locate the selected EBs, I obtained detailed maps from the Census office. ${ }^{50}$ The Census EB maps are somewhat different than a regular street map. Using the help of the landmarks provided in the Census EB maps, ${ }^{51}$ the interviewers survey identified the exact geographical location of the EBs and drew a rough sketch map. (This is known as mapping.) Thereafter, all the households in the selected EBs were enumerated. (This is known as listing.) Households were defined as a set of persons who are related to one

\footnotetext{
${ }^{49}$ A detailed table showing the number of EBs selected from each Ward is presented in the Appendix.

5053 of the selected EBs from the original selection were unavailable or refused entry or ineligible according to screening criteria to yield at least 3 interviews. In order to maintain the weights used in the sample selection, I thus replaced them with other EBs of the same Ward with similar population levels

${ }^{51}$ The Census of India does not provide EB maps with exact street identifications to avoid comprising respondent privacy and confidentiality. For the same reason, EB maps are available to researchers only under special circumstances.
} 
another and reside together, and eat their meals from the same kitchen. ${ }^{52}$ Each EB is comprised of 150-300 households.

Three interviews were required from each EB. Thus, in the second stage, three households were identified in each EB based on a systematic sampling rule. The interviewer was first required to count the number of valid households as defined above based on the right hand rule, i.e., to count the households beginning on the right side of a street by turning right each time (listing). The total number of households obtained was then divided by three to determine the sampling interval. Using a random number generator, the first household was selected. The next two households were determined by adding the sampling number to the listing number of the first household.

All adult members of the selected household were administered the screening questions. A randomly selected available adult who satisfied all five screening criteria described in Box 5.1 was chosen for the interview. The interview either took place at the time of the screening or by appointment at a later date. I also defined replacement procedures to ensure that the selection of the respondent was not subject to bias. Specifically, if no member of the household qualified for the survey according to the screening criteria, then the immediate next household was selected according to the household listing created. Since the sampling interval in most cases was larger than fifty, this strategy ensured that the interviewer did not contact two households situated next to each other. This might create biases in the responses if the respondents were close by and listening when the interviewer contacted their neighbors. This is because in many

\footnotetext{
${ }^{52}$ This is the definition used in the 2001 Census of India. Boarding houses, messes, hotels, etc. were not included in this definition. Persons not related but sharing an accommodation not described above were considered as separate households.
} 
cases the interviewer stood outside the house to conduct the interview. In a few cases, when fewer than three respondents qualified from a particular EB (this occurred mostly due to the education criteria), a replacement interview was obtained from other EBs in the same Ward. In extremely rare situations when it was not possible to obtain any interview at all from a particular EB, replacements were made from other EBs of the same Ward.

\subsection{Respondent Screening Criteria}

When setting requirements for participation in the survey, I took into account the fact that young males in Delhi are the group most vulnerable to road accidents. In fact, young males in the 15-44 age-group constitute about $70 \%$ of road accident fatalities. This could be partly attributable to the fact that men in that age-group are highly exposed to traffic since they commute to work. My screening criteria were based on two considerations. First, the sample should target people who are most exposed to traffic risks; second it should be as representative of this population as possible.

This implied targeting working people, a majority of whom commute five to six days a week. I excluded persons whose commuting patterns varied from day to day, such as contractors and daily wage earners, because it would be difficult to obtain their average traffic exposure (kilometers traveled). I also set the age requirements for participation in the survey as 18-65 years. This age-group covers most working adults, which comprises roughly 60 percent $^{53}$ of the total urban population (Census of India

\footnotetext{
${ }^{53}$ Children in the age-group 0-14 constitute about 32 percent of the urban population. Teenagers in the 1518 age-group constitute another 6 percent of the population. Thus with my age-group requirements, I have
} 
(Delhi), 2001). Persons not engaged in any gainful economic activity were also excluded from participation in the survey because they were not as likely to be exposed to the same level of risk as their working counterparts and might not have an income out of which to pay for road safety. ${ }^{54}$ This excludes primarily women in the 18-65 age-group since only 14.7 percent of urban women aged 15 and older are employed outside the home in Delhi $\left(55^{\text {th }}\right.$ Round NSS, 2001). ${ }^{55}$ The corresponding figure for urban men is 74.3 percent. People who had not completed middle school (eighth grade) were excluded since they would be less likely to comprehend probabilities. ${ }^{56}$ This criterion excludes roughly 30 percent of the population of Delhi above 13 years $\left(60^{\text {th }}\right.$ Round NSS, 2005). ${ }^{57}$ Last, only persons who were residents of Delhi for at least three months were included so that respondents would be familiar with the city's traffic situation.

The total sample size was 1200 ( $400 \mathrm{EBs} \times 3$ interviews per EB). The survey was administered in four versions. I assigned specific EBs to each version in a manner so as to geographically disperse the versions and ensure that each EB within a particular Ward was assigned a different version of the questionnaire. If the number of EBs selected from

potentially only left out 8 percent of the urban population, one-fourth of whom do not commute much (aged 65 and higher) and are thus not at as high a risk as the ones included.

${ }^{54}$ I recognize that even though certain individuals are not engaged in gainful economic activity, nevertheless they may have preferences for their safety. However there also existed certain individuals in this category like older people, etc. who (a) were probably not as exposed to road risks, and/or (b) who may not have control over any money to place on their mortality risk valuation. Thus to eliminate the problems above I had to exclude this category of individuals.

${ }^{55}$ This is the latest information available yet.

${ }^{56}$ It is quite possible that persons with less than formal middle school education are able to interpret and value exercises involving probabilities, but given my experience with some initial one-on-one interviews I found that it is less probable. Thus this category was excluded from my sample.

${ }^{57} 60^{\text {th }}$ Round National Sample Survey of India (NSS) states that 48 percent of the population of Delhi had completed middle school education or higher. The 52 percent of the population that is not middle school educated also includes children below 13 who comprise of 30 percent of the urban population. 


\section{BOX 5.1: SCREENING CRITERIA FOR RESPONDENT SELECTION}

The following five criteria were used to select a respondent for the survey:

a. Respondent must have resided at least for 3 months in Delhi so that he/she can be presumed to be aware of the traffic situation in the city.

b. Respondent must be engaged in gainful full-time or part-time economic activity. With this requirement, I wanted to ensure that people would provide meaningful WTP responses. Besides, working adults are most vulnerable to traffic risks because of higher exposures than the rest.

c. Respondent must be in the $18-65$ age group to represent active working population as well as the majority of the victims of road accidents.

d. Respondent must commute at least once each workday to a fixed workplace: this rules out people whose traffic exposure varies on a daily basis (uncertain) like contractors, etc. The purpose for setting this as a criterion was to be able to make an assessment of the respondent's exposure to traffic. This would be difficult to assess for people who had varying exposures each day (since our questions elicit annual risks and payments, we need annualized exposures for comparability) hence these persons are excluded from the survey.

e. Respondent must have completed middle school, i.e., grade 8 education or higher in order to be eligible to participate in the survey. The valuation questions required understanding of probabilities. In a city where $18 \%$ of the population is illiterate, this was a way to ensure that most of the respondents would be able to understand the questions. This judgment was based on initial one-on-one interviews conducted in the early stages of the questionnaire preparation. 
a particular Ward was a multiple of four, then an equal number of interviews from each version was conducted. When the number of EBs selected from a Ward was not a multiple of four, I ensured that the version with least number of interviews was compensated in another EB from a neighboring Ward. The prior assignment of versions to each EB also avoided errors and confusion that could have resulted from the interviewers choosing versions at their convenience. 


\section{CHAPTER 6: THE DATA}

The data collection for the final survey took place in the months of October through December 2005. The survey was an interviewer administered in-person household interview of the respondent. A total of 1200 interviews were collected. Versions 1 and 4 had a sample size of 299 each whereas versions 2 and 3 had a sample size of 301 each. Each version had three valuation questions: one to be answered as a pedestrian, one as a daily commuter and one as a two-wheeler driver. Versions 1 and 2 were similar in all aspects except for the baseline commuting cost specified in the city scenario. This was also true of versions 3 and 4 . Thus for analysis purposes, results from versions 1 and 2 can be combined to form a pooled sample, ${ }^{58}$ as can versions 3 and 4 . Table 4.4 in Chapter 4 summarizes the study design across the four versions of the questionnaire.

\subsection{Socio-demographics}

The sample characteristics for each of the pooled samples are provided in Table 6.1. The two pooled samples are roughly similar in their socio-economic profile except for education levels. Versions 1 and 2 had a much higher proportion of respondents who had completed a bachelor's degree or higher than Versions 3 and 4. The average age of the respondents was roughly 35 years and $95 \%$ of the respondents were men. As noted in Ch. 5, the reason for such a low proportion of females in my sample is because only

\footnotetext{
${ }^{58}$ Preliminary analyses proved that the baseline commuting bid did not have any impact on the responses to the city WTP question. Thus, data from versions 1 and 2 can be pooled together as one sample. This is true for versions 3 and 4 too.
} 
about 15 percent of women in Delhi are employed outside the home. Many of these employed women work in jobs that require more or less no formal schooling such as parttime domestic help. Since the screening criteria required formal middle school (grade $8^{\text {th }}$ )

TABLE 6.1: DEMOGRAPHIC PROFILE OF THE SAMPLE

\begin{tabular}{|c|c|c|c|}
\hline & $\begin{array}{c}\text { All } \\
\text { Sample } \\
\end{array}$ & $\begin{array}{c}\text { Versions } \\
1 \& 2 \\
\end{array}$ & $\begin{array}{c}\text { Versions } \\
3 \text { \& } 4 \\
\end{array}$ \\
\hline Sample Size & 1200 & 600 & 600 \\
\hline Average age (years)* & $\begin{array}{l}35.09 \\
(11.03)\end{array}$ & $\begin{array}{l}35.35 \\
(10.90)\end{array}$ & $\begin{array}{l}34.83 \\
(11.16)\end{array}$ \\
\hline$\%$ Male & 94.67 & 93.17 & 96.17 \\
\hline$\%$ Currently Married & 77.00 & 76.17 & 77.83 \\
\hline$\%$ Have Children & 69.67 & 69.33 & 70.00 \\
\hline Average Household Size* & $\begin{array}{l}5.01 \\
(2.54)\end{array}$ & $\begin{array}{l}5.10 \\
(2.48)\end{array}$ & $\begin{array}{c}4.93 \\
(2.61)\end{array}$ \\
\hline \% Completed High school/ Vocational or Higher & 48.33 & 54.00 & 42.67 \\
\hline \% Completed Bachelor's Degree or Higher & 27.92 & 35.67 & 20.17 \\
\hline \multicolumn{4}{|l|}{ Personal Income } \\
\hline$\%$ Low ( $<$ Rs. 8,000 per month) & 43.75 & 44.83 & 42.67 \\
\hline \% Middle (Rs. 8,000-19,999 per month) & 52.58 & 50.67 & 54.50 \\
\hline \% High (> Rs. 20,000 per month) & 3.67 & 4.50 & 2.83 \\
\hline \multicolumn{4}{|l|}{ Household Income } \\
\hline$\%$ Low ( $<$ Rs. 10,000 per month) & 44.50 & 44.50 & 44.50 \\
\hline \% Middle (Rs. 10,000-19,999 per month) & 43.08 & 42.50 & 43.67 \\
\hline \% High (> Rs. 20,000 per month) & 12.42 & 13.00 & 11.83 \\
\hline \multicolumn{4}{|l|}{ Socio-Economic Class (based on education \& occupation) } \\
\hline \% Category C, D \& E (low) & 56.42 & 54.83 & 58.00 \\
\hline \% Category B (middle) & 29.75 & 28.50 & 31.00 \\
\hline$\%$ Category A (high) & 13.83 & 16.67 & 11.00 \\
\hline \% Primary Wage Earners & 67.08 & 68.17 & 66.00 \\
\hline
\end{tabular}

*: Figures in parentheses are standard deviations. 
completion, working women in those job categories were generally excluded from the sample. This is not a serious concern for my study since adult women have one-tenth the fatality risk from road accidents as adult men (refer to Table 3.2 in Chapter 3) in Delhi.

Roughly three-fourths of the respondents in my sample were currently married and 70 percent of them also had children. Two-thirds were also primary wage earners for their family. The average household size was 5 persons. This matches official figures from the 2001 Census. About 12 percent of the respondents belonged to high-income households, another 43 percent to middle-income households and the rest 45 percent to low-income households.

\subsection{Commuting Characteristics}

Table 6.2 presents the commuting characteristics of the pooled samples. The average respondent traveled for 36 minutes from home to reach his/her workplace. About one quarter drove two-wheelers to work, while another one quarter took the bus and another one quarter walked to work. Only 7 percent drove their own cars to work. This distribution of commute modes justifies the three scenarios that I presented in the valuation exercise.

The average monthly commute cost to the workplace was roughly Rs. 490. Half of the respondent households owned a motorized vehicle (see Table 6.2). About 15 percent owned cars and 43 percent owned two-wheelers (motorbikes or scooters). The corresponding official figures according to the 2001 Census of Delhi are 14 percent and 28 percent, respectively. Half the respondents knew how to drive a two-wheeler. 
TABLE 6.2: COMMUTING CHARACTERISTICS

\begin{tabular}{|l|c|c|c|}
\hline & $\begin{array}{c}\text { All } \\
\text { Sample }\end{array}$ & $\begin{array}{c}\text { Versions } \\
\mathbf{1 ~ \& ~ 2 ~}\end{array}$ & $\begin{array}{c}\text { Versions } \\
\mathbf{3 ~ \& ~ 4}\end{array}$ \\
\hline Sample Size & 1200 & 600 & 600 \\
Average Commuting Time from Home to & 36.02 & 35.05 & 37.00 \\
Workplace (minutes) & $(28.39)$ & $(28.07)$ & $(28.69)$ \\
Average Monthly Commuting Cost from & 490.55 & 476.75 & 504.35 \\
Home to Workplace (Rupees)* & $(771.49)$ & $(761.96)$ & $(781.29)$ \\
\% Travel for Job other than commuting from & 30.58 & 29.67 & 31.50 \\
home to workplace and back & & & \\
& 51.17 & 50.67 & 51.67 \\
\% Drive Two-wheelers & & & \\
& & & \\
Commute Characteristics & 25.17 & 24.83 & 25.50 \\
\% Drive Two-wheelers to Work & 7.00 & 6.83 & 7.17 \\
\% Drive Cars to Work & 26.17 & 26.34 & 26.00 \\
\% Travel by Bus to Work & 26.08 & 25.67 & 26.50 \\
\% Walk to Work & 8.92 & 9.67 & 8.17 \\
\% Ride the Bike to Work & 6.66 & 6.66 & 6.66 \\
\% Use All Other Modes to Work & & & \\
\% Households Own a Motorized Vehicle & 50.08 & 50.00 & 50.17 \\
\% HHs Own a Two-wheeler & 43.25 & 43.33 & 43.17 \\
\% HHs Own a Car/Van/Jeep & 14.67 & 14.17 & 15.17 \\
\hline
\end{tabular}

*: Figures in parentheses are standard deviations.

\subsection{Perception of Risks and Government Safety Policies}

Table 6.3 summarizes the responses to accident history and attitudes about governmental policies regarding road safety. About one quarter of the respondents had met with a road accident during their lifetimes. Roughly 14 percent of them knew 
someone who had met with a road accident. Together about one-third of respondents had either met with an accident themselves or knew a relative who met with one. Familiarity with road accidents may affect the respondent's WTP to reduce risk of death in a traffic crash.

Roughly 23 percent of respondents believed that they had higher mortality risks than the average pedestrian, 17 percent believed they had higher risks than the average driver and 25 percent believed that they had higher risks than the average passenger in a motorized vehicle. Such responses may reflect people's perceptions about the controllability of risks. In the focus groups, several people commented that as a driver they were able to control some risks, whereas as a passenger they could not control risks. This may have influenced the responses to these questions.

Averting behavior such as wearing seatbelts or strapping helmets also reflects people's attitudes and perceptions towards various risks. The traffic laws in Delhi require people to wear seatbelts when driving or sitting in the front seat of car. For two-wheeler drivers it is mandatory to wear helmets. Thus, one finds almost all motorcyclists in Delhi wearing helmets. However, many people do not actually strap their helmets. This dramatically reduces the helmet's effectiveness in protecting the wearer from head injuries. In my sample 60 percent of the respondents stated that they wore the seatbelt almost all the time when they were driving or sitting in the front seat of a car whereas only 54 percent of the two-wheeler drivers stated that they strapped their helmet most of the time when driving a two-wheeler. The responses to the latter question differ somewhat different between the pooled versions of the sample. 
TABLE 6.3: ACCIDENT HISTORY \& ATTITUDES TOWARDS PERSONAL RISK, AVERTING BEHAVIOR AND GOVERNMENTAL POLICIES

\begin{tabular}{|l|c|c|c|}
\hline & $\begin{array}{c}\text { All } \\
\text { Sample }\end{array}$ & $\begin{array}{c}\text { Versions } \\
\mathbf{1 ~ \& ~ 2 ~}\end{array}$ & $\begin{array}{c}\text { Versions } \\
\mathbf{3 ~ \& ~ 4}\end{array}$ \\
\hline Sample Size & 1200 & 600 & 600 \\
\% Had accident & 23.25 & 26.50 & 20.00 \\
\% Injured in an accident & 17.33 & 20.17 & 14.50 \\
\% Know someone with accident & 13.58 & 15.83 & 11.33 \\
\% Had/Know someone with accident & 31.33 & 36.50 & 26.17 \\
\% Think they have higher risk than average as a: & & & \\
$\quad$ Pedestrian & 22.92 & 22.83 & 23.00 \\
$\quad$ Driver & 16.83 & 18.83 & 14.83 \\
$\quad$ Passenger & 24.92 & 27.67 & 22.17 \\
\% Wear Seatbelts always/most of the time when & 59.67 & 60.50 & 58.83 \\
driving/ sitting in the front seat of a car & & & \\
\% Think Having & & & \\
risk of dying in an accident: & & \\
$\quad$ More Pedestrian Subways & 95.42 & 96.17 & 94.67 \\
$\quad$ Broader Roads & 87.83 & 87.83 & 87.83 \\
$\quad$ More Buses & 37.50 & 35.83 & 39.17 \\
$\quad$ More Flyovers (overpass) & 85.50 & 84.00 & 87.00 \\
$\quad$ Separate lanes for Bicycles and Cycle & 93.33 & 92.67 & 94.00 \\
Rickshaws & & & \\
\hline
\end{tabular}

The majority of respondents thought that four out of the five governmental policies presented would, if introduced, greatly reduce their personal risks of dying in road accidents. These policies are pedestrian subways, broader roads, more overpasses and separate lanes for slower moving traffic like bicycles or cycle rickshaws. By contrast, more public buses were considered only by one-third of the respondents to increase their 
road safety. This may reflect awareness that public buses are the cause of a big proportion of fatal accidents in the city. ${ }^{59}$

\subsection{Characteristics of Drivers of Motorcycles}

Table 6.4 shows the characteristics of people who drive two-wheelers. The average age and commute time in this sub-group is similar to that for the entire sample. However, the monthly commuting cost is about 25 percent higher than the sample average. A higher percentage of respondents who are two-wheeler drivers travel for work purposes (other than the regular commute) compared to the entire sample. Roughly onethird of the two-wheeler drivers have met with accidents, 20 percent of them have also been injured in a road accident in the past. These figures vary between the two pooled versions. They are also higher than for the entire sample, possibly indicating the vulnerability of two-wheeler drivers to road accidents. There are fewer two-wheeler drivers in the high-income group and more in the middle-income group compared to the entire sample. A greater proportion of these persons have completed a bachelor's degree than compared to the entire sample. However, even though their commute characteristics differ from those of the entire sample, their attitudes and perceptions towards risk are roughly similar.

\footnotetext{
${ }^{59}$ Public buses are the vehicles at fault for at least 22 percent of fatal accidents in Delhi. Bus riders however account for a mere 5 percent of total road fatalities (see Figures 3.1 and 3.2; Table 3.3, Chapter3).
} 
TABLE 6.4: DEMOGRAPHIC AND COMMUTING CHARACTERISTICS, ACCIDENT HISTORY \& ATTITUDES TOWARDS PERSONAL RISK AND SAFETY POLICIES OF TWO-WHEELER DRIVERS

\begin{tabular}{|c|c|c|c|}
\hline & $\begin{array}{c}\text { All } \\
\text { Sample }\end{array}$ & $\begin{array}{l}\text { Versions } \\
1 \& 2 \\
\end{array}$ & $\begin{array}{l}\text { Versions } \\
3 \text { \& } 4 \\
\end{array}$ \\
\hline Sample Size & 614 & 304 & 310 \\
\hline Average age (years)* & $\begin{array}{l}34.38 \\
(10.50)\end{array}$ & $\begin{array}{l}34.87 \\
(10.45)\end{array}$ & $\begin{array}{l}33.90 \\
(10.54)\end{array}$ \\
\hline $\begin{array}{l}\text { Average Commuting Time from Home to Workplace } \\
\text { (minutes)* }\end{array}$ & $\begin{array}{l}36.88 \\
(28.86)\end{array}$ & $\begin{array}{l}35.32 \\
(27.75)\end{array}$ & $\begin{array}{l}38.41 \\
(29.87)\end{array}$ \\
\hline $\begin{array}{l}\text { Average Monthly Commuting Cost from Home to } \\
\text { Workplace (Rupees)* }\end{array}$ & $\begin{array}{l}627.27 \\
(721.34)\end{array}$ & $\begin{array}{l}625.92 \\
(720.62)\end{array}$ & $\begin{array}{l}628.59 \\
(723.21)\end{array}$ \\
\hline $\begin{array}{l}\% \text { Travel for Job other than commuting from home to } \\
\text { workplace and back }\end{array}$ & 40.39 & 39.80 & 40.97 \\
\hline$\%$ Had accident & 31.11 & 36.51 & 25.81 \\
\hline$\%$ Injured in an accident & 18.89 & 22.70 & 15.16 \\
\hline$\%$ Think they have higher risk than average as a Driver & 16.61 & 19.08 & 14.19 \\
\hline $\begin{array}{l}\% \text { Wear and Strap a helmet always/most of the time } \\
\text { when driving a two-wheeler }\end{array}$ & 53.75 & 61.18 & 46.45 \\
\hline $\begin{array}{l}\% \text { Think Having } \\
\text { risk of dying in a road accident: }\end{array}$ & & & \\
\hline Broader Roads & 86.16 & 85.20 & 87.10 \\
\hline More Buses & 32.08 & 30.26 & 33.87 \\
\hline More Flyovers (overpass) & 85.83 & 82.57 & 89.03 \\
\hline $\begin{array}{l}\text { Separate lanes for Bicycles and Cycle } \\
\text { Rickshaws }\end{array}$ & 93.49 & 92.43 & 94.52 \\
\hline$\%$ Completed High school/ Vocational or Higher & 48.70 & 54.61 & 42.90 \\
\hline \% Completed Bachelor's Degree or Higher & 37.52 & 33.55 & 21.61 \\
\hline \% Low-Income Group(< Rs. 10,000 per month) & 43.32 & 43.42 & 43.23 \\
\hline \% Middle-Income Group (Rs. 10,000-19,999 per month) & 47.88 & 46.71 & 49.03 \\
\hline \% High-Income Group (> Rs. 20,000 per month) & 8.79 & 9.87 & 7.74 \\
\hline \% Primary Wage Earners & 66.12 & 65.79 & 66.45 \\
\hline
\end{tabular}

*: Figures in parentheses are standard deviations. 


\subsection{Characteristics of Persons with a High School Diploma}

Table 6.5 shows the characteristics of people who have a high-school diploma. The average age and commute time in this sub-group is similar to that for the entire sample. However, the monthly commuting cost is about 15 percent higher than the sample average for high school diploma holders. High-school diploma holders exhibit similar accident trends as two-wheeler drivers, the percentage who met with accidents is higher, at 35 percent. There is a smaller proportion of high-school diploma holders in the low-income group and more in the middle-income and high-income groups compared to the entire sample. This may not be surprising since income is positively correlated with education. One major characteristic that stands out for this sub-group is attitudes and perceptions towards risk as indicated by averting behaviors. A much higher proportion of the respondents in this sub-group wears seatbelts and straps their helmets than is true of the entire sample. 
TABLE 6.5: DEMOGRAPHIC, COMMUTING, ACCIDENT HISTORY \& ATTITUDES TOWARDS PERSONAL RISK AND SAFETY POLICIES OF PERSONS WITH AT LEAST A HIGH SCHOOL DIPLOMA

\begin{tabular}{|l|c|c|c|}
\hline & $\begin{array}{c}\text { All } \\
\text { Sample }\end{array}$ & $\begin{array}{c}\text { Versions } \\
\mathbf{1} \text { \& 2 }\end{array}$ & $\begin{array}{c}\text { Versions } \\
\mathbf{3} \text { \& 4 }\end{array}$ \\
\hline Sample Size & 580 & 324 & 256 \\
& 36.36 & 36.41 & 36.29 \\
Average age (years)* & $(11.28)$ & $(11.15)$ & $(11.45)$ \\
Average Commuting Time from Home to Workplace & 36.08 & 37.54 & 34.23 \\
(minutes)* & $(27.96)$ & $(28.55)$ & $(27.13)$ \\
Average Monthly Commuting Cost from Home to & 574.24 & 549.71 & 605.29 \\
Workplace (Rupees)* & $(909.05)$ & $(853.36)$ & $(975.82)$ \\
\% Travel for Job other than commuting from home to & 29.48 & 29.01 & 30.08 \\
workplace and back & 35.17 & 38.89 & 30.47 \\
\% Had accident & 19.48 & 21.30 & 17.19 \\
\% Injured in an accident & & & \\
\% Think they have higher risk than average as a: & 20.86 & 19.75 & 22.27 \\
$\quad$ Pedestrian & 17.24 & 20.06 & 13.67 \\
$\quad$ Driver & 23.97 & 27.78 & 19.14 \\
$\quad$ Passenger & & & \\
\% Wear and Strap a helmet always/most of the time & 57.93 & 54.32 & 62.50 \\
when driving a two-wheeler & & & \\
\% Wear Seatbelts always/most of the time when driving/ & 73.97 & 71.30 & 77.34 \\
sitting in the front seat of a car & & & \\
\% Think Having & & & \\
risk of dying in an accident: & & \\
$\quad$ More Pedestrian Subways & & \\
$\quad$ Broader Roads & 93.66 & 95.06 & 94.14 \\
$\quad$ More Buses & 86.03 & 85.49 & 86.72 \\
$\quad$ Separa Flyovers (overpass) & 36.38 & 32.72 & 41.02 \\
\% Low-Income Group Bicycles and Cycle Rickshaws & 93.62 & 91.98 & 96.72 \\
\% Middle-Income Group (Rs. 10,000-19,999 per month) & 61.55 & 57.10 & 67.19 \\
\% High-Income Group ( $>$ Rs. 20,000 per month) & 16.03 & 16.67 & 15.23 \\
\% Primary Wage Earners & 64.31 & 64.51 & 64.06 \\
\hline
\end{tabular}

*: Figures in parentheses are standard deviations. 


\section{CHAPTER 7: MODELS OF WILLNGNESS TO PAY, ESTIMATION AND RESULTS}

In this chapter I present theoretical models of willingness to pay, estimation procedures and the results. I analyze the data for the willingness to pay for safety in each of the three valuation scenarios - as a pedestrian, as a two-wheeler driver and in general while commuting to and from work in a city - separately as well as pooled together. Table 7.1 presents the Mean and Median WTP, implied VSLs and the percentage of respondents indicating a zero WTP for each of the three scenarios — pedestrian, city and helmet - for each version of the questionnaire. Actual values as pointed out from the payment card or announced by the respondent themselves were used to compute these measures of central tendency.

Two striking results emerge here. First, WTP varies dramatically across scenarios and levels of risk reduction. Second, sizeable shares of the sample announced zero willingness to pay. Mean WTP amounts are generally the highest for the City scenario, followed by Pedestrian scenario and then the Helmet scenario. This is consistent with economic theory since WTP should increase with the size of the mortality risk reduction. Median WTP amounts for the Helmet scenario are greater than those for the Pedestrian scenario. Initially, I speculated that such behavior could be a reflection of scenario rejection or protest bidding amongst some respondents since pedestrian subways are assumed to be financed with existing tax revenues without any additional payment for use. Another reason could be due to the fact that most residents consider the existing pedestrian subways in Delhi unclean and unsafe. However, the spontaneous comments by most of the respondents who announced a "zero" willingness to pay do not indicate any 
such protest behavior or scenario rejection. ${ }^{60}$ Thus these responses were included in the final analysis of the study.

TABLE 7.1

MEAN AND MEDIAN WILLINGNESS TO PAY AND THE VALUE OF A STATISTICAL LIFE BY SCENARIOS AND VERSION

\begin{tabular}{|c|c|c|c|c|c|c|c|c|}
\hline \multirow[t]{2}{*}{ Version } & \multirow[t]{2}{*}{$\begin{array}{c}N \\
\text { Obs }\end{array}$} & \multirow[t]{2}{*}{ Scenario } & \multirow[t]{2}{*}{$\begin{array}{c}\text { Annual } \\
\text { Risk } \\
\text { Reduction }\end{array}$} & \multicolumn{2}{|c|}{$\begin{array}{c}\text { Willingness to Pay } \\
\text { (Rupees) }\end{array}$} & \multicolumn{2}{|c|}{$\begin{array}{c}\text { Value of a } \\
\text { Statistical Life } \\
\text { (PPP\$) }\end{array}$} & \multirow[t]{2}{*}{$\begin{array}{c}\% \\
\text { Zeros }\end{array}$} \\
\hline & & & & Mean & Median & Mean & Median & \\
\hline \multirow[t]{3}{*}{1} & \multirow[t]{2}{*}{299} & Pedestrian & $15 / 100,000$ & 56.05 & 5.00 & 41,519 & 3,704 & 47.83 \\
\hline & & City A/B & $30 / 100,000$ & 205.91 & 10.00 & 76,262 & 3,704 & 38.13 \\
\hline & \multirow{4}{*}{301} & Helmet & $8 / 100,000$ & 35.98 & 16.67 & 49,969 & 23,148 & 25.42 \\
\hline \multirow[t]{3}{*}{2} & & Pedestrian & $15 / 100,000$ & 29.10 & 5.00 & 21,555 & 3,704 & 48.50 \\
\hline & & City A/B & $30 / 100,000$ & 166.89 & 10.00 & 61,812 & 3,704 & 38.21 \\
\hline & & Helmet & $8 / 100,000$ & 24.31 & 16.67 & 33,766 & 23,148 & 29.24 \\
\hline \multirow[t]{3}{*}{3} & \multirow[t]{2}{*}{301} & Pedestrian & $7 / 100,000$ & 35.82 & 0.00 & 56,858 & 0 & 52.16 \\
\hline & & City A/B & $15 / 100,000$ & 169.93 & 15.00 & 125,877 & 11,111 & 40.20 \\
\hline & \multirow{4}{*}{299} & Helmet & $4 / 100,000$ & 27.82 & 16.67 & 77,289 & 46,296 & 28.24 \\
\hline \multirow[t]{3}{*}{4} & & Pedestrian & $7 / 100,000$ & 37.14 & 5.00 & 58,953 & 7,937 & 49.83 \\
\hline & & City A/B & $15 / 100,000$ & 212.23 & 20.00 & 157,205 & 14,815 & 36.45 \\
\hline & & Helmet & $4 / 100,000$ & 33.72 & 16.67 & 93,667 & 46,296 & 23.08 \\
\hline
\end{tabular}

The percentage of respondents who announced a zero WTP is the lowest in the Helmet scenario. This is consistent with my findings from the focus groups where participants indicated that they found this scenario the most believable as compared to the other two. Another factor that could have influenced this was that more than half the respondents in the survey were two-wheeler drivers.

\footnotetext{
${ }^{60}$ Respondents who stated a WTP amount of zero based on their income constraints or who stated that they would rather spend more time than money on their safety, etc. cannot be regarded as protest bidders.
} 
The VSL based on Mean WTP values ranges from $\$ 21,555$ to $\$ 157,205$, the highest value corresponding version 4 for the city scenario. The mean WTP responses in particular are the highest for the city scenario. This is reasonable, since the city scenario incorporates risks from all modes and time spent on them and baseline risks in the city scenario are higher than the risks in other scenarios. In addition, expenditure on commuting is greater than expenditure on helmets.

Table 7.2 presents the mean and median WTP amounts and corresponding VSL by the size of risk reduction. Mean WTP increases with the size of risk reduction (except from $7 / 100,000$ to $8 / 100,000$ ). However, the incremental increase is not proportional to the increase in the size of the risk reduction. Thus, the VSL obtained varies by the size of risk reduction, rather than being a constant for small risk reductions. The VSL based on mean WTP ranges from $\$ 41,840$ to $\$ 86,496$.

TABLE 7.2

MEAN AND MEDIAN WILLINGNESS TO PAY AND THE VALUE OF A STATISTICAL LIFE BY LEVELS OF RISK REDUCTION

\begin{tabular}{|c|c|c|c|c|c|c|c|}
\hline \multirow[t]{2}{*}{$\begin{array}{c}\text { Deltarisk } \\
\text { (Annual Risk } \\
\text { Reduction) }\end{array}$} & \multirow[t]{2}{*}{ N Obs } & \multirow[t]{2}{*}{ Scenario } & \multicolumn{2}{|c|}{$\begin{array}{c}\text { Willingness to } \\
\text { Pay } \\
\text { (Rupees) }\end{array}$} & \multicolumn{2}{|c|}{$\begin{array}{c}\text { Value of a } \\
\text { Statistical Life } \\
\text { (PPP\$) }\end{array}$} & \multirow[t]{2}{*}{$\begin{array}{c}\% \\
\text { Zeros }\end{array}$} \\
\hline & & & Mean & Median & Mean & Median & \\
\hline $4 / 100,000$ & 600 & Helmet & 30.76 & 16.67 & 85,451 & 46,296 & 25.67 \\
\hline $7 / \mathbf{1 0 0 , 0 0 0}$ & 600 & Pedestrian & 36.48 & 0.00 & 57,902 & 0 & 51.00 \\
\hline $8 / 100,000$ & 600 & Helmet & 30.13 & 16.67 & 41,840 & 23,148 & 27.33 \\
\hline $15 / 100,000$ & 1200 & $\begin{array}{l}\text { Pedestrian } \\
\text { \& City A/B }\end{array}$ & 116.77 & 8.50 & 86,496 & 6,296 & 43.25 \\
\hline $30 / 100,000$ & 600 & City A/B & 186.34 & 10.00 & 69,013 & 3,704 & 38.17 \\
\hline
\end{tabular}


I would have also expected the percentage of respondents announcing a zero WTP to vary by the size of risk reduction and to be higher for lower levels of risk reduction. However, it is evident from Tables 7.1 and 7.2 that the percentage of respondents announcing a zero WTP varied with the scenario presented but is not monotonic with the size of risk reduction.

\subsection{Graphical Analysis of WTP Responses}

Respondents in Versions 1 and 2 were presented with nearly twice higher levels of risk reduction to be valued in all the scenarios as were respondents in versions 3 and 4 . In the pedestrian safety scenario, WTP amounts ranged from Rs. 0 to Rs. 3600 for Versions 1 and 2; and Rs. 0 to Rs. 1500 for versions 3 and 4. In the city scenario the range of WTP amounts were Rs. 0 to Rs. 5000 for both Versions 1 and 2 pooled together and Versions 3 and 4 pooled together.

Figures 7.1 and 7.2 show kernel density smoothed graphs depicting the distribution of willingness to pay amounts for each of the three scenarios by the pooled versions of the questionnaire given. Within each version, the risk reductions to be valued varied with the scenarios. The city scenario entailed nearly twice the risk reduction as the pedestrian scenario. Similarly, the pedestrian scenario entailed nearly twice as large a risk reduction as the helmet scenario. The plots in Figures 7.1 and 7.2 demonstrate that people do tend to report greater WTP amounts in the scenarios positing larger risk reductions. 
FIGURE 7.1:

KERNEL DENSITY SMOOTHED DISTRIBUTION OF WTP (VERSIONS 1 AND 2)

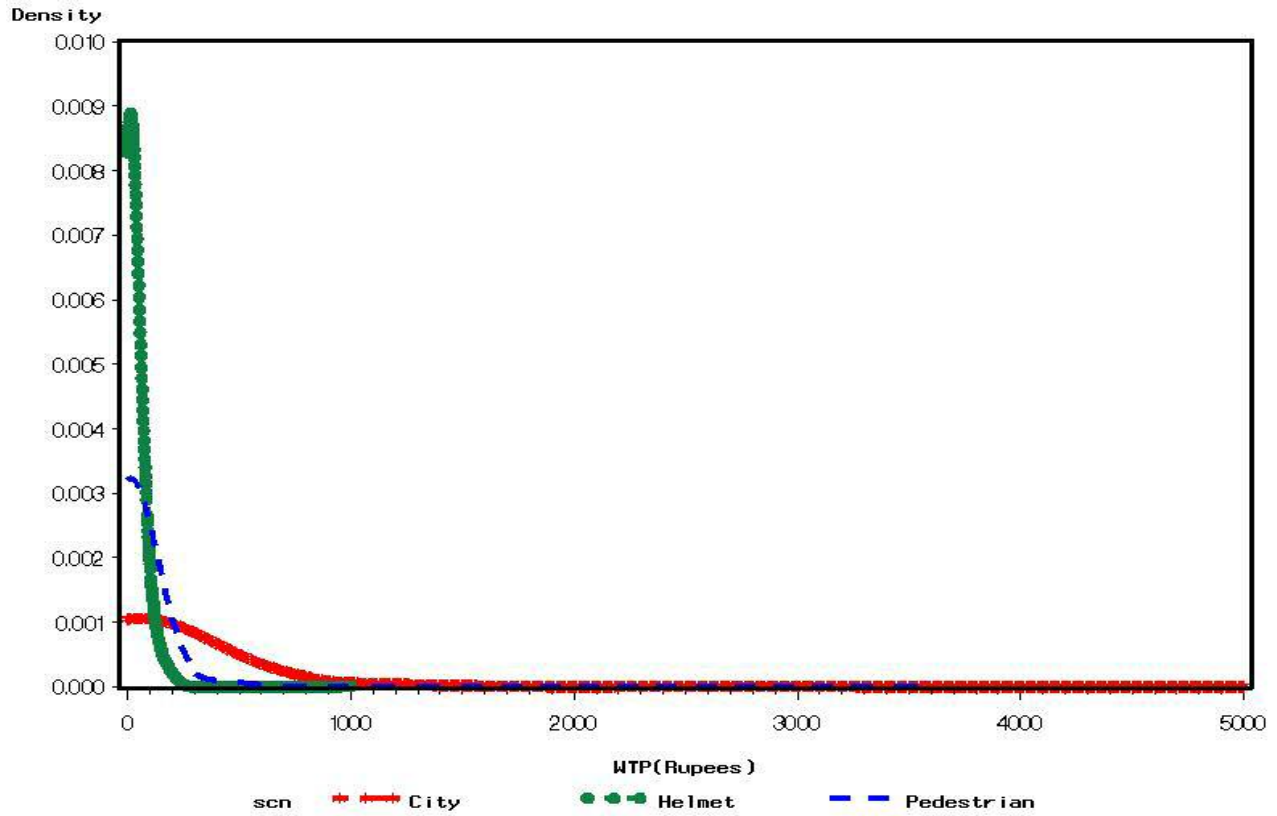

FIGURE 7.2:

KERNEL DENSITY SMOOTHED DISTRIBUTION OF WTP (VERSIONS 3 AND 4)

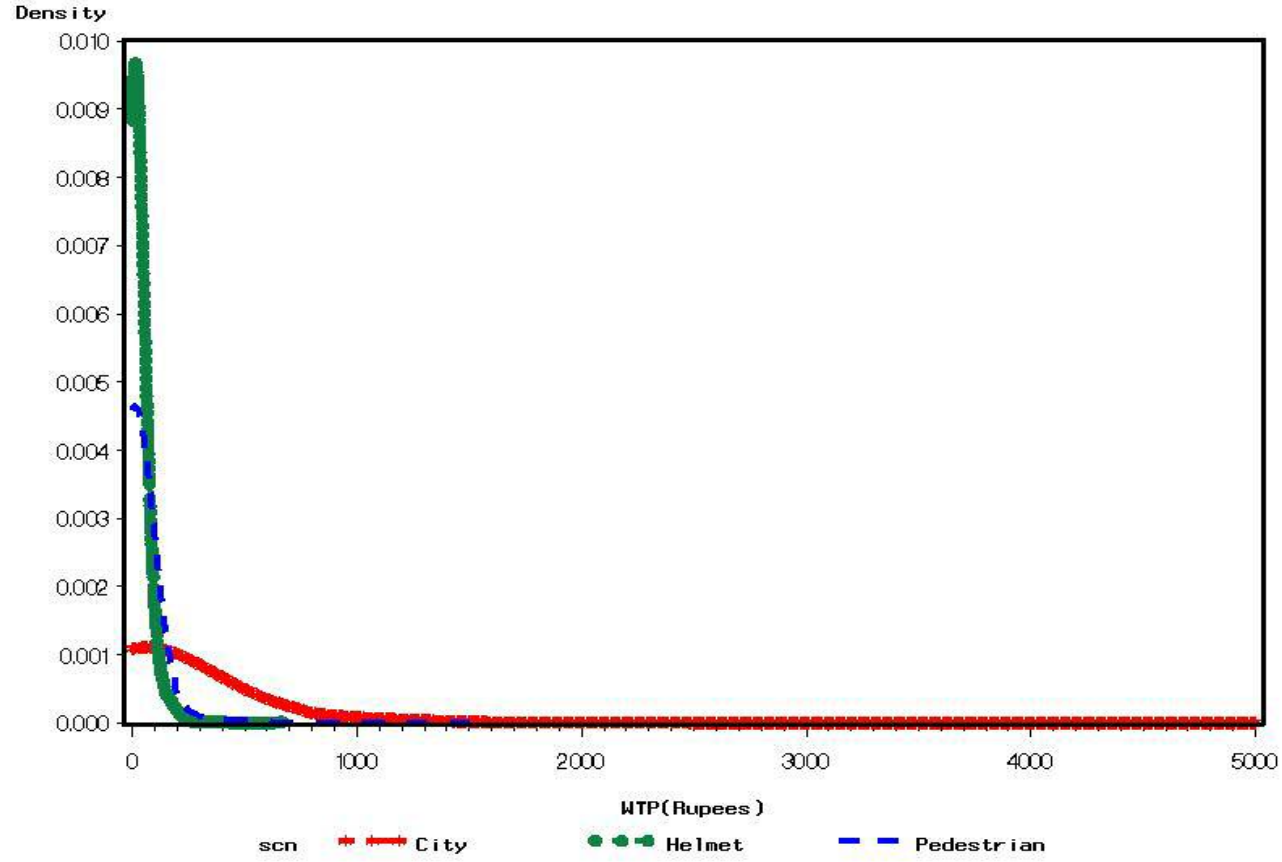




\subsection{Model of Zero Willingness to Pay}

About 20 percent of the respondents (242 out of 1200) refused to pay anything at all for any of the three scenarios. In the literature, zero willingness to pay responses are sometimes treated as scenario rejections or some sort of strategic behavior like free-riding or protest behavior by the respondent (Boyle, 2003). Scenario rejections occur when the respondent does not believe the hypothetical scenario to be valued as plausible. Strategic behavior, on the other hand, stems from respondents announcing WTP amounts that differ from their true values in an attempt to influence survey results. Zero protest bids reflect objections to some aspects of the scenario by a respondent who in reality does have a positive WTP for that good (Bateman et al., 2002).

If the responses are indeed protest bids, strategic behavior or scenario rejections, including them in the analysis would bias the measures of central tendency downward. On the other hand, if these zero WTPs are indeed honest valuations, excluding them from the analysis would also bias the results (Boyle, 2003). Researchers have suggested various techniques to identify such responses such as probing respondents' understanding of the responses (Morrison et al., 1999) and statistical techniques to identify responses that have undue influence on estimation results (Desvousges, Smith and Fisher, 1987) like trimming lower and upper values (Mitchell and Carson, 1989).

Thus, I estimate a probit model to investigate whether zero WTP responses for all the three $\mathrm{CV}$ questions are systematically associated with individual characteristics or scenario features. The model is:

$$
\operatorname{Pr}[\text { "Zero" } \mid \mathrm{X}]=\Phi(\alpha+\beta \mathrm{X})
$$


where $\Phi(\cdot)$ is the cumulative distribution function of the standard normal distribution, $\alpha$ and $\beta$ are regression parameters and $\mathrm{X}$ is the vector of individual characteristics such as age, income, education, number of dependents, commuting time, whether he drives a two-wheeler (risky commute mode), knowledge of accident, etc. The dependent variable "zero" is a dummy indicating a value of 1 if the respondent stated a Rs. 0 as his/her response to all three valuation questions, and zero otherwise. The log-likelihood function for this model is:

$$
\operatorname{Ln} \mathrm{L}=\Sigma \mathrm{Y}[\ln \Phi(\alpha+\beta \mathrm{X})]+\Sigma[1-\mathrm{Y}][\ln \{1-\Phi(\alpha+\beta \mathrm{X})\}]
$$

where $\mathrm{Y}$ equals 1 for respondents who reported zero willingness to pay for all three valuation questions; and 0 for all other respondents. The SAS econometric package was used to obtain the maximum likelihood estimates for the regression parameters.

The results of the probit equation are displayed in Table 7.3. Higher exposure to road traffic risks- proxied by the daily commute time from home to workplace (in minutes) and whether one drives a two-wheeler or not- as well as socio-demographic characteristics like age, education (whether at least high school educated) greatly influences the likelihood of reporting a positive WTP for road safety. Specifically, if a respondent possesses a high school diploma or drives a two-wheeler, he is less likely to announce a zero WTP to all three safety-enhancing scenarios. Also, the longer the daily commute time from home to workplace, the less likely is the respondent to announce a zero WTP for all three scenarios. If however, the respondent is the breadwinner for the family with a large number of dependents, he is more likely to pay nothing at all for any 


\section{TABLE 7.3 a: PROBIT MODEL FOR THOSE WHOSE WILLINGNESS TO PAY IS ZERO IN ALL THREE SCENARIOS}

\begin{tabular}{|l|c|c|c|}
\hline Variable & Coeff & $\begin{array}{c}\text { Standard } \\
\text { Error }\end{array}$ & P-Value \\
\hline Intercept & 0.6924 & 0.491 & 0.1585 \\
Age & $-0.0541^{* *}$ & 0.0249 & 0.03 \\
Age squared & $0.000651^{* *}$ & 0.000324 & 0.0447 \\
Low income dummy & -0.0462 & 0.1849 & 0.8027 \\
Middle income dummy & 0.0849 & 0.1736 & 0.6248 \\
Primary wage earner * household size & $0.0362^{* *}$ & 0.0156 & 0.0204 \\
High school diploma & $-0.2328^{* *}$ & 0.0986 & 0.0182 \\
Has had an accident (or knows someone who did) & -0.041 & 0.095 & 0.6662 \\
Whether travels as part of the job & 0.0365 & 0.099 & 0.7127 \\
Commute time (minutes) & $-0.00542^{* * *}$ & 0.00165 & 0.001 \\
High risk version of questionnaire & -0.0201 & 0.088 & 0.8194 \\
Whether drives a two-wheeler & $-0.8123^{* * *}$ & 0.0921 & $<.0001$ \\
\hline -2 Log-Likelihood & & 1087.901 & \\
Percent Correctly Predicted & & 71.8 & \\
\hline
\end{tabular}

TABLE 7.3 b: PROBABILITY OF PAYING NOTHING IN ALL THREE SCENARIOS

THE EFFECT OF AGE AND MODE*

\begin{tabular}{|l|c|c|c|}
\hline & $\begin{array}{c}18 \text { Years } \\
\text { Old }\end{array}$ & $\begin{array}{c}35 \text { Years } \\
\text { Old }\end{array}$ & $\begin{array}{c}50 \text { Years } \\
\text { Old }\end{array}$ \\
\hline Drives a two-wheeler & 0.15 & 0.08 & 0.09 \\
Does not Drive a two-wheeler & 0.41 & 0.29 & 0.30 \\
\hline
\end{tabular}

* Assume: HS diploma, middle income, primary earner with household of 5, does not travel on the job, commute time equal to average

THE EFFECT OF EDUCATION*

\begin{tabular}{|l|r}
\hline Has a High School Diploma or Higher & 0.08 \\
Does Not have a High School Diploma & 0.13
\end{tabular}

* Assume: 35 years old, middle income, primary earner with household of 5, does not travel on the job, drives a two-wheeler, commute time equal to average 
road safety scenario. This suggests that budget constraints play a big role in how much the respondent may be willing to allocate for his own safety. I would have expected income to have a negative effect on the probability to announce zero WTP for the three scenarios, however Table 7.3 shows that it has no significant effects. The propensity to pay for the higher baseline risks and risk reductions ${ }^{61}$ does not depend on whether people were shown high baseline risks and large risk reductions. In sum, there seems to be a definite pattern amongst persons who are willing to pay nothing at all for any of the three scenarios. This pattern suggests that these people may be constrained by income and may have lower exposure to traffic, and therefore does not constitute protest behaviors. Thus, responses from these individuals were also included in the analysis of WTP.

Whether a person drives a two-wheeler or not affects his probability of paying anything at all for personal road safety. As shown in Table 7.3b, at any given age (and assuming the average values of all other regressors), people who do not drive a twowheeler are about three times as likely to refuse to pay for risk reductions. Education is another determinant of willingness to pay anything at all for safety. For a person who is 35 years old and is the primary wage earner of his family with 4 dependents, belongs to middle income category, has a commute time equal to 36 minutes (average), does not travel for work purposes other than the commute from home to workplace and drives a two-wheeler, not having a high school diploma raises the probability of zero WTP by 5 percentage points.

${ }^{61}$ The risk reductions and baseline risks varied across different versions of the questionnaire. 


\subsection{Models of Willingness to Pay}

In this section I fit models of willingness to pay. As mentioned earlier, willingness to pay is defined as the amount of money an individual is willing to pay for a lower risk of death (increased safety) from road accidents so as to maintain the same level of utility, i.e. a compensating variation measure (Chapter 2).

Suppose an individual's indirect utility function can be expressed as $V(p, m, r)$ where $p$ is the price, $m$ is income and $r$ is level of road safety. Now suppose that the level of road safety is improved from $r_{0}$ to $r_{1}$. Thus, by definition, the compensating variation measure, WTP, can be defined as:

$$
\mathrm{V}\left(\mathrm{p}, \mathrm{m}-\mathrm{WTP}, \mathrm{r}_{1}\right)=\mathrm{V}\left(\mathrm{p}, \mathrm{m}, \mathrm{r}_{0}\right)
$$

The change in the level of risk of dying (inverse of safety), $\Delta \mathrm{r}$, can be written as:

$$
\mathrm{r}_{1}=\mathrm{r}_{0}-\Delta \mathrm{r}
$$

Willingness to pay for increased road safety should thus depend on the baseline and final risk levels, income and other individual characteristics.

$$
\mathrm{WTP}=\mathrm{f}\left(\mathrm{r}_{0}, \Delta \mathrm{r}, \mathrm{X}\right)
$$

where $\mathrm{X}$ is a vector of individual characteristics like age, income level, family size, whether primary wage earner for the family, education level, etc. and other variables though to affect WTP. The choice of the distribution for equation (7.5) determines the estimation procedures. 
Here I use a Weibull distribution because it only admits positive values (Haab and McConnell, 1997; Alberini, 2004). The cumulative distribution function and the density of a Weibull variate $y$ are:

$$
F(y ; \sigma, \theta)=1-\exp \left[-\left(\frac{y}{\sigma}\right)^{\theta}\right]
$$

and

$$
f(y ; \sigma, \theta)=\left(\frac{\theta}{\sigma}\right) \bullet\left(\frac{y}{\sigma}\right)^{\theta-1} \bullet \exp \left[-\left(\frac{y}{\sigma}\right)^{\theta}\right]
$$

where $\sigma$ is the scale parameter and $\theta$ is the shape parameter. For a parametric model with a Weibull distribution, the mean and median WTP are computed using the following formulae:

$$
\begin{aligned}
& \text { Mean WTP }=\sigma \bullet \Gamma\left(1+\frac{1}{\theta}\right) \\
& \text { Median WTP }=\sigma[-\ln (0.5)]^{1 / \theta}
\end{aligned}
$$

where $\Gamma($.$) is the gamma function, and \hat{\sigma}$ and $\hat{\theta}$ are the scale and shape parameters of the Weibull distribution estimated using the method of maximum likelihood.

The WTP values for each question were elicited using the aid of payment cards. ${ }^{62}$ Payment cards provide the respondents with an ordered array of amounts. The amounts picked from a payment card usually indicate an interval within which true valuation lies.

\footnotetext{
${ }^{62}$ Note that $3.50,5.33$ and 3.25 percent responses for the pedestrian, city and helmet scenarios respectively were stated without the aid of the payment card by the respondent.
} 
Accordingly, in my model I used the stated WTP amount from the payment card as the lower limit of the interval and the next highest value on the payment card as the upper limit of the interval. This is based on the assumption that respondents choose the lower value of their payment interval from the payment card. Thus for a respondent who stated Rs. 0 as his/her WTP, the lower limit was set to Rs. 0 whereas the upper limit was considered as Rs. 5, which was the next highest value in the payment card. For those respondents who stated values without the aid of the payment card, the upper and lower limits were defined as the same i.e., whatever they stated.

The log-likelihood function for the interval-based model is:

$$
L n L=\sum_{i=1}^{n} \ln \left[\exp \left(-\left(\frac{W T P_{i}^{L}}{\sigma}\right)^{\theta}\right)-\exp \left(-\left(\frac{W T P_{i}^{U}}{\sigma}\right)^{\theta}\right)\right]
$$

where $\mathrm{WTP}^{\mathrm{L}}$ and $\mathrm{WTP}^{\mathrm{U}}$ are lower and upper bounds of the interval around the respondent's willingness to pay values.

TABLE 7.4a: MEAN AND MEDIAN WILLINGNESS TO PAY AND THE VALUE OF A STATISTICAL LIFE BY SCENARIO AND RISK REDUCTION

\begin{tabular}{|c|c|c|c|c|c|c|c|}
\hline \multirow[t]{2}{*}{$\begin{array}{l}\text { Pooled } \\
\text { Versions }\end{array}$} & \multirow[t]{2}{*}{ N Obs } & \multirow[t]{2}{*}{ Variable } & \multirow{2}{*}{$\begin{array}{c}\Delta \text { risk } \\
\text { (Annual } \\
\text { Risk } \\
\text { Reduction) }\end{array}$} & \multicolumn{2}{|c|}{$\begin{array}{l}\text { Willingness to Pay } \\
\text { (Rupees) }\end{array}$} & \multicolumn{2}{|c|}{$\begin{array}{c}\text { Value of a } \\
\text { Statistical Life } \\
\text { (PPPS) }\end{array}$} \\
\hline & & & & Mean & Median & Mean & Median \\
\hline \multirow[t]{3}{*}{1 and 2} & \multirow[t]{3}{*}{600} & Pedestrian & $15 / 100,000$ & 45.42 & 5.53 & 34,409 & 4,189 \\
\hline & & City A/B & $30 / 100,000$ & 260.46 & 16.75 & 98,659 & 6,345 \\
\hline & & Helmet & $8 / 100,000$ & 36.47 & 11.66 & 51,804 & 16,563 \\
\hline \multirow[t]{3}{*}{3 and 4} & \multirow[t]{3}{*}{600} & Pedestrian & $7 / 100,000$ & 42.55 & 4.64 & 69,075 & 7,532 \\
\hline & & City A/B & $15 / 100,000$ & 283.22 & 18.95 & 214,561 & 14,356 \\
\hline & & Helmet & $4 / 100,000$ & 36.85 & 13.33 & 104,688 & 37,869 \\
\hline
\end{tabular}


TABLE 7.4b: MEAN AND MEDIAN WILLINGNESS TO PAY AND THE VALUE OF A STATISTICAL LIFE BY LEVELS OF RISK REDUCTION

\begin{tabular}{|c|c|c|c|c|c|c|}
\hline \multirow[t]{2}{*}{$\begin{array}{c}\Delta \text { risk } \\
\text { (Annual Risk } \\
\text { Reduction) }\end{array}$} & \multirow[t]{2}{*}{ N Obs } & \multirow[t]{2}{*}{ Scenario } & \multicolumn{2}{|c|}{$\begin{array}{l}\text { Willingness to Pay } \\
\text { (Rupees) }\end{array}$} & \multicolumn{2}{|c|}{$\begin{array}{c}\text { Value of a } \\
\text { Statistical Life } \\
\text { (PPP\$) }\end{array}$} \\
\hline & & & Mean & Median & Mean & Median \\
\hline $4 / 100,000$ & 600 & Helmet & 36.85 & 13.33 & 104,688 & 37,869 \\
\hline $7 / \mathbf{1 0 0 , 0 0 0}$ & 600 & Pedestrian & 42.55 & 4.64 & 69,075 & 7,532 \\
\hline $8 / 100,000$ & 600 & Helmet & 36.47 & 11.66 & 51,804 & 16,563 \\
\hline $15 / 100,000$ & 1200 & $\begin{array}{c}\text { Pedestrian \& } \\
\text { City A/B }\end{array}$ & 146.25 & 9.41 & 110,795 & 7,129 \\
\hline $30 / 100,000$ & 600 & City A/B & 260.46 & 16.75 & 98,659 & 6,345 \\
\hline
\end{tabular}

Table 7.4 presents the mean and median willingness to pay based on an interval based Weibull distribution. Mean Willingness to Pay increases with the size of the risk reduction for all cases except from a 7/100,000 risk reduction to a 8/100,000 risk reduction. However this increase, if present is not proportional to the size of the risk reduction.

\subsection{WTP Models with Covariates}

To incorporate covariates, I assume an accelerated life model and write the scale as $\sigma_{\mathrm{i}}=\exp \left[\left(\beta_{1} \cdot \mathrm{X}_{\mathrm{i}}\right)+\left(\beta_{3} \cdot \ln \Delta \mathrm{r}_{\mathrm{i}}\right)+\left(\beta_{4} \cdot \ln \mathrm{r}_{0 \mathrm{i}}\right)\right]$. Thus, if I assume that the WTP is a Weibull variate, I can write equation (7.5) for an individual $i$ as follows:

$$
\mathrm{WTP}_{\mathrm{i}}=\exp \left[\left(\beta_{1} \cdot \mathrm{X}_{\mathrm{i}}\right)+\left(\beta_{3} \cdot \ln \Delta \mathrm{r}_{\mathrm{i}}\right)+\left(\beta_{4} \cdot \ln \mathrm{r}_{0 \mathrm{i}}\right)+\left(\varepsilon_{i}\right)\right]
$$

where $\varepsilon_{i}$ is a Type I extreme value error with a scale equal to $\theta$. 
As mentioned in Chapters 5 and 6, both baseline risk and risk reduction were varied within and across the individuals. I assume that while answering the WTP questions the respondents accepted the risk reductions stated to them, but subjectively assessed their own baseline risks by combining their prior beliefs on exposure to road traffic risks, $\pi_{\mathrm{i}}$, with the baseline risk stated to them in the questionnaire. Consequently, I replace $r_{0 \mathrm{i}}$ in equation (7.11) with $\mathrm{r}_{0 \mathrm{i}}{ }^{*}$, the subjectively assessed baseline risk obtained through Bayesian updating. This can be written as a weighted sum of prior beliefs and given baseline risk:

$$
r_{0 i}^{*}=\frac{\alpha \pi_{i}+\lambda r_{0 i}}{\alpha+\lambda}
$$

where $\alpha$ and $\lambda$ are the weights assigned to the prior and to the questionnaire information, respectively. Since $\pi_{\mathrm{i}}$ and hence $\mathrm{r}_{0 \mathrm{i}}{ }^{*}$ are not directly observable, I proxy the latter with two components: $r_{0 \mathrm{i}}$ which is the baseline risk assigned to the respondent in the survey, and $\mathbf{C}_{\mathrm{i}}$, which is a vector of variables capturing exposure to road traffic risks, such as commute time and commute mode. Accordingly, equation (7.11) for WTP can be modified and expressed as:

$$
\mathrm{WTP}_{\mathrm{i}}=\exp \left(\mathrm{X}_{\mathrm{i}} \beta_{1}\right) \cdot \exp \left(\mathrm{Ci} \beta_{2}\right) \cdot\left(\Delta_{\mathrm{i}}^{\beta^{3}}\right) \cdot\left(\mathrm{r}_{0 \mathrm{i}}^{\beta^{3}}\right) \cdot \exp \left(\varepsilon_{i}\right)
$$

On taking the log of equation (7.13) :

$$
\operatorname{Ln} \mathrm{WTP}_{\mathrm{i}}=\mathrm{X}_{\mathrm{i}} \beta_{1}+\mathrm{Ci} \beta_{2}+\beta_{3} \ln \left(\Delta \mathrm{r}_{\mathrm{i}}\right)+\beta_{4} \ln \left(\mathrm{r}_{0 \mathrm{i}}\right)+\varepsilon_{i}
$$

Due to practical considerations and the need to create credible scenarios, larger baseline risks in the survey were accompanied by larger risk reductions. This unfortunately 
implies that the baseline risks were highly correlated with the risk reductions in each version. Thus, baseline risk, $\mathrm{r}_{0 \mathrm{i}}$, is excluded from the final estimation equation to yield equation (7.15) below which is then estimated using maximum likelihood methods.

$$
\operatorname{Ln} \mathrm{WTP}_{\mathrm{i}}^{*}=\mathrm{X}_{\mathrm{i}} \beta_{1}+\mathrm{C}_{\mathrm{i}} \beta_{2}+\beta_{3} \ln \left(\Delta \mathrm{r}_{\mathrm{i}}\right)+\varepsilon_{i}
$$

Economic theory suggests that the WTP for a greater amount of good should be higher than the WTP of a lesser amount of the same good. In the case of this study, this good is increased safety or a reduction in risk of dying from traffic accidents. Therefore, I conducted the two scope tests-internal (within sample) and external (between samples)to check whether mean willingness to pay increases significantly with the size of risk reduction. Using an interval-data Weibull model, the internal scope test is passed when comparing Mean WTP in the city scenario with the pedestrian or helmet scenario. However this internal scope test is not passed when I compare Mean WTP of the pedestrian scenario with that of the helmet scenario. The external scope test that compares sensitivity between the various versions of the questionnaire is not passed for any of the scenarios.

\subsection{Combined Scenarios}

Finally, all the responses were pooled together as a panel. There were a total of three responses from all three scenarios, Pedestrian, City and Helmet per respondent. Thus, the pooled set involved a total of 3600 responses. Table 7.6 reports the results for the pooled model using interval-data and continuous-interval mixed models based on the Weibull distribution. Continuous-interval mixed models assume an interval between Rs. 
0 - Rs. 5 for the "zero" or Rs. 0 stated WTP responses; and point estimates on a continuous scale for all other stated WTP responses.

Since each individual is queried about his/her willingness to pay for a total of three risk reductions, equation (7.15) is modified to reflect the panel structure of the data now:

$$
\operatorname{Ln} \mathrm{WTP}_{\mathrm{ij}}=\mathrm{X}_{\mathrm{i}} \beta_{1}+\mathrm{C}_{\mathrm{i}} \beta_{2}+\beta_{3} \ln \left(\Delta \mathrm{r}_{\mathrm{ij}}\right)+\varepsilon_{i j}
$$

where $i=1,2, \ldots, n$ reflect the 1200 individuals who were surveyed and $j=1,2,3$ reflect the pedestrian, city and helmet scenarios respectively. The log-likelihood function for the continuous-interval mixed model and the interval-data models are as follows respectively:

$$
\sum_{i=1}^{n} \sum_{j=1}^{3}\left[Y_{i j} \bullet \log F(5 ; \sigma)+\left(1-Y_{i j}\right) \bullet \log f\left(W T P_{i j} ; \sigma\right)\right]
$$

and

$$
\sum_{i=1}^{n} \sum_{j=1}^{3} \log \left[F\left(W T P_{i j}^{H} ; \sigma\right)-F\left(W T P_{i j}^{L} ; \sigma\right)\right]
$$

where $Y$ is a dummy variable that equals unity for a zero WTP response and is zero for all positive WTP responses, $F(\cdot)$ and $f(\cdot)$ are the cdf and pdf of the WTP, respectively, $\sigma$ is a vector of parameters indexing the distribution of WTP, and WTP is the observed continuous WTP amount.

There is not much difference in the magnitudes of the coefficients between the continuous-interval mixed model and the interval data model (see Table 7.5). 
Comparison was also done with a lognormal model, but I found that the fit of the Weibull was superior to that of the lognormal using the Akakike information criterion.

TABLE 7.5: WEIBULL MODELS WITH ALL SCENARIOS

\begin{tabular}{|c|c|c|c|c|c|c|}
\hline \multirow[t]{2}{*}{ Variable } & \multicolumn{3}{|c|}{$\begin{array}{l}\text { ALL PERSONS } \\
\text { (Interval Data) }\end{array}$} & \multicolumn{3}{|c|}{$\begin{array}{c}\text { ALL PERSONS } \\
\text { (Interval Data for Zero WTP } \\
\text { Responses \& Continuous } \\
\text { for Non-Zero Responses) }\end{array}$} \\
\hline & Coeff & $\begin{array}{l}\text { Standard } \\
\text { Error }\end{array}$ & P-Value & Coeff & $\begin{array}{c}\text { Standard } \\
\text { Error }\end{array}$ & P-Value \\
\hline \multirow{13}{*}{$\begin{array}{l}\text { Intercept } \\
\text { Log of risk reduction } \\
\text { Age } \\
\text { Age squared } \\
\text { Low income dummy } \\
\text { Middle income dummy } \\
\text { Primary wage earner * } \\
\text { household size } \\
\text { High school diploma } \\
\text { Has had an accident (or } \\
\text { knows someone who did) } \\
\text { Whether travels as part of } \\
\text { the job } \\
\text { Commute time (minutes) } \\
\text { Risk reduction*high school } \\
\text { Whether drives a two- } \\
\text { wheeler }\end{array}$} & 0.53 & 0.51 & 0.30 & 0.58 & 0.49 & 0.24 \\
\hline & $0.55^{\star * *}$ & 0.09 & $<.0001$ & $0.54^{* * *}$ & 0.08 & $<.0001$ \\
\hline & 0.03 & 0.02 & 0.18 & 0.03 & 0.02 & 0.20 \\
\hline & -0.0002 & 0.0003 & 0.46 & 0.00 & 0.00 & 0.53 \\
\hline & $-0.37^{* *}$ & 0.16 & 0.02 & $-0.37^{* *}$ & 0.16 & 0.02 \\
\hline & -0.19 & 0.15 & 0.22 & -0.18 & 0.15 & 0.23 \\
\hline & $-0.04^{* *}$ & 0.01 & 0.01 & $-0.03^{* *}$ & 0.01 & 0.02 \\
\hline & $-0.51^{*}$ & 0.30 & 0.09 & $-0.52^{*}$ & 0.29 & 0.07 \\
\hline & 0.09 & 0.09 & 0.33 & 0.10 & 0.08 & 0.25 \\
\hline & $0.32^{* * *}$ & 0.09 & 0.00 & $0.32^{\star \star *}$ & 0.08 & 0.00 \\
\hline & $0.01^{* * *}$ & 0.0015 & $<.0001$ & $0.01^{* \star *}$ & 0.00 & $<.0001$ \\
\hline & $0.24^{* *}$ & 0.12 & 0.04 & $0.24^{* *}$ & 0.11 & 0.04 \\
\hline & $0.85^{\star \star *}$ & 0.08 & $<.0001$ & $0.80^{* * *}$ & 0.08 & $<.0001$ \\
\hline $\begin{array}{l}\text { Scale } \\
\text { Weibull Shape } \\
\text { Log Likelihood } \\
\text { Number of Observations }\end{array}$ & & $\begin{array}{c}2.28 \\
0.44 \\
-8296.37 \\
3600\end{array}$ & & & $\begin{array}{c}2.27 \\
0.44 \\
-5940.56 \\
3600\end{array}$ & \\
\hline
\end{tabular}




\section{TABLE 7.6: EFFECT OF EDUCATION ON WTP (WEIBULL, INTERVAL DATA)}

\begin{tabular}{|c|c|c|c|c|c|c|}
\hline \multirow[t]{2}{*}{ Variable } & \multicolumn{3}{|c|}{$\begin{array}{l}\text { ONLY Persons with High } \\
\text { School diploma \& Above }\end{array}$} & \multicolumn{3}{|c|}{$\begin{array}{l}\text { ONLY Persons with } \\
\text { Undergraduate Degree } \\
\text { (College) \& Above }\end{array}$} \\
\hline & Coeff & $\begin{array}{c}\text { Standard } \\
\text { Error }\end{array}$ & P-Value & Coeff & $\begin{array}{c}\text { Standard } \\
\text { Error }\end{array}$ & P-Value \\
\hline Intercept & -0.35 & 0.68 & 0.61 & -1.77 & 0.90 & 0.05 \\
\hline Log of risk reduction & $0.80^{* * *}$ & 0.08 & $<.0001$ & $0.89^{* * *}$ & 0.11 & $<.0001$ \\
\hline Age & 0.05 & 0.03 & 0.16 & $0.13^{* *}$ & 0.05 & 0.01 \\
\hline Age squared & -0.0004 & 0.0004 & 0.33 & $-0.0016^{* *}$ & 0.0006 & 0.01 \\
\hline Low income dummy & -0.31 & 0.19 & 0.11 & $-0.79^{* * *}$ & 0.27 & 0.00 \\
\hline Middle income dummy & -0.05 & 0.16 & 0.76 & -0.27 & 0.18 & 0.14 \\
\hline $\begin{array}{l}\text { Primary wage earner * } \\
\text { household size }\end{array}$ & $-0.04^{*}$ & 0.02 & 0.09 & -0.03 & 0.03 & 0.39 \\
\hline $\begin{array}{l}\text { Has had an accident (or } \\
\text { knows someone who did) }\end{array}$ & 0.14 & 0.12 & 0.24 & -0.04 & 0.15 & 0.81 \\
\hline $\begin{array}{l}\text { Whether travels as part of } \\
\text { the job }\end{array}$ & 0.20 & 0.13 & 0.12 & 0.04 & 0.17 & 0.81 \\
\hline Commute time (minutes) & $0.01^{* * * *}$ & 0.0022 & $<.0001$ & $0.01^{* * *}$ & 0.0028 & $<.0001$ \\
\hline $\begin{array}{l}\text { Whether drives a two- } \\
\text { wheeler }\end{array}$ & $0.80^{* * * *}$ & 0.12 & $<.0001$ & $1.16^{* * *}$ & 0.15 & $<.0001$ \\
\hline Scale & \multicolumn{3}{|c|}{2.35} & \multicolumn{3}{|c|}{2.29} \\
\hline Weibull Shape & \multicolumn{3}{|c|}{0.42} & \multicolumn{3}{|c|}{0.44} \\
\hline Log Likelihood & \multicolumn{3}{|c|}{-4163.04} & \multicolumn{3}{|c|}{-2404.86} \\
\hline Number of Observations & \multicolumn{3}{|c|}{1740} & \multicolumn{3}{|c|}{1005} \\
\hline
\end{tabular}

As can be seen in Table 7.5, the elasticity of WTP with respect to the level of risk reduction, $\beta_{3}$, is 0.55 and is highly significant in both the full interval model and the mixed model. This indicates that for every 1 percent increase in the risk reduction, WTP increases by 0.55 percent. In theory, WTP should be perfectly elastic with the risk reduction. However, this is seldom found in empirical studies. 
Hakes and Viscusi (2004) find that better educated people (college degree or higher) have more accurate risk beliefs. If I restrict the sample to respondents with higher levels of education like those with high school diploma or above (580 respondents); or just to those with a college degree and above (335 respondents), I find that the elasticity of WTP with respect to risk reduction nearly approaches unity as predicted by economic theory (see Table 7.6).

I find that respondents belonging to lower-income group and those who are the primary wage earners with large families have a lower willingness to pay for their own safety. This suggests that the budget constraints play a significant role in individuals' willingness to pay for their own safety. Variables like commute time, whether the person has to travel for job other than commuting to regular workplace and whether the person drives a two-wheeler are highly significant suggesting that respondents who are more exposed to the traffic have a higher WTP for their safety as compared to those who are not that greatly exposed. Previous accident experience or knowledge about someone in the family with a road accident does not seem to influence WTP. This also confirms the assumptions of the Bayesian updating model that the baseline risk levels perceived by individuals is a function of both what is indicated in the survey as well their own prior beliefs which are in turn based on their exposure to traffic and experience with traffic crashes.

Age also seems to be a significant factor only for individuals with college (undergraduate) degree or above. It appears to have a quadratic effect that peaks at the age of 41 implying that WTP increases with age until the age of 41 and then declines. 


\subsection{Implied VSL}

Using the coefficients of interval-data Weibull model above in Table 7.5, mean WTP is predicted and thus corresponding VSL amounts at average levels of income, age and education. Thus, for a person who is 35 years old and belongs to middle-income group, drives a two-wheeler, has a high-school diploma and has to travel for job purposes, VSL is approximately $\$ 149,000$ (PPP). If, however, this individual does not drive a two-wheeler, his VSL drops to $\$ 64,000$ (PPP). And if further he does not travel for job purposes, then his/her VSL further drops to $\$ 46,000$ (PPP) ${ }^{63}$ VSL also varies by income levels (see Table 7.7). If the above described individual belongs to higher-income category then his/her VSL increases to $\$ 179,000$ (PPP) whereas if he/she belonged to lower-income category, his/her VSL drops to $\$ 126,000$ (PPP). Education and number of dependents also influenced VSL. If my reference individual does not have a high school diploma, then his/her VSL drops to $\$ 133,000$ (PPP) and if he has no dependents then his mean WTP for safety increases and thus VSL increases to $\$ 172,000$ (PPP).

\footnotetext{
${ }^{63}$ These estimates for the VSL are roughly similar for the specified average individual using an intervaldata Weibull model with responses only from the city and the helmet scenario (i.e., excluding responses from the pedestrian scenario where I find the most prevalence of "zero" WTP responses.)
} 

TABLE 7.7: MEAN WTP AND VSL FROM ALL THREE SCENARIOS
BASED ON AN INTERVAL BASED WEIBULL MODEL

THE EFFECT OF TRAVEL PATTERNS AND MODE*

\begin{tabular}{|l|c|c|}
\hline & $\begin{array}{r}\text { Mean WTP } \\
\text { (Rupees) }\end{array}$ & $\begin{array}{c}\text { VSL } \\
\text { (PPP\$) }\end{array}$ \\
\hline Does not travel on the job, does not drive two-wheeler & 54 & 46,000 \\
& $(5)$ & $(3,000)$ \\
Travels on the job, does not drive two-wheeler & 74 & 64,000 \\
Travels on the job \& drives two-wheeler & $(4)$ & $(3,400)$ \\
& 173 & 149,000 \\
& $(9)$ & $(7,600)$ \\
\hline
\end{tabular}

* Assume: 35 years old, middle income, primary earner with household of 5, HS diploma, commute time equal to average. Standard errors in parentheses.

THE EFFECT OF INCOME LEVELS*

\begin{tabular}{|l|c|c|}
\hline & $\begin{array}{c}\text { Mean WTP } \\
\text { (Rupees) }\end{array}$ & $\begin{array}{c}\text { VSL } \\
\text { (PPP\$) }\end{array}$ \\
\hline Low Income & 143 & 123,000 \\
Middle Income & $(7)$ & $(6,000)$ \\
High Income & 173 & 149,000 \\
& $(9)$ & $(7,600)$ \\
179,000 \\
\end{tabular}

* Assume: 35 years old, primary earner with household of 5 , HS diploma, commute time equal to average, drives a two-wheeler, travels on the job. Standard errors in parentheses. 


\section{7 Comparison with Transferred Values from Other Studies}

Based on the analysis presented above, an estimate of $\$ 150,000$ (PPP) for VSL of individuals highly exposed to road traffic risks is recommended by this study for benefitcost analysis of road safety projects in Delhi. We wish to compare this figure with the ones that we obtain by transferring estimates of the VSL used in the transportation safety context in developed or other developing countries. Consider for example the VSL used by the US DOT, which reflects a blend of stated and revealed preference studies and is equal to $\$ 3$ million. This figure can be transferred to Delhi India with a simple adjustment for the different incomes in the two locales:

$$
V S L_{\text {Delhi }}=V S L_{U S} \frac{\text { Per Capita GDP (PPP\$) of Delhi }}{\text { Per Capita GDP (PPP\$) of US }}
$$

This approach results in a predicted VSL for Delhi of $\$ 419,000$ (2005 PPP). If the same approach is applied to a VSL of $£ 1.49$ million used by the Department for Transportation in UK for project appraisals, we obtain a VSL for Delhi of \$639,000 (2005 PPP).

By contrast, if we transfer, using equation (7.19), the VSL estimated by Vassanadumrongdee and Matsuoka (2005) for Bangkok, Thailand at \$1.48 million, the value assigned for Delhi would be $\$ 434,000$ (2005 PPP) for Delhi. These three incomeadjusted estimates are about thrice the value I obtained in my study. Thus, it is clear that all of these transferred figures overstate the value of safety relative to what reported directly by Delhiites.

It is possible that such differences are attenuated when one uses a different estimate of the income elasticity of VSL, which equation (7.19) assumes to be equal to 
one. $^{64}$ deBlaleij et al. (2003) find the income elasticity of WTP to be 1.33 for road safety studies. Thus if I apply this income elasticity, the transferred estimates from US, UK and Thailand translate to $\$ 219,000 ; \$ 369,000$ and $\$ 290,000$ (2005 PPP), respectively for Delhi. These are still higher, yet much closer to my estimates. Nevertheless, these estimates accentuate the need for an original study.

My estimate of VSL is also approximately 1.9 times the discounted flow of personal income over the rest of the working life ${ }^{65}$ of an average respondent in the sample who drives a two-wheeler and also commutes for job purposes besides traveling to and from home to work. This ratio is obtained using a 12 percent rate of discount. ${ }^{66}$ This clearly implies that human capital methodologies would underestimate the value of mortality risk reductions specifically in the case of road safety. My ratio is lower than that of the developed countries where VSL is roughly 3 times the discounted annual income over lifetime.

\footnotetext{
${ }^{64}$ Most economists contend that the income elasticity is less than unity for developing countries. Therefore, the transferred estimates from developed to developing countries using an elasticity of one are an underestimation.

${ }^{65}$ Assuming that the average individual works for another 30 years and earns the same salary.

${ }^{66}$ The Planning Commission of India currently uses a social discount rate of $12 \%$.
} 


\section{CHAPTER 8: SUMMARY OF RESULTS AND DISCUSSION}

This study provides estimates of the value of mortality risk reductions from road traffic accidents in Delhi, India using contingent valuation. It is the first study conducted in a developing country that values the mortality risks in situations faced by the majority

of the victims of road accidents. ${ }^{67}$ As in most developing countries, pedestrians constitute over half of traffic fatalities. Drivers of two-wheelers account for one-fourth of traffic fatalities. Thus together they comprise three-fourths of the victims of road accidents in Delhi. The valuation scenarios employed in studies conducted in the developed countries — such as using seat belts or purchasing cars with greater safety features — are not applicable here.

A contingent valuation survey was conducted in which 1200 respondents were selected randomly using stratified sampling procedures based on data from the 2001 Census of India. Respondents were screened using criteria to ensure that they worked outside the home, commuted to work regularly, and had obtained at least middle school education. They were asked their willingness to pay (WTP) for safety in three different scenarios: as a pedestrian, two-wheeler driver and a commuter to work. The pedestrian scenario asked their WTP for an annual pass to use a new pedestrian subway across from their workplace that would reduce their risk of dying from crossing the road. The twowheeler driver scenario asked their WTP for a safer helmet that would last exactly three years. The commuting scenario asked about the annual additional WTP, given baseline

\footnotetext{
${ }^{67}$ There are only three other developing countries - Thailand, Malaysia and Chile, where valuation of mortality risk from road traffic accidents has been conducted. However, they have all used valuation scenarios similar to ones conducted in the developed countries - like safer cars or bus travel - in spite of the fact that majority of road accident victims in these countries are not car or bus travelers.
} 
commuting costs, for living in a safer city. These three valuation scenarios capture the conditions of highly exposed and vulnerable residents of Delhi to road traffic risks. Baseline risks as well as the risk reductions to be valued were varied both across and within respondents.

The contingent valuation questions were asked in an open-ended format using a payment card. This methodology was adopted because pretests and pilot studies suggested that individuals were prone to choose the safer option regardless of cost. The pedestrian scenario yielded the highest percentage of zero responses $(50 \%)$ followed by the city scenario (38\%) and the helmet scenario (27\%), which was the most realistic of the three scenarios. Overall, about 20 percent of the respondents expressed a zero WTP in all three scenarios. A probit analysis of these responses suggested that they were not protest bids or scenario rejections. The analysis indicated that older people were less likely to state a zero WTP for all three cases, as were two-wheeler drivers, more educated people, more exposed individuals such as those who had higher commute times or who had to travel for job purposes in the city other than their regular commute.

The valuation scenarios were analyzed individually as well as jointly. WTP was analyzed assuming it to be a Weibull variate. It was assumed that respondents updated their prior beliefs about road traffic risks with the information provided in the survey using a Bayesian updating approach. WTP was modeled as a function of sociodemographic variables such as income, age, education, and whether the respondents is a primary wage earner for the family times the family size dependent on his/her income. WTP was also assumed to depend on the magnitude of risk reduction, on traffic exposure, measured by commute time and by whether the respondent has to travel for job purposes 
other than commuting. It was also allowed to depend on the respondent's prior knowledge of or experience with accidents and on whether a person drives a twowheeler. This equation, an interval data model, was estimated using maximumlikelihoood techniques.

WTP is sensitive to socio-demographic variables as well as factors capturing traffic exposure and to whether the respondent drives a two-wheeler. Thus WTP increases with income level, education, whether the respondent drives a two-wheeler, commute time (minutes), and whether he travels for job purposes other than commuting to work. If the respondent is the primary wage earner of a large family, his WTP is lower than that of the breadwinner of a smaller family or a person who is not the primary wage earner. WTP is also sensitive to scope, implying that it increases with the size of risk reduction. Hakes and Viscusi (2004) found that that highly educated individuals have more accurate risk beliefs. In my case, WTP increases almost proportionally for respondents who have completed at least a college (bachelors) degree. This result is consistent with a constant marginal utility of small risk reduction (Hammitt, 2000).

The results indicate that mean willingness to pay and thus the VSL, which is the average rate at which people are willing to trade-off money for safety, is "individuated." This implies that VSL varies across groups of potential beneficiaries of traffic safety programs (two-wheeler drivers, persons with a college degree, etc.). For the most likely beneficiaries of road safety programs - the most highly exposed individuals - the VSL is about \$150,000 (2005 PPP dollars). 
The VSL obtained in this study is much lower than the value obtained by transferring estimates from developed countries, such as the $\$ 3$ million used by Department of Transportation in the US or the $£ 1.49$ million used by the Department for Transportation in UK for project appraisals. These figures yield \$419,000 (2005 PPP) and $\$ 639,000$ (2005 PPP) respectively for Delhi assuming an income elasticity of one. ${ }^{68}$ One would reach a similar conclusion if the results from a recent contingent valuation study in Bangkok (Vassanadumrongdee and Matsuoka, 2005) were transferred to Delhi. Adjusting for income, I would predict the VSL in Delhi to be \$434,000 (PPP US dollars).

My estimate of VSL is also approximately 1.9 times the discounted flow of personal income over the rest of the working life of an average respondent in the sample using a 12 percent rate of discount. ${ }^{69}$ This ratio is lower than that of the U.S. DoT which uses a VSL that is roughly 3 times discounted annual earnings. These findings suggest the importance of conducting original valuation studies at the site where one wishes to value changes in risk of death.

\footnotetext{
${ }^{68}$ Most economists contend that the income elasticity is less than unity for developing countries. Therefore, the transferred estimates from developed to developing countries using an elasticity of "one" are an underestimate. However a recent study (DeBlaeij, 2003) found that the income elasticity for risk reductions from road safety was 1.33 . Even using an income elasticity of 1.33 , the transferred estimates still turn out to be much higher than my estimate.

${ }^{69}$ The Planning Commission of India currently uses a social discount rate of $12 \%$.
} 


\section{APPENDIX}

\section{A. Comparison of India's Traffic Crash Rates with Some Other Countries}

With 90,000 fatalities, ${ }^{70}$ India, which comprises roughly one-sixth of the world's population, had the second highest number of road traffic fatalities in the world ${ }^{71}$ and $7.5 \%$ of the worldwide total in the year 2004 . The number of fatalities per 100,000 people in India was 8.33 in 2004 . Fatality rates per 100,000 people increased by about $80 \%$ during the period 1980-1998. This is in sharp contrast to developed countries where fatality rates declined considerably for the same period (WHO, 2004). At first glance, India's fatality rate per 100,000 people does not compare unfavorably with that of other countries. For example, the corresponding figures for Sweden and Iran are 5.33 and 38.70 respectively ${ }^{72}$ for the same year (Table A.1). The crash fatality rate in the United States at 14.53 per 100,000 is significantly higher than India's. On the other hand, the fatality rate per 10,000 motor vehicles, which declined from 20.3 in 1995 to 12 in 2004, is still much higher than the corresponding figure in highly motorized countries where it averages around 2 per 10,000 motor vehicles. Moreover, road traffic deaths in India are expected to grow by 147 percent between 1990 and 2020 (World Health Report, 2003). In fact, Kopits and Cropper (2004) predict that India's road accident death rate is expected to rise until 2042.

\footnotetext{
${ }^{70}$ Source: WHO, 2005

${ }^{71}$ China reported the highest number of road accident deaths at 107,077 in 2004 (official government figures). However, it is alleged that the actual road death toll is vastly higher than the one reported by the Chinese Government (WHO, 2005).

${ }^{72}$ These figures are reported for the year 2004. For a more detailed comparison across more countries please see the table in the Appendix.
} 
TABLE A.1: ROAD ACCIDENT FATALITY RATES IN SELECTED COUNTRIES (2004)

\begin{tabular}{|l|c|c|}
\hline Country & No. of Traffic Fatalities & Death Rate/ 100,000 People \\
\hline Malta & 13 & 3.25 \\
Netherlands & 804 & 4.93 \\
Sweden & 480 & 5.33 \\
United Kingdom & 3,221 & 5.34 \\
Japan & 7,358 & 5.76 \\
Switzerland & 510 & 6.85 \\
Australia & 1,596 & 7.94 \\
China & 107,077 & 8.26 \\
India & $\mathbf{9 0 , 0 0 0}$ & $\mathbf{8 . 3 3}$ \\
New Zealand & 436 & 10.74 \\
Spain & 4,751 & 11.79 \\
Delhi, India & $\mathbf{1 , 8 3 2}$ & $\mathbf{1 2 . 5 5}$ \\
United States & 42,636 & 14.53 \\
Malaysia & 6,223 & 21.04 \\
Russian Federation & 34,506 & 24.01 \\
Iran & 26,280 & 38.70 \\
\hline
\end{tabular}

Source: Compiled data from respective governmental agencies by Drive and Stay Alive, 2005 Inc, 2005 


\section{B. Sampling Criteria: Number of Census Enumeration Blocks Selected by Ward}

\begin{tabular}{|c|c|c|c|c|c|}
\hline $\begin{array}{l}\text { Ward } \\
\text { No. }\end{array}$ & $\begin{array}{c}\text { Ward } \\
\text { Population }\end{array}$ & $\begin{array}{c}\text { Percentage of } \\
\text { Ward Population } \\
\text { to Total } \\
\text { Population of the } \\
132 \text { wards }\end{array}$ & $\begin{array}{l}\text { No. of EBs } \\
\text { Selected for } \\
\text { Sampling }\end{array}$ & $\begin{array}{l}\text { No. of } \\
\text { EBs in } \\
\text { the } \\
\text { Ward }\end{array}$ & $\begin{array}{l}\text { Sampling } \\
\text { Interval }\end{array}$ \\
\hline 1 & 86579 & 0.67 & 3 & 157 & 52 \\
\hline 2 & 148182 & 1.15 & 5 & 274 & 55 \\
\hline 3 & 112204 & 0.87 & 3 & 208 & 69 \\
\hline 4 & 96344 & 0.75 & 3 & 172 & 57 \\
\hline 5 & 111304 & 0.86 & 3 & 200 & 67 \\
\hline 6 & 116509 & 0.90 & 4 & 205 & 51 \\
\hline 7 & 187456 & 1.45 & 6 & 313 & 52 \\
\hline 8 & 113207 & 0.88 & 4 & 209 & 52 \\
\hline 9 & 155533 & 1.21 & 5 & 285 & 57 \\
\hline 10 & 75331 & 0.58 & 2 & 123 & 62 \\
\hline 11 & 97824 & 0.76 & 3 & 156 & 52 \\
\hline 12 & 73871 & 0.57 & 2 & 129 & 65 \\
\hline 13 & 66563 & 0.52 & 2 & 117 & 59 \\
\hline 14 & 64151 & 0.50 & 2 & 120 & 60 \\
\hline 15 & 85297 & 0.66 & 3 & 147 & 49 \\
\hline 16 & 63004 & 0.49 & 2 & 104 & 52 \\
\hline 17 & 100949 & 0.78 & 3 & 166 & 55 \\
\hline 18 & 74355 & 0.58 & 2 & 142 & 71 \\
\hline 19 & 88101 & 0.68 & 3 & 162 & 54 \\
\hline 20 & 76827 & 0.60 & 2 & 128 & 64 \\
\hline 21 & 88980 & 0.69 & 3 & 148 & 49 \\
\hline 22 & 88294 & 0.68 & 3 & 149 & 50 \\
\hline 23 & 69867 & 0.54 & 2 & 110 & 55 \\
\hline 24 & 86663 & 0.67 & 3 & 142 & 47 \\
\hline 25 & 92992 & 0.72 & 3 & 157 & 52 \\
\hline 26 & 85349 & 0.66 & 3 & 154 & 51 \\
\hline 27 & 63006 & 0.49 & 2 & 106 & 53 \\
\hline 28 & 70317 & 0.54 & 2 & 121 & 61 \\
\hline 29 & 94437 & 0.73 & 3 & 155 & 52 \\
\hline 30 & 101870 & 0.79 & 3 & 172 & 57 \\
\hline 31 & 81664 & 0.63 & 3 & 140 & 47 \\
\hline 32 & 93380 & 0.72 & 3 & 152 & 51 \\
\hline 33 & 260085 & 2.02 & 8 & 445 & 56 \\
\hline 34 & 153294 & 1.19 & 5 & 248 & 50 \\
\hline 35 & 190015 & 1.47 & 6 & 320 & 53 \\
\hline 36 & 119969 & 0.93 & 4 & 228 & 57 \\
\hline 37 & 34816 & 0.27 & 1 & 52 & 52 \\
\hline 38 & 163333 & 1.27 & 5 & 268 & 54 \\
\hline
\end{tabular}




\begin{tabular}{|c|c|c|c|c|c|}
\hline $\begin{array}{c}\text { Ward } \\
\text { No. }\end{array}$ & $\begin{array}{c}\text { Ward } \\
\text { Population }\end{array}$ & $\begin{array}{c}\text { Percentage of } \\
\text { Ward Population } \\
\text { to Total } \\
\text { Population of the } \\
132 \text { wards } \\
\end{array}$ & $\begin{array}{l}\text { No. of EBs } \\
\text { Selected for } \\
\text { Sampling }\end{array}$ & $\begin{array}{l}\text { No. of } \\
\text { EBs in } \\
\text { the } \\
\text { Ward }\end{array}$ & $\begin{array}{l}\text { Sampling } \\
\text { Interval }\end{array}$ \\
\hline 39 & 115603 & 0.90 & 4 & 183 & 46 \\
\hline 40 & 101798 & 0.79 & 3 & 154 & 51 \\
\hline 41 & 89702 & 0.70 & 3 & 153 & 51 \\
\hline 42 & 82422 & 0.64 & 3 & 134 & 45 \\
\hline 43 & 165619 & 1.28 & 5 & 251 & 50 \\
\hline 44 & 84161 & 0.65 & 3 & 123 & 41 \\
\hline 45 & 68069 & 0.53 & 2 & 129 & 65 \\
\hline 46 & 104274 & 0.81 & 3 & 182 & 61 \\
\hline 47 & 169284 & 1.31 & 5 & 276 & 55 \\
\hline 49 & 121476 & 0.94 & 4 & 199 & 50 \\
\hline 50 & 0 & 0.00 & 0 & 0 & 0 \\
\hline 51 & 107910 & 0.84 & 3 & 174 & 58 \\
\hline 52 & 169461 & 1.31 & 5 & 257 & 51 \\
\hline 53 & 132895 & 1.03 & 4 & 217 & 54 \\
\hline 54 & 164057 & 1.27 & 5 & 250 & 50 \\
\hline 55 & 97477 & 0.76 & 3 & 163 & 54 \\
\hline 56 & 96805 & 0.75 & 3 & 173 & 58 \\
\hline 57 & 99094 & 0.77 & 3 & 166 & 55 \\
\hline 58 & 39674 & 0.31 & 1 & 62 & 62 \\
\hline 59 & 79387 & 0.62 & 2 & 140 & 70 \\
\hline 60 & 164365 & 1.27 & 5 & 243 & 49 \\
\hline 61 & 77946 & 0.60 & 2 & 132 & 66 \\
\hline 62 & 85981 & 0.67 & 3 & 133 & 44 \\
\hline 63 & 105698 & 0.82 & 3 & 178 & 59 \\
\hline 64 & 194378 & 1.51 & 6 & 316 & 53 \\
\hline 65 & 212383 & 1.65 & 7 & 320 & 46 \\
\hline 66 & 89486 & 0.69 & 3 & 174 & 58 \\
\hline 67 & 156098 & 1.21 & 5 & 219 & 44 \\
\hline 68 & 80147 & 0.62 & 2 & 116 & 58 \\
\hline 69 & 76436 & 0.59 & 2 & 118 & 59 \\
\hline 70 & 149451 & 1.16 & 5 & 223 & 45 \\
\hline 71 & 74810 & 0.58 & 2 & 126 & 63 \\
\hline 72 & 139614 & 1.08 & 4 & 220 & 55 \\
\hline 73 & 80081 & 0.62 & 2 & 139 & 70 \\
\hline 74 & 90070 & 0.70 & 3 & 157 & 52 \\
\hline 75 & 60109 & 0.47 & 2 & 93 & 47 \\
\hline 76 & 67375 & 0.52 & 2 & 102 & 51 \\
\hline 77 & 70051 & 0.54 & 2 & 128 & 64 \\
\hline 78 & 81337 & 0.63 & 3 & 143 & 48 \\
\hline 79 & 120883 & 0.94 & 4 & 179 & 45 \\
\hline
\end{tabular}




\begin{tabular}{|c|c|c|c|c|c|}
\hline $\begin{array}{c}\text { Ward } \\
\text { No. }\end{array}$ & $\begin{array}{c}\text { Ward } \\
\text { Population }\end{array}$ & $\begin{array}{c}\text { Percentage of } \\
\text { Ward Population } \\
\text { to Total } \\
\text { Population of the } \\
\mathbf{1 3 2} \text { wards }\end{array}$ & $\begin{array}{c}\text { No. of EBs } \\
\text { Selected for } \\
\text { Sampling }\end{array}$ & $\begin{array}{c}\text { No. of } \\
\text { EBs in } \\
\text { the } \\
\text { Ward }\end{array}$ & $\begin{array}{c}\text { Sampling } \\
\text { Interval }\end{array}$ \\
\hline 80 & 87080 & 0.67 & 3 & 155 & 52 \\
\hline 81 & 78624 & 0.61 & 2 & 125 & 63 \\
\hline 82 & 79591 & 0.62 & 2 & 141 & 71 \\
\hline 83 & 110888 & 0.86 & 3 & 199 & 66 \\
\hline 84 & 106693 & 0.83 & 3 & 184 & 61 \\
\hline 85 & 0 & 0.00 & 0 & 0 & 0 \\
\hline 86 & 134076 & 1.04 & 4 & 207 & 52 \\
\hline 87 & 71963 & 0.56 & 2 & 119 & 60 \\
\hline 88 & 93619 & 0.73 & 3 & 161 & 54 \\
\hline 89 & 78820 & 0.61 & 2 & 128 & 64 \\
\hline 90 & 100576 & 0.78 & 3 & 150 & 50 \\
\hline 91 & 95718 & 0.74 & 3 & 147 & 49 \\
\hline 92 & 82474 & 0.64 & 3 & 133 & 44 \\
\hline 93 & 80036 & 0.62 & 2 & 129 & 65 \\
\hline 94 & 89907 & 0.70 & 3 & 146 & 49 \\
\hline 95 & 77802 & 0.60 & 2 & 124 & 62 \\
\hline 96 & 75454 & 0.58 & 2 & 120 & 60 \\
\hline 97 & 244664 & 1.90 & 8 & 365 & 46 \\
\hline 98 & 137427 & 1.06 & 4 & 199 & 50 \\
\hline 99 & 82565 & 0.64 & 3 & 144 & 48 \\
\hline 100 & 64235 & 0.50 & 2 & 115 & 58 \\
\hline 101 & 85675 & 0.66 & 3 & 154 & 51 \\
\hline 102 & 25448 & 0.20 & 1 & 36 & 36 \\
\hline 103 & 118483 & 0.92 & 4 & 204 & 51 \\
\hline 104 & 116491 & 0.90 & 4 & 168 & 42 \\
\hline 105 & 100349 & 0.78 & 3 & 189 & 63 \\
\hline 106 & 100153 & 0.78 & 3 & 169 & 56 \\
\hline 107 & 60719 & 0.47 & 2 & 95 & 48 \\
\hline 108 & 59393 & 0.46 & 2 & 105 & 53 \\
\hline 109 & 67049 & 0.52 & 2 & 102 & 51 \\
\hline 110 & 91353 & 0.71 & 3 & 151 & 50 \\
\hline 111 & 58012 & 0.45 & 2 & 99 & 50 \\
\hline 112 & 62676 & 0.49 & 2 & 118 & 59 \\
\hline 113 & 51139 & 0.40 & 2 & 87 & 44 \\
\hline 114 & 73931 & 0.57 & 2 & 130 & 65 \\
\hline 115 & 83685 & 0.65 & 3 & 147 & 49 \\
\hline 116 & 83000 & 0.64 & 3 & 138 & 46 \\
\hline 117 & 85127 & 0.66 & 0.56 & 147 & 49 \\
\hline 118 & 72306 & 0.42 & 95 & 63 \\
\hline 119 & 54126 & & & & \\
\hline & & & 3 & 3 \\
\hline
\end{tabular}




\begin{tabular}{|c|c|c|c|c|c|}
\hline $\begin{array}{c}\text { Ward } \\
\text { No. }\end{array}$ & $\begin{array}{c}\text { Ward } \\
\text { Population }\end{array}$ & $\begin{array}{c}\text { Percentage of } \\
\text { Ward Population } \\
\text { to Total } \\
\text { Population of the } \\
\mathbf{1 3 2} \text { wards }\end{array}$ & $\begin{array}{c}\text { No. of EBs } \\
\text { Selected for } \\
\text { Sampling }\end{array}$ & $\begin{array}{c}\text { No. of } \\
\text { EBs in } \\
\text { the } \\
\text { Ward }\end{array}$ & $\begin{array}{c}\text { Sampling } \\
\text { Interval }\end{array}$ \\
\hline 120 & 70622 & 0.55 & 2 & 118 & 59 \\
\hline 121 & 66823 & 0.52 & 2 & 114 & 57 \\
\hline 122 & 55661 & 0.43 & 2 & 92 & 46 \\
\hline 123 & 67497 & 0.52 & 2 & 119 & 60 \\
\hline 124 & 99944 & 0.77 & 3 & 187 & 62 \\
\hline 125 & 74641 & 0.58 & 2 & 126 & 63 \\
\hline 126 & 76555 & 0.59 & 2 & 136 & 68 \\
\hline 127 & 71715 & 0.56 & 2 & 124 & 62 \\
\hline 128 & 87232 & 0.68 & 3 & 137 & 46 \\
\hline 129 & 51035 & 0.40 & 2 & 88 & 44 \\
\hline 130 & 73061 & 0.57 & 2 & 116 & 58 \\
\hline 131 & 69490 & 0.54 & 2 & 113 & 57 \\
\hline 132 & 66925 & 0.52 & 2 & 130 & 65 \\
\hline 133 & 66328 & 0.51 & 2 & 122 & 61 \\
\hline 134 & 112007 & 0.87 & 3 & 179 & 60 \\
\hline & & & & & \\
\hline TOTAL & $\mathbf{1 2 , 9 0 5 , 7 8 0}$ & $\mathbf{1 0 0 . 0 0}$ & $\mathbf{4 0 0}$ & $\mathbf{2 1 4 7 4}$ & \\
\hline & & & & & \\
\hline & & & & & \\
\hline
\end{tabular}

Note: Ward number 50 and 85 are rural wards, which are not included in the study. 


\section{Location of Delhi, India on the World Map}

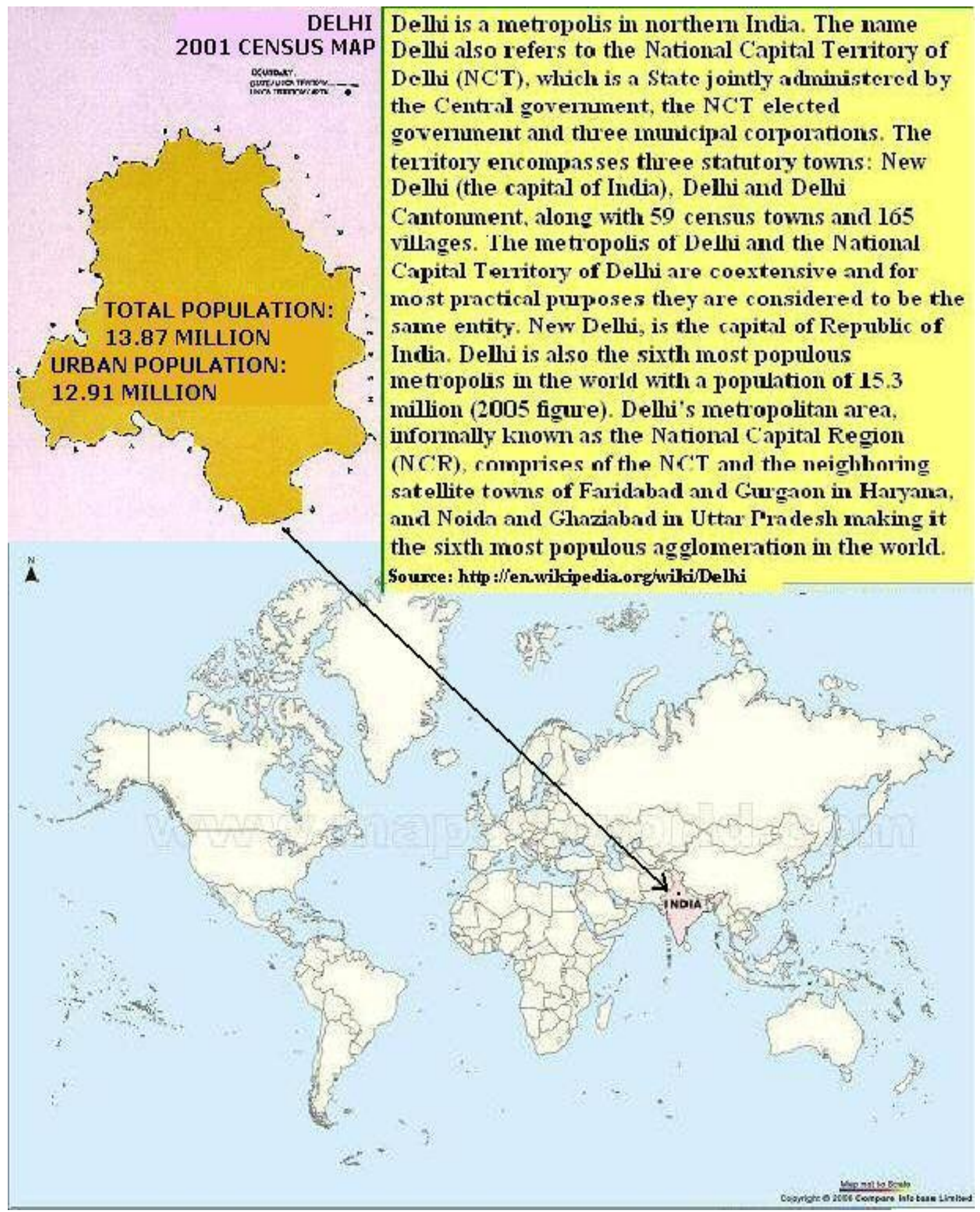




\section{Analysis of WTP Responses for the Pedestrian, City and Helmet Scenario}

Table A.2 presents the estimation results for equation (7.15) for each of the three scenarios. I expect the coefficient $\beta_{3}$ to be positive in all the three cases since this coefficient determines the sensitivity of willingness to pay to scope, i.e., to the size of the risk reduction. However this coefficient is negative $\mathrm{e}^{73}$ and insignificant except for the city scenario. ${ }^{74}$ Respondents belonging to low-income groups had lower WTP figures for each of the three scenarios, as did respondents who were the breadwinners for large families. Variables indicating higher traffic exposure like commute time to workplace, whether travel for job purposes other than the regular home to workplace commute and whether drives a two-wheeler all had a positive impact on WTP as expected. ${ }^{75}$ People with prior experience or knowledge about road accidents, on the contrary, did not have a significant impact on their WTP for increased safety.

\footnotetext{
${ }^{73}$ The coefficient becomes positive (but insignificant) for the pedestrian scenario if I only consider a sample of high school graduates or persons with a college (undergraduate) degree or above, or for twowheeler drivers.

${ }^{74}$ The size of this coefficient increases for the city scenario and decreases for the pedestrian and helmet scenarios if I restrict the sample to persons with a college degree or higher indicating education has an impact on the sensitivity of WTP to the size of the risk reduction.

${ }^{75}$ Willingness to pay did not exhibit any sensitivity to the baseline commute costs in the City scenario, which were set to Rs. 2400/year in Versions 1 and 3 and Rs. 4800/yr in Versions 2 and 4.
} 
TABLE A.2 (a): INTERVAL DATA WEIBULL MODEL FOR WTP FROM PEDESTRIAN SCENARIO

\begin{tabular}{|l|c|c|c|}
\hline Variable & Coeff & $\begin{array}{c}\text { Standard } \\
\text { Error }\end{array}$ & P-Value \\
\hline Intercept & 1.58 & 1.01 & 0.12 \\
\hline Log of risk reduction & -0.19 & 0.26 & 0.47 \\
\hline Age & 0.05 & 0.04 & 0.24 \\
\hline Age squared & 0.00 & 0.00 & 0.41 \\
\hline Low income dummy & $-0.49^{*}$ & 0.28 & 0.08 \\
\hline Middle income dummy & -0.40 & 0.27 & 0.14 \\
\hline Primary wage earner ${ }^{*}$ household size & $-0.07^{* * *}$ & 0.03 & 0.01 \\
\hline High school diploma & -1.28 & 0.89 & 0.15 \\
\hline Has had an accident (or knows someone who did) & 0.17 & 0.15 & 0.26 \\
\hline Whether travels as part of the job & $0.35^{* *}$ & 0.16 & 0.02 \\
\hline Commute time (minutes) & $0.01^{* * *}$ & 0.00 & 0.00 \\
\hline Risk reduction*high school & 0.52 & 0.38 & 0.16 \\
\hline Whether drives a two-wheeler & $0.67^{* * *}$ & 0.14 & $<.0001$ \\
\hline Scale & & 2.41 & \\
Weibull Shape & & 0.42 \\
Log Likelihood \\
Number of Observations & -2248.75 \\
\hline
\end{tabular}


TABLE A.2 (b): INTERVAL DATA WEIBULL MODEL FOR WTP FROM CITY SCENARIO

\begin{tabular}{|l|c|c|c|}
\hline Variable & Coeff & $\begin{array}{c}\text { Standard } \\
\text { Error }\end{array}$ & P-Value \\
\hline Intercept & $4.11^{* * *}$ & 1.36 & 0.00 \\
\hline Log of risk reduction & $-0.73^{* *}$ & 0.33 & 0.03 \\
\hline Age & 0.04 & 0.05 & 0.45 \\
\hline Age squared & 0.00 & 0.00 & 0.68 \\
\hline Low income dummy & -0.21 & 0.33 & 0.53 \\
\hline Middle income dummy & -0.01 & 0.31 & 0.97 \\
\hline Primary wage earner ${ }^{*}$ household size & -0.03 & 0.03 & 0.36 \\
\hline High school diploma & -2.26 & 1.46 & 0.12 \\
\hline Has had an accident (or knows someone who did) & 0.12 & 0.18 & 0.49 \\
\hline Whether travels as part of the job & $0.39^{* *}$ & 0.18 & 0.03 \\
\hline Commute time (minutes) & $0.01^{* * *}$ & 0.00 & 0.00 \\
\hline Risk reduction*high school & $0.86^{*}$ & 0.48 & 0.07 \\
\hline Whether drives a two-wheeler & $1.01^{* * *}$ & 0.17 & $<.0001$ \\
\hline Scale & & & \\
Weibull Shape & & 2.78 \\
Log Likelihood & & -2907.22 \\
\hline Number of Observations & & 1200 & \\
\hline
\end{tabular}


TABLE A.2 (c): INTERVAL DATA WEIBULL MODEL FOR WTP FROM HELMET SCENARIO

\begin{tabular}{|l|c|c|c|}
\hline Variable & Coeff & $\begin{array}{c}\text { Standard } \\
\text { Error }\end{array}$ & P-Value \\
\hline Intercept & $2.44^{* * *}$ & 0.76 & 0.00 \\
\hline Log of risk reduction & -0.23 & 0.19 & 0.24 \\
\hline Age & 0.05 & 0.03 & 0.11 \\
\hline Age squared & 0.00 & 0.00 & 0.25 \\
\hline Low income dummy & $-0.56^{* * *}$ & 0.19 & 0.00 \\
\hline Middle income dummy & $-0.45^{* *}$ & 0.18 & 0.01 \\
\hline Primary wage earner * household size & -0.01 & 0.02 & 0.46 \\
\hline High school diploma & -0.45 & 0.79 & 0.57 \\
\hline Has had an accident (or knows someone who did) & 0.13 & 0.10 & 0.23 \\
\hline Whether travels as part of the job & $0.22^{* *}$ & 0.11 & 0.04 \\
\hline Commute time (minutes) & $0.01^{* * *}$ & 0.00 & 0.00 \\
\hline Risk reduction*high school & 0.19 & 0.28 & 0.50 \\
\hline Whether drives a two-wheeler & $0.75^{* * *}$ & 0.10 & $<.0001$ \\
\hline Scale & & 1.64 & \\
Weibull Shape & & -3040.14 \\
Log Likelihood & 1200 & \\
\hline Number of Observations & & & \\
\hline
\end{tabular}




\section{E. The Questionnaire for Version 1 of the Final Survey}

\begin{tabular}{|l|l|l|l|l|l|l|l|l|l|l|}
\hline 0 & 1 & & & & & & & & & $1-10$ \\
\hline
\end{tabular}

COMMUTING BEHAVIOR QUESTIONNAIRE FOR DELHI, INDIA

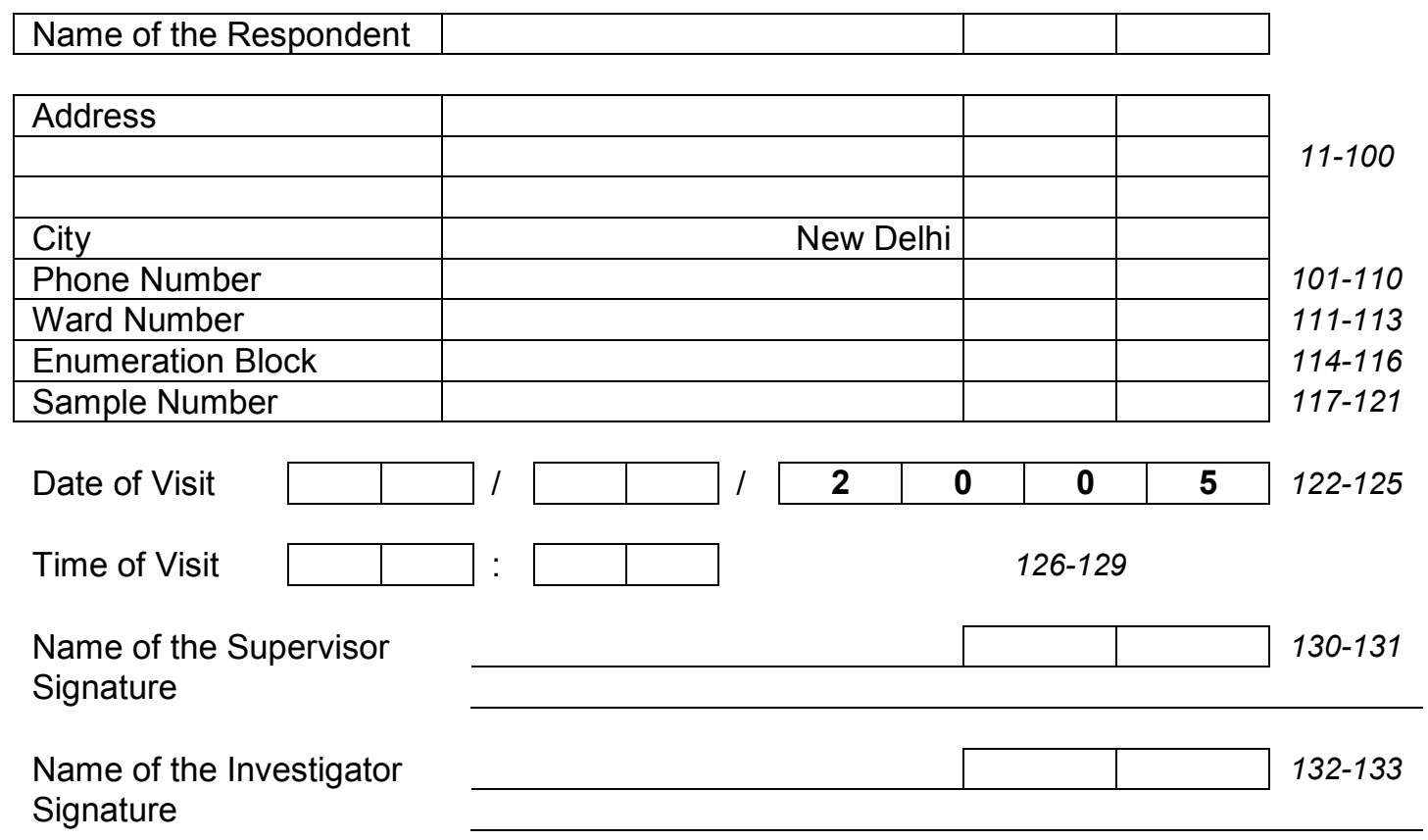

\begin{tabular}{|l|c|c|c|c|}
\hline & Accompanied & Back Checked & Scrutinized & Data Transferred \\
\hline Editor & 1 & 1 & 1 & 1 \\
\hline EIC & 2 & 2 & 2 & 2 \\
\hline OFE & 3 & 3 & 3 & 3 \\
\hline FM & 4 & 4 & 4 & 4 \\
\hline \multicolumn{7}{r}{$134-138$} & $139-142$ & $143-146$ & $147-150$
\end{tabular}

\section{ASK TO SPEAK WITH THE SELECTED RESPONDENT}

Hello. Good (Morning/Afternoon/Evening). My name is . I have

come from Social and Rural Research Institute of IMRB International. IMRB is a leading research organization and we conduct a lot of studies on various social issues such as agriculture, education, health, water, sanitation etc. Currently, we are conducting a study on Commuting Behavior. During this survey we are interviewing individuals from various localities of Delhi. The survey will take about 45 minutes to complete. Whatever information you provide will be kept strictly confidential and will not be shown to other persons. May I continue? 


\section{PART A: OCCUPATION DETAILS AND TRAVEL PATTERNS}

This is the first section out of a total of six sections in the survey. In this section I will be asking you a few questions about your occupation and commuting behaviour.

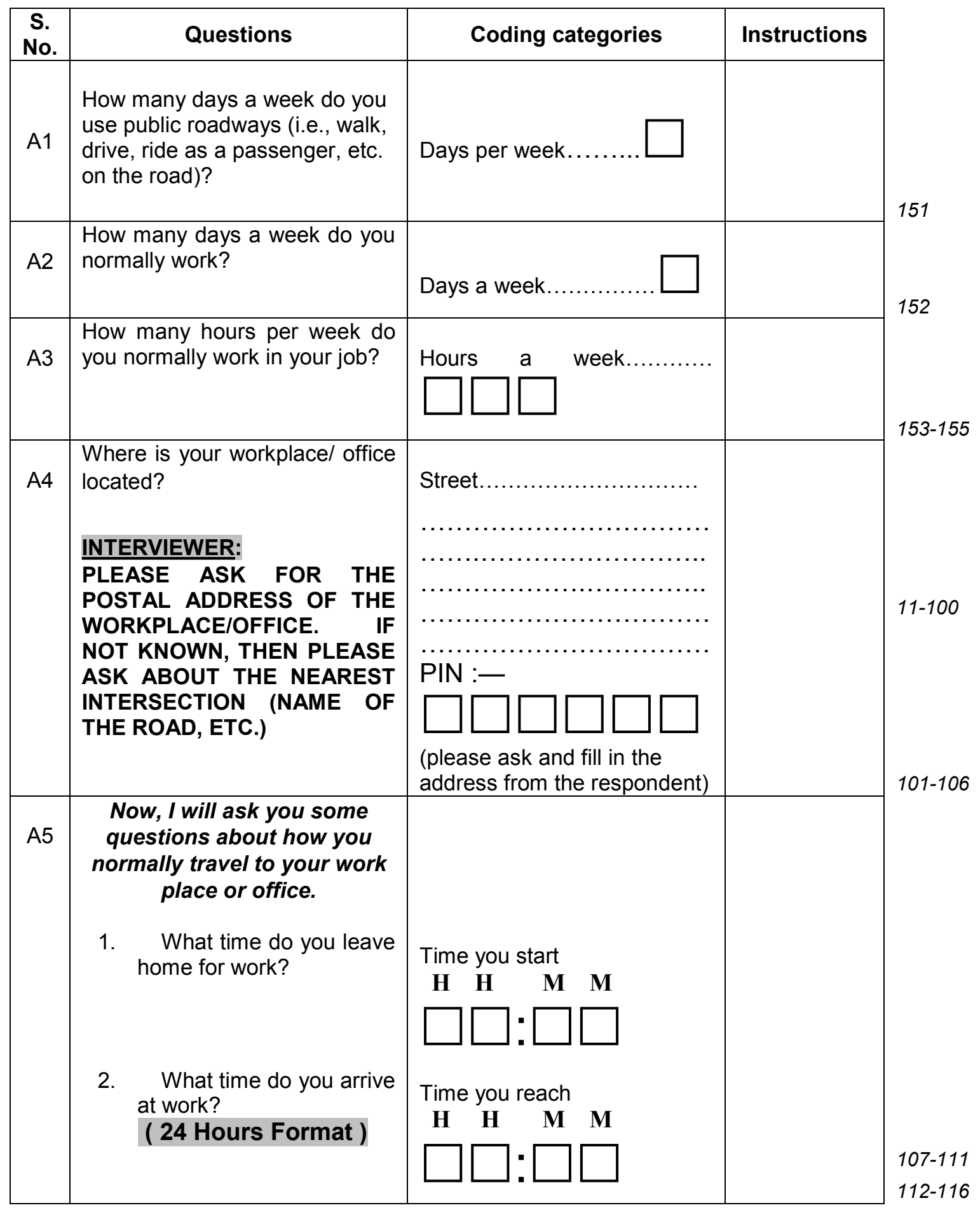


A6 Please describe one complete trip from home to work.

(INTERVIEWER: PLEASE USE THE CODES GIVEN BELOW FOR THE MODES OF TRANSPORT. IF NONE OF THE ABOVE, THEN PLEASE SPECIFY THE MODE BELOW IN THE TABLE)

\begin{tabular}{|c|c|c|c|c|c|c|c|c|c|}
\hline \multirow[t]{2}{*}{ Mode } & $\begin{array}{l}\text { How Do } \\
\text { You Go? }\end{array}$ & $\begin{array}{l}\text { Wait Time } \\
\text { (in min.) }\end{array}$ & \multicolumn{2}{|c|}{ Travel Time* } & \multicolumn{2}{|c|}{$\begin{array}{c}\text { Do you } \\
\text { use a } \\
\text { Pass? }\end{array}$} & $\begin{array}{c}\text { Pass } \\
\text { Duration } \\
\text { (Days) }\end{array}$ & $\begin{array}{c}\text { Cost (Rs.) of } \\
\text { Pass }\end{array}$ & $\begin{array}{l}\text { Cost } \\
\text { (Rs.) }\end{array}$ \\
\hline & $\begin{array}{l}\text { Which } \\
\text { Mode? }\end{array}$ & $\begin{array}{c}\text { (Excld } \\
\text { Mode 11, } \\
12,13 \text { \& } \\
14)\end{array}$ & $\begin{array}{l}\mathrm{Hrs} \\
\mathrm{HH}\end{array}$ & $\begin{array}{l}\text { Min. } \\
\text { MM }\end{array}$ & $\begin{array}{l}\text { Yes } \\
\text { No } \\
\text { (Or } \\
\text { fo } \\
\text { BU } \\
\text { Met } \\
\text { Tra }\end{array}$ & & $\begin{array}{l}\text { (Only if } \\
\text { Pass is } \\
\text { YES) }\end{array}$ & $\begin{array}{c}\text { (Only if Pass } \\
\text { is YES) }\end{array}$ & $\begin{array}{c}\text { (Excld. } \\
11, \\
12,13 \\
\text { and } 14\}, \\
\text { and if } \\
\text { Pass is } \\
\text { NO) } \\
* *\end{array}$ \\
\hline A & & & & & 1 & 2 & & & \\
\hline B & & & & & 1 & 2 & & & \\
\hline C & & & & & 1 & 2 & & & \\
\hline D & & & & & 1 & 2 & & & \\
\hline$E$ & & & & & 1 & 2 & & & \\
\hline $\mathrm{F}$ & & & & & 1 & 2 & & & \\
\hline G & & & & & 1 & 2 & & & \\
\hline $\mathrm{H}$ & & & & & 1 & 2 & & & \\
\hline
\end{tabular}

\begin{tabular}{|r|l|r|l|r|l|}
\hline 11 & On foot & 15 & In someone else's Car / Jeep / Van & 19 & By Train \\
\hline 12 & By Bicycle & 16 & In someone else's Two-wheeler & 20 & By Metro \\
\hline 14 & By own Car & 17 & By Bus & 21 & By Taxi \\
\hline 13 & $\begin{array}{l}\text { By own } \\
\text { Two-wheeler }\end{array}$ & 18 & By Auto-rickshaw & 22 & $\begin{array}{l}\text { By Cycle- } \\
\text { rickshaw }\end{array}$ \\
\hline 23 & \multicolumn{6}{|l|}{ Others (Please Specify)......................................... } \\
\hline
\end{tabular}

* INTERVIEWER:

$\rightarrow$ If total travel time is more than 20 minutes; GOTO A7

$\rightarrow$ If total travel time is less than 20 minutes; GOTO A9 


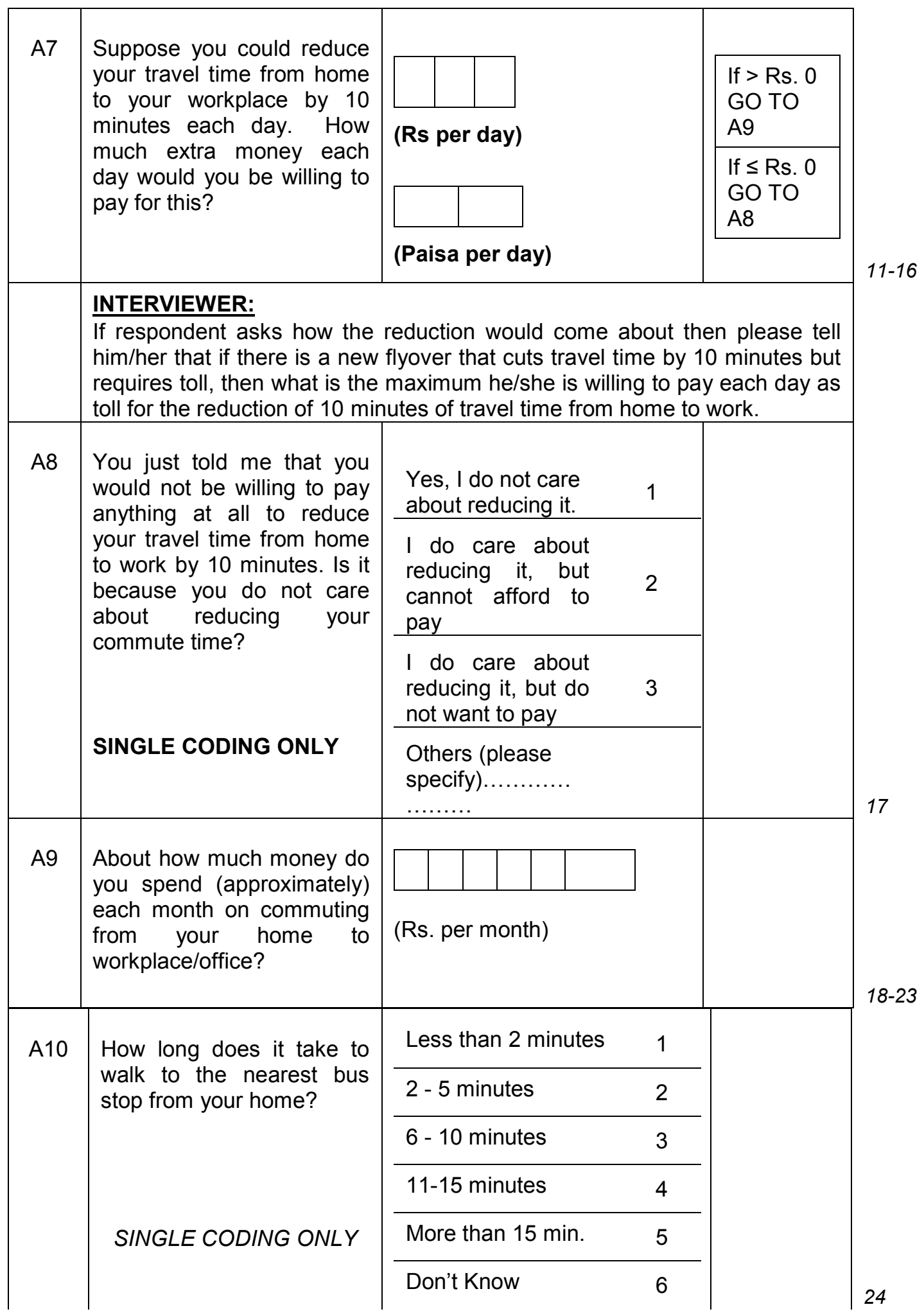




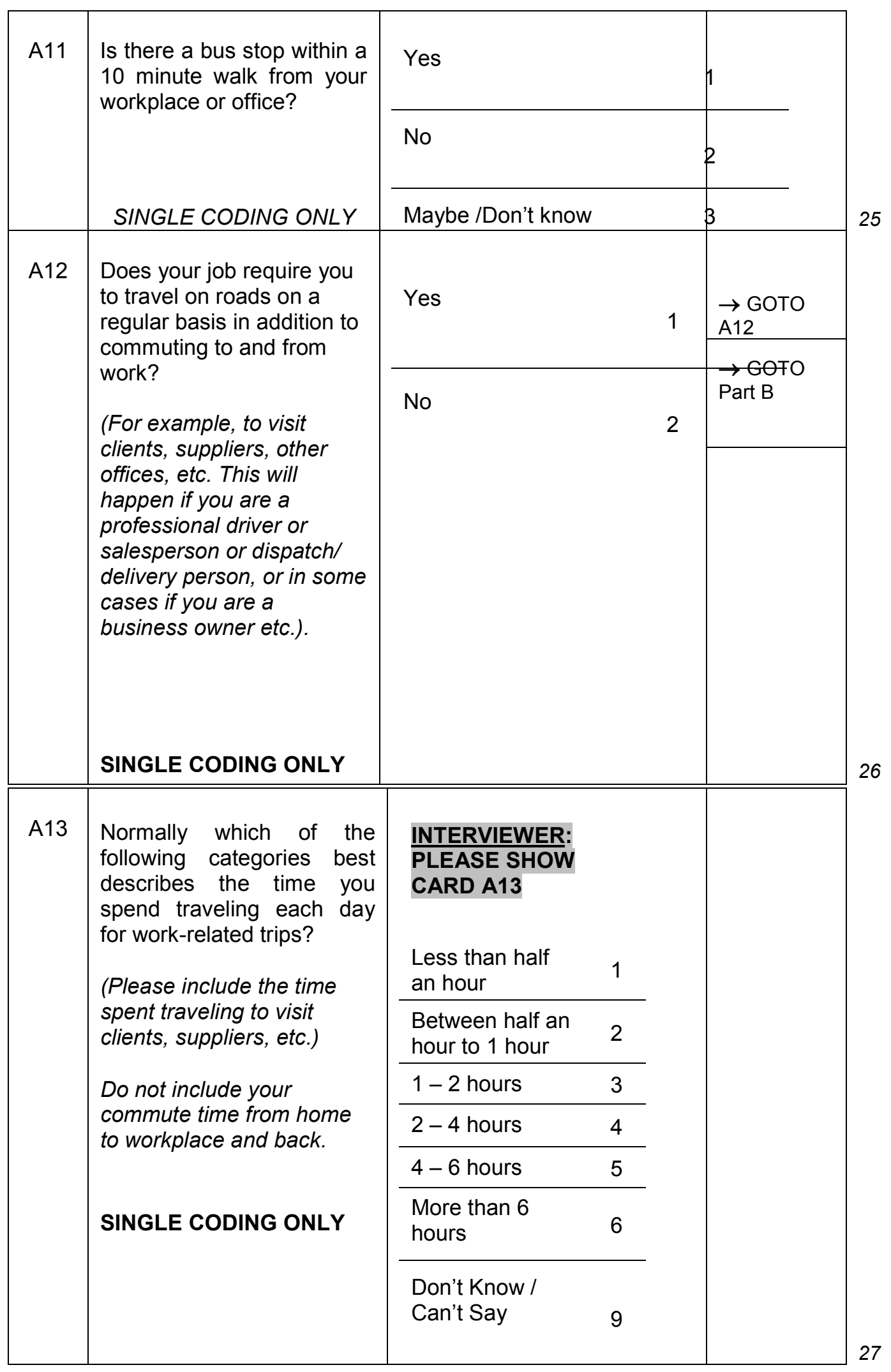




\section{PART B: PROBABILITY TUTORIAL AND QUIZ}

In this part of the survey, we will talk about the chance of an event occurring.

Suppose we have a rupee coin, it has a head and a tail.

If we toss it in the air, then we have 2 possibilities- a head or a tail. The chance of getting a head if it is a fair coin will be $1 / 2$. This means that in half of the tosses we expect to see a 'head' and in the other half we expect to see a 'tail'.

Similarly, if we have a die then the chance of rolling a ' 6 ' is $1 / 6$. Similarly, the chance of rolling a ' 4 ' is also $1 / 6$. 


\section{PART C: ROAD ACCIDENTS}

We will now examine the chance of dying from various causes using squares on a piece of paper. This is called a grid.

\section{INTERVIEWER: PLEASE SHOW THE BLANK GRID.}

I have here with me a grid that has 400 squares in width and 250 squares in length and hence a total of 100,000 (1 lakh) squares in it. Each white square here represents a person. If the square is white, the person is alive. A red colored square represents a dead person.

\section{INTERVIEWER: PLEASE SHOW CARD NO. 1}

1 in every 100,000 (1 lakh) persons in India dies each year in a fire.

INTERVIEWER: PLEASE SHOW THE GRID WITH 1 RED SQUARE.

This means that the chance of dying from fire in India is 1 square out of 100,000 (1 lakh) squares. 10 in every 100,000 (1 lakh) persons in India die each year in road accidents.

\section{INTERVIEWER: PLEASE SHOW THE GRID WITH 10 RED SQUARES.}

This means that the chance of dying from road accidents in India is 10 squares out of 100,000 (1 lakh) squares.

INTERVIEWER: PLEASE SHOW THE TWO GRIDS SIDE BY SIDE — ONE WITH 1 RED SQUARE AND THE OTHER WITH 10 RED SQUARES.

C1) Based on this information, do more people die in fires or road accidents in India?

\begin{tabular}{|l|c|}
\hline Fire & 1 \\
\hline Road accident & 2 \\
\hline
\end{tabular}

SINGLE CODING ONLY

In Delhi, the chances of dying in a road accident are higher than in the rest of India.

\section{INTERVIEWER: PLEASE SHOW CARD NO. 2 TO THE RESPONDENT}

For example, 21 in every 100,000 (1 lakh) adults living in Delhi are killed each year in road accidents as pedestrians, passengers and drivers.

\section{INTERVIEWER: PLEASE SHOW THE GRID WITH 21 RED SQUARES.}

This is represented by the 21 red squares on this grid. Since half the victims are pedestrians, we can therefore say that 11 in every 100,000 (1 lakh) adults in Delhi die each year as pedestrians.

\section{INTERVIEWER: PLEASE SHOW THE GRID WITH 11 RED SQUARES.}

This is represented by the 11 red squares on this grid. The chance of dying for people who commute each day to work is much higher. Your own chance of dying in a road accident will depend on how much you travel and how safely you travel, compared to an average person. 


\section{PART D: BEHAVIORAL QUESTIONS}

In this section I am going to ask you a few questions about travel and travel safety. I will describe situations where you are a pedestrian or a two-wheeler driver and will ask you to tell me what you would do if you were in that situation. There is no right or wrong answer to any of the questions in this section. Please answer whatever you honestly feel you would do if you were actually in such a situation in real life.

\section{Question D1}

D1. Suppose that to get to work in the morning you have to cross a very busy street in front of your workplace/ office. You need to cross that street 240 days in a year. You have two options available to you for crossing the busy street in the morning:

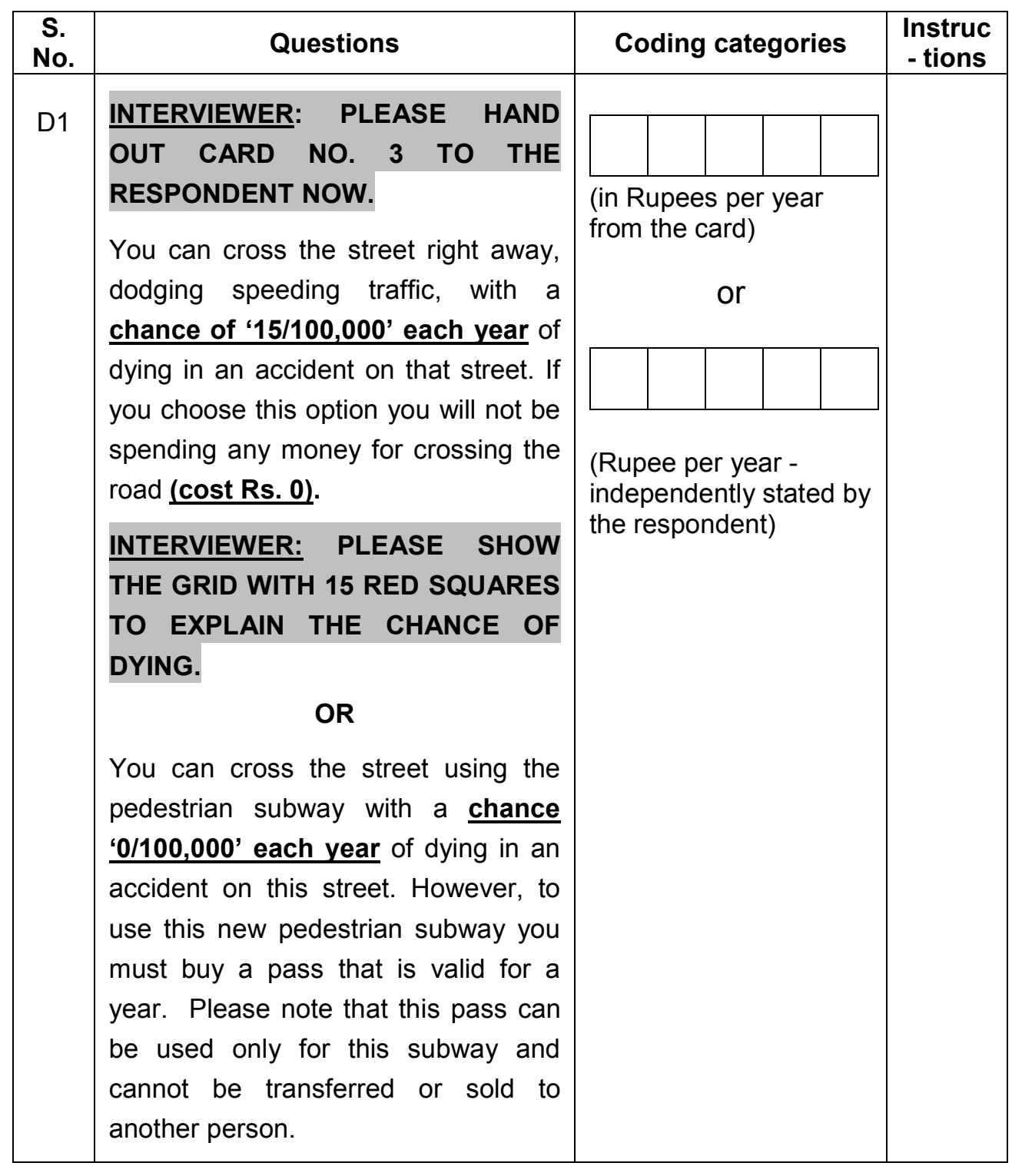




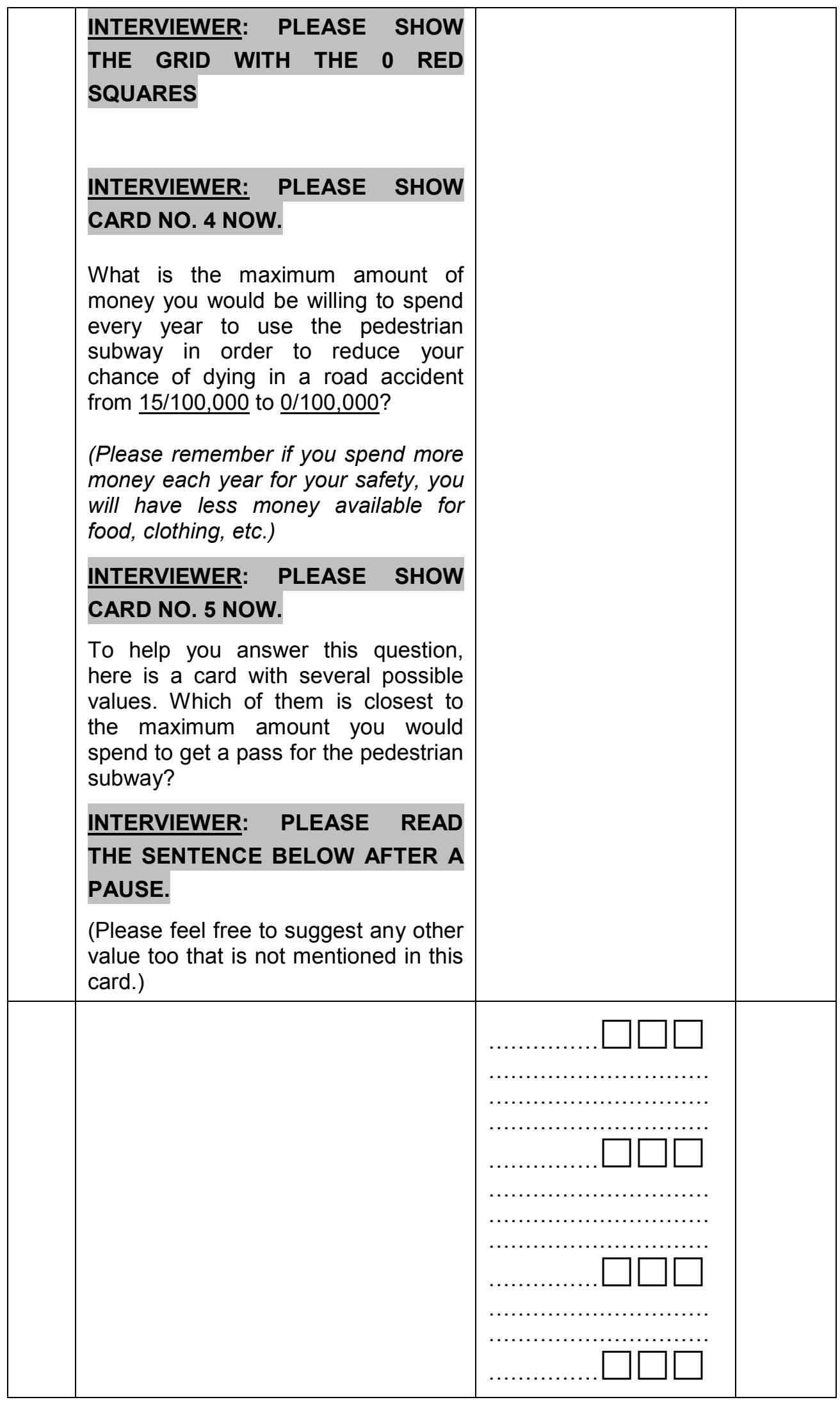




\section{Question D2}

D2. Suppose that there are two cities. The two cities are identical in all respects except the chance of dying from road accidents and transportation costs. Assume that you live the same distance away from your workplace/ office in either of these two cities.

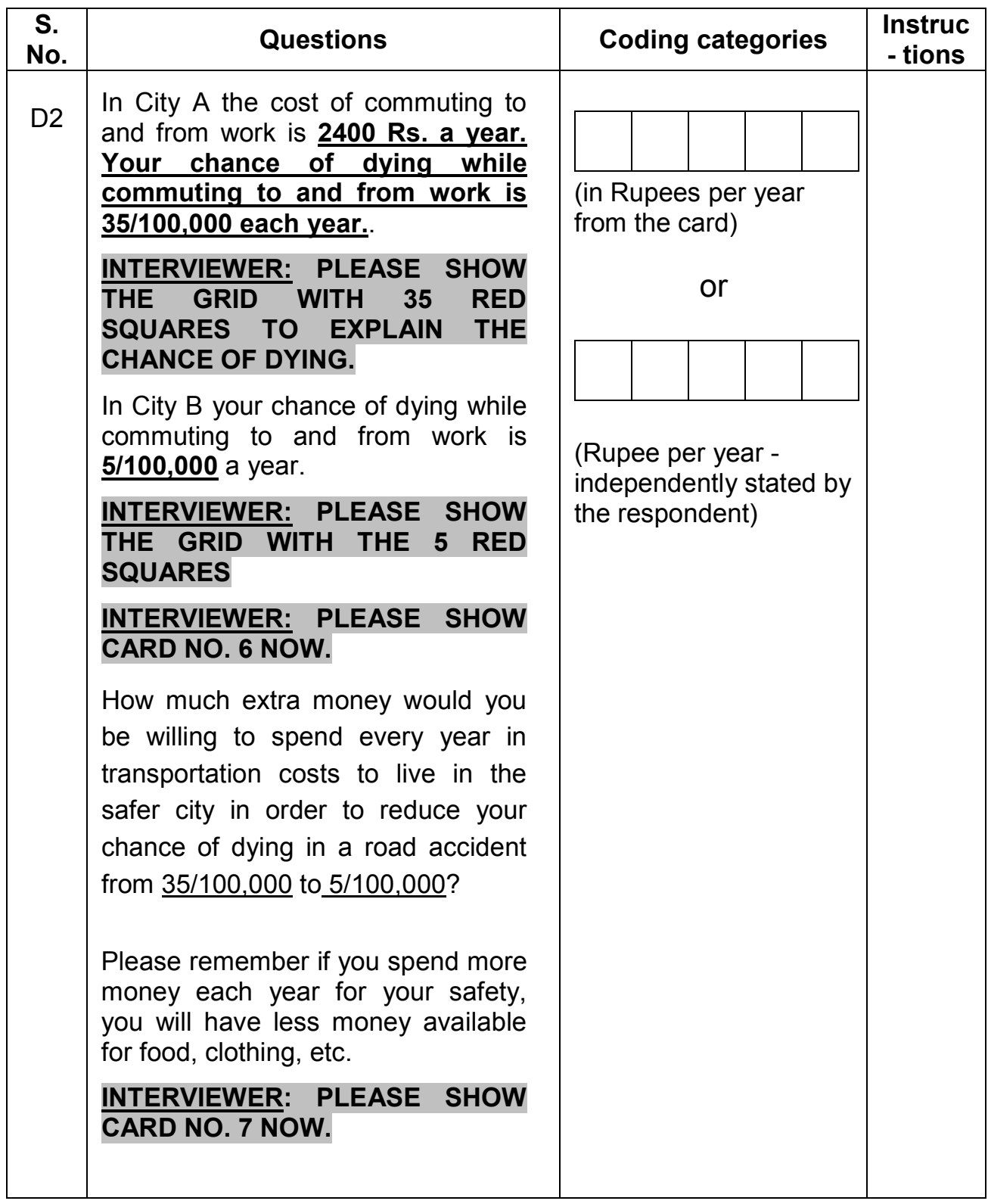




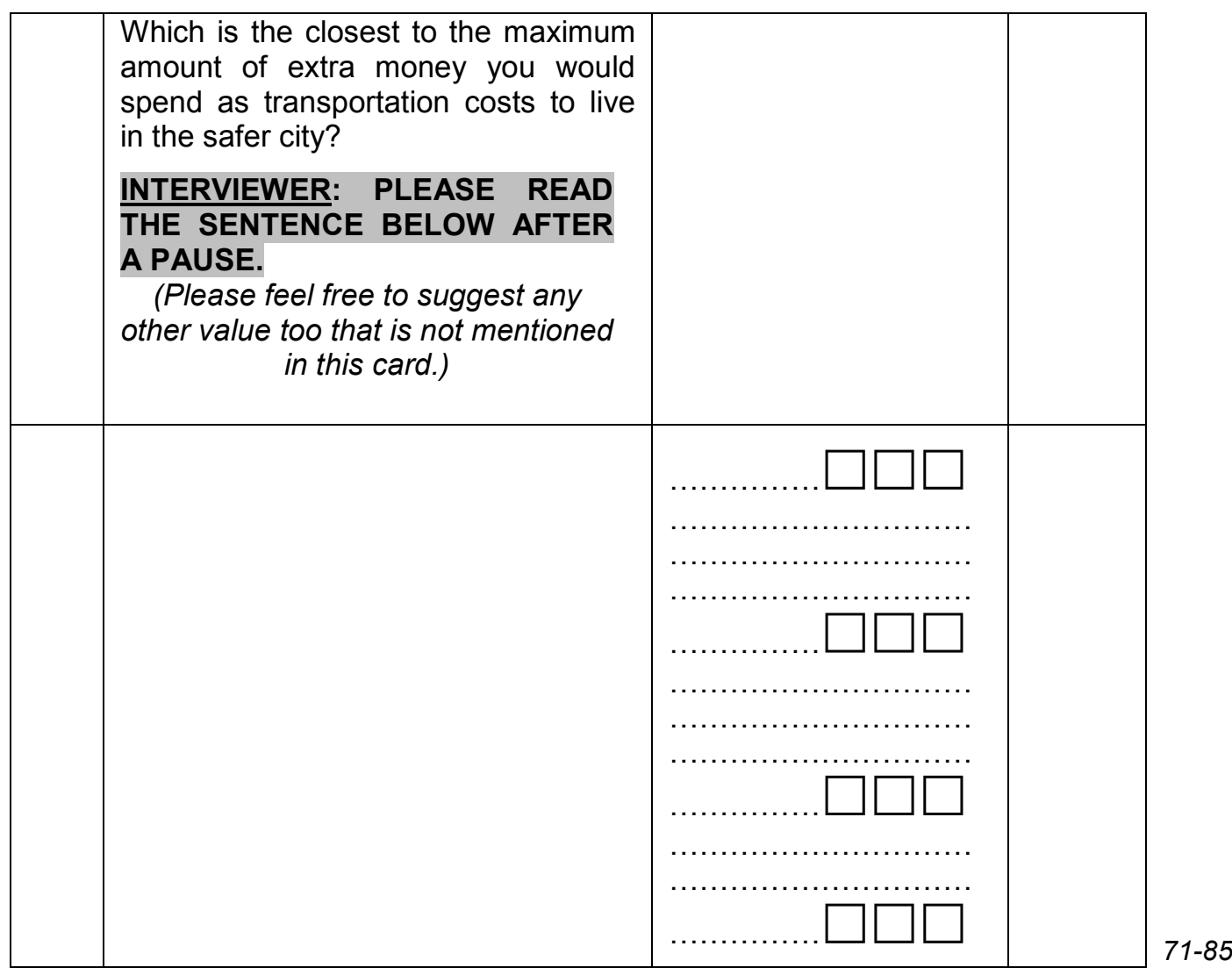

\section{Question D3}

\begin{tabular}{|l|l|l|l|}
\hline D3 & $\begin{array}{l}\text { Do you drive a two- } \\
\text { wheeler? }\end{array}$ & Yes 1 & $\rightarrow$ GOTO SEC D4 \\
\cline { 3 - 5 } & SINGLE CODING ONLY & No 2 & $\rightarrow$ GOTO SEC D5 \\
\cline { 3 - 4 }
\end{tabular}

\section{Question D4}

D4 Suppose it is time to replace the two-wheeler helmet that you wear. Imagine that you are shown two helmets that look exactly identical but differ in price and quality. Please note that both helmets last for three years. Assume that you will be the only person wearing this helmet. 
INTERVIEWER: IN CASE, IF THE RESPONDENT OBJECTS BY SAYING THAT HE DOES NOT HAVE A HELMET (EVEN IF REQUIRED BY LAW), THEN SAY “WELL, PLEASE IMAGINE THAT YOU HAVE ONE, AND THAT IT NEEDS TO BE REPLACED, OR THAT YOU ARE BUYING ONE FOR THE FIRST TIME."

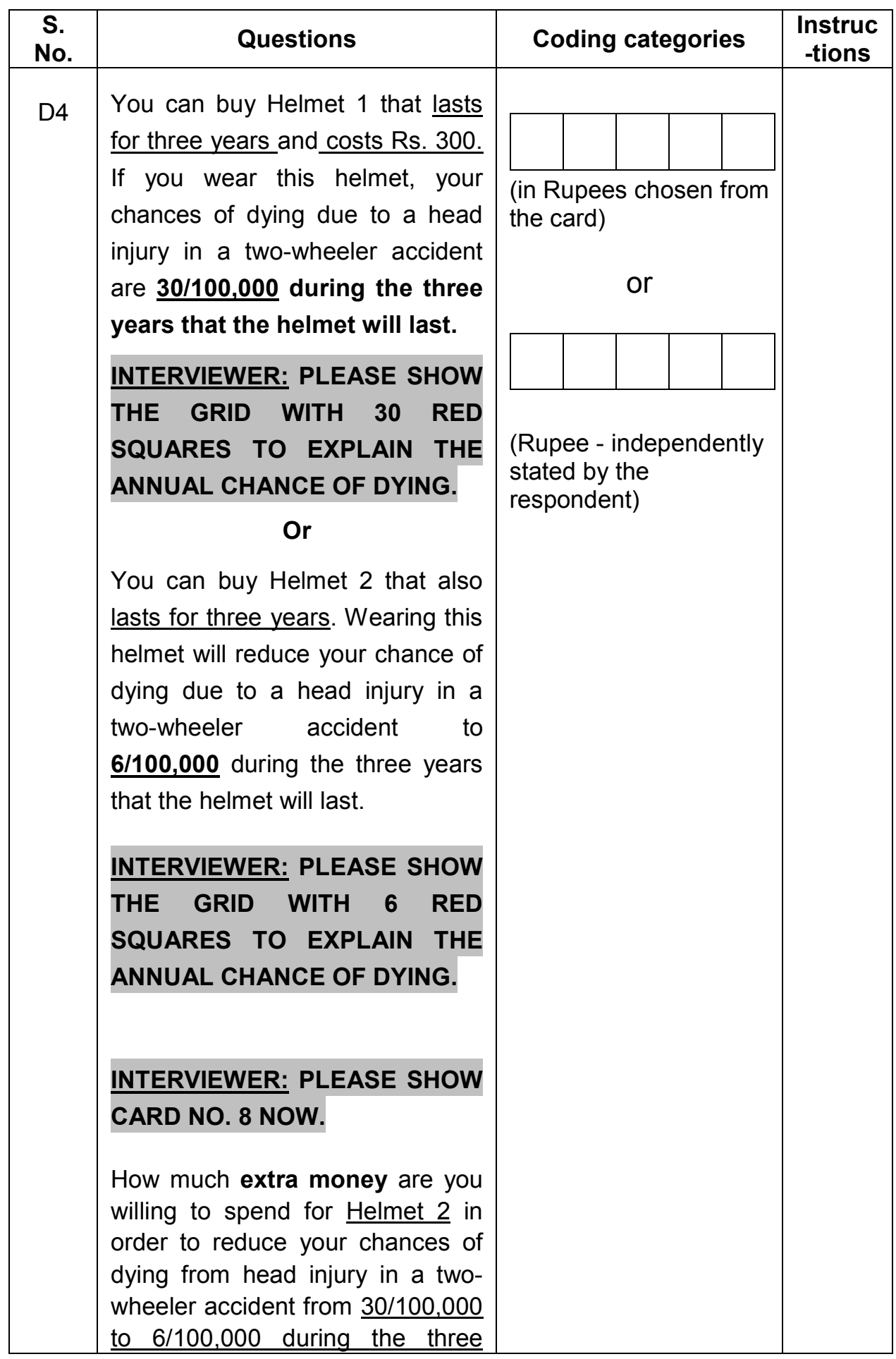




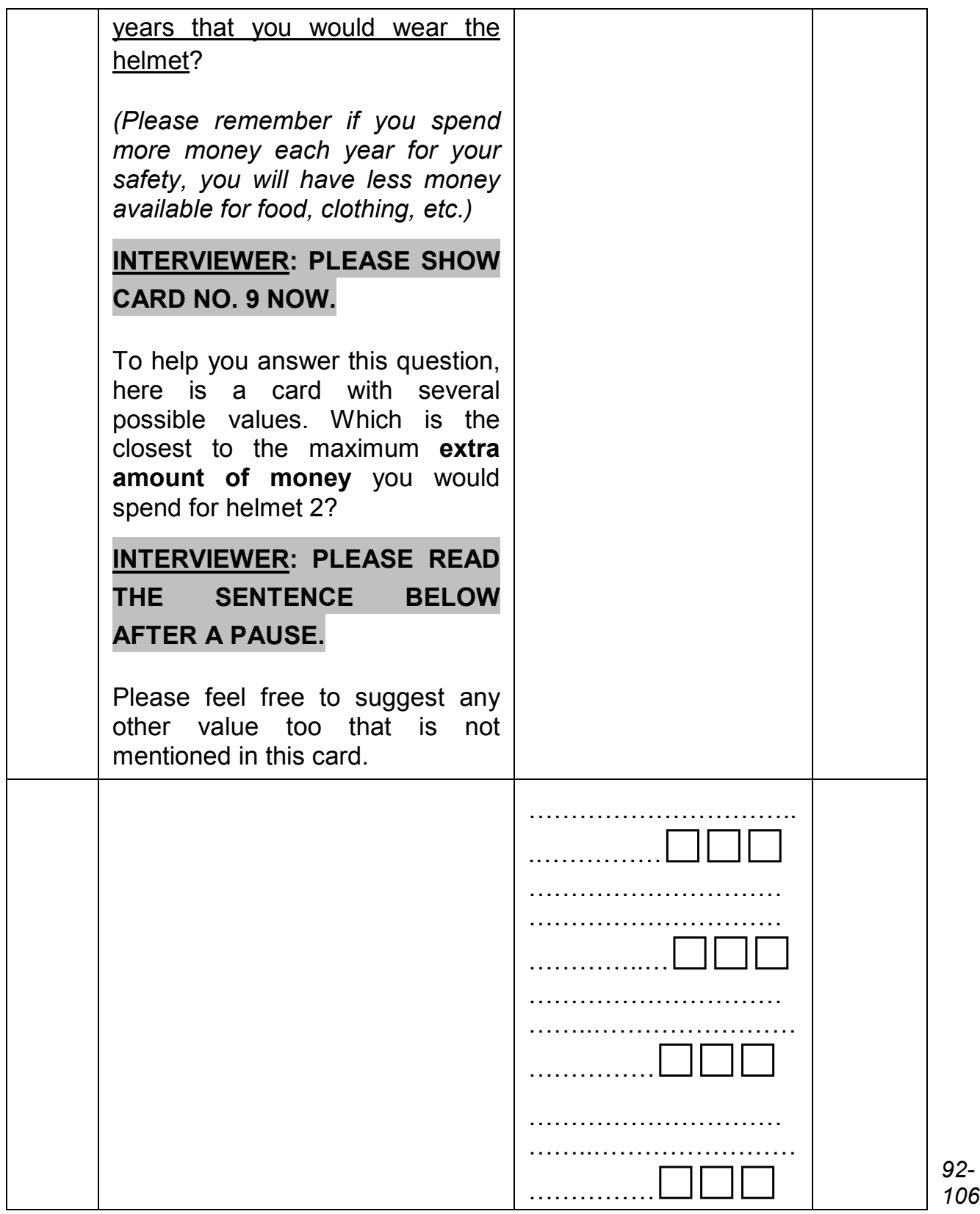

\section{$(\rightarrow$ GO TO PART E)}

\section{Question D5}

D5) Suppose that you drive a two-wheeler to go to work every day. Under the law all drivers of two-wheelers must wear a helmet. Imagine that you are shown two helmets that look exactly identical but differ in price and quality. Please note that both helmets last for three years. Assume that you will be the only person wearing this helmet. 
INTERVIEWERS: IN CASE, IF THE RESPONDENT OBJECTS BY SAYING THAT HE DOES NOT HAVE A HELMET (EVEN IF REQUIRED BY LAW), THEN SAY "WELL, PLEASE IMAGINE THAT YOU HAVE ONE, AND THAT IT NEEDS TO BE REPLACED, OR THAT YOU ARE BUYING ONE FOR THE FIRST TIME."

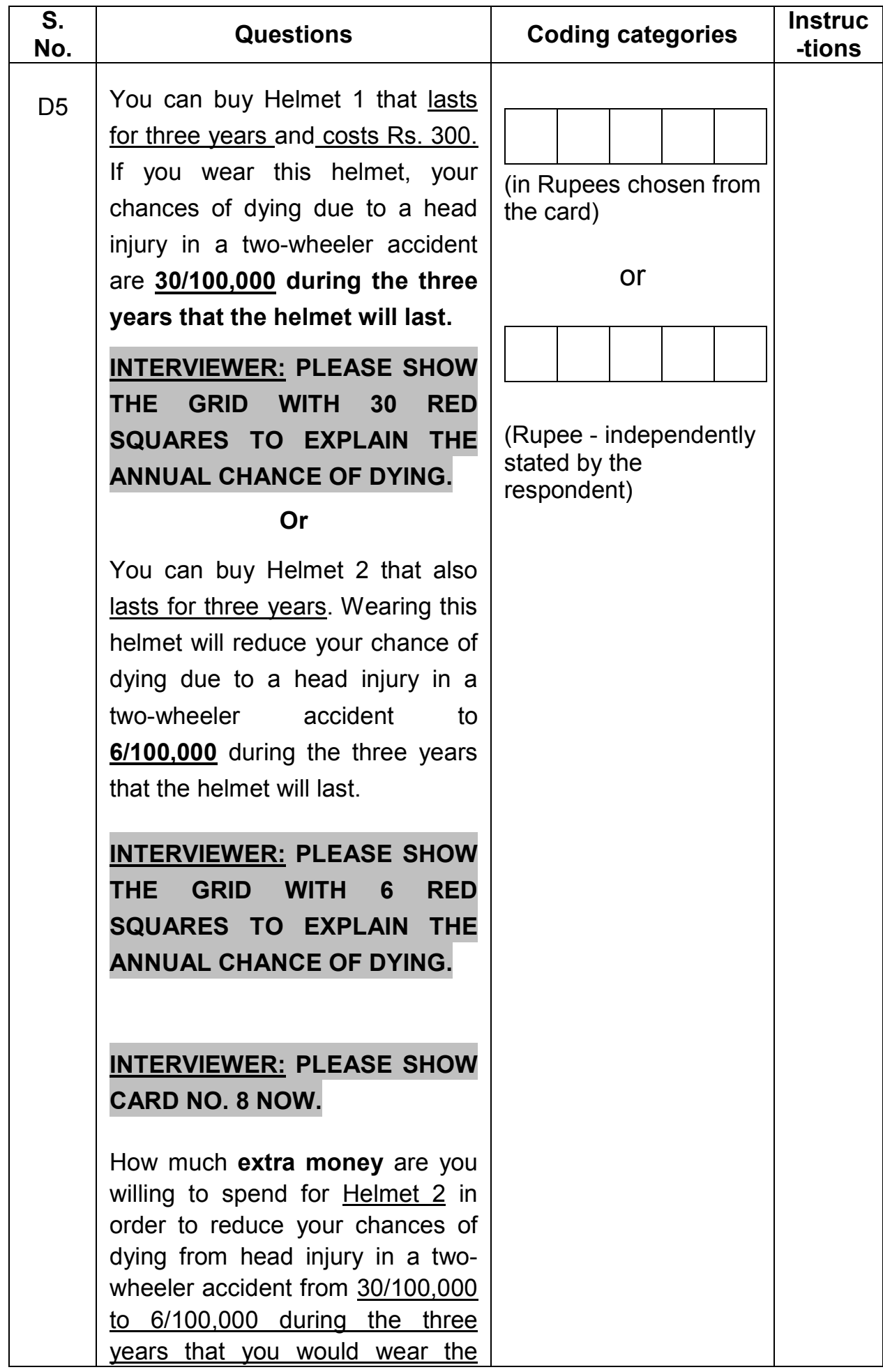




\begin{tabular}{|c|c|}
\hline $\begin{array}{l}\text { helmet? } \\
\text { (Please remember if you spend } \\
\text { more money each year for your } \\
\text { safety, you will have less money } \\
\text { available for food, clothing, etc.) } \\
\text { INTERVIEWER: PLEASE SHOW } \\
\text { CARD NO. } 9 \text { NOW. } \\
\text { To help you answer this question, } \\
\text { here is a card with several } \\
\text { possible values. Which is the } \\
\text { closest to the maximum extra } \\
\text { amount of money you would } \\
\text { spend for helmet } 2 \text { ? } \\
\text { INTERVIEWER: PLEASE READ } \\
\text { THE SENTENCE BELOW } \\
\text { AFTER A PAUSE. } \\
\text { Please feel free to suggest any } \\
\text { Other value too that is not } \\
\text { mentioned in this card. }\end{array}$ & \\
\hline & (1) \\
\hline
\end{tabular}




\section{Section E}

\section{PART E: DEBRIEFING \& OTHER QUESTIONS}

In the previous section we saw that on average, an adult living in Delhi has a chance of dying in a road accident of 21 in 100,000 in a year. This includes pedestrians, drivers and passengers. Pedestrians account for half of those deaths.

\section{INTERVIEWER: PLEASE SHOW CARD NO. E1}

E1) How do you think this compares to your own chance of dying in a road accident? In answering this question please take into account your own modes of travel, whether you are mostly a driver, or a passenger, or a pedestrian, how careful and alert you are and the distance you normally travel.

\begin{tabular}{|l|l|c|c|c|c|}
\hline \multicolumn{2}{|l|}{ Would you say that } & Lower & Same & Higher & I am never a \\
\hline E1a & $\begin{array}{l}\text { Your own chance of } \\
\text { dying in a road accident } \\
\text { is lower, the same, or } \\
\text { higher than that of } \\
\text { average pedestrian? }\end{array}$ & 1 & 2 & 3 & Pedestrian \\
\hline E1b & $\begin{array}{l}\text { Your own chance of } \\
\text { dying in a road accident } \\
\text { is lower, the same, or } \\
\text { higher than that of the } \\
\text { average driver? }\end{array}$ & 1 & 2 & 3 & 4 \\
\hline E1c & $\begin{array}{l}\text { Your own chance of } \\
\text { dying in a road accident } \\
\text { is lower, the same, or } \\
\text { higher than that of the } \\
\text { average passenger in a } \\
\text { motorized vehicle? }\end{array}$ & 1 & 2 & 3 & Passenger \\
\hline
\end{tabular}


E2) How would you rate each of the following policies in reducing your "own" chance of dying in a road accident? Please rate each of them on a scale from 1 to 5 , where-

- 1 means not at all effective in reducing your chance of dying in a road accident,

- 5 means greatly effective in reducing your chance of dying in a road accident.

INTERVIEWER: PLEASE SHOW CARD NO. E2

INTERVIEWER: PLEASE READ OUT THE CATEGORIES AND THEN CIRCLE THE APPROPRIATE RESPONSE. SINGLE CODING ONLY FOR EACH OF THE STATEMENTS

\begin{tabular}{|c|c|c|c|c|c|c|}
\hline & & \multicolumn{5}{|c|}{$\begin{array}{l}\text { Would be effective in reducing your chance } \\
\text { of dying }\end{array}$} \\
\hline & & $\begin{array}{l}\text { Not } \\
\text { at } \\
\text { all }\end{array}$ & $\begin{array}{c}\text { A } \\
\text { little }\end{array}$ & Some & $\begin{array}{l}\text { Quite a } \\
\text { lot }\end{array}$ & Greatly \\
\hline E2a & $\begin{array}{l}\text { Separate lanes for } \\
\text { bicycles and cycle } \\
\text { rickshaws }\end{array}$ & 1 & 2 & 3 & 4 & 5 \\
\hline$E 2 b$ & Broader roads & 1 & 2 & 3 & 4 & 5 \\
\hline E2c & More flyovers & 1 & 2 & 3 & 4 & 5 \\
\hline E2d & More public buses & 1 & 2 & 3 & 4 & 5 \\
\hline E2e & More pedestrian subways & 1 & 2 & 3 & 4 & 5 \\
\hline
\end{tabular}




\section{Section F}

\section{PART F: PERSONAL CHARACTERISTICS}

We are almost finished with the survey. In this section I will ask you a few questions about yourself.

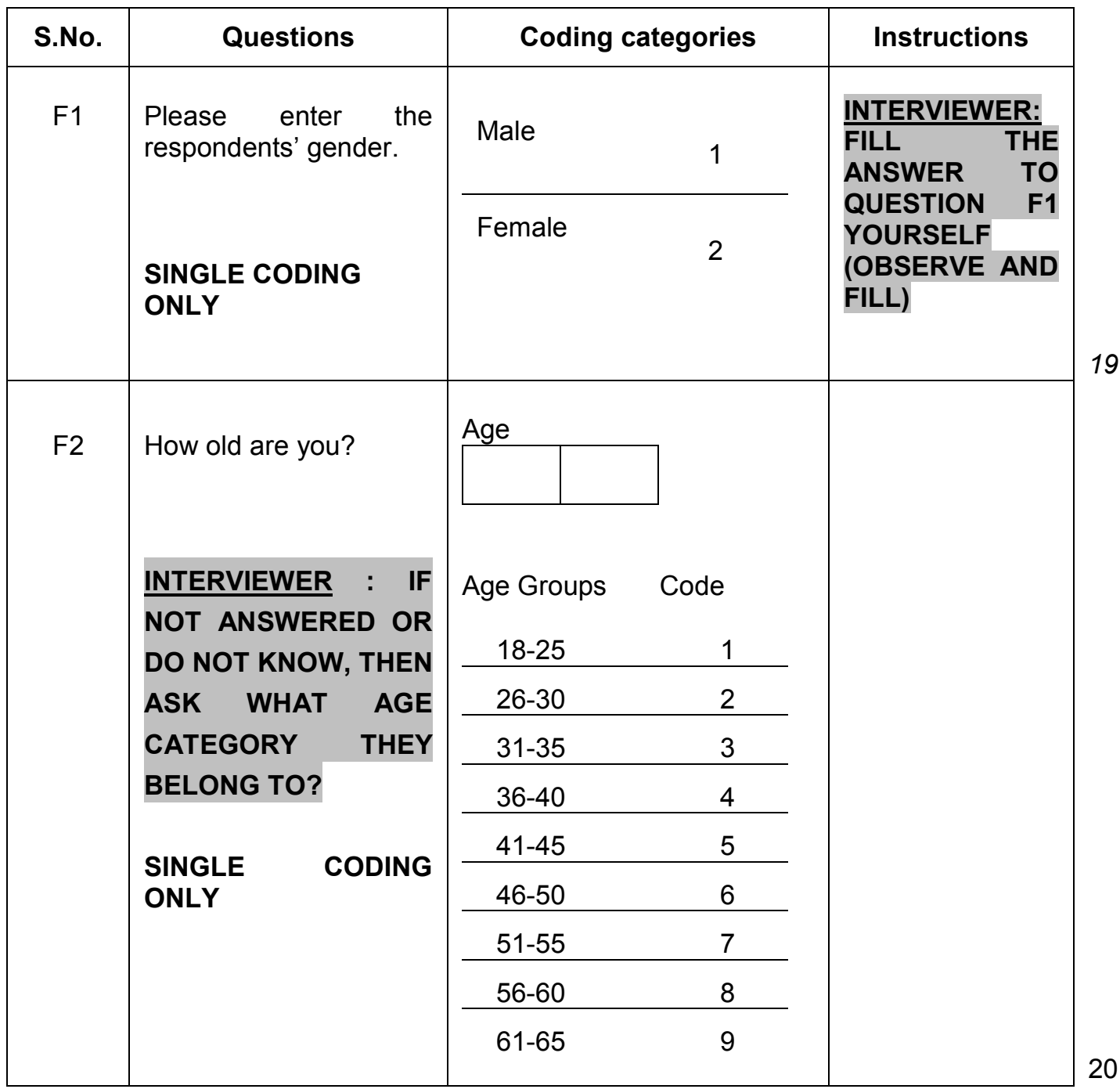




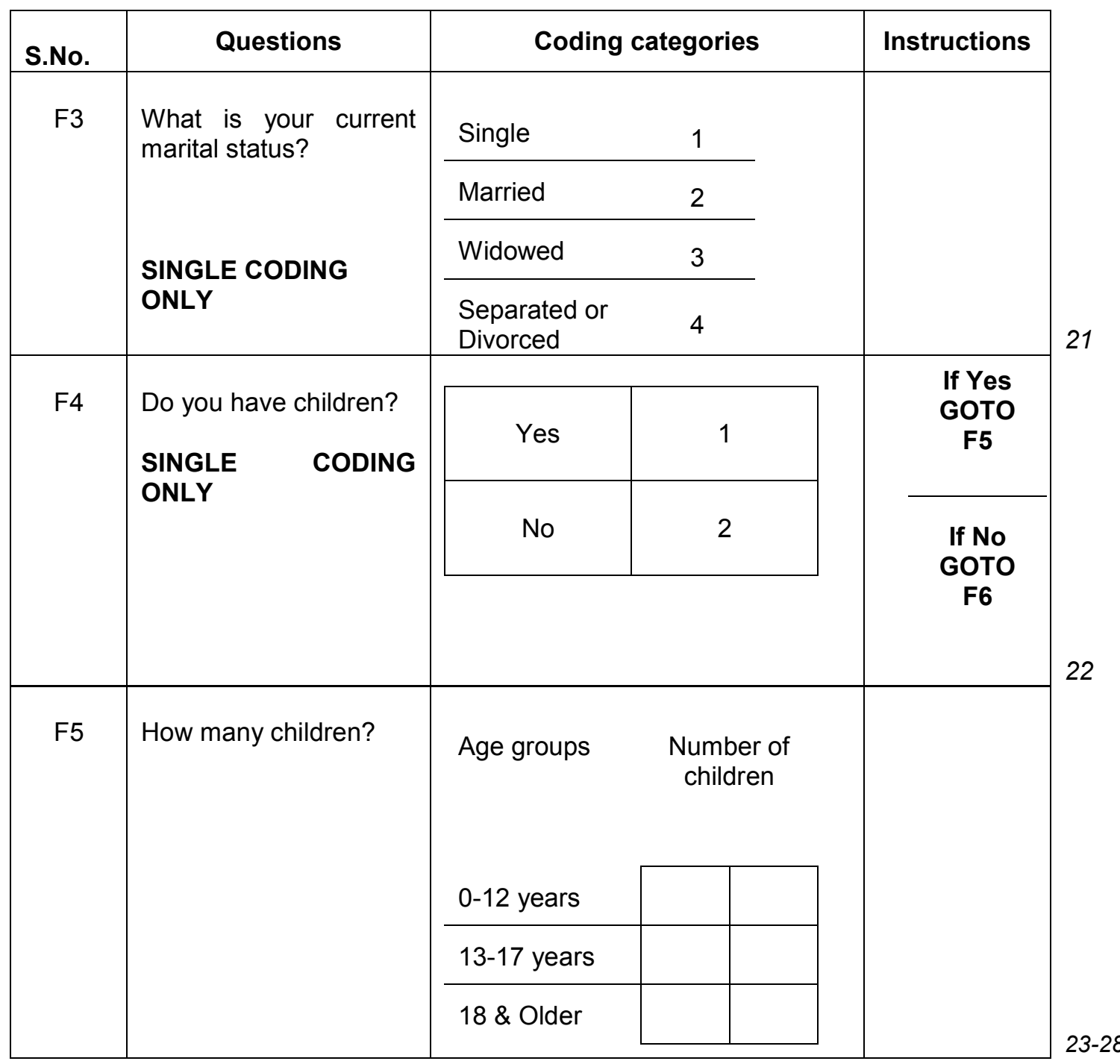

\begin{tabular}{|l|l|l|}
\hline F6 & $\begin{array}{l}\text { How many members } \\
\text { are there in your } \\
\text { household? } \\
\text { (By household - All } \\
\text { those members of your } \\
\text { family who live in the } \\
\text { same house with you } \\
\text { and share meals from } \\
\text { the same kitchen as } \\
\text { you.) }\end{array}$ & members...... \\
\hline
\end{tabular}




\begin{tabular}{|c|c|c|c|c|}
\hline S.No. & Questions & Codi & ategories & Instructions \\
\hline \multirow[t]{7}{*}{ F7 } & \multirow{7}{*}{$\begin{array}{l}\text { How many members in } \\
\text { your household } \\
\text { (including you) are in } \\
\text { the following age- } \\
\text { groups? }\end{array}$} & & $\begin{array}{l}\text { Number of } \\
\text { Members }\end{array}$ & \multirow{7}{*}{$\begin{array}{l}\text { Fill in the } \\
\text { number of } \\
\text { members } \\
\text { across the } \\
\text { various age } \\
\text { groups. } \\
\text { Do the } \\
\text { totaling } \\
\text { also. }\end{array}$} \\
\hline & & $11-15$ years & & \\
\hline & & $16-25$ years & & \\
\hline & & $26-50$ years & & \\
\hline & & $51-60$ years & & \\
\hline & & $61+$ & & \\
\hline & & $\begin{array}{l}\text { Total } \\
\rightarrow\end{array}$ & & \\
\hline
\end{tabular}

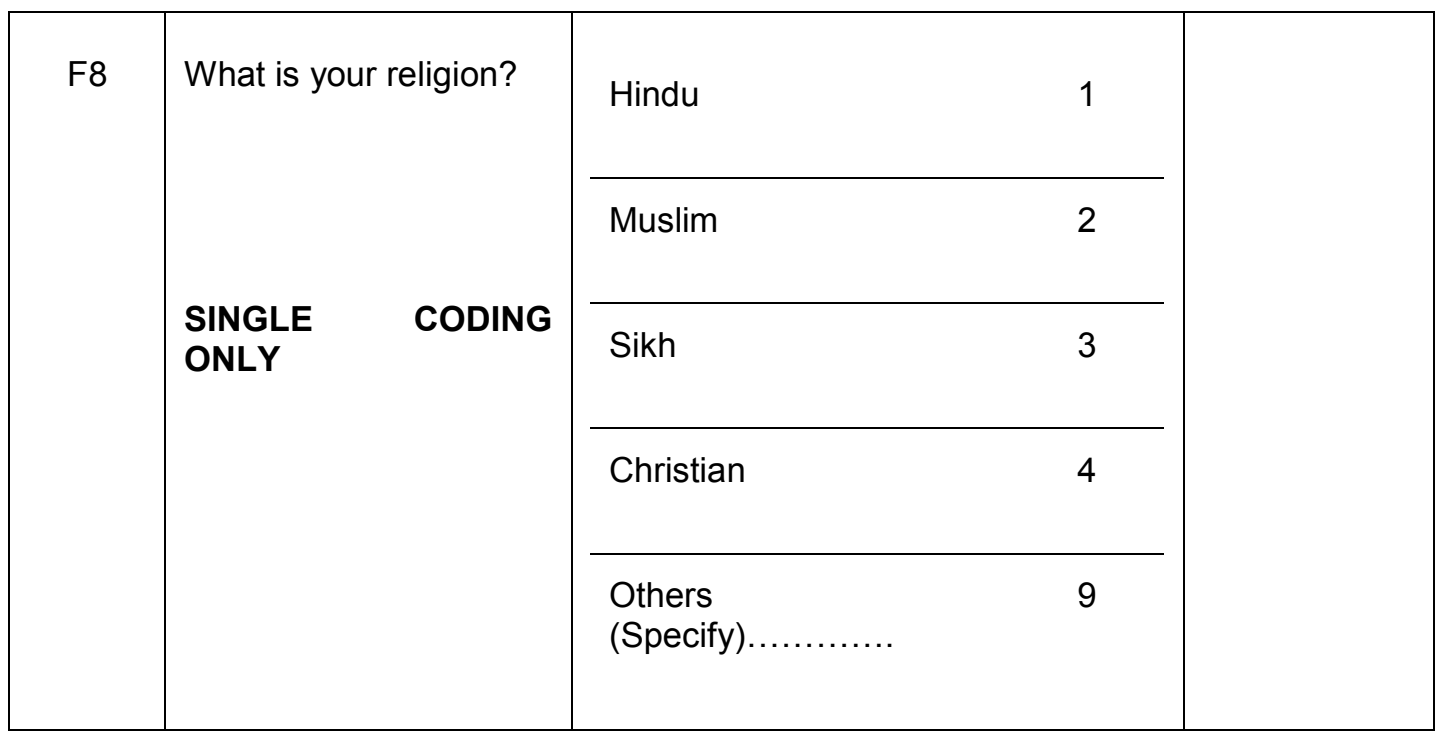

\begin{tabular}{|l|l|l|l|}
\hline S.No. & Questions & Coding categories & Instructions \\
\hline
\end{tabular}




\begin{tabular}{|c|c|c|c|}
\hline \multirow[t]{6}{*}{ F9 } & \multirow{2}{*}{$\begin{array}{l}\text { What is the highest } \\
\text { degree you have } \\
\text { earned/class you } \\
\text { studied (passed)? }\end{array}$} & $\begin{array}{l}\text { Middle school [upto } \\
\text { class 8] }\end{array}$ & 1 \\
\hline & & $\begin{array}{l}\text { Few years of high } \\
\text { school [upto class 11] }\end{array}$ & 2 \\
\hline & & $\begin{array}{l}\text { Higher Secondary [upto } \\
\text { class 12] }\end{array}$ & 3 \\
\hline & & $\begin{array}{l}\text { Vocational school } \\
\text { (Diploma like ITI etc., } \\
\text { hotel management, } \\
\text { typing school, nursing, } \\
\text { etc.) }\end{array}$ & 4 \\
\hline & $\begin{array}{l}\text { SINGLE } \\
\text { ONLY }\end{array}$ & $\begin{array}{l}\text { Bachelors [B.A., B.Sc., } \\
\text { B.E., B.Com., B.Tech, } \\
\text { etc.] }\end{array}$ & 5 \\
\hline & & $\begin{array}{l}\text { Masters or higher [M.A., } \\
\text { M.Sc., M.Com., M.Arch., } \\
\text { Ph.D, MBBS, M.D. etc.] }\end{array}$ & 6 \\
\hline
\end{tabular}

\begin{tabular}{|c|c|c|c|}
\hline \multirow[t]{12}{*}{ F10 } & \multirow{3}{*}{$\begin{array}{l}\text { In what range do your } \\
\text { monthly earnings fall } \\
\text { before taxes? }\end{array}$} & Less than Rs. 2000 & 11 \\
\hline & & Rs. 2000 - Rs. 2999 & 12 \\
\hline & & Rs. 3000- Rs. 4999 & 13 \\
\hline & . & Rs. 5000- Rs. 7999 & 14 \\
\hline & (rlease mictude your & Rs. 8000 -Rs. 9999 & 15 \\
\hline & & Rs. $10000-$ Rs. 14999 & 16 \\
\hline & INTERVIEWER: & Rs. 15000- Rs. 19999 & 17 \\
\hline & PLEASE SHOW CARD & Rs. 20000-Rs. 29999 & 18 \\
\hline & NO. F10 & Rs. 30000-Rs. 39999 & 19 \\
\hline & & Rs. 40000-Rs. 49999 & 20 \\
\hline & & Rs. $50000+$ & 21 \\
\hline & & $\begin{array}{l}\text { Others } \\
\text { (Specify)............ }\end{array}$ & \\
\hline
\end{tabular}




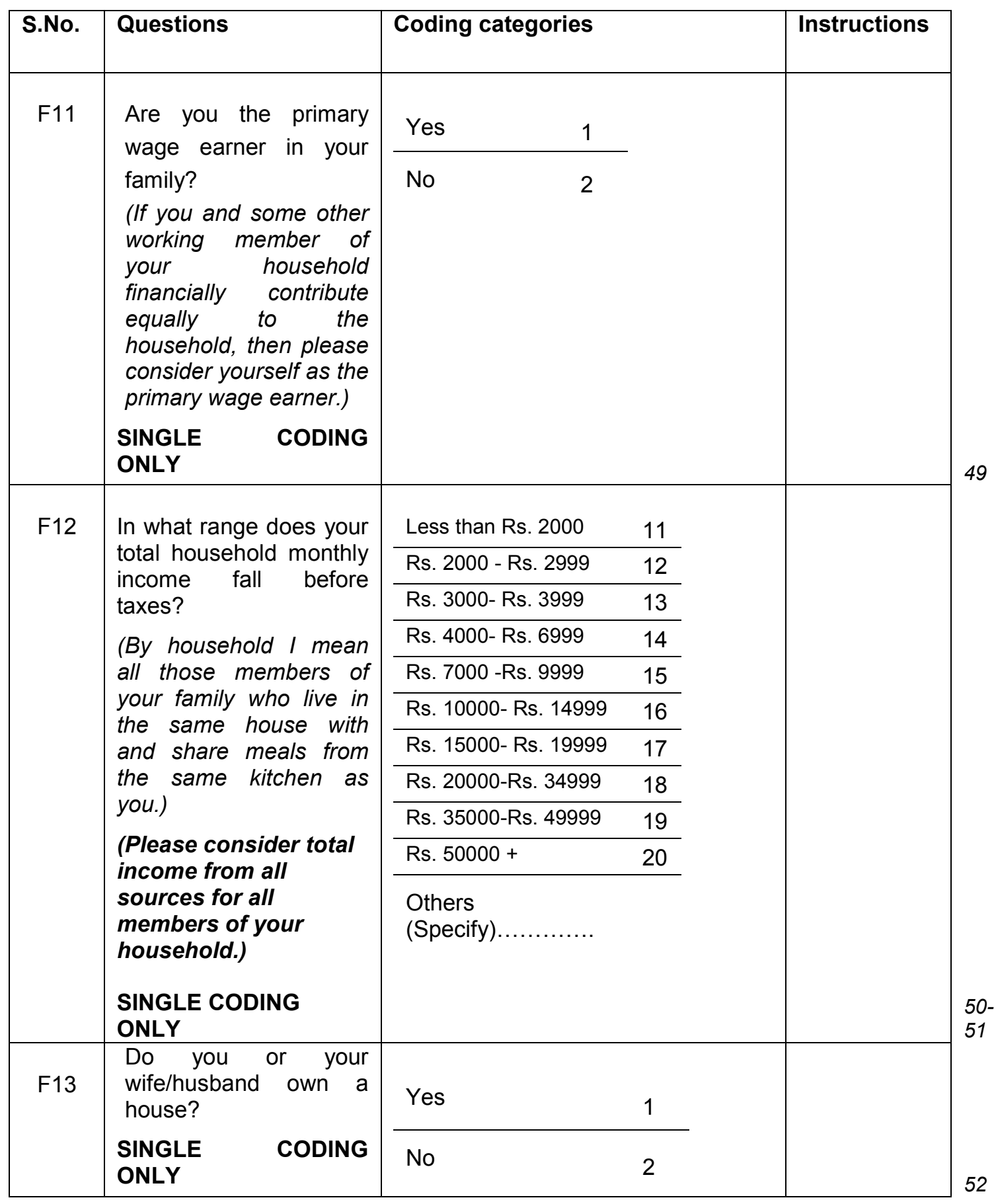




\begin{tabular}{|c|c|c|c|c|}
\hline S.No. & Questions & Coding ca & ries & Instructions \\
\hline \multirow[t]{4}{*}{ F14 } & \multirow{4}{*}{$\begin{array}{l}\text { How much money did you } \\
\text { spend last month in the } \\
\text { following categories? }\end{array}$} & Category & Rs. & \\
\hline & & $\begin{array}{l}\text { Public Bus } \\
\text { Chartered } \\
\text { Bus tickets } \\
\text { Monthly bus } \\
\text { pass/metro } 8 \\
\text { train fare }\end{array}$ & & \\
\hline & & $\begin{array}{l}\text { Taxi \& } \\
\text { autorickshaw } \\
\text { fare }\end{array}$ & & \\
\hline & & $\begin{array}{l}\text { Cycle } \\
\text { Rickshaw } \\
\text { Fare }\end{array}$ & & \\
\hline \multirow[t]{2}{*}{ F15 } & \multirow{2}{*}{$\begin{array}{l}\text { Do you or your household } \\
\text { member own a motor } \\
\text { vehicle? } \\
\text { (By household I mean all } \\
\text { those who live in the same } \\
\text { house with and share } \\
\text { meals from the same } \\
\text { kitchen as you.) } \\
\text { SINGLE coDING ONLY }\end{array}$} & Yes & 1 & \multirow{2}{*}{$\begin{array}{l}\rightarrow \text { GOTO } \\
\text { F16 } \\
\rightarrow \text { GOTO } \\
\text { F17 }\end{array}$} \\
\hline & & No & 2 & \\
\hline
\end{tabular}

S.No.

Please list below the makes and model of the vehicles owned in your household.

\begin{tabular}{|c|c|c|c|c|}
\hline F16 & VEHICLE & BRAND & MODEL & YEAR \\
\hline & Car & & & \\
\hline & Van / Jeep & & & \\
\hline & \multirow{3}{*}{$\begin{array}{l}\text { Scooter / Motor- } \\
\text { bike/ Three } \\
\text { Wheeler }\end{array}$} & & & \\
\hline & & & & \\
\hline & & & & \\
\hline
\end{tabular}




\begin{tabular}{|c|c|c|c|}
\hline S. No. & Questions & Coding categories & Instructions \\
\hline \multirow[t]{6}{*}{ F17 } & \multirow[t]{6}{*}{$\begin{array}{l}\text { Please tell us how } \\
\text { much money did you } \\
\text { spend last month on } \\
\text { the following items } \\
\text { related to the use of } \\
\text { your vehicle? }\end{array}$} & $\begin{array}{l}\text { Category In Rupees } \\
\text { Personal vehicle repair } \\
\& \quad \text { maintenance } \\
\text { (car,/two-wheeler, } \\
\text { bicycle, auto } \\
\text { rickshaw/cycle } \\
\text { rickshaw, etc.,) }\end{array}$ & \\
\hline & & $\begin{array}{l}\text { Petrol/Diesel (personal } \\
\text { vehicle) }\end{array}$ & \\
\hline & & $\begin{array}{l}\text { Vehicle ownership } \\
\text { related costs (loan } \\
\text { payments) }\end{array}$ & \\
\hline & & $\begin{array}{l}\text { Vehicle insurance (per } \\
\text { year) }\end{array}$ & \\
\hline & & Parking & \\
\hline & & Others (Specify) & \\
\hline
\end{tabular}

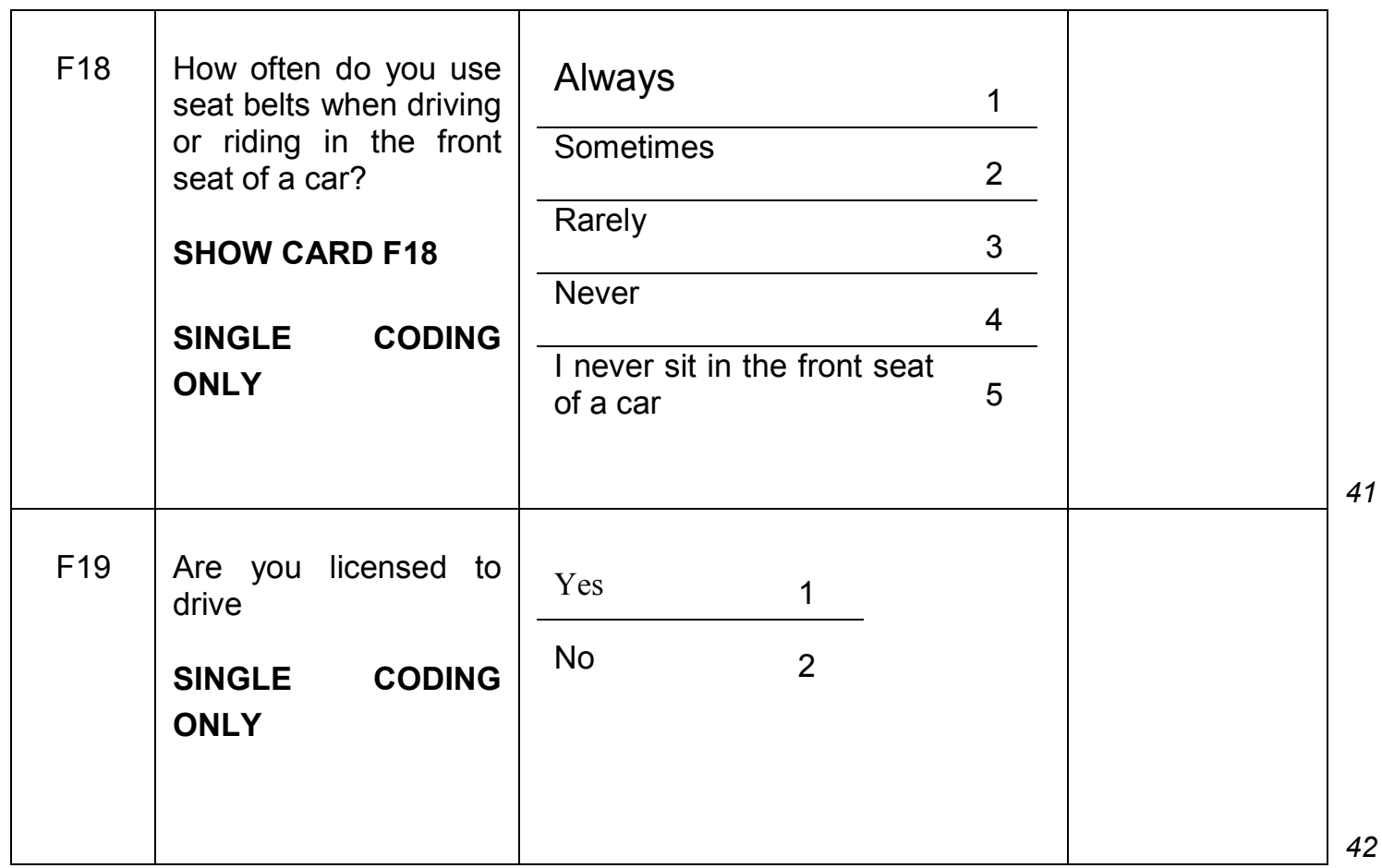




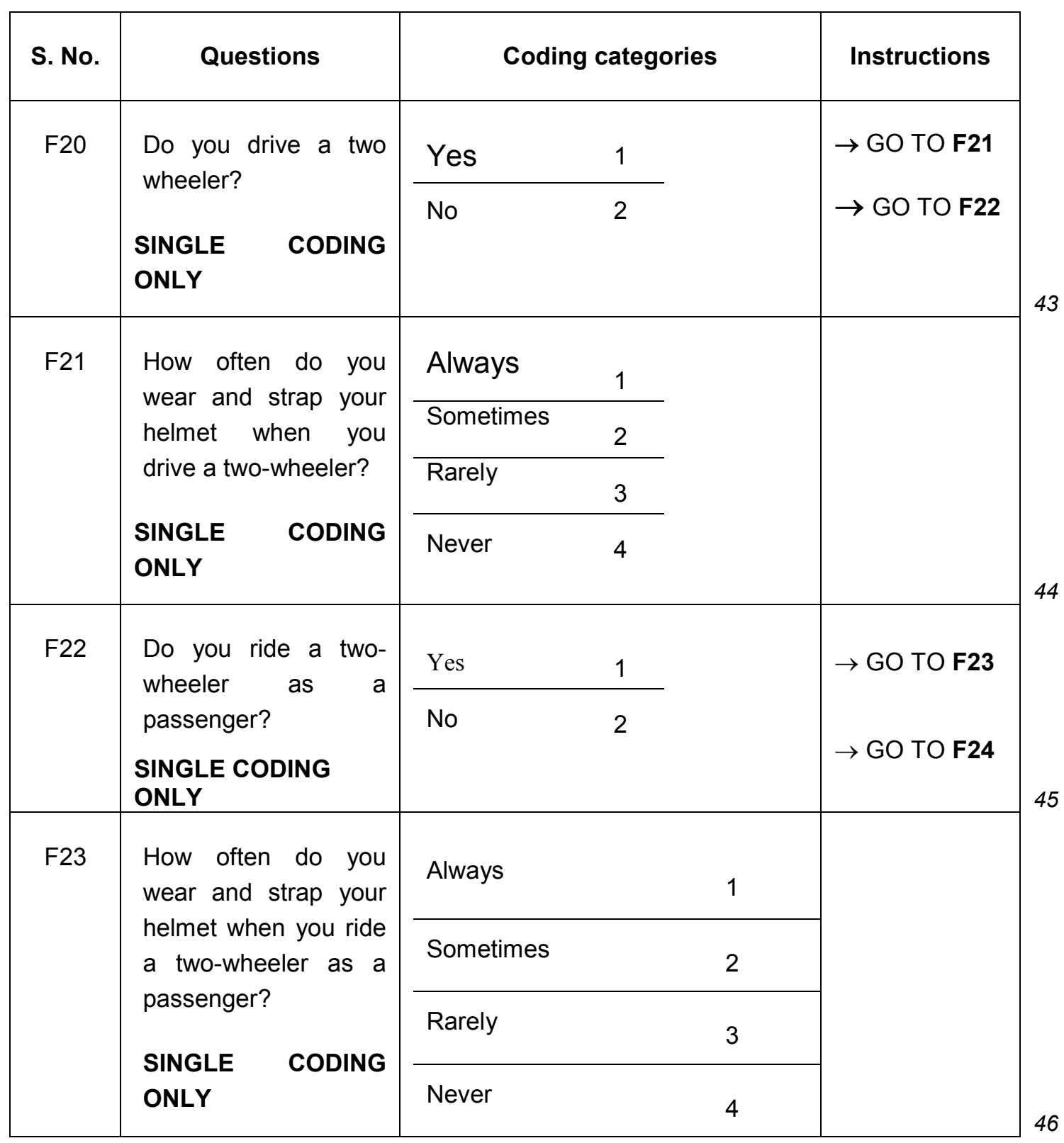

\begin{tabular}{|l|l|ll|l|}
\hline F24 & $\begin{array}{l}\text { Have you ever had a } \\
\text { road accident? }\end{array}$ & Yes & No \\
\cline { 2 - 3 } $\begin{array}{l}\text { (By road accident }- \\
\text { mean a collision with } \\
\text { another vehicle, a } \\
\text { pedestrian, or an } \\
\text { object like a house, a } \\
\text { tree, etc.) } \\
\text { SINGLE CODING } \\
\text { ONLY }\end{array}$ & $\rightarrow$ GOTO F30 \\
\hline
\end{tabular}




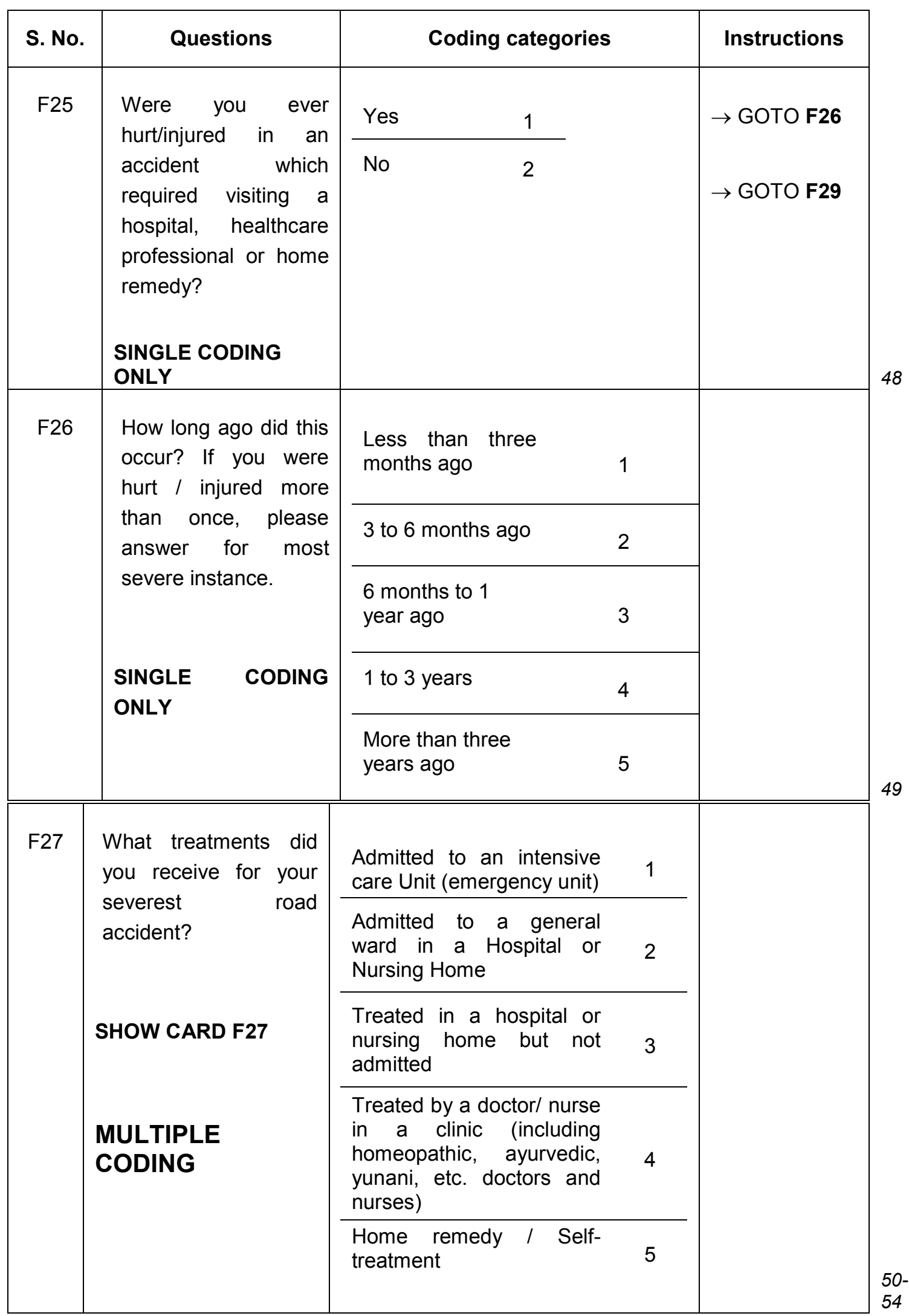




\begin{tabular}{|c|c|c|c|c|}
\hline $\begin{array}{l}\text { S. } \\
\text { No. }\end{array}$ & Questions & Coding categories & & Instructions \\
\hline \multirow[t]{7}{*}{ F28 } & \multirow{4}{*}{$\begin{array}{l}\text { How long did it take for } \\
\text { you to recover from } \\
\text { the injury? } \\
\text { (By recover, I mean } \\
\text { that you were able to } \\
\text { return to normal } \\
\text { activities) }\end{array}$} & $\begin{array}{l}\text { Less than two } \\
\text { weeks }\end{array}$ & & \\
\hline & & $\begin{array}{l}\text { Two weeks to } 1 \\
\text { month }\end{array}$ & & \\
\hline & & 1 to 3 months & & \\
\hline & & 3 to 6 months & & \\
\hline & & $\begin{array}{l}6 \text { months or } \\
\text { more }\end{array}$ & & \\
\hline & SINGLE CODING & $\begin{array}{l}\text { Never } \\
\text { recovered } \\
\text { (permanently } \\
\text { disabled) } \\
\end{array}$ & & \\
\hline & & Still recovering & & \\
\hline \multirow[t]{5}{*}{ F29 } & \multirow{2}{*}{$\begin{array}{l}\text { Which one of the } \\
\text { following categories } \\
\text { describes you the in the } \\
\text { severest accident? }\end{array}$} & \multicolumn{2}{|c|}{$\begin{array}{l}\text { I was a pedestrian who } \\
\text { was hit }\end{array}$} & \\
\hline & & $\begin{array}{l}\text { I was driving a two- } \\
\text { wheeler/ motor vehicle } \\
\text { (bus, autorickshaw, taxi, } \\
\text { car, van, truck, etc.) }\end{array}$ & 2 & \\
\hline & SHOW CARD F29 & $\begin{array}{l}\text { I was a passenger in a } \\
\text { two-wheeler/ motor } \\
\text { vehicle (bus, } \\
\text { autorickshaw, taxi, car, } \\
\text { van, truck, etc.) }\end{array}$ & 3 & \\
\hline & \multirow[b]{2}{*}{$\begin{array}{l}\text { SINGLE } \\
\text { ONLY }\end{array}$} & $\begin{array}{l}\text { I was driving a non- } \\
\text { motorized vehicle (bicycle, } \\
\text { cycle rickshaw, handcart, } \\
\text { cycle cart, etc.) }\end{array}$ & 4 & \\
\hline & & $\begin{array}{l}\text { I was a passenger in a } \\
\text { non-motorized vehicle } \\
\text { (bicycle, cycle-rickshaw, } \\
\text { handcart, cyclecart, etc.) }\end{array}$ & 5 & \\
\hline
\end{tabular}




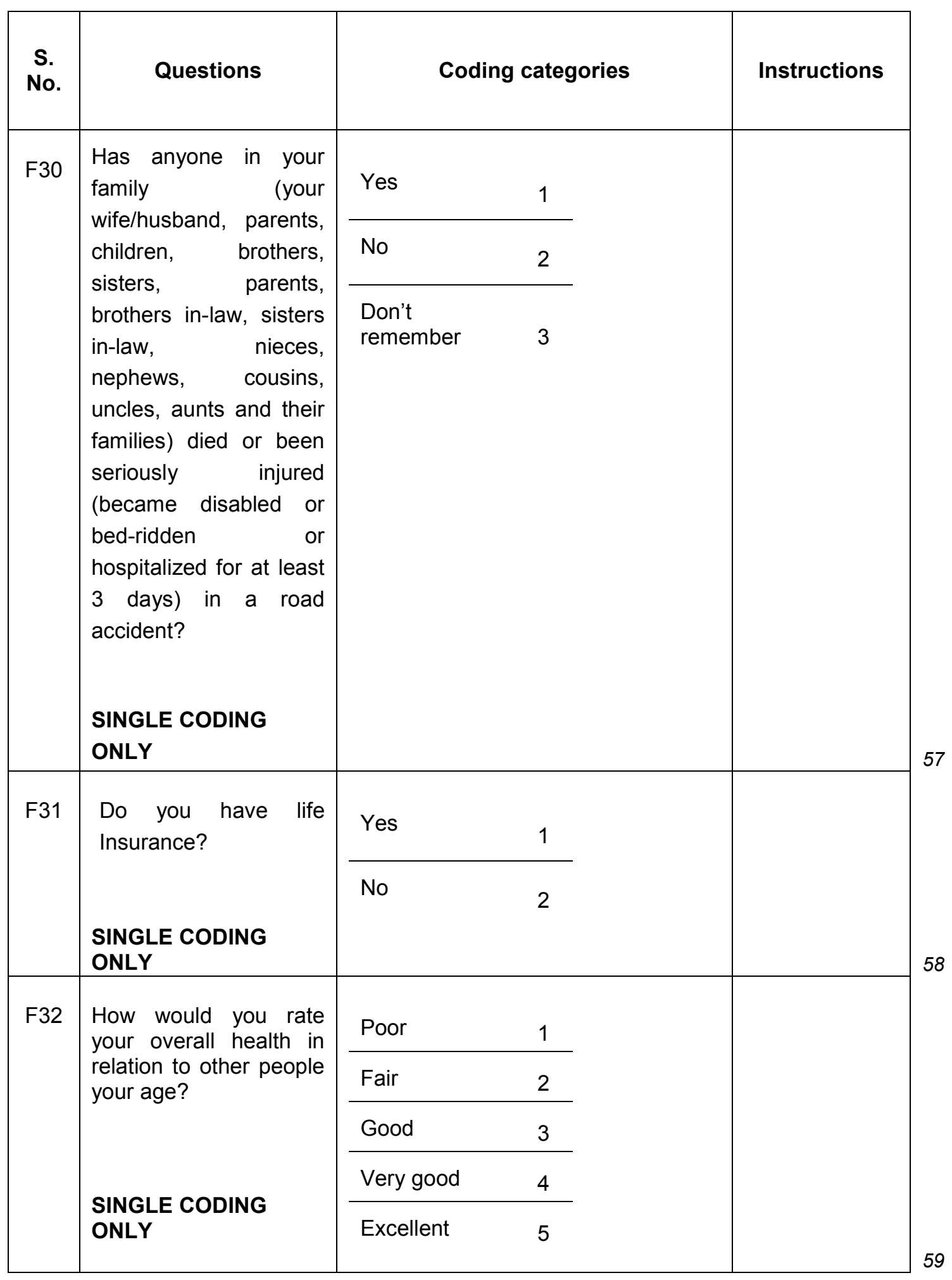




\section{Section G: DEBRIEFING QUESTIONNAIRE FOR THE INTERVIEWER}

\begin{tabular}{|c|c|c|c|}
\hline G1 & $\begin{array}{l}\text { Approximately how long } \\
\text { did this interview last? }\end{array}$ & Hours & \\
\hline \multirow[t]{3}{*}{ G2 } & \multirow{2}{*}{$\begin{array}{l}\text { How easily was the } \\
\text { respondent able to } \\
\text { answer the questions in } \\
\text { the probability tutorial } \\
\text { section? }\end{array}$} & \multicolumn{2}{|l|}{ Easily } \\
\hline & & $\begin{array}{l}\text { Not Easily. } \\
\text { (Materials had to be } \\
\text { explained again } \\
\text { before the } \\
\text { respondent was able } \\
\text { to answer the } \\
\text { questions) }\end{array}$ & 2 \\
\hline & SINGLE CODING ONLY & $\begin{array}{l}\text { The respondent was } \\
\text { not able to answer } \\
\text { the questions }\end{array}$ & 3 \\
\hline
\end{tabular}

G3. Do you feel that the respondent was confused with questions in any of the sections of the Questionnaire?

\section{SINGLE CODING for each of the statements}

\begin{tabular}{|c|c|c|c|c|}
\hline \multicolumn{2}{|r|}{ Particulars } & $\begin{array}{l}\text { Respondent } \\
\text { understood the } \\
\text { questions and } \\
\text { the Material }\end{array}$ & $\begin{array}{c}\text { Respondent } \\
\text { was } \\
\text { somewhat } \\
\text { confused or } \\
\text { unclear }\end{array}$ & $\begin{array}{l}\text { Respondent } \\
\text { was very } \\
\text { confused or } \\
\text { unclear }\end{array}$ \\
\hline 1 & $\begin{array}{l}\text { Section A: Travel } \\
\text { Pattern \& Occupation }\end{array}$ & 1 & 2 & 3 \\
\hline 2 & $\begin{array}{l}\text { Section B: Probability } \\
\text { Tutorial }\end{array}$ & 1 & 2 & 3 \\
\hline 3 & $\begin{array}{l}\text { Section C: } \quad \text { Road } \\
\text { Accidents }\end{array}$ & 1 & 2 & 3 \\
\hline 4 & $\begin{array}{l}\text { Section D: Behavioral } \\
\text { Questions }\end{array}$ & 1 & 2 & 3 \\
\hline 5 & Section E: Debriefing & 1 & 2 & 3 \\
\hline 6 & $\begin{array}{l}\text { Section F: Personal } \\
\text { Characteristics }\end{array}$ & 1 & 2 & 3 \\
\hline
\end{tabular}


G4. Was the respondent...

\section{SINGLE CODING for each of the statements}

\begin{tabular}{|c|l|c|c|}
\hline & & Yes & No \\
\hline A & Interested in the survey materials and questions? & 1 & 2 \\
\hline B & Annoyed or bored with the length of the survey? & 1 & 2 \\
\hline C & Eager to please the INTERVIEWER? & 1 & 2 \\
7
\end{tabular}

G5) Additional Observations/ Comments:

TRANSLATIONS
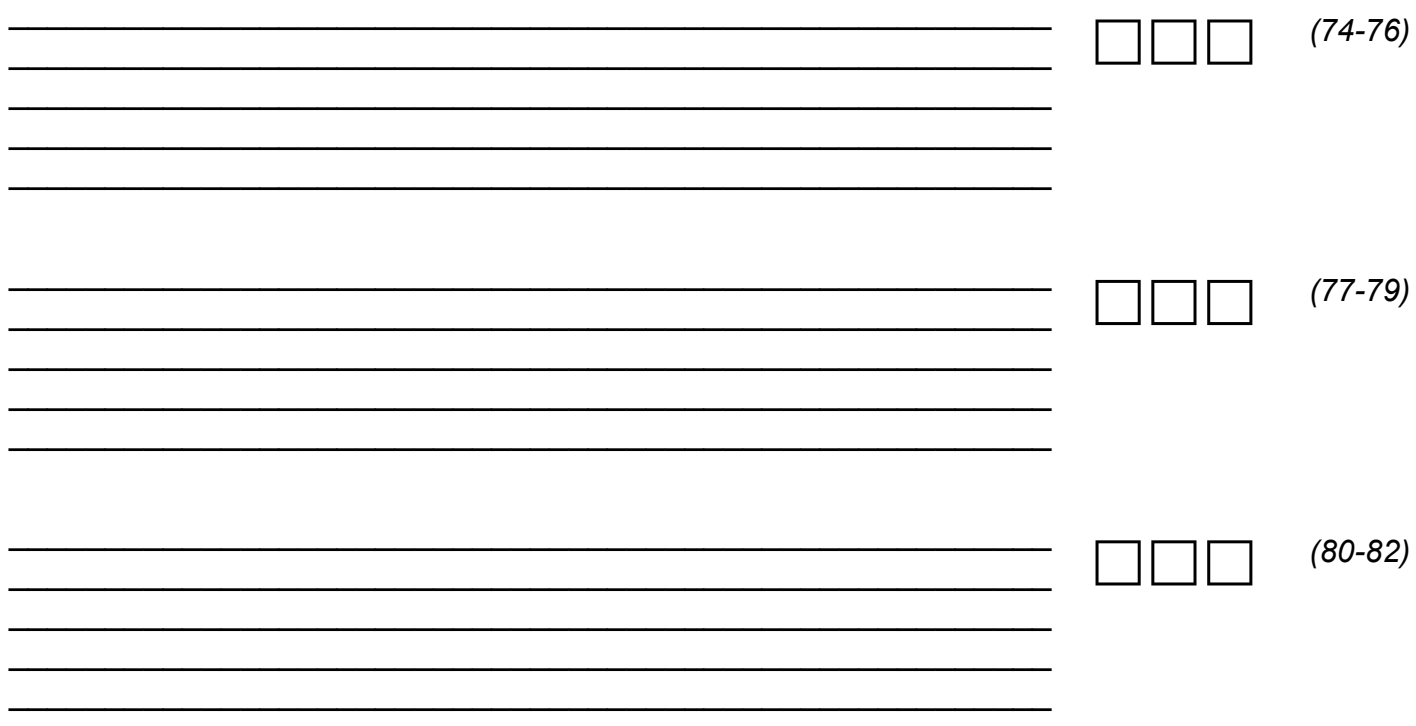

Thank you 


\section{REFERENCES}

Adamowicz, W., P. Boxall, M. Williams and J. Louviere. (1998), "Stated Preference Approaches to Measuring Passive Use Values: Choice Experiments versus Contingent Evaluation," American Journal of Agricultural Economics, 80(1): 64-75.

ADB (1996), "Economic Evaluation of Environmental Impacts: A Workbook," Office of the Environment and Social Development, Asian Development Bank. Manila, Philippines.

Alberini, Anna, Alistair Hunt and Anil Markandya (2006), "Willingness to Pay to Reduce Mortality Risks: Evidence from a Three-Country Contingent Valuation Study," Environmental and Resource Economics, 33(2): 251-264.

Alberini, Anna (2005), "What Is a Life Worth? Robustness of VSL Values from Contingent Valuation Surveys," Risk Analysis, 25 (4): 783-800.

Alberini, Anna and Aline Chiabai (2005), "Urban Environmental Health and Sensitive Populations: How Much are the Italians Willing to Pay to Reduce Their Risks?," Working Papers 2005.105, Fondazione Eni Enrico Mattei.

Alberini, Anna (2004), "Willingness to Pay for Mortality Risk Reductions: A Re-examination of the Literature," Final report to the US Environmental Protection Agency under Cooperative Agreement 015-29528, College Park, July.

Alberini, Anna, Maureen Cropper, Alan Krupnick and Natalie Simon (2004), "Does the Value of a Statistical Life Vary with Age and Health Status? Evidence from the U.S. \& Canada," Journal of Environmental Economics and Management, July 2004.

Alberini, Anna and Alan Krupnick (2000), "Cost-of-Illness and WTP Estimates of the Benefits of Improved Air Quality: Evidence from Taiwan," Land Economics, 76(1).

Alberini, Anna, Maureen L. Cropper, Nathalie B. Simon, Seema Arora (1999), "Valuing Mortality Reductions in India: A Study of Compensating-Wage Differentials," The World Bank, Policy Research Working Paper Series: 2078

Alberini, Anna, Maureen Cropper, Tsu-Tan Fu, Alan Krupnick, Jin-Tan Liu, Daigee Shaw and Winston Harrington (1997), "Valuing Health Effects of Air Pollution in Developing Countries: The Case of Taiwan," Journal of Environmental Economics and Management, 34, 107-126.

Andersson, H. (2005), "The Value of Safety as Revealed in the Swedish Car Market: An Application of the Hedonic Pricing Approach," Journal of Risk and Uncertainty, 30 (3): 211-239.

Arrow, K., R. Solow, P. R. Portney, E. E. Leamer, R. Radner, and H. Schuman. (1993), "Report of the NOAA Panel on Contingent Valuation," Federal Register, 58(10): 4601-4614.

Ashenfelter, Orley and Michael Greenstone (2004), "Using Mandated Speed limits to measure the Value of a Statistical Life," Journal of Political Economy, 112(1, Pt. 2): 226-267.

Atkinson, Scott E. and Robert Halvorsen (1990), "The Valuation of Risks to Life: Evidence from the Market for Automobiles," Review of Economics and Statistics, 72 (1): 133-136.

Ball, D.J., D.P. Ives, I.G. Wilson and M. Postle (1997), "The Optimisation of Consumer Safety," Department of Trade and Industry, Consumer Safety Unit, UK. CSU 4773/96/1.

Barton, D. N. (1999), "The Transferability of Benefit Transfer: An Experiment in Varying the Context of Willingness to Pay for Water Quality Improvements," Discussion Paper No. 10/99, Department of Economics and Social Sciences, Agricultural University of Norway. 
Bateman, Ian, and Roy Brouwer (2005), "Consistency and Construction in Stated WTP for Health Risk Reductions: A novel Scope-Sensitivity Test," CSERGE Working Paper, EDM 05-05, University of East Anglia.

Bateman, Ian, Richard Carson, Brett Day, Michael Hanemann, Nick Hanley, Tannis Hett, Michael Jones-Lee, Graham Loomes, Susana Mourato, Ece Ozdemiroglu, David W. Pearce, Robert Sugden, John Swanson (2002), Economic Valuation with Stated Preference Technique: A Manual, Edward Elgar.

Bateman, I.J., N. Nishikawa and R. Brouwer (1999), 'Benefit Transfer in Theory and Practice: A Review," Paper presented at recent developments in Environmental valuation. Forestry Commission/ Civil Service, Barony Castle, Scotland, May.

Beattie, I., Covey, I., Dolan, P., Hopkins, L., Jones-Lee, M., Loomes, G., Pidgeon, N., Robinson, A. and Spencer, A. (1998), "On the Contingent Valuation of Safety and the Safety of Contingent Valuation: Part 1 - Caveat Investigator," Journal of Risk and Uncertainty, 17: 5-25.

Bergland, O., K. Magnussen and S. Navrud (1995), "Benefit Transfer: Testing for Accuracy and Reliability," Discussion Paper, \#D-03/1995, Department of Economics and Social Sciences, Agricultural University of Norway.

Bergstrom, John C. (1996), "Current Status of Benefits transfer in the US: A Review," Faculty Series 96-09, University of Georgia, Department of Agricultural and Applied Economics.

Bergstrom, Ted (1982), "When is a Man's life Worth More than his Human Capital?," University of California at Santa Barbara, Economics Working Paper Series 1160, Department of Economics, UC Santa Barbara.

Black, D. and T. Kniesner (2003), "On the Measurement of Job Risk in Hedonic Wage Models," Journal of Risk and Uncertainty, 27(3): 205-220.

Blomquist, Glenn C. (2004), "Self Protection and Averting Behavior, Values of Statistical Lives, and Benefit Cost Analysis of Environmental Policy," Review of Economics of the Household, 2(1): 89-110.

Blomquist, Glenn C., Ted R. Miller, and David T. Levy (1996), "Values of Risk Reduction Implied by Motorist Use of Protection Equipment: New Evidence from Different Populations," Journal of Transport Economics and Policy, 30(1): 55-66.

Blomquist, Glenn C. (1991), "Motorist Use of Safety Equipment: Expected Benefits or Risk Incompetence?" Journal of Risk and Uncertainty 4(2): 135-152.

Blomquist, Glenn (1979). "Value of Life Saving: Implications of Consumption Activity," Journal of Political Economy, 87(3): 540-558.

Blomqvist, Å. (2002), "Defining the Value of a Statistical Life: A Comment," Journal of Health Economics, 21(1): 169-175.

Bloom, David E. and Jaypee Sevilla (2004), "Willingness to Pay for Environmental Quality: Testable Empirical Implications of the Growth and Environment Literature: Comment," Contributions to Economic Analysis and Policy: 3(1): Article 7.

Boyle, K.J. (2003), “Contingent Valuation in Practice," in A Primer on Non-Market Valuation, edited by P.A. Champ, K.J. Boyle, and T.C. Brown. Boston: Kluwer Academic Publishers.

Boyle, K.J., T.P. Holmes, M.F. Teisl and B. Roe (2001), "A Comparison of Conjoint Analysis Response Formats," American Journal of Agricultural Economics, 83(2): 441-454. 
Boyle, K.J., D. McCollum, W. Desvousges, R. Dunford and S. Hudson (1996), "Valuing Public Goods: Discrete Versus Continuous Contingent Valuation responses, Land Economics, 72: 381396.

Brouwer, Roy and Ian J. Bateman (2005), "Benefits Transfer of Willingness to Pay Estimates and Functions for Health-Risk Reductions: A Cross-Country Study," Journal of Health Economics, 24(3): 591-611.

Brouwer, R. and A. Spaninks (1999), "The Validity of Environmental Benefit Transfer: Further Empirical Testing," Environmental and Resource Economics, 14: 95-117.

Brox, James A., Ramesh C. Kumar and Kenneth R. Stollery (2003), "Estimating Willingness to Pay for Improved Water Quality in the Presence of Item Nonresponse Bias," American Journal of Agricultural Economics, 85(2): 414-428.

Bussolo, Maurizio and David O'Connor (2001), "Clearing the Air in India: The Economics of Climate Policy with Ancilliary Benefits," Development Centre Working Paper 182, CD/DOC (2001) 14, OECD.

Cameron, T. A., G. L. Poe, R. G. Ethier and W. D. Schulze (2002), "Alternative non-market value-elicitation methods: Are the underlying preferences the same?" Journal of Environmental Economics and Management, 44 (3): 391-425.

Cameron, T. A. and J. Quiggin (1994), "Estimation Using Contingent Valuation Data from a Dichotomous Choice with Follow-up Questionnaire," Journal of Environmental Economics and Management, 27 (3): 218-234.

Cameron, T. A. and D. D. Huppert (1989), "OLS Versus ML Estimation of Non-Market Resource Values with Payment Card Interval Data," Journal of Environmental Economics and Management, 17 (3): 230-246.

Carlin, Paul S. and Robert Sandy. (1991). "Estimating the Value of a Young Child's Life," Southern Economic Journal, 58: 186-202.

Carlsson, Fredrik, Olof Johansson-Stenman and Peter Martinsson (2004), "Is Transport Safety More Valuable than Air?," Journal of Risk and Uncertainty, 28(2): 147-163.

Carson, Richard T. and Robert Cameron Mitchell (2006), "Public Preferences Toward Environmental Risks The Case of Trihalomethanes," in Anna Alberini, David Bjornstad and Jim Kahn, eds., Handbook of Contingent Valuation, Brookfield, VT: Edward Elgar.

Carson, Richard T., Nicholas E. Flores and Norman F. Meade (2001), "Contingent Valuation: Controversies and Evidence," Environmental and Resource Economics 19: 173-210.

Carthy, T., S. Chilton, I. Covey, L. Hopkins, M. Jones-Lee, G. Loomes, N. Pidgeon, N. and A. Spencer (1999), "On the Contingent Valuation of Safety and the Safety of Contingent Valuation: Part 2- The CV /SG 'Chained' Approach," Journal of Risk and Uncertainty, 17: 187-213.

Chand, Mahesh (2001), "The Cost of Road Accidents in India," Conference Report, 1st Safe Community-Conference on Cost Calculation and Cost-effectiveness in Injury Prevention and Safety Promotion, Denmark, 2001.

Chilton, Susan, Judith Covey, Michael W. Jones-Lee, Graham Loomes and H. Metcalf (2004), "Valuation of Health Benefits Associated with Reductions in Air Pollution," Final Report, May 2004. Department for Environment Food and Rural Affairs, UK.

Chilton, Susan, Judith Covey, Lorraine Hopkins, Michael W. Jones-Lee, Graham Loomes, Nick F. Pidgeon and Anne Spencer (2002), "Public Perceptions of Risk and Preference Based Values of Safety," Journal of Risk and Uncertainty, 25(3): 211-232. 
Ciriacy-Wantrup, S.V. (1947), "Capital Returns from Soil Conversation Practices," Journal of Farm Economics, 29: 1181-1196.

Corso, Phaedra S., James K. Hammit and John D. Graham (2001), "Valuing Mortality-Risk Reduction: Using Visual Aids to Improve the Validity of Contingent Valuation," Journal of Risk and Uncertainty, 23 (2): 165-184.

Cropper, Maureen and Wallace Oates (1992), "Environmental Economics: A Survey," Journal of Economic Literature, 30: 675-740.

Cropper, M. L. and F. G. Sussman (1990), "Valuing Future Risks to Life," Journal of Environmental Economics and Management, 19(2): 160-174.

Cummings, Ronald G. and Laura O. Taylor. (1999) "Unbiased Value Estimates for Environmental Goods: A Cheap Talk Design for the Contingent Valuation Method," American Economic Review, 89: 649-665.

de Blaeij, Arianne, R.J.G.M. Florax, P. Rietveld and E. Verhoef (2003), "The Value of a Statistical Life in Road Safety: A Meta-Analysis", Accident Analysis and Prevention, 35(6): 97386.

deShazo, J.R. (2002), "Designing Transactions without Framing Effects in Iterative Question Formats," Journal of Environmental Economics and Management, 44(1): 123-143.

Delhi Traffic Police, http://www.delhitrafficpolice.nic.in/road-accidents-and-prosecution.htm.

Desaigues, B. and Ari Rabl (1995), "Reference Values For Human Life: An Econometric Analysis of a Contingent Valuation in France". in Natalie G. Schwab Christie and Nils C. Soguel (eds.) Contingent Valuation, Transport Safety and the Value of Life, Kluwer Academic Publishers.

Dickie, Mark and Shelby Gerking. (1996), "Formation of Risk Beliefs, Joint Production and Willingness to Pay to Avoid Skin Cancer," Review of Economics and Statistics, 78(3): 451-464.

Dillingham, A.E. and R.S. Smith. (1984), "Union Effects on the Valuation of Fatal Risk," in Dennis, B.O. (ed.), Proceedings of the Industrial Relations Research Association 36th Annual Meeting, San Francisco, CA, December 28-30, 1983, Madison, WI: Industrial Relations Research Association, pp. 270-277.

Dionne, Georges and Lanoie, Paul (2004), "How to Make a Public Choice About the Value of a Statistical Life: The Case of Road Safety," Journal of Transport Economics and Policy, 38(2): 247-274.

Donaldson, C. (1999), "Developing the Method of 'Willingness to Pay' for Assessment of Community Preferences for Health Care," Final Report to Biomed 2 Programme (PL950832) of the European Commission, Health Economics Research Unit, University of Aberdeen and Departments of Economics and Community Health Sciences, University of Calgary.

Dorman, P. and P. Hagstrom (1998), "Wage Compensation for Dangerous Work Revisited," Industrial and Labor Relations Review, 52(1): 116-135.

Dreyfus, Mark Kallison and W. Kip Viscusi. (1995). "Rates of Time Preference and Consumer Valuation of Automobile Safety and Fuel Efficiency," Journal of Law and Economics, 38: 79105.

Drèze, Jacques (1962), "L'utilité Sociale D'une vie Humaine," Revue Française de Recherche Opérationnelle, 6: 93-118. 
Dubourg, W.R., M.W. Jones-Lee, and Graham Loomes (1997). "Imprecise Preferences and Survey Design in Contingent Valuation," Economica, 64: 681-702.

Dubourg, W.R., M. W. Jones-Lee and Graham Loomes (1994), "Imprecise Preferences and the WTP- WTA Disparity," Journal of Risk and Uncertainty, 9: 115-33.

Eeckhoudt, L. R. and J. K. Hammitt. (2001), "Background Risks and Value of a Statistical Life," Journal of Risk and Uncertainty, 23; 261-279.

Elvik, Rune. (1995) “A Meta-Analysis of Value of Life Estimates for Occupational and Transport Safety" Institute of Transport Economics, Oslo, Norway.

Ernst, Lawrence (2003), "Sample Expansion for Probability Proportional to Size without Replacement Sampling," Proceedings of the Section on Survey Research Methods, American Statistical Association.

Fairris, David (1989), "Compensating Wage Differentials in the Union and Nonunion Sectors," Industrial Relations, 28(Fall): 356-372.

Fischhoff, Baruch (1990), "Understanding Long Term Environmental Risks," Journal of Risk and Uncertainty, 3: 315-30.

Fisher, Ann, Lauraine G. Chestnut and Daniel M. Violette (1989), “The value of Reducing Risks of Death: A Note on New Evidence", Journal of Policy Analysis and Management 8(1): 88-100.

Flachaire, Emmanuel and Guillaume Hollard (2006), "Controlling Starting-Point Bias in DoubleBounded Contingent Valuation Surveys," Land Economics, 82(1): 103-111.

Foster, V. and S. Mourato (2003), "Elicitation Format and Sensitivity to Scope: Do Contingent Valuation and Choice Experiments Give the Same Results?" Environmental and Resource Economics 24: 141-160.

Freeman, A.M. (2003), "Economic Valuation: What and Why" in Champ, Patricia A.; Boyle, K.J.; Brown, Thomas C. (Eds.), A Primer in Non-Market Valuation, Boston: Kluwer Academic Publishers.

Freeman, A. Myrick (1993), The Measurement of Environmental and Resource Values, Resources for the Future, Washington, DC.

Gayer, Ted, James T. Hamilton, and W. Kip Viscusi (2000), "Private Values of Risk Tradeoffs at Superfund Sites: Housing Market Evidence on Learning about Risk," Review of Economics and Statistics 82(3): 439-451.

Gegax, D., S. Gerking, and W. Schulze (1991), "Perceived Risk and the Marginal Value of Safety," Review of Economics and Statistics, 73(4): 589-596.

Gerking, Shelby, Menno de Haan and William Schulze (1988), "The Marginal Value of Job Safety: A Contingent Valuation Study," Journal of Risk and Uncertainty, 1(2): 185-199.

Ghosh, Debapriya, Dennis Lees, and William Seal. (1975). "Optimal Motorway Speed and Some Valuations of Time and Life" Manchester School of Economic and Social Studies 43(2): 134-143.

Guria, J., J. Leung, M.W. Jones-Lee and G. Loomes (2005), "The Willingness to accept Value of a Statistical Life Relative to the Willingness to Pay: Evidence and Policy Implications," Environmental and Resource Economics, 32: 113-27.

Haab, Timothy C. and Kenneth E. McConnell (2002), Valuing Environmental and Natural Resources: The Econometrics of Non-Market Valuation, Edward Elgar Publishers, Cheltenham, UK. 
Haab, T. C, and K. E. McConnell (1997), "Referendum Models and Negative Willingness to Pay: Alternative Solutions" Journal of Environmental Economics and Management, 32 (2): 251-70.

Hakes J. and K.W. Viscusi (1997), "Mortality Risk Perceptions: A Bayesian Reassessment," Journal of Risk and Uncertainty, 15(2): 135-150.

Hammitt, J.K. and J. T. Liu (2004), "Effects of Disease Type and Latency on the Value of Mortality Risk," Journal of Risk and Uncertainty, 28(1): 73-95.

Hammitt, J. K. (2000), "Valuing mortality risk: Theory and Practice," Environmental Science \& Technology, 34(8): 1396-1400.

Hammitt, J. K. (2000), 'Evaluating Contingent Valuation of Environmental Health Risks: The Proportionality Test', AERE Newsletter 20(1): 14-19.

Hammitt, James K. and John D. Graham (1999), "Willingness to Pay for Health Protection: Inadequate Sensitivity to Probability?" Journal of Risk and Uncertainty, 18(1): 33-62.

Hanley, N., M. Ryan, M. and R. Wright (2003), "Estimating the Monetary Value of Health Care: Lessons from Environmental Economics," Health Economics, 12(1): 3-16.

Hanley, N., D. MacMillan, R. Wright, C. Bullock, I. Simpson, D. Parsisson and B. Crabtree (1998), "Contingent Valuation vs. Choice Experiments: Estimating the Benefits of Environmentally Sensitive Areas in Scotland," Journal of Agricultural Economics, 49(1): 1-15.

Hauer, E (1994), "Can One Estimate the Value of Life or Is It Better to be Dead than Stuck in Traffic?” Transportation Research Part A: Policy and Practice, 28(2): 109-118.

Hersch, Joni and W. Kip Viscusi (2005), 'The Generational Divide in support for Environmental Policies: The European Evidence," NBER Working Paper No. 11859, National Bureau of Economic Research, Inc.

Hills, P J and M W Jones-Lee (1983), "The Role of Safety in Highway Investment Appraisal for Developing Countries," Accident Analysis and Prevention, 15(5): 355-369.

Hoehn, J. P. and A. Randall (1987), "A Satisfactory Benefit Cost Indicator from Contingent Valuation," Journal of Environmental Economics and Management, 14(3): 226-47.

Hojman P., J. de D. Ortúzar and L.I. Rizzi (2005), "On the Joint Valuation of averting Fatal and Severe Injuries in Highway Accidents," Journal of Safety Research, 36(4): 377-386.

Horowitz, John K. and Kenneth E. McConnell (2002), "A Review of WTA/WTP Studies," Journal of Environmental Economics and Management, 44: 426-447.

Hultkrantz, Lars, Gunnar Lindberg and Camilla Andersson (2006), "The Value of Improved Road Safety," Journal of Risk and Uncertainty, 32(2): 151-170.

Jacobs, G.D. (1995), "Costing Road Accidents in Developing Countries," TRL Overseas Road Note 10. Transport Research Laboratory, Crowthorne, UK.

Jenkins, Robin R., Nicole Owens and Lanelle Bembenek Wiggins (2001), "Valuing Reduced Risks to Children: the Case of Bicycle Safety Helmets," Contemporary Economic Policy, 19(4): 397-408.

Johannesson, M. and P-O Johansson (1996), "To be or not to be, that is the question: An empirical study of the WTP for an increased life expectancy at an advanced age," Journal of Risk and Uncertainty, 13: 163-174.

Johannesson, M., P. O. Johansson and R. O'Connor (1996), “The Value of Private Safety Versus the Value of Public Safety," Journal of Risk and Uncertainty, 13(3): 263-275. 
Jones-Lee, M. and G. Loomes (2004), "Eliciting Measures for Value of Health and Safety," ACM International Conference Proceeding Series, Vol. 110, Proceedings of the 9th Australian workshop on Safety critical systems and software - Volume 47.

Jones-Lee, M.W. (2002), "An Anomaly in the Valuation of Transport Safety," Applied Health Economics and Health Policy, 1(1): 7-8.

Jones-Lee, Michael W., Graham Loomes and Angela Robinson (1995), "Why Did Two Theoretically Equivalent Methods Produce Two Very Different Values?" in Natalie G. Schwab Christie and Nils C. Soguel (eds.) Contingent Valuation, Transport Safety and the Value of Life, Kluwer Academic Publishers.

Jones-Lee, M., G. Loomes, and P. Philips (1995), "Valuing the Prevention of Non-Fatal Road Injuries: Contingent Valuation Versus Standard Gambles," Oxford Economic Papers, 47: 676695.

Jones-Lee, M. and G. Loomes (1995), "Scale and Context Effects in the Valuation of Transport Safety," Journal of Risk and Uncertainty, 11(3): 183-203.

Jones-Lee, M.W. (1991), "Altruism and the Value of Other People's Safety," Journal of Risk and Uncertainty, 4: 213-219.

Jones-Lee, M.W. (1990), "The Value of Transport Safety," Oxford Economic Review of Economic Policy, 6(2): 39-60.

Jones-Lee, Michael (1989), The Economics of Safety and Physical Risk, Oxford, Basil Blackwell.

Jones-Lee, M.W., M. Hammerton and P.R. Philips (1985), "The Value of Safety: Results of a National Sample Survey,” Economic Journal, 95(377): 49-72.

Jones-Lee, M. W. (1976), The Value of Life: An Economic Analysis, University of Chicago Press, Chicago.

Jones-Lee, Michael W. (1974), "The Value of Changes in the Probability of Death or Injury," Journal of Political Economy, 82(4): 835-849.

Kniesner, Thomas J. and W. Kip Viscusi (2005), "Value of a Statistical Life: Relative Position vs. Relative Age," American Economic Review, 95(2): 142-146.

Kopits, Elizabeth and Maureen Cropper (2003), "Traffic Fatalities and Economic Growth," World Bank Research Policy Working Paper 3035.

Koyama, S. and K. Takeuchi (2004), "Economic Valuation of Road Injuries by Standard Gamble in Japan," Environmental Economics and Policy Studies, 6(2): 119-146.

Krupnick, Alan, Anna Alberini, Maureen Cropper, Natalie Simon, Bernie O'Brien, Ron Goeree, M.Heintzelman (2002), "Age, Health and the Willingness to Pay for Mortality Risk Reductions: A Contingent Valuation Survey of Ontario Residents," Journal of Risk and Uncertainty, 24: 161186.

Krupnick, Alan, Maureen Cropper, Anna Alberini, Nathalie Simon, Kenshi Itaoka and Makoto Akai (1999), "Mortality Risk Valuation for Environmental Policy," Discussion Papers dp-99-47, Resources For the Future.

Lipkus, I.M. and J.G. Hollands (1999), "The Visual Communication of Risk," Journal of the National Cancer Institute Monographs, 25: 149-163.

Liu, J. T. and J.K. Hammitt (1999), "Perceived Risk and Value of Workplace Safety in a Developing Country," Journal of Risk Research 2: 263-275. 
Loomis, J. (1996), "Measuring the Benefits of Removing Dams and Restoring the Elwha River: Results of a Contingent Valuation Survey," Water Resources Research, 32: 441-447.

Ludwig, Jens and Philip J. Cook (2001), "The Benefits Of Reducing Gun Violence: Evidence From Contingent-Valuation Survey Data," Journal of Risk and Uncertainty, 22(3): 207-226.

Lusk, Jayson L. and Norwood F. Bailey (2005), "Effect of Experimental Design on Choice-Based Contingent Valuation Estimates," American Journal of Agricultural Economics, 87(3): 771-785.

MacKenzie, J. (1993), “A Comparison of Contingent Preference Models,” American Journal of Agricultural Economics, 75(3): 593-603.

Madheswaran, Subramaniam and Shanmugam, Kumarapalayam R. (2003), "Impact of Trade Unions on the Compensation for Job Risks; Evidence from the Indian Labor Market," RISEC: International Review of Economics and Business, 50(1): 121-41.

Markandya, A., Hunt, A., Ortiz, R and Alberini, A. (2004), "EC NewExt Research Project: Mortality Risk Valuation - Final Report - UK, ” Brussels: European Commission.

Melhuish, C., A. Ross, M. Goodge, K.K.C. Mani, M.F.M. Yusoff and R. Umar (2005), “Accident Costing Report AC5: Malaysia," Asian Development Bank-Association of Southeast Asian Nations Regional Road Safety Program.

Miller, Ted R. (2000), "Variations between Countries in Values of Statistical Life," Journal of Transport Economics and Policy 34: 169-188.

Mishan, E.J., (1971), "Evaluation of Life and Limb: A Theoretical Approach," Journal of Political Economy 79: 687-705.

Mitchell, Robert Cameron and Richard T. Carson (1989), Using Surveys to Value Public Goods: The Contingent Valuation Method, Resources for the Future/Johns Hopkins University Press, Washington DC, $480 \mathrm{pp}$.

Mohan, Dinesh (2001), "Social Cost of Road Traffic Crashes in India," Proceedings 1st Safe Community Conference on Cost of Injuries, Viborg: Denmark.

Moore, Michael J., and W. Kip Viscusi (1990), Compensation Mechanisms for Job Risks: Wages, Workers' Compensation, and Product Liability. Princeton, NJ: Princeton University Press.

Mount, T., W. Weng, W. Schulze, and L. Chestnut (2000), "Automobile safety and the value of statistical life in the family: Valuing reduced risk for children, adults and the elderly," United States Environmental Protection Agency Report, June.

Morris, J. and J.K. Hammitt (2001), "Using Life Expectancy to Communicate Benefits of Health Care Programs in Contingent Valuation Studies," Medical Decision Making, 21(6): 468-478.

Morrison, M., R. Blamey, J. Bennett, J. Louviere, J. (1999), "A Review of Conjoint for Estimating Environmental Values," mimeo, University of New South Wales.

Mrozek, James R. and Laura O. Taylor (2002), "What Determines the Value of Life? A MetaAnalysis," Journal of Policy Analysis and Management 21(2): 253-270.

Murray, Christopher J, L. Murray and Alan D. Lopez (1996), The Global Burden of Disease: a comprehensive assessment of mortality and disability from diseases, injuries, and risk factors in 1990 and projected to 2020, WHO, Harvard University and the World Bank.

National Sample Survey of India (2005), "Employment and Unemployment Situation in India," Report No. 506, Ministry of Statistics and Programme Implementation, Govt. of India. 
Norinder, A., K. Hjalte and U. Persson (2001), "Scope and Scale Insensitivities in a Contingent Valuation Study of Risk Reductions," Health Policy, 57: 141-153.

O'Reilly, D., J. Hopkin, G. Loomes, M. Jones-Lee, P. Philips, K. McMahon, D. Ives, B. Soby, D. Ball, and R. Kemp (1994), "The Value of Road Safety: UK Research on the Valuation of Preventing Non-Fatal Injuries" Journal of Transport Economics and Policy, 28(1): 45-59.

Ortúzar, J. de D., L.A. Cifuentes, H.C.W.L. Williams (2000), “Applications of willingness-to-pay methods to value transport externalities in less developed countries," Environment and Planning A, 32: 2007-2018.

Persson, Ulf, Anna Norinder, Krister Hjalte and Katrina Gralen (2001), "The Value of a Statistical Life in Transport: Findings from a New Contingent Valuation Study in Sweden," Journal of Risk and Uncertainty, 23(2): 121-134.

Persson, Ulf, Anna Norinder, and Marianne Svensson (1995), "Valuing the Benefits of Reducing the Risk of Non-Fatal Road Injuries: The Swedish Experience," in Natalie G. Schwab Christie and Nils C. Soguel (eds.) Contingent Valuation, Transport Safety and the Value of Life, Kluwer Academic Publishers.

Ready, Richard et al. (2004), "Benefit Transfer in Europe: How Reliable Are Transfers between Countries?" Environmental and Resource Economics, 29(1): 67-82.

Ready, R. C., S. Navrud and W. R. Dubourg (2001), "How Do Respondents with Uncertain Willingness to Pay Answer Contingent Valuation Questions?" Land Economics, 77(3): 315-326.

Rizzi L.I. and J.de Ortúzar (2003), "Stated Preference in the Valuation of Interurban Road Safety," Accidental Analysis and Prevention, 35: 9-22.

Romer, Anselm U, Werner W. Pommerehne and Lars P. Feld (1998), "Revealing Preferences for Reductions of Public Risks: An Application of the CV Approach," Journal of Environmental Planning \& Management, 41 (4): 477-503.

Rowlatt, P., M. Spackman, S. Jones, M. Latremoliere, M.W. Jones-Lee and G. Loomes (1998), "Valuation of Deaths from Air Pollution: A report for the Department of Environment," Transport and the Regions. NERA, London and CASPAR - University of Newcastle.

Ryan, Mandy, David A. Scott, Can Donaldson (2004), "Valuing Health Care Using Willingness to Pay: A Comparison of the Payment Card and Dichotomous Choice Methods," Journal of Health Economics, 23(2): 237-258.

Savage, I. (1993), "An Empirical Investigation into the Effect of Psychological Perceptions on the Willingness-to-Pay to Reduce Risk," Journal of Risk and Uncertainty 6: 75-90.

Scarpa, Riccardo, K.G. Willis and G.D. Garrod (2001), "Estimating willingness-to-pay for speed reduction from dichotomous-choice contingent valuation responses with follow-up: the case of rural trunk roads," Environmental and Resource Economics, 20(4), 281-304.

Schelling, T. C. (1968), "The Life You Save May Be Your Own," in Problems in Public Expenditure Analysis, S.B. Chase (ed.). Washington, D.C.: Brookings Institute.

Schwab Christe, N. and N. Soguel (1996), "The Pain of Road Accident Victims and the Bereavement of their Relatives: A Contingent Valuation Experiment," Journal of Risk and Uncertainty, 13: 277-291.

Schwab Christie, Natalie G. and Nils C. Soguel (eds.) (1995), Contingent Valuation, Transport Safety and the Value of Life, Kluwer Academic Publishers. 
Shanmugam, K. R. (2001), "Self-Selection Bias in the Estimates of Compensating differentials for job Risks in India," Journal of Risk and Uncertainty, 22(3): 263-75.

Shanmugam, K. R. (1997), "Value of Life and Injury Risks: Estimating Using Flexible Functional Form," Indian Journal of Applied Economics, 6(3): 125-36.

Shepard, D.S. and R.J. Zeckhauser (1984), "Survival versus Consumption," Management Science, 30(4): 423-439.

Simon, Nathalie B., Maureen L. Cropper, Anna Alberini and Seema Arora (1999), "Valuing Mortality Reductions in India: A Study of Compensating-Wage Differentials," World Bank Working Paper Series 2078.

Slovic, P., Fischhoff, B., and Lichtenstein, S. (1985), "Characterizing Perceived Risk," in: Kates, R.W. et al. Perilous Progress: Technology as Hazard, Westview, Boulder, Colorado.

Slovic, P., Fischhoff, B. \& Lichtenstein, S. (1979), "Rating the Risks," Environment, 21: 14-20, 36-39.

Smith, Richard D. (2004), "The Reliability of Willingness to Pay for Changes in Health Status," Applied Health Economics and Health Policy, 3(1): 35-38.

Swait, J. and W. Adamowicz (1996), "The Effect of Choice Environment and Task Demands on Consumer Behavior: Discriminating between Contribution and Confusion," Staff Paper 96-09, Department of Rural Economy, University of Alberta.

Thaler, Richard and Sherwin Rosen (1975), "The Value of Saving a Life: Evidence from the Labor Market," in N. Terleckyj, ed., Household Production and Consumption. Cambridge: NBER, 265-298, 1975.

Trawén, A., P. Maraste and U. Persson (2002), "International Comparison of Cost of Fatal Casualty of Road Accidents in 1990 and 1999," Accident Analysis and Prevention, 34: 323-332.

Tsuge, T., A. Kishimoto and K. Takeuchi (2005), "A Choice Experiment Approach to the Valuation of Mortality," Journal of Risk and Uncertainty, 31(1): 73-95.

Tversky, A. and D. Kahneman (1974), "Judgement Under Uncertainty- Heuristics and Basics," Science, 185 (4157): 1124-1131.

Vassanadumrongdee, Sujitra and Shunji Matsuoka (2005), "Risk Perceptions and Value of a Statistical Life for Air Pollution and Traffic Accidents: Evidence from Bangkok, Thailand," Journal of Risk and Uncertainty, 30(3): 261-287.

Viscusi, W. Kip, and Richard Zeckhauser (2005), "The Perception and Valuation of the Risks of Climate Change: A Rational and Behavioral Blend," Kennedy School of Government Working Paper No. RWP05-062, November 2005.

Viscusi, W.K. (2004), "The Value of Life: Estimates with Risks by Occupation and Industry." Economic Inquiry 42(1): 29-48.

Viscusi, W.K. and J.E. Aldy (2003), "The Value of a Statistical Life: A Critical Review of Market Estimates Throughout the World," Journal of Risk and Uncertainty 27: 5-76.

Viscusi, Kip W. (2000), "The Value of Life for Legal Contexts; Survey and Critique," American Law and Economics Review, 2(1): 195-222.

Viscusi, W. Kip (1995), “The Automobile Risk Metric for Valuing Health Risks," published in Natalie G. Schwab Christie and Nils C. Soguel (eds.) Contingent Valuation, Transport Safety and the Value of Life, Kluwer Academic Publishers. 
Viscusi, W. Kip (1993), “The Value of Risks to Life and Death," Journal of Economic Literature, 31(4): 1912-46.

Viscusi, W. Kip (1992), Fatal Tradeoffs: Public and Private Responsibilities for Risk, Oxford University Press.

Viscusi, W.K., Wesley A. Magat and Joel Huber (1991), "Pricing Environmental Health Risks: Survey Assessments of Risk-Risk and Risk-Dollar Tradeoffs for Chronic Bronchitis," Journal of Environmental Economics and Management, 21(1): 32-51.

Viscusi, W. Kip (1989), "Prospective Reference Theory: Toward an Explanation of the Paradoxes," Journal of Risk and Uncertainty, 2(3): 235-264.

Viscusi, W.K. (1981). "Occupational Safety and Health Regulation: Its Impact and Policy Alternatives." In J.P. Crecine (ed.), Research in Public Policy Analysis and Management. Greenwich, CT: JAI Press, vol. 2, pp. 281-299.

Willet, Walter, Jeff Koplan, Shanthi Mendis, Rachel Nugent, Pekka Puska and Tanuja Rastogi (2006), "Lifestyle and Noncommunicable Disease," in Jamison et. al (eds.) Disease Control Priorities in Developing Countries (2nd Edition), World Bank, 2006

World Bank (2002), "India's Transport Sector: The Challenges Ahead- Vol. 1 Main Report." WHO (2004), "World Report on Road Traffic Injury Prevention."

Zeckhauser, Richard J. (1975), "Procedures for Valuing Lives,” Public Policy 23(4): 419-464. 